\title{
Towards successful Web-based smoking relapse prevention : the efficacy of a computer tailored program incorporating post-motivational components \& an attentional bias modification program
}

Citation for published version (APA):

Elfeddali, I. (2013). Towards successful Web-based smoking relapse prevention : the efficacy of a computer tailored program incorporating post-motivational components \& an attentional bias modification program. [Doctoral Thesis, Maastricht University]. Universitaire Pers Maastricht.

https://doi.org/10.26481/dis.20130627ie

Document status and date:

Published: 01/01/2013

DOI:

10.26481/dis.20130627ie

Document Version:

Publisher's PDF, also known as Version of record

Please check the document version of this publication:

- A submitted manuscript is the version of the article upon submission and before peer-review. There can be important differences between the submitted version and the official published version of record. People interested in the research are advised to contact the author for the final version of the publication, or visit the DOI to the publisher's website.

- The final author version and the galley proof are versions of the publication after peer review.

- The final published version features the final layout of the paper including the volume, issue and page numbers.

Link to publication

\footnotetext{
General rights rights.

- You may freely distribute the URL identifying the publication in the public portal. please follow below link for the End User Agreement:

www.umlib.nl/taverne-license

Take down policy

If you believe that this document breaches copyright please contact us at:

repository@maastrichtuniversity.nl

providing details and we will investigate your claim.
}

Copyright and moral rights for the publications made accessible in the public portal are retained by the authors and/or other copyright owners and it is a condition of accessing publications that users recognise and abide by the legal requirements associated with these

- Users may download and print one copy of any publication from the public portal for the purpose of private study or research.

- You may not further distribute the material or use it for any profit-making activity or commercial gain

If the publication is distributed under the terms of Article 25fa of the Dutch Copyright Act, indicated by the "Taverne" license above,

Download date: 26 Apr. 2023 


\section{Towards successful Web-based smoking relapse prevention}

The efficacy of a computer tailored program incorporating post-motivational components $\&$ an attentional bias modification program 


\section{Colofon}

Cover design: Datawyse | Universitaire Pers Maastricht Production: Datawyse | Universitaire Pers Maastricht ISBN 9789461592385

(c) Copyright Iman Elfeddali, 2013.

The research presented in this thesis was conducted at the School for Public Health and Primary Care: CAPHRI, Department of Health Promotion, of Maastricht University. CAPHRI participates in the Netherlands School of Primary Care Research CaRe. CAPHRI was classified as 'excellent'by the external evaluation committee of leading international experts that reviewed CAPHRI in December 2010 .

The research presented in this thesis was financially supported by ZonMw -the Netherlands Organisation for Health Research and Development (grant number: 6130-0030). 


\title{
Towards successful Web-based smoking relapse prevention
}

\author{
The efficacy of a computer tailored program \\ incorporating post-motivational components \\ $\&$ an attentional bias modification program
}

\begin{abstract}
PROEFSCHRIFT
ter verkrijging van de graad van doctor aan de Universiteit Maastricht op gezag van de Rector Magnificus, prof. dr. L.L.G. Soete, volgens het besluit van het College van Decanen, in het openbaar te verdedigen op donderdag 27 juni 2013 om 14.00 uur
\end{abstract}

door

Iman Elfeddali

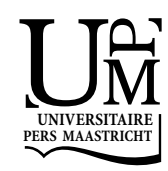




\section{Promotores}

Prof. dr. H. de Vries

Prof. dr. R.W. Wiers, Universiteit van Amsterdam

\section{Co-promotor}

Dr. C. Bolman, Open Universiteit Nederland

\section{Beoordelingscommissie}

Prof. dr. N.K. de Vries (voorzitter)

Dr. D. Kotz

Prof. dr. L. Lechner, Open Universiteit Nederland

Prof. dr. Ir. C.P. van Schayck

Prof. dr. M. Willemsen 


\section{CONTENT}

\section{CHAPTER 1}

General introduction ...................................................................................................

\section{CHAPTER 2}

Factors underlying smoking relapse prevention: results of an international Delphi study.

\section{CHAPTER 3}

The role of self-efficacy, recovery self-efficacy, and preparatory planning in predicting short-term smoking relapse 45

\section{CHAPTER 4}

SQ4U - A computer tailored smoking relapse prevention program incorporating planning strategy assignments and multiple feedback time points after the quit-attempt: development and design protocol

\section{CHAPTER 5}

Preventing Smoking Relapse via Web-Based Computer-Tailored Feedback: A Randomized Controlled Trial.

\section{CHAPTER 6}

The role of adherence in a computer tailored smoking relapse prevention program: six months results of the SQ4U study.

\section{CHAPTER 7}

Situational and affective risk situations of relapse and the quality of implementation intentions in an e-health smoking relapse prevention programme

\section{CHAPTER 8}

Preventing smoking relapse among smokers via a Web-based multiple-session attentional bias modification training: a randomized controlled trial

\section{CHAPTER 9}

General discussion 
SUMMARY

SAMENVATTING..........................................................................................................195

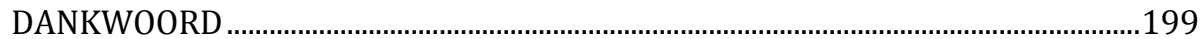

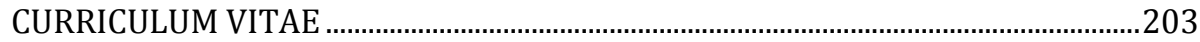

LIST OF PUBLICATIONS ................................................................................................205 
CHAPTER 1

General introduction 


\section{ABSTRACT}

Tobacco use is a serious threat to human health. Although most smokers want to quit smoking, only a very few are successful in their attempts. The fallback into smoking after a quit-attempt is referred to as smoking relapse and presents an evident problem in the process of successful smoking cessation. Furthermore, smoking relapse prevention programs have shown only modest behavioral effects. Theoretical models on explicit and implicit processes in behavior change can be consulted in order to understand and influence the process of smoking relapse.

The research reported in this dissertation serves two central goals. The first goal was to better understand the factors that are important in the process of smoking relapse. The second goal was to develop and test two Web-based relapse prevention programs: a) Stay Quit for You (SQ4U), a program consisting of two versions that both provide tailored feedback at baseline and incorporate six action planning assignments (three before and three after the quit-date), but with only one of the programs also providing tailored feedback after the quitdate; and b) Train Yourself Smoke-free, an attentional bias modification training program.

This introductory chapter will present the problem of smoking relapse and discuss theoretical frameworks that were consulted. The theoretical frameworks will be used to reflect on the current state of knowledge about the factors that are important in the process of smoking relapse and crucial knowledge gaps. Finally, this chapter will discuss the rationalization for the series of studies reported in this dissertation, including the considerations taken for the development of SQ4U and Train Yourself Smoke-free. 


\section{INTRODUCING THE PROBLEM OF SMOKING RELASPE}

\section{The case of Eliza1: an adult daily smoker who is motivated to quit smoking}

Eliza smoked her first cigarette when she was fifteen and has been a daily smoker ever since. She has been smoking for twenty-five years now and has suffered health and hygiene complaints such as frequent coughs and colds, increased blood pressure, stains on fingers, bad breath and decreased physical endurance due to her smoking behavior. Even her nieces and nephews complain about her smoking when they visit her, because the cigarette smoke irritates their throats. The thought of these negative consequences made her plan a significant change: to quit smoking forever! The day she chose was November 22, 2012, and she made a note of it on her calendar:

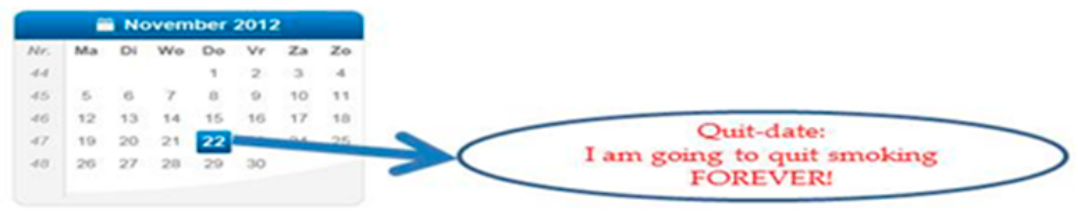

On her quit-date Eliza told herself: "no more smoking for me, I am definitely going to quit successfully!" She was very motivated to quit smoking and she managed not to touch a cigarette on Thursday (November 22) or Friday (November 23). Eliza did experience some craving, but she distracted herself by staying home and eating candy.

Saturday evening she went to a birthday party at her friend's home and Eliza smelled the cigarettes upon entering the living room...she really wanted to smoke a cigarette. She socialized with her friends and hoped for distraction. Unfortunately, Eliza started wanting to smoke even more; she missed her cigarette, the party felt weird without smoking and it seemed like the smoking-related attributes (ashtrays, cigarettes and cigarette packages) were all over the place! Eliza lost her motivation when a friend offered her a cigarette: she accepted the cigarette and started smoking again. Her quit-attempt lasted for two days and after smoking again she felt like a complete failure. She reflected on her failed quit-attempt and thought: "How was this possible? I was so motivated to quit smoking. I am aware of the negative consequences, so what went wrong? Wasn't I prepared enough or was it something else?" Eliza realized that she might need some help in order to quit smoking successfully, but what kind of help?

${ }^{1}$ Eliza is a fictional character. 


\section{Tobacco smoking}

Tobacco smoking (referred to as 'smoking' in this dissertation) is one of the main preventable causes of heart disease, stroke, lung disease and premature death (Ezzati et al., 2002; CDC, 2008; Gelder, Poos and Zantinge, 2011). Worldwide, smoking causes more than five million deaths per year, and current trends show that smoking will cause more than eight million deaths annually by 2030 (WHO, 2009). The health-damaging effects of smoking go beyond the active smoker due to secondhand smoking, which can be defined as the inhalation of smoke by people other than the active smoker. Secondhand smoking increases respiratory symptoms in adolescents and adults and is a well-established risk for smoking initiation (Lam et al., 2005; Lai, Ho, Wang and Lam, 2009; LeonardiBee, Jere and Britton, 2011). Furthermore, smoking creates an economic and social burden (European-Commission, 2004).

Although some fluctuations can be observed, during the last decades the decline of smoking has slowed considerably in the developed countries resulting in a smoking prevalence of $19 \%$ in the United States and $25 \%$ in the Netherlands (CDC, 2011; STIVORO, 2012). A further decrease of the smoking prevalence is necessary to reduce the smoking-related health burden and other detrimental effects such as economic and social costs.

\section{Smoking cessation and relapse}

Just like in the case of Eliza, most smokers are aware of the health risks of smoking and the majority of them want to quit smoking (CDC, 2002; Dijkstra, 2005; CDC, 2011; STIVORO, 2011). Unfortunately, the majority of the smokers who act on their intentions to quit smoking fail in their attempts to remain abstinent (Garvey and Bliss, 1992; Hughes et al., 1992; Zhu et al., 1996; Hughes, Keely and Naud, 2004). A review describing the relapse curve and rates of abstinence among smokers who tried to quit without treatment pointed out that most relapses occur in the first days after the quit-attempt, with relapse rates varying from $49 \%$ to $76 \%$ (Hughes, Keely and Naud, 2004). Only 3-5\% of quitters manage to remain smoke-free for six months and multiple quit attempts are usually needed before a smoker quits smoking successfully (Canada, 2001; Hughes, Keely and Naud, 2004; ACS, 2010). These relapse rates confirm that relapse is a serious problem in the process of successful smoking cessation and that effective prevention strategies are essential.

Accordingly, in recent years efforts have been made to develop effective smoking relapse prevention programs; however, a recent study reviewing the effects of these programs concluded that current relapse prevention programs are ineffective (Hajek, Stead, West, Jarvis and Lancaster, 2009). The review pointed out that brief behavioral interventions and interventions based on writ- 
ten materials, mailings and telephone sessions are not successful in preventing smoking relapse and that the traditional skill training strategies (in which respondents need to identify risk situations and make coping plans) were especially ineffective. The authors noted that these approaches may be valid, but the skills may not be taught effectively. Moreover, it is noted that most current prevention programs utilize only one prevention approach, while more intensive approaches can have better behavioral effects if carried out properly. In addition, the authors recommended considering alternative possibilities in order to successfully prevent relapse since current attempts have mostly failed. This lack of effective prevention programs and the high relapse rates underline the need for further understanding of the factors that predict smoking relapse and the development of new effective smoking relapse prevention programs.

\section{THEORETICAL FRAMEWORKS}

Theoretical frameworks confirmed by empirical research are essential for the development of public health interventions as they form a guidance tool for the planning and evaluation of interventions and the selection of intervention strategies and delivery modes (Glanz and Bishop, 2010). Over the past two decades, the use of dual-process approaches has become prevalent in several areas including the research of addictive behaviors (see examples in, Strack and Deutsch, 2004; Bechara, 2005; Deutsch and Strack, 2006; Wiers and Stacy, 2006; Wiers et al., 2007). Dual-process approaches propose the existence of two different systems that determine a person's motivational system and behavior: 1) a reflective system that is slow, controlled and rule-based and relates behavior to a decision process, and 2) an impulsive system that is fast, associative and unconscious (behavior may take place without intention). Thus, in order to understand the process of smoking relapse, perspectives on explicit and implicit cognition approaches can be consulted. Both approaches will be addressed in this dissertation. In the following section, the two approaches and their underlying processes will be further explained and used to describe the most important determinants of smoking relapse, strategies that can be utilized to target these factors and the gaps in current knowledge.

\section{Explicit cognition approach}

Research on addictive behaviors in general and smoking cessation and relapse in particular has mainly been based on theoretical models with a "rational" behavioral decision-making base that mostly emphasizes the importance of making conscious decisions that take into account the perceived pros and cons of the addiction in the process of behavior and behavioral change. These models 
focus on explicit cognitions such as feelings or thoughts that are consciously accessible by introspection and are mostly assessed by questionnaires. The IChange Model, a theoretical model integrating several social cognitive approaches, will be described in order to depict and influence the explicit cognitions underlying smoking relapse.

\section{The I-Change Model}

The I-Change Model (de Vries et al., 2003; de Vries, Kremers, Smeets, Brug and Eijmael, 2008) is widely used in smoking cessation studies and originates from the Attitude-Social influence-Self efficacy model, which originated from the Theory of Reasoned Action (Fishbein and Ajzen, 1975). It is a comprehensive model including aspects from socio-cognitive theories like the Theory of Planned Behavior (Ajzen, 1988; Ajzen, 1991; Fishbein and Ajzen, 2010), the Transtheoretical Model (Prochaska and DiClemente, 1983), Social Cognitive Theory (Bandura, 1986), the Precaution Adoption Model (Weinstein, 1988), the Relapse Prevention Model (Marlatt and Gordon, 1985; Marlatt and Donovan, 2005) and goal-setting theories (Latham and Locke, 1991; Gollwitzer and Moskowitz, 1996).

\section{Intention in the I-Change Model}

The I-Change Model includes the traditional approach of emphasizing the role of intention in line with traditional health behavior theories that stress the critical role of intention (see for instance, Fishbein and Ajzen, 1975; Prochaska and DiClemente, 1983; Rogers, 1983; Bandura, 1986; Ajzen, 1988; Ajzen, 1991; Prochaska and Velicer, 1997; Fishbein and Ajzen, 2010). These theories assume that intention is the most proximal determinant of behavior and that it is therefore important to change intentions in order to enable behavior change (Armitage and Conner, 2000). Although a meta-analysis showed that intention indeed plays an important role in the prediction of behavior by accounting for $28 \%$ of the variance, the unexplained variance (also referred to as the gap between intention and behavior) should not be neglected (Sheeran, 2002). Moreover, another meta-analysis pointed out that medium to large changes in intention result in only small to medium effects on behavior (Webb and Sheeran, 2006).

The discrepancy between the expected and actual prediction of behavior by intention resulted in criticism of models that assume intention alone is enough for behavioral enactment. This criticism especially relates to the focus on intentional and pre-intentional factors, while the intention-behavior gap suggest a post-intentional phase in which plans need to be made in order to actually act on the intended behavior (Gollwitzer, 1993; Schwarzer, 2001; Sniehotta, Scholz and Schwarzer, 2005; Gollwitzer and Sheeran, 2006). In general, these plans are postulated as strategies for overcoming barriers (such as beginning a task, continuing a task when confronted with difficulties and resuming a task after a dis- 
ruption) in the process of successful task performance (Gollwitzer, 1996). Paying attention to these plans is not a new idea; for instance, it can be found in the cognitive theory that states that planning is needed in order to translate intentions into behaviors (Miller, Galanter and Pribram, 1960). Over the years, planning has gained renewed attentions in several theories: for instance, the goalsetting theory that claims that plans are particularly essential in complex environments and the action theory that sees plans as critical for the translation of intentions into action (Gollwitzer, 1999). Consequently, these notions have been developed further by recent integrative models, such as the I-Change Model, resulting in the addition of action planning as a determinant of behavior. The IChange Model integrates these post-intentional components (referred to as post-motivational factors) that predict behavior over and above intention with the traditional approach of emphasizing the role of intention including the intentional and pre-intentional factors (referred to as motivational and premotivational factors, respectively). It is therefore an optimal integrative model for studying smoking relapse.

\section{Post-motivational factors in the I-Change Model}

Self-efficacy and action planning are post-motivational components of the IChange Model. Self-efficacy can be defined as a person's perception of his/her ability to cope with a high-risk situation and is included as a motivational and a post-motivational factor in the I-Change Model. Low self-efficacy has consistently been reported as a predictor of smoking relapse (Mudde, Kok and Strecher, 1995; Dijkstra and de Vries, 2000; Ockene et al., 2000; Dijkstra and Borland, 2003; Amodei and Lamb, 2005; Gwaltney, Shiffman, Balabanis and Paty, 2005; Segan, Borland and Greenwood, 2006; Gwaltney, Metrik, Kahler and Shiffman, 2009; Herd, Borland and Hyland, 2009). The occurrence of a high-risk situation combined with an ineffective coping response is assumed to decrease selfefficacy and increase the positive outcome expectancies of drug use, resulting in relapse (Marlatt and Gordon, 1985; Marlatt and Donovan, 2005). It is, therefore, important to prepare smokers for high-risk situations that may impede the maintenance of smoking abstinence and provoke relapse. The process of increasing self-efficacy is also related to action planning (another postmotivational factor in the I-Change Model) that explicitly invites smokers to prepare their smoking cessation attempt and to make plans for dealing with these high-risk situations.

According to the I-Change Model, action planning can be defined as the process of planning and executing several specific actions that may help a person to successfully adopt and maintain new health behavior (de Vries et al., 2003; de Vries, Kremers, Smeets, Brug and Eijmael, 2008). Action planning consists of two planning components: preparatory planning and coping planning. Preparatory planning focuses on beginning a task and involves making sub-plans that need to be undertaken to prepare for and attain a certain goal (Zimmermann, 
2000; de Vries et al., 2003). Coping planning aims at maintaining the new behavior by planning how a person will overcome barriers (Sniehotta, Schwarzer, Scholz and Schüz, 2005) such as dealing with situations that hinder the maintenance of the health behavior. Preparatory planning has been associated with smoking relapse and can be improved by providing tailored feedback on how to make adequate plans (Hoving, Mudde and de Vries, 2006; Te Poel, Bolman, Reubsaet and de Vries, 2009). Moreover, some coping planning interventions that aim at identifying and dealing with risk situations have been shown to have a positive influence on smoking abstinence ( $O^{\prime}$ Connell, Hosein and Schwartz, 2007; van Osch, Lechner, Reubsaet, Wigger and de Vries, 2008).

Following older initiatives (Anderson, 1983), Gollwitzer (Gollwitzer, 1999) studied these plans in the sense of "if-then" statements (e.g., "if situation X occurs, then I will do Y"), which are referred to as implementation intentions. It has been suggested that forming "if-then" implementation intentions that identify a response that can be initiated when a certain situation occurs increases the efficacy of coping planning (e.g., Gollwitzer, 1993; Gollwitzer, 1996; Gollwitzer, 1999; Gollwitzer and Sheeran, 2006; Sniehotta, 2009). Formation of implementation intentions has already proved to be a successful strategy for promoting several health-related behaviors in general (Luszczynska, 2006; Sniehotta, Scholz and Schwarzer, 2006; Kwak, Kremers, van Baak and Brug, 2007; Armitage, 2009; Luszczynska and Haynes, 2009; Chatzisarantis and Hagger, 2010) and smoking cessation and abstinence, specifically (Armitage, 2007; Armitage, 2008; van Osch, Lechner, Reubsaet, Wigger and de Vries, 2008). Furthermore, the quality of the plans is likely to affect the success of a quit-attempt since it has been demonstrated that the quality of these plans is associated with short-term smoking abstinence (van Osch, Lechner, Reubsaet and de Vries, 2010). Since these post-motivational factors seem to have potential for smoking relapse prevention, further understanding their role in that process and integrating strategies that increase self-efficacy and facilitate preparatory and coping planning all together in one smoking relapse prevention program are central to this dissertation.

\section{Motivational and pre-motivational factors in the I-Change Model}

Motivational factors are formed by attitudes, social influence and self-efficacy and are seen as the core elements in predicting intention according to the IChange Model. Research has indicated associations between relapse and perceived outcome expectancies, social situations and the presence of other smokers, respectively (Dijkstra and Borland, 2003; Shiffman, 2004; Gwaltney, Shiffman, Balabanis and Paty, 2005). As previously mentioned, studies have conclusively found that low levels of self-efficacy predict smoking relapse (Mudde, Kok and Strecher, 1995; Dijkstra and de Vries, 2000; Ockene et al., 2000; Dijkstra and Borland, 2003; Amodei and Lamb, 2005; Gwaltney, Shiffman, 
Balabanis and Paty, 2005; Segan, Borland and Greenwood, 2006; Gwaltney, Metrik, Kahler and Shiffman, 2009; Herd, Borland and Hyland, 2009).

The pre-motivational factors in the I-Change Model consist of three types of determinants: 1) 'Pre-disposing factors' formed by behavioral, psychological, biological and social-cultural factors, 2) 'Awareness factors' formed by knowledge, cues to action and risk perception, and 3) 'Information factors' formed by messages, channels and sources. Craving is a pre-motivational biological factor that has consistently been associated with smoking relapse (Killen and Fortmann, 1997; Shiffman, 2004; Piasecki, 2006). Regarding gender, which can also be seen as a biological factor, it has been demonstrated that women are more likely to relapse (Ockene et al., 2000; Bohadana, Nilsson, Rasmussen and Martinet, 2003; Pomerleau et al., 2005) and that after overnight abstinence female smokers experienced more negative mood than male smokers and enjoyed greater relief from withdrawal symptoms after smoking a cigarette than male smokers did (Xu et al., 2008).

Studies on social-cultural factors such as social class and education have generally shown that patients from more affluent social classes or with higher education levels were less likely to relapse (Ferguson, Bauld, Chesterman and Judge, 2005; Fernandez et al., 2006; Pisinger, Aadahl, Toft and Jørgensen, 2011). However, one study found that lower socioeconomic status predicted one-day initial abstinence (Amodei and Lamb, 2005). The researchers suggested that the latter finding might have been the result of participants with lower socioeconomic status being more affected by the financial reward they could earn for that one-day abstinence.

Findings with regard to affective psychological states such as stress and negative affect are still inconclusive. Though high stress levels have been associated with smoking relapse in various studies (Kassel, Stroud and Paronis, 2003; Brown, Lejuez, Kahler, Strong and Zvolensky, 2005; Shaw and al'Absi, 2008), a study in which a prospective analysis of stress and negative affect prior to initial lapse was performed found that day-to-day changes in stress and negative affect did not predict relapse on the following day (Shiffman and Waters, 2004). Yet, on the relapse day itself, negative affect was already significantly increasing hours before the relapse, but only for episodes attributed to stress or bad mood (Shiffman and Waters, 2004). The relationship between negative affect and smoking relapse is complex (Piasecki, 2006) as smokers themselves often attribute relapses to negative affect situations (Shiffman, Paty, Gnys, Kassel and Hickcox, 1996). Ecological momentary assessments, however, have shown inconclusive findings: sometimes significant associations have been found and sometimes those associations have been missing (Shapiro, Jamner, Davydov and Prochaska, 2002; Shiffman et al., 2002; Shiffman, 2004; Shiffman et al., 2007).

According to the I-Change Model, these pre-motivational factors are postulated to influence motivational factors and consequently start the formation of intentions. One of the goals of this dissertation was to gain more insight into the 
role of different pre-motivational and motivational factors in the process of smoking relapse and to target these factors together with the post-motivational factors in order to prevent negative inferences due to lack of pre-motivational or motivational strengths that may impede acting on the intention to quit (or maintaining the behavior after the quit-attempt).

\section{Implicit cognition approach}

Perspectives on addiction from the last decades argue that explicit cognitions only determine a part of addictive behaviors and that the other part takes place through automatic or implicit processes (see examples in, Strack and Deutsch, 2004; Bechara, 2005; Deutsch and Strack, 2006; Wiers and Stacy, 2006; Wiers et al., 2007). The implicit cognition approach assumes that decisions are partly influenced by memory associations that are learned by experience and become automatically activated in certain circumstances; this approach thus differs from the rational explicit cognition approach which assumes that behavior is the result of a rational decision-making process (Stacy and Wiers, 2010). Note that implicit cognitive processes are not measured by self-report assessments of feelings and thoughts, but indirectly mostly using reaction time paradigms. The next section will explain two processes (i.e., habit learning processes and incentive salience) that are assumed to underlie implicit cognition according to neurobiological theories of addiction. Furthermore, we will discuss the assessment of implicit cognitions and their role in smoking behavior.

\section{Neurobiological theories of addiction}

Learning and habit theories play a substantial role in research on addictive behaviors (see for instance, Tiffany, 1990; Berke and Hyman, 2000; Everitt, Dickinson and Robbins, 2001; Hyman, Malenka and Nestler, 2006). Learning and habit theories generally assume that addictive substances promote strong 'automatized' stimulus-response learning, and that habits are formed after repeated use and lead to addictive behavior. For instance, Tiffany (1990) proposed that substance-use behavior is formed by specific skills (involving the attainment and consumption of the substance) that become automatic by repeated use. Substance-use behavior thus tends to be fast, automatic and carried out in the absence of awareness. Furthermore, substance-related stimuli are theorized to evoke automatic processes that result in pursuing and using the substance (Tiffany, 1990).

While these habit and learning processes are generally acknowledged in the field of addictive behaviors, it is proposed that learning processes alone are unlikely to lead to compulsive substance-use and that learning processes do not form the core process in addiction (Robinson and Berridge, 2003; Robinson and Berridge, 2008). Robinson and others (Robinson and Berridge, 2003; Robinson 
and Berridge, 2008), therefore, claim in their Incentive Sensitization Theory of Addiction that motivational processes, which can also be part of a non-rational process, need to be taken into account over and above learning processes in order to explain substance-use behavior.

The Incentive Sensitization Theory of Addiction postulates that repeated substance use can change neural substrates that assign incentive salience to reward-related stimuli and consequently cause a 'sensitization' to the incentive motivational effect ('wanting') of the substance and substance-related stimuli (Robinson and Berridge, 1993). The theory distinguishes between two affective processes in addiction: 'liking' and 'wanting'. The 'liking' response refers to experienced pleasurable effects that encourage the intake of the substance, but can decrease over time. The 'wanting' response is associated with dopamine release and refers to approach behavior elicited by the substance and substance-related stimuli (they become 'wanted' as a result of the incentive salience attributed to them due to neuro-adaptations caused by repeated use). The 'wanting' response can even occur despite reduced liking over time (Robinson and Berridge, 2008); it is related to implicit cognitive biases such as attentional bias (which implies that a person's attention is drawn by attractive substance-related cues (Robinson and Berridge, 2003; Wiers, van de Luitgaarden, Van den Wildenberg and Smulders, 2005; Field and Cox, 2008; Robinson and Berridge, 2008)) and approach bias (which can be defined as the tendency to approach attractive substance-related cues faster than one can avoid them (Field, Kiernan, Eastwood and Child, 2008; Robinson and Berridge, 2008; Wiers, Rinck, Dictus and van den Wildenberg, 2009)).

Although habit learning theories and the Incentive Sensitization Theory of Addiction provide somewhat different explanations for substance-use behavior, both agree that reactivity to substance-related stimuli forms an important component in addictive behaviors. Research in the field of addiction has, therefore, focused on the assessment of this reactivity to substance-related cues in order to unravel implicit cognitive processes that underlie addictive behaviors, with a focus on attentional and approach biases triggered by the substance and substance-related cues (Stacy and Wiers, 2010).

\section{Attentional bias and approach bias in addictive behaviors}

Implicit cognitive biases such as attentional and approach biases can undermine performance of the desired behavior (e.g., not smoking). Studies in the field of addictive behaviors have demonstrated that implicit cognitions predict a unique variance in behavior and suggest that explicit and implicit cognitions independently predict behavior (Stacy, 1997; Wiers et al., 2002; Strack and Deutsch, 2004; Rooke, Hine and Thorsteinsson, 2008). As a consequence, in the last decade researchers have started to use implicit measures to assess substancerelated cognitions (Stacy, 1997; Wiers et al., 2002; Wiers, van Woerden, Smulders and de Jong, 2002; Wiers and Stacy, 2006). As mentioned before these 
implicit cognitive processes are not measured by self-report assessments: it is assumed that by measuring these cognitions indirectly, processes that involve self-reflection can be avoided and important implicit processes are more likely to be revealed (Stacy and Wiers, 2010).

Attentional bias has mostly been measured using applications of the Visual Probe (VP) task (for a review see, Field and Cox, 2008), which normally presents two pictures on a screen (one substance-related picture and one matched neutral picture) followed by the presentation of a probe (e.g., an arrow pointing up or down). In this example, the participant is generally asked to identify the direction of the arrow. In the assessment version of the task, the arrow appears equally often behind the substance-related picture and the neutral picture: attentional bias is then calculated by subtracting the response times on the substance-related pictures from the reaction times on the neutral pictures. Studies have associated substance use in general and smoking behavior specifically with a stronger attentional bias towards the substance-related stimulus (for reviews see, Cox, Fadardi and Pothos, 2006; Field and Cox, 2008).

Approach bias is often measured with the Stimulus Response Compatibility (SRC) task (see e.g., De Houwer, Crombez, Baeyens and Hermans, 2001; Mogg, Bradley, Field and De Houwer, 2003) which also consists of a substance-related and a neutral picture, but which are now presented one by one. Respondents in the SRC task receive the instruction to move a manikin (little man) towards substance-related pictures and away from neutral pictures in the one block (approach block) and vice versa in another block (avoidance block). Studies have shown that addictive behaviors in general and smoking specifically are related to a relatively fast approach of substance-related cues (Mogg, Bradley, Field and De Houwer, 2003; Field, Eastwood, Bradley and Mogg, 2006; Field and Cox, 2008).

These fairly consistent findings from research on the role of attentional and approach biases in the field of substance use in general and smoking behavior specifically provide an alternative base for smoking relapse prevention programs. An important goal of this dissertation was, therefore, to gain more insight into the role of implicit cognitive biases (i.e., attentional bias and approach bias) in the process of smoking relapse and to develop a smoking relapse prevention program that targets implicit cognitions and fosters abstinence in smokers who are motivated to quit smoking. The content of this program is explained in the following section.

\section{PREDICTING AND PREVENTING SMOKING RELAPSE}

All in all, the theoretical frameworks and empirical studies outlined in the previous section suggest that implicit cognitions and a range of pre-motivational, motivational and post-motivational factors may need to be targeted in order to 
prevent relapse successfully. These conclusions led to the series of studies described in this dissertation.

As a first step, two preparatory studies were needed to further understand the most important factors that predict smoking relapse since our understanding of these factors needed further sharpening and action planning components and implicit cognitions were relatively under-studied with regard to smoking relapse. Next, the studies reported on in this dissertation aimed to target the most evident pre-motivational, motivational and post-motivational factors using a Web-based computer-tailored program and to combine this feedback with preparatory and coping planning strategies. Since most current health education interventions, including computer-tailored interventions, are based on the assumption that behavior is determined by explicit processes and ignore less conscious processes, an important goal of this dissertation was also to make a first step towards targeting smoking relapse using implicit cognitive bias modification strategies. This was done by developing an attentional bias modification training program in order to target implicit cognitions underlying smoking relapse.

Consequently, the two prevention programs developed and tested in a randomized trial were: a) The SQ4U (Stay Quit for You) program, consisting of two computer-tailored versions that both incorporated six planning strategy assignments (with one version providing tailored feedback only once and the other on multiple moments after the quit-attempt), and b) Train Yourself Smokefree, an implicit attentional bias modification training. The programs were based on the results from the two preparatory studies, combined with what is known from theory and empirical studies. The development and evaluation of these programs were part of the present dissertation and are briefly outlined below.

\section{The SQ4U program}

The rationale for the most important decisions made in the development of the SQ4U program is outlined below.

\section{Computer-tailored approaches}

Translation of theoretical factors into practice can be realized via different practical strategies (Bartholomew, Parcel, Kok, Gottlieb and Fernandez, 2011). One successful self-help strategy concerns computer-tailored approaches to changing various health-related behaviors (Kreuter, Strecher and Glassman, 1999; Kreuter, 2000; Al-Ahmadi and Oraif, 2009; Shahab and McEwen, 2009). Computer tailoring refers to a process of developing personalized intervention materials and strategies and is defined as "any combination of information or change strategies intended to reach one specific person, based on characteristics 
that are unique to that person, related to the outcome of interest, and derived from an individual assessment (p1)" (Kreuter, 2000). Feedback can contain information or strategies and is based on the respondents' individual answers to questions that are related to health or the behavioral outcome of interest (Kreuter, 2000). If-then algorithms are used to link the respondents' input to feedback that fits their unique situations and are based on theoretical frameworks and empirical studies (Brug, Campbell and van Assema, 1999; Kreuter, 2000).

Computer-tailored interventions have been shown to be effective in fostering healthy behavior in general and smoking cessation in particular. Several studies have shown that computer tailoring is generally more effective than no feedback or usual care (Brug, Kok, van Breukelen, Glanz and van Assema, 1998; Dijkstra, De Vries and Roijackers, 1998; Etter, 2005; Oenema, Tan and Brug, 2005; Strecher, Shiffman and West, 2005; Kroeze, Werkman and Brug, 2006). Due to their behavioral successes and potential to change the factors from the IChange Model, computer-tailored approaches form a promising tool for preventing smoking relapse. Therefore, the SQ4U program was imbedded in a computer-tailored format that provided information and specific behavioral change techniques to change the pre-motivational, motivational and post-motivational factors that are emphasized in the I-Change Model as well as the factors derived from the two preparatory studies conducted in this dissertation.

\section{Delivery mode, number of feedback moments and type of feedback}

Computer-tailored feedback can be delivered using printed materials or modern technologies such as the Internet and mobile devices. Both approaches have advantages and limitations.

Traditional computer-tailored approaches utilizing printed materials may be limited because they make it impossible to provide tailored feedback immediately after the respondents give their input (Brug, Oenema and Campbell, 2003). A longer time interval between answering the questions and receiving feedback may be a limitation because the respondent's situation may change over time, resulting in the provision of inadequate feedback (Brug, Oenema and Campbell, 2003). In recent years, computer-tailored feedback has also been provided using the Internet, which has been shown to be a promising delivery mode for computer-tailored health promoting and lifestyle changing interventions (see for instance, Brug, Campbell and van Assema, 1999; Walters, Wright and Shegog, 2006; Vandelanotte, Spathonis, Eakin and Owen, 2007; Te Poel, Bolman, Reubsaet and de Vries, 2009)). In the Netherlands, 91\% of households have Internet access so it could potentially reach large numbers of people (CBS, 2011). Using the Internet to provide computer-tailored feedback has many advantages such as lower costs, higher reach and more interactivity. It also takes less time to provide feedback and the time frame between filling out the questionnaire and receiving the feedback is short, so that adequate feedback can be 
provided (Brug, Oenema and Campbell, 2003). Based on these advantages, the SQ4U program is built in a Web-based format.

Next, providing intensive support has been demonstrated to increase smoking abstinence rates (Fiore, 2008). Computer-tailored programs can consist of a single or multiple feedback moments. With regard to smoking cessation and abstinence, it has been demonstrated that providing tailored feedback at multiple moments is more effective than providing a single tailored feedback moment (Dijkstra, De Vries, Roijackers and van Breukelen, 1998; Borland, Balmford and Hunt, 2004). This was confirmed by a meta-analysis that showed that multiple feedback time points result in more change (Noar, Benac and Harris, 2007). Furthermore, as previously mentioned, studies using ecological momentary assessments to gain in-depth day-to-day information on the process of quitting suggest that factors that fluctuate over time and are important in the process of smoking relapse (such as self-efficacy) should be targeted from day to day after the quit-attempt (Shiffman, Paty, Gnys, Kassel and Hickcox, 1996; Shiffman et al., 1997; Gwaltney, Shiffman, Balabanis and Paty, 2005; Shiffman et al., 2007). Following these results, our computer-tailored program provided tailored feedback at multiple time points after the quit-attempt.

Finally, various types of tailored feedback can be provided (Dijkstra and De Vries, 1999). The most common types of feedback are normative and ipsative: normative feedback includes comparisons with others while ipsative feedback targets the respondent's current situation compared to previous states by reporting on decline, maintenance or progress with regard to certain behaviorrelated factors, motivation or behavior itself (Noar, Benac and Harris, 2007). It is suggested that providing ipsative feedback will increase the behavioral successes of a computer-tailored intervention. Since our intervention needed progress reports aimed at targeting crucial factors such as self-efficacy from day to day after the quit-attempt, the program included normative as well as ipsative feedback.

\section{Strategies used for modifying explicit motivational processes}

According to the I-Change Model, it is important to address multiple factors in order to achieve behavioral change and maintenance. In order to increase and reinforce motivation, it is important that behavior change programs foster the development of a positive attitude (in this context, a positive attitude towards smoking cessation). Social support is relevant since this may help smokers to start and maintain their quit-attempts. Furthermore, self-efficacy information is needed to prepare a smoker with tips on how to cope effectively with difficult situations that may trigger relapse. These strategies have been used successfully in various Dutch programs on smoking cessation, via counseling (for instance, Pieterse, Seydel, DeVries, Mudde and Kok, 2001; Bolman, de Vries and van Breukelen, 2002) and later via computer-tailored approaches (Dijkstra, De Vries 
and Roijackers, 1998; Te Poel, Bolman, Reubsaet and de Vries, 2009; Smit, de Vries and Hoving, 2012).

Two main strategies are recommended for behavior maintenance: reinforcing self-efficacy and action planning. It is important to prepare smokers for situations that may provoke relapse and to motivate them to make plans for dealing with these situations. Since coping planning interventions which aimed at identifying and dealing with risk situations have the potential to have a positive influence on smoking abstinence (O'Connell, Hosein and Schwartz, 2007; van Osch, Lechner, Reubsaet, Wigger and de Vries, 2008), the SQ4U intervention included coping planning assignments in which respondents were asked to identify high-risk smoking-related situations and to make implementation intentions in order to deal with these situations. However, because a review on prevention programs has pointed out that the effects of coping planning assignments alone may be limited (Hajek, et al., 2009), the SQ4U program combined the coping planning components with preparatory planning assignments and computer tailored feedback (the feedback targeted multiple factors from the I-Change Model) altogether in one program.

\section{Train Yourself Smoke-free program}

The rationale for the tasks used to assess and modify implicit cognitive biases in the Train Yourself Smoke-free study is outlined below.

\section{Measuring and modifying implicit cognitive biases}

As explained earlier, the VP task is an assessment instrument for attentional bias. It was introduced by MacLeod and colleagues (MacLeod, Mathews and Tata, 1986) and is widely used to measure attentional processes in substance abuse (Stomark, Field, Hugdahl and Horowitz, 1997; Townshend and Duka, 2001; Waters, Shiffman, Bradley and Mogg, 2003; Field, Mogg, Zetteler and Bradley, 2004; Noel et al., 2006; Townshend and Duka, 2007). The Visual Probe task can be used as a measurement of attentional bias as well as a retraining task (the set-up of the task was explained earlier). In measurement, the probe appears behind the neutral stimulus in $50 \%$ of the cases and behind the substance-related cue in the other $50 \%$ of the cases. Approach-avoidance tendencies are measured with the SRC task (the set-up of this task was explained earlier). The Train Yourself Smoke-free program included both the VP task and the SRC tasks as measures of implicit cognitive biases.

In addition to assessing cognitive biases, first steps have been made to manipulate these biases: a process labeled cognitive bias modification (CBM). MacLeod and colleagues (2002) adapted a version of the VP task in order to modify attentional bias towards threat-related stimuli in students with medium levels of anxiety (MacLeod, Rutherford, Campbell, Ebsworthy and Holker, 2002). In 
this adapted version of the Visual Probe task that was developed to modify attentional bias, a contingency was introduced with the probe appearing more often behind the neutral stimulus to modify the attention away from the threatrelated pictures (or behind the threat-related picture in order to modify the attention towards the threat-related picture). The training program used in the Train Yourself Smoke-free study was also based on the Visual Probe task and included a contingency with the probe appearing more often behind the neutral pictures to modify the attention away from the smoking related pictures. In assessment, however, the probe appeared equally often behind the smokingrelated pictures and the neutral pictures.

\section{Generalization effects and number of sessions}

An important question about the results of attentional bias modification programs is whether the effects generalize. Two kinds of generalization effects are generally distinguished: 'close generalization', which refers to generalized effects to untrained/new stimuli, and 'further generalization', which refers to effects on other measures of implicit cognitive bias, for instance, measures of approach bias when the training is an attentional bias modification training (see for instance, Wiers, Gladwin, Hofmann, Salemink and Ridderinkhof, in press). Note that generalization in this context does not imply generalization to other behaviors, but towards new stimuli and other cognitive biases with regard to the same behavior. 'Close generalization' is important because it indicates that the respondents' attention is modified away from substance-related stimuli in general and not only for the task-specific stimuli. 'Further generalization' is important because it shows that, for instance, an attentional bias modification program can also result in positive effects with regard to approach biases and vice versa.

The first studies to test an attentional bias modification training approach in addictive behaviors used a single-session training and showed that an attentional bias for alcohol (Field et al., 2007; Schoenmakers, Wiers, Jones, Bruce and Jansen, 2007) and smoking (Attwood, O'Sullivan, Leonards, Mackintosh and Munafo, 2008; Field, Duka, Tyler and Schoenmakers, 2009) could be modified towards and away from the substance-related stimuli. Studies utilizing a singlesession training session, however, showed no evidence of generalization effects. Next, alcohol-related studies on multiple-session attentional bias modification programs found that the results of the program did generalize to new/or untrained stimuli and even resulted in reduced drinking (Fadardi and Cox, 2009; Schoenmakers et al., 2010). Given that these studies concern alcohol, an important goal of this dissertation was to apply a multiple-session attentional bias modification training program to preventing smoking relapse. The measurement tasks included untrained pictures to assess close generalization effects and another measure of implicit bias (i.e., approach bias) to assess further generalization effects. 
Delivery mode of the attentional bias modification program

Cognitive bias modification approaches consist of computerized training and can be delivered over the Internet. However, a recent study found no effects of Internet-delivered attentional bias modification training in social anxiety (Carlbring et al., 2012), which contrasted with more positive findings from comparable trainings delivered in a clinical setting for the same disorder (Amir, Beard, Burns and Bomyea, 2009; Schmidt, Richey, Buckner and Timpano, 2009). In addition, positive effects of repeated attentional bias modification training in controlled studies of alcoholism have mostly been reported when they were added to more traditional cognitive motivational interventions. Hence, an interesting quest for this dissertation is to analyze whether a multiple-session attentional bias modification program delivered over the Internet alone can help smokers to remain abstinent after a quit-attempt.

\section{OUTLINE OF THE DISSERTATION}

This dissertation will provide an overview of studies conducted in order to understand and prevent smoking relapse among smokers who are highly motivated to quit smoking. The chapters in this dissertation report on the findings from two phases of our smoking relapse prevention project. Phase 1 aimed at gaining insight into the factors that predict relapse; it consisted of a Delphi study involving experts in the field of smoking cessation and relapse prevention and a quasiexperimental longitudinal study of smokers who were motivated to quit smoking. Phase 2 aimed at preventing smoking relapse; it consisted of two randomized controlled trials to test the efficacy of a computer-tailored relapse prevention program (SQ4U) and an attentional bias modification training program (Train Yourself Smoke-free). Seven research questions were central to these two phases.

\section{Phase 1: Predicting smoking relapse}

$\rightarrow$ In the opinion of researchers and coaches working in the area of smoking cessation and relapse prevention, what are the factors that predict and prevent smoking relapse?

$\rightarrow$ Do post-motivational factors predict smoking relapse among smokers who are highly motivated to quit smoking?

Chapter 2 describes the results of a Delphi study conducted among researchers from the field of smoking cessation and relapse prevention and coaches working with smokers in practice. The Delphi study aimed at providing an overview of the current state of knowledge with regard to the factors that are associated with smoking relapse and, in particular, the role of action planning components and implicit tendencies. Chapter 3 discusses the results of a quasi-experimental 
longitudinal study that aimed to gain insight into the role of preparatory planning and self-efficacy with regard to smoking relapse among smokers who are motivated to quit smoking. The study furthermore assessed differential effects of these post-motivational factors for smokers who quit individually (selfquitters) and smokers who quit with the help of a national smoking cessation course (group-quitters).

\section{Phase 2: Preventing smoking relapse}

- Can a computer-tailored program combined with multiple action planning assignments prevent smoking relapse?

- What is the role of making instrumental and specific action plans in the process of smoking relapse prevention?

- Can an attentional bias modification program reduce smoking-related attentional bias?

- Can an attentional bias modification program also influence another implicit cognitive bias (i.e., approach bias)?

$\vartheta$ Can an attentional bias modification program prevent smoking relapse?

Chapter 4 describes the development and design process of the SQ4U study and its two computer-tailored smoking relapse prevention programs that incorporate planning components and multiple feedback time points after the quitattempt. Chapter 5 discusses the effects of the SQ4U programs with regard to longer-term abstinence. In addition, chapter 6 shortly reports on the short-term effects of the SQ4U programs. Chapter 7 discusses in-depth analyses which use data from the two SQ4U programs and aimed to provide an overview of perceived risk situations for smoking and to assess plan quality and the role of this plan quality with regard to fostering short and longer-term abstinence. Furthermore, the latter study distinguished between situational and affective risk situations. Chapter 8 describes the short-term effects of Train Yourself Smokefree (attentional bias modification training). Finally, Chapter 9 provides a general discussion of the findings outlined in the previous chapters. 



\section{CHAPTER 2}

\section{Factors underlying smoking relapse prevention: results of an international Delphi study}

This chapter is published ${ }^{2}$ as:

Elfeddali, I, Bolman, C., Mesters, I., Wiers. R.W. and de Vries, H. (2010). Factors underlying smoking relapse prevention: results of an international Delphi study, Health Education Research, 25(6):1008-1020.

2 Note that this chapter is written in British English conform the guidelines of the journal 


\section{ABSTRACT}

No definitive picture of the factors determining smoking relapse exists, and many smoking relapse prevention programmes have only modest behavioural effects. This study aims to identify the level of consensus among and compare the opinions of two groups of experts (researchers and coaches who provide smoking cessation courses) regarding factors already studied in relation to smoking relapse, factors that have not yet been addressed and ideas on how to improve prevention programmes. A three-round Delphi method was employed. In the first round, 15 researchers completed an electronic questionnaire on factors associated with relapse. The results were used to develop a structured questionnaire for the second round, which was completed by 47 researchers and 61 coaches. The second-round results were then presented to the same experts in the third round, enabling them to re-rate their answers. Results revealed high consensus on some factors already identified as predicting relapse (e.g. self-efficacy), new factors (e.g. action planning) and several methods to improve prevention programmes. Generally speaking, the researchers and coaches provided similar suggestions. The results paint a picture of the current state of knowledge on relapse-related factors and point the way to areas for further research. 


\section{INTRODUCTION}

Smoking is the most important preventable behavioural cause of premature death and disability worldwide. In The Netherlands, $>25 \%$ of cancer-related deaths before the age of 70 result from smoking (Bonneux, Looman and Coebergh, 2003). Approximately 28\% of Dutch adults smoke (TNS-NIPO, 2009), with more men (31\%) doing so than women (25\%). At least $63 \%$ have unsuccessfully tried to quit one or more times (TNS-NIPO, 2009). Similarly, 70\% of smokers worldwide want to quit smoking (CDC, 2002), but only $7 \%$ of all attempts are generally successful (Baillie, Mattick and Hall, 1995) and multiple quit attempts are needed even then (Canada, 2001; ACS, 2010). Relapse rates are particularly high during the first weeks of an attempt (Hughes et al., 1992; Hughes, Keely and Naud, 2004).

Several studies regarding smoking relapse have been conducted. Ockene et al. (Ockene et al., 2000) emphasized being older, male and married; smoking fewer cigarettes per day and for fewer years and having a lower addiction level, more previous quit attempts, higher motivation to quit and higher self-efficacy as preventive factors of smoking relapse. Moreover, according to the relapse prevention (RP) model of Marlatt and Gordon (Marlatt and Donovan, 2005), risk factors for relapse include covert (e.g. lifestyle imbalances, urges and cravings) and immediate (e.g. high-risk situations) determinants. In addition, empirical studies mention self-efficacy, smoking outcome expectancies, craving levels, nicotine dependence, withdrawal symptoms, stress, depression, negative affect (NA) and gender (West, Hajek and Belcher, 1989; Cohen and Lichtenstein, 1990; Velicer, DiClemente, Rossi and Prochaska, 1990; Shiffman, Paty, Gnys, Kassel and Hickcox, 1996; Killen and Fortmann, 1997; Dijkstra and de Vries, 2000; West, Mcewen, Bolling and Owen, 2001; Killen, Fortmann, Varady and Kraemer, 2002; Bohadana, Nilsson, Rasmussen and Martinet, 2003; de Vries et al., 2003; Dijkstra and Borland, 2003; Kassel, Stroud and Paronis, 2003; Doran, Spring, McChargue, Pergadia and Richmond, 2004; Shiffman and Waters, 2004; Amodei and Lamb, 2005; Brown, Lejuez, Kahler, Strong and Zvolensky, 2005; Gwaltney, Shiffman, Balabanis and Paty, 2005; Pomerleau et al., 2005; Fernandez et al., 2006; Hoving, Mudde and de Vries, 2006; Shiffman et al., 2007; Shaw and al'Absi, 2008; Xu et al., 2008; Zhou et al., 2009) as associated with smoking relapse. For some of these factors, various studies have yielded conclusive findings; for others, there are only inconclusive findings.

Conclusive findings have positively associated relapse with low self-efficacy, positive smoking outcome expectancies, high craving levels and high nicotine dependence (Velicer, DiClemente, Rossi and Prochaska, 1990; Killen and Fortmann, 1997; Dijkstra and de Vries, 2000; West, Mcewen, Bolling and Owen, 2001; Dijkstra and Borland, 2003; Amodei and Lamb, 2005; Gwaltney, Shiffman, Balabanis and Paty, 2005; Zhou et al., 2009). With respect to inconclusive findings, however, one review found a positive association between withdrawal 
symptoms and relapse in only 6 of 15 studies (Patten and Martin, 1996). Furthermore, Brown et al. (Brown, Lejuez, Kahler, Strong and Zvolensky, 2005) suggested that relapse might not be predicted by the withdrawal symptoms themselves but by the NA associated with these symptoms. The literature is also inconclusive when it comes to the role of NA (including feelings of depression) and stress. Several prospective and retrospective studies (Brandon, Tiffany, Obremski and Baker, 1990; Cohen and Lichtenstein, 1990; Covey and Tam, 1990; Kinnunen, Doherty, Militello and Garvey, 1996; Kassel, Stroud and Paronis, 2003; Brown, Lejuez, Kahler, Strong and Zvolensky, 2005; Shiffman et al., 2007; Shaw and al'Absi, 2008) have positively associated relapse with NA and stress, whereas in one prospective study, daily changes in NA and stress did not predict the first lapse on the following day; yet, a rapid and immediate increase in NA did precede lapsing on that day (Shiffman and Waters, 2004). Regarding gender, being female is associated with smoking relapse in some studies (Ockene et al., 2000; Bohadana, Nilsson, Rasmussen and Martinet, 2003; Xu et al., 2008) but not in others (Killen, Fortmann, Varady and Kraemer, 2002; Hoving, Mudde and de Vries, 2006).

Other factors have received relatively less emphasis. Although the concept of planning is not new, the role of making action and coping plans in preventing smoking relapse has only recently received attention (Hoving, Mudde and de Vries, 2006; O'Connell, Hosein and Schwartz, 2007; van Osch, Lechner, Reubsaet, Wigger and de Vries, 2008). Action plans are sets of sub-goals in which thoughts, feelings and actions are aimed towards attaining a certain goal (Zimmermann, 2000; de Vries et al., 2003), whereas coping plans set out how the individual will deal with risky situations for (re)lapse, such as going to a bar (Sniehotta, Schwarzer, Scholz and Schüz, 2005). Next, some studies (such as a meta-regression analysis of 11 smoking-related studies (Cox, Fadardi and Pothos, 2006)) have indicated that implicit cognitions (e.g. attentional bias) may also play a role (Waters and Feyerabend, 2000; Ehrman et al., 2002; Waters et al., 2003). Implicit cognitions are defined as indirect measures or procedures in which constructs such as attitudes are indirectly derived from behaviour (e.g. reaction times) (Fazio and Olsen, 2003). This suggests that smokers' attention is unconsciously drawn to smoking-related stimuli, which causes cravings and subsequent relapse. Finally, the evidence to date does not support the effectiveness of relapse prevention programmes, which remain scarce in any case (Lancaster, Hajek, Stead, West and Jarvis, 2006; Hajek, Stead, West, Jarvis and Lancaster, 2009).

As the factors determining relapse are clearly not yet fully understood, this study was set up with four objectives: to gain an overview of factors that researchers and coaches (giving smoking cessation courses) consider as important for smoking relapse, to identify their opinions of relatively new concepts such as action planning and implicit cognitions, to identify factors that they feel should be included in relapse prevention programmes and to compare 
their opinions on the factors involved to examine how far the scientific findings to date have been translated to daily practice. For this purpose, we used a threeround Delphi method (a method to structure communication processes on a certain problem area among expert groups: see Methods below).

In this study, 'relapse' is defined as smoking more than five cigarettes after a quit attempt. This is in line with the Russell Standard for outcome criteria in smoking cessation trials (Robert West, 2005).

\section{METHODS}

The Delphi method - a technique for structuring communication processes among many individuals to gain consensus on certain subjects (Adler and Ziglio, 1996) - has proved valuable in providing insight into health-related issues (Pill, 1971; Meyrick, 2003; De Vet, Brug, De Nooijer, Dijkstra and Vries, 2005). It begins with an open-ended questionnaire investigating selected experts' opinions on a certain topic. The results are used to make a structured second-round questionnaire, which is presented to a larger group of panel members. Finally, this group re-evaluates the second-round outcomes in the third round (Custer, Scarcella and Stewart, 1999; Meyrick, 2003). This iterative approach allows participants to adjust their opinions when needed, and they obtain feedback from the research team on the group results after each round (Pill, 1971; Linstone and Turoff, 1975; De Vet, Brug, De Nooijer, Dijkstra and Vries, 2005). Experts remain anonymous to exclude conformity biases. Two groups of experts participated to our study: (i) researchers from the field of smoking cessation and relapse prevention and (ii) coaches giving smoking cessation courses.

\section{First round}

\section{First-round procedure and participants}

The participants for the first round were selected by the members of our project advisory board, which consisted of international and national researchers from the field of smoking cessation and relapse prevention. The members were asked to list the most important experts (according to them) from their own network using the following criteria: (i) the experts have experience in the field of smoking cessation and relapse prevention and (ii) the experts come from various fields (e.g. medical, health promotion, etc). This resulted in a list of 30 experts. These 30 smoking cessation and relapse prevention experts were invited to participate. Non-responders received a reminder after 3 weeks. Eight Dutch and seven non-Dutch experts ( $\mathrm{N}=15 ; 50 \%$ response rate) from various professional backgrounds (e.g. medicine, health promotion, pharmacology and psychology) participated. Coaches were sought only for subsequent rounds, as some first- 
round participants indicated that not all researchers have practical experience in training groups, and thus, the inclusion of coaches may be worthwhile. Hence, the later addition of the coaches.

\section{First-round questionnaire}

The first-round Internet-based questionnaire had nine open-ended questions, all aimed at eliciting the factors important for smoking relapse. These stemmed from three overarching themes. The first aimed to identify the factors that the researchers considered important in this context ('Which factors do you think are associated with smoking relapse?'). The second focused on the role of constructs that have received relatively less attention in smoking relapse prevention and on the potential importance of goal setting, action plans and implicit cognitions (e.g. 'How should action plans be used to successfully prevent smoking relapse?'). We provided definitions (the same as those provided in the introduction) of the latter two concepts, as they may have been unknown for some respondents. The final theme related to factors that the researchers felt should be integrated into smoking relapse prevention programmes.

\section{First-round analyses}

The answers resulted in a long list of various terms for comparable factors. In line with De Vet's Delphi study (De Vet, Brug, De Nooijer, Dijkstra and Vries, 2005), three different researchers grouped different terms for the same factors into one variable separately to exclude interpretation bias.

\section{Second round}

\section{Second-round procedure and participants}

The aim here was to gain a quantitative overview of the factors that researchers and coaches associate with relapse and insight into the level of consensus on these factors within and between the groups. This round started 3 months after the first, with reminders sent after 3 weeks.

Researchers' group. The researchers were identified using our project advisory board's contacts and names derived from a PsycINFO and Medline literature search, using the keywords 'smoking relapse' and 'smoking relapse prevention'. The search resulted in 176 published papers (including double hits). We selected the first authors of papers published from 2004 onwards but excluded papers about specific groups, like pregnant women, and those only about smoking cessation. This resulted in 150 researchers (including participants from the first round), of whom 47 (31\% response rate) participated in the second round. The second-round questionnaire was emailed with a link and user account to access the questionnaire. The researchers were invited to participate in the second round (and also the third round, as is common practice in Delphi stud- 
ies). Although we did not measure reasons for refusal, emails from some of the targeted researchers indicated that a lack of time was a likely factor.

Coaches' group. This group consisted of coaches professionally licensed by the Dutch Foundation for a Smoke-Free Future (Stivoro) to give smoking cessation courses. Stivoro emailed our invitations to 247 coaches. Those who agreed to participate $(\mathrm{N}=61 ; 25 \%$ response rate) were emailed a user account and link to the questionnaire. Approximately $85 \%$ had a higher vocational educational background in nursing; a few had a psychology degree. All had received training from Stivoro to give smoking cessation courses.

\section{Second-round questionnaire}

The coaches' questionnaire was in Dutch, while the researchers' questionnaire was in English to accommodate the international experts involved. The questionnaires were otherwise identical. For this second round, they consisted of 6 parts with 44 statements, 9 open-ended questions and 1 multiple-choice question (Table 2.1). The items in the first part were derived from the literature and the answers to the open-ended questions from the first round. The second, third, fourth and fifth parts were, respectively, about goal setting, action plans, implicit cognitions and relapse prevention programmes and also included items resulting from the first round. For all statements (except that referring to the time frame needed for successful relapse prevention), answers were given on a 7 -point Likert scale ( $1=$ totally agree to 7 = totally disagree); it was also possible to answer 'I don't know'.

General relapse predictors. The first part included 20 items with 17 statements about factors potentially associated with relapse. Participants were asked to rate how far they agreed with the statements (e.g. 'being female is associated with relapse') and whether they considered the factors mentioned as important relapse predictors. Two open-ended questions followed on the role of personality and emotions. A final open-ended question then asked participants to list the five most important relapse predictors.

Goal setting. The second part contained five closed-ended statements about the importance of goal setting and how to accomplish it successfully.

Action planning. The third part contained eight closed-ended statements about the role of action planning and how to achieve it successfully.

Implicit cognitions. The fourth part contained five closed-ended statements about the role of implicit cognitions in relapse prevention and one open-ended question allowing the respondent to elaborate on other important aspects of implicit cognitions.

Smoking relapse prevention programmes. The fifth part consisted of 14 items: 9 questions focusing on whether the concepts mentioned (e.g. skills training) should be included in relapse prevention programmes and 5 open-ended questions ( 2 seeking in-depth information about a given statement and 3 asking 
whether education- and gender-specific items should be included in relapse prevention programmes and if so, which).

Time frame. A final multiple-choice question asked about the time (duration of an intervention) needed for successful smoking relapse prevention. The answers were given using the following answer categories: 1 = a couple of days, 2 $=$ a couple of weeks, $3=1-5$ months, $4=6$ months, $5=$ one year, $6=$ two years and 7 = five years.

\section{Second-round analyses}

The closed-ended statements were analysed using median scores to characterize the score above and below which $50 \%$ of the answers fell and interquartile deviations (IQDs) to represent the data spread. The measure for the data spread was used to analyse whether consensus was reached on a certain statement. The IQD is the distance between the 25 th and the 75 th percentiles, with a smaller value indicating a small data spread. An IQD $<1$ is considered to be good consensus on a 7 -point scale, meaning that $50 \%$ of all cases fall within 1 point of one another (Linstone and Turoff, 1975). Differences in consensus between the researchers and the coaches were analysed using Wilcoxon signed-rank sum tests.

\section{Third round}

\section{Third-round procedure and participants}

The researchers $(\mathrm{N}=47)$ and coaches $(\mathrm{N}=61)$ were invited to participate in the third round 3 months after the second round. A reminder was sent to nonresponders after 3 weeks. In total, 39 of the 47 researchers (83\% response rate) and 52 of the 61 coaches (85\% response rate) participated. The aim of this round, in line with the Delphi method (see the first paragraph of the Methods section), was to gain more consensus on the statements by presenting the second-round results in a questionnaire and giving the participants a chance to rerate their answers on the basis of the summary of expert opinions. Each median answer from the second round was written in capital letters and the IQD score appeared after each statement (see Third-round questionnaire below).

\section{Third-round questionnaire}

The second-round questionnaire built on the second-round results of each participant group was used as the third-round questionnaire. Information on interpreting the results was provided. Items on which the participants already showed consensus were excluded, as were the open-ended questions. The researchers' and coaches' questionnaires consisted of 15 and 8 closed-ended questions, respectively. Participants were asked to fill out the questionnaire and to re-rate their answers based on the second-round results. 


\section{Third-round analyses}

Again, agreement and consensus were measured using median scores and IQD. Wilcoxon signedrank tests were used to analyse the changes in consensus between the second and third rounds for both groups separately.

Table 2.1 Second- and third-round results of the 'researchers' and 'coaches' groups per item

\begin{tabular}{|c|c|c|c|c|c|c|c|c|c|c|c|c|c|c|c|c|}
\hline & \multicolumn{8}{|c|}{ Researchers } & \multicolumn{8}{|c|}{ Coaches } \\
\hline & \multicolumn{4}{|c|}{ Second round } & \multicolumn{4}{|c|}{ Third round } & \multicolumn{4}{|c|}{ Second round } & \multicolumn{4}{|c|}{ Third round } \\
\hline & $N$ & Mdn & IQD & $\%$ & $N$ & Mdn & IQD & $\%$ & $N$ & Mdn & IQD & $\%$ & $N$ & Mdn & IQD & $\%$ \\
\hline \multicolumn{17}{|l|}{ Part 1. factors associated with relapse* } \\
\hline Being female is associated with relapse & 44 & 3.5 & 2.75 & 10.6 & 34 & 4 & 1 & 7.7 & 57 & 6 & 2 & 4.9 & 51 & 6 & $\mathbf{0}$ & 1.9 \\
\hline $\begin{array}{l}\text { There is no association between being } \\
\text { younger and relapse }\end{array}$ & 45 & 6 & 2 & 25.5 & 38 & 5.5 & 1 & 10.3 & 52 & 4 & 3 & 19.7 & 49 & 5 & 2 & 7.7 \\
\hline $\begin{array}{l}\text { A high number of years' smoking is } \\
\text { associated with relapse }\end{array}$ & 45 & 2 & 1 & 36.2 & & & & & 48 & 3 & 1 & & & & & \\
\hline $\begin{array}{l}\text { Relapse is associated with a high addiction } \\
\text { level }\end{array}$ & 46 & 2 & 1 & 83 & & & & & 61 & 2 & 1 & 54.1 & & & & \\
\hline Craving is associated with relapse & 46 & 2 & 1 & 74.5 & & & & & 60 & 2 & 1 & 60.7 & & & & \\
\hline $\begin{array}{l}\text { The number of unsuccessful quit attempts is } \\
\text { NOT associated with relapse }\end{array}$ & 43 & 5 & 3 & 34 & 38 & 6 & 1 & 33.3 & 61 & 5 & 3 & 27.9 & 51 & 5 & 1 & 21.2 \\
\hline $\begin{array}{l}\text { Low abstinence self-efficacy is associated } \\
\text { with relapse }\end{array}$ & 44 & 2 & 1 & 72.3 & & & & & 61 & 2 & 1 & 80.3 & & & & \\
\hline $\begin{array}{l}\text { Having positive outcome expectations of } \\
\text { smoking is associated with relapse }\end{array}$ & 43 & 2 & 1 & 34 & & & & & 60 & 2 & 1 & 63.9 & & & & \\
\hline $\begin{array}{l}\text { Relapse is associated with negative emotions } \\
\text { Open: if you think negative emotions are } \\
\text { associated with smoking, what kind of } \\
\text { emotions do you mean? }\end{array}$ & 45 & 2 & 1 & 53.2 & & & & & 61 & 2 & 1 & 70.5 & & & & \\
\hline $\begin{array}{l}\text { Depression after smoking cessation is } \\
\text { associated with relapse }\end{array}$ & 45 & 2 & 1 & 55.3 & & & & & 56 & 2 & 1 & 54.1 & & & & \\
\hline $\begin{array}{l}\text { There is no association between relapse and } \\
\text { personality }\end{array}$ & 36 & 5 & 2 & 21.3 & 36 & 6 & 1 & 15.4 & 58 & 5.5 & 1 & 39.3 & & & & \\
\hline \multicolumn{17}{|l|}{$\begin{array}{l}\text { Open: if you think personality is associated } \\
\text { with relapse, what kind of personality do } \\
\text { you mean? }\end{array}$} \\
\hline Relapse is associated with high stress levels & 45 & 2 & 1 & 68.1 & & & & & 60 & 2 & 0.75 & 78.7 & & & & \\
\hline $\begin{array}{l}\text { Having psychosocial problems is associated } \\
\text { with relapse }\end{array}$ & 45 & 2 & 1 & 59.6 & & & & & 61 & 2 & 1 & 77 & & & & \\
\hline $\begin{array}{l}\text { Relapse is not associated with the presence of } \\
\text { smokers in the social environment }\end{array}$ & 45 & 6 & 1 & 72.3 & & & & & 61 & 6 & 1 & & & & & \\
\hline $\begin{array}{l}\text { Not having adequate coping strategies is } \\
\text { associated with relapse }\end{array}$ & 45 & 2 & 1 & 61.7 & & & & & 60 & 2 & 0.75 & 68.9 & & & & \\
\hline Relapse is associated with lack of motivation & 45 & 2 & 2 & 61.7 & 35 & 2 & 1 & 61.5 & 60 & 2 & 2 & 72.1 & 50 & 2 & $\mathbf{0}$ & 86.5 \\
\hline $\begin{array}{l}\text { Not using pharmacological aids is associated } \\
\text { with relapse }\end{array}$ & 45 & 3 & 3 & 36.2 & 38 & 3 & 1 & 30.8 & 60 & 4 & 3 & 19.7 & 52 & 4 & 2 & 7.7 \\
\hline \multicolumn{17}{|l|}{ Open: top five of predictors of relapse } \\
\hline \multicolumn{17}{|l|}{ Part 2: goal setting* } \\
\hline $\begin{array}{l}\text { Goal setting plays an important role with } \\
\text { regard to relapse }\end{array}$ & 43 & 2 & 1 & & & & & & 60 & 2 & 1 & & & & & \\
\hline \multicolumn{17}{|l|}{ Effective goal setting can be achieved by ... } \\
\hline Setting specific, concrete, proximal goals & 42 & 2 & 1 & & & & & & 59 & 2 & 1 & & & & & \\
\hline Setting challenging goals & 42 & 4 & 3 & & 38 & 4 & 2.25 & & 60 & 3 & 1.75 & & 50 & 3 & 1 & \\
\hline Setting realistic and attainable goals & 43 & 2 & 1 & & & & & & 60 & 1.5 & 1 & & & & & \\
\hline Being committed to the goal & 42 & 2 & 1 & & & & & & 59 & 1 & 1 & & & & & \\
\hline
\end{tabular}


Table 2.1 Continued

\begin{tabular}{|c|c|c|c|}
\hline \multicolumn{2}{|l|}{ Researchers } & \multicolumn{2}{|l|}{ Coaches } \\
\hline Second round & Third round & Second round & Third round \\
\hline
\end{tabular}

Part 3: action plans*

Action plans are very important in relapse prevention

Action plans should aim at ...

4521

$\begin{array}{lll}60 & 1 & 1\end{array}$

Identifying risky situations

Bringing risky situations for certain individuals to light

Users' commitment to the action plan

Developing coping strategies for risky

situations

Practicing coping skills for risky situations

Making emergency plans to deal with weak

moments or even relapse

Evaluating success/failure (e.g. why did

relapse occur, what can be changed in order

to prevent relapse, which factors

contributed to successful abstinence?)

\section{Part 4: implicit cognitions*}

Implicit cognitions are very important in

relapse prevention

Implicit cognitions are especially important for ...

Gathering information about anticipatory cognitions

Gathering information about functional cognitions

Mediating urges and craving

$\begin{array}{lll}45 & 1 & 1\end{array}$

4021

$\begin{array}{lll}60 & 2 & 1\end{array}$

4322

$\begin{array}{lll}45 & 1 & 1\end{array}$

$\begin{array}{lll}38 & 2 \quad 0\end{array}$

60111

4421

$\begin{array}{lll}45 & 2 & 1\end{array}$

4521

$\begin{array}{lll}37 & 2 & 1\end{array}$

$\begin{array}{lll}32 & 3 & 2\end{array}$

3132

$\begin{array}{lll}35 & 2 & 1\end{array}$

Bringing to light what leads people when they $\begin{array}{lll}36 & 2 & 1\end{array}$

are not conscious of their actions

Open: something else?

Part 5: relapse prevention programmes*

The following concepts should definitely be included in relapse prevention programmes Cognitive and behavioural coping skills

Skills training

Identifying risky situations

Emergency plans to deal with moments of weakness

Preparation for failure

Recognition of early-relapse warning signs Intensive support

Open: if you think intensive support should be included, what kind of support do you mean?

Pharmacotherapy
$42 \quad 1 \quad 1$

$\begin{array}{lll}40 & 2 & 1\end{array}$

$42 \quad 2 \quad 1$

$\begin{array}{lll}41 & 2 & 1\end{array}$

$\begin{array}{lll}40 & 2 & 2.75\end{array}$

$\begin{array}{lll}42 & 2 & 1\end{array}$

$\begin{array}{lll}42 & 3 & 2\end{array}$

4223

$\begin{array}{lll}60 & 2 & \text { 1 } \\ 60 & 2 & \text { 1 } \\ 60 & 1 & \mathbf{1} \\ 60 & 1 & \mathbf{1} \\ 59 & 2 & 2 \\ 60 & 1 & \mathbf{1} \\ 60 & 2 & \mathbf{1}\end{array}$

$\begin{array}{lll}60 & 1 & 1\end{array}$

$\begin{array}{lll}60 & 1 & 1\end{array}$

$\begin{array}{lll}60 & 2 \quad 1\end{array}$

$\begin{array}{lll}60 & 2 \quad 1\end{array}$

$\begin{array}{lll}60 & 1 & 1\end{array}$

$\begin{array}{lll}58 & 2 & 1\end{array}$

$\begin{array}{lll}53 & 2 & 1\end{array}$

$\begin{array}{lll}53 & 2 & 1\end{array}$

$\begin{array}{lll}58 & 2 & \mathbf{1 . 2 5}\end{array}$

$\begin{array}{lll}57 & 21\end{array}$

$\begin{array}{llllll}38 & 2 & 1 & 59 & 2 & 2 \\ 38 & 2 & 2 & 60 & 1 & \mathbf{1} \\ 38 & 2 & \mathbf{1}\end{array}$

$382 \quad 2$

$502 \quad$ 0

$\begin{array}{llll}50 & 2 & \mathbf{0} \\ 51 & 3 & \mathbf{1}\end{array}$


Table 2.1 Continued

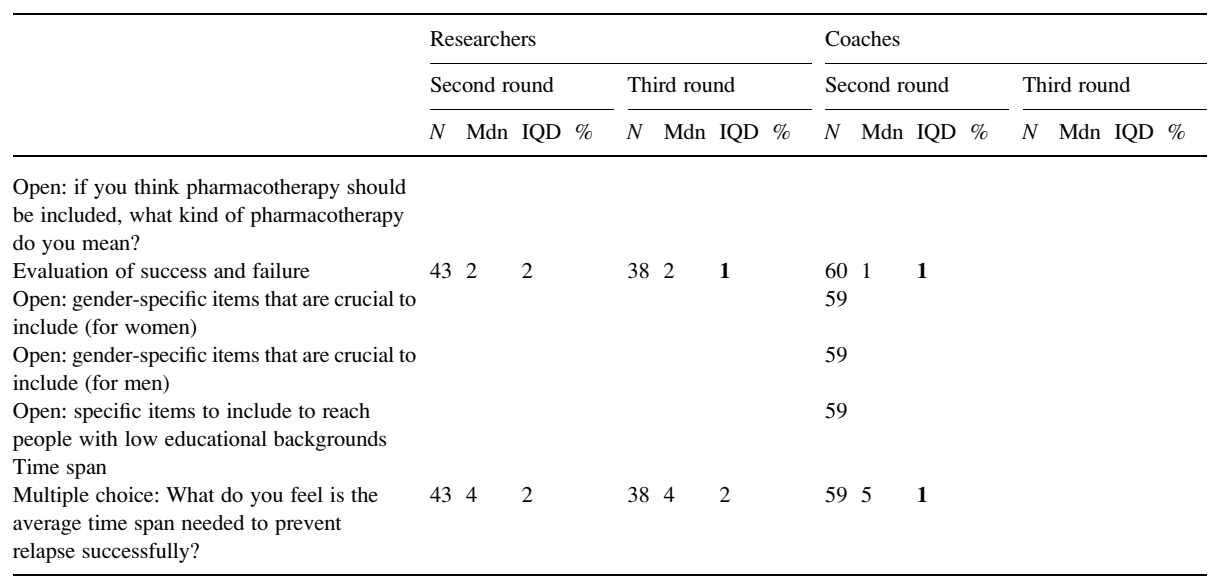

All questionnaire items are included, including the open-ended questions. The parts marked with * were answered on a 7 -point scale $(1=$ totally agree, $2=$ agree, $3=$ agree a little, $4=$ neutral, $5=$ disagree a little, $6=$ disagree, $7=$ totally disagree and $8=\mathrm{I}$ don't know). The multiple choice question was answered with 1 = a couple of days, 2 = a couple of weeks, $3=1-5$ months, $4=6$ months, $5=$ one year, 6 = two years, 7 = five years. Statements on which consensus (IQD $\leq 1$ ) was reached in the second round were excluded from the third-round questionnaire. Numbers for these therefore do not appear in the table. $\mathrm{N}$ represents the number of participants who answered the question. The percentages behind the closed-ended statements in Part 1 represent the percentage (only asked in the first part of the questionnaire) of respondents who answered that the concept in question is an important predictor of relapse. The bold values represent the items on which consensus (IQD $\leq 1$ ) was reached.

\section{RESULTS}

The results showed how much consensus had been reached on the outlined factors, as well as the discrepancies and similarities in the expert opinions. Indepth information on the open-ended questions is reported below.

\section{First-round results}

The first round yielded 45 closed-ended and 9 open-ended relevant items for the second-round questionnaire. Table 2.1 shows the second-round questionnaire, including all determinants mentioned in the first round.

\section{Second-round results}

The second-round results provided insight into the level of expert consensus (IQD $\leq 1)$, implying conformity, on a certain answer. Median scores (Mdn) were 
given to show whether there was agreement $(\mathrm{Mdn} \leq 3)$ or disagreement $(\mathrm{Mdn} \geq$ 5) within the item on which consensus was reached, with a score of 4 indicating neutrality.

\section{Second-round researchers' results}

Consensus (IQD $\leq 1$ ) was reached on 30 of the 45 items (see Table 2.1). For 29 of these, the researchers reached consensus by way of agreeing $(M d n \leq 3)$ with the item. These included the positive association between relapse and a high number of years of smoking, high addiction level, craving, low abstinence selfefficacy, positive outcome expectations of smoking, negative emotions, depression, high stress levels, psychosocial problems and inadequate coping strategies.

The results also indicated that goal setting, action planning and implicit cognitions were seen as important factors in relapse prevention. According to the researchers, effective goal setting could be reached by committing to and setting specific and realistic goals. They pointed out that in action planning, one should aim at identifying risky situations, developing coping strategies for these situations, practising the coping strategies and making emergency plans in case of failure. Finally, the results showed that success and failure need to be subsequently evaluated.

Implicit cognitions were mentioned as important in mediating urges and cravings and in providing information about how people are unconsciously led by their implicit associations. In this section, which consisted of five statements, $20-35 \%$ of the researchers answered 'I don't know'.

Cognitive and behavioural coping skills, skills training in general, emergency plans, the identification of risky situations and the recognition of early-relapse warning signs were seen as key aspects of successful relapse prevention programmes.

For one item in Part 1, consensus was reached by way of disagreement (Mdn $\geq 5$ ) with the item. However, the negative formulation of the sentence ('relapse is NOT associated with the presence of smokers in the social environment') implied that the experts agreed with the association between relapse and the presence of smokers in the social environment.

\section{Second-round coaches' results}

The coaches' group results are depicted in Table 2.1. In this group, consensus (IQD $\leq 1)$ was reached on 37 of the 45 items and agreement (Mdn $\leq 3)$ on 35 of those 37. The coaches reached consensus not only on all statements as the researchers but also on concepts like the association between relapse and personality/a high number of cigarettes smoked. Commitment to the action plan was seen as important, and consensus was also reached on the role of implicit cognitions in gathering information. In this section, $3-12 \%$ of the coaches answered 'I don't know'. Intensive support and the evaluation of success and failure were seen as important for successful relapse prevention in addition to the factors 
already mentioned in the researchers' group. Finally, consensus was reached about the time span of 1 year being needed to successfully prevent relapse. Coaches disagreed that there is $\mathrm{NO}$ association between relapse and personality and that relapse is NOT associated with the presence of smokers in the social environment. Thus, they were of the opinion that personality and smokers in the environment do matter.

\section{Similarities and differences between the researchers' and coaches' groups}

Many similarities were observed in the researchers' and coaches' opinions, although the statistical data showed a non-significant $(z=-1.774, P=0.076)$ difference between the overall consensus in the two groups. Therefore, more consensus was reached by the coaches than by the researchers. Comparing both groups' consensus in each part of the questionnaire separately revealed no significant differences.

\section{Open-ended questions}

The open-ended questions highlighted several unique factors mentioned by only some experts. Anger management for male smokers, weight management for female smokers, social support, relaxation training, the use of multiple sensory modalities and the use of visually attractive information for low-socioeconomic status (SES) smokers were suggested as possible key factors in preventing relapse in these particular groups.

\section{Third-round results}

\section{Third-round researchers' results}

In the third round, the researchers reached consensus (IQD $\leq 1$ ) on 40 of the 45 items and agreement on 34 of those 40 (Mdn $\leq 3$; see Table 2.1). Besides the items mentioned in the second round, consensus was reached on the positive association between relapse and lack of motivation and on the importance of developing coping strategies for risky situations, while some consensus was reached by agreeing on the association between relapse and not using pharmacological aids. Both preparation for failure and evaluation of success and failure were seen as important for successful smoking relapse prevention programmes.

On four items, consensus was reached by way of disagreement $(\mathrm{Mdn} \geq 5)$. In addition to the factors mentioned in the second round, the researchers disagreed that there is no association between relapse and being younger, the number of unsuccessful quit attempts and personality, suggesting that these concepts do matter. Lastly, the researchers were neutral about the associations between relapse and being female and the function of implicit cognitions in gathering information about functional cognitions. 


\section{Third-round coaches' results}

In this group, consensus was reached on 43 of the 45 items (see Table 2.1): consensus by agreement for 39 and consensus by disagreement for 4 of these 43 items. In addition to the factors mentioned in the second round, the coaches reached consensus on the association between relapse and lack of motivation, the importance of setting specific, concrete goals, the importance of preparation for failure and the inclusion of pharmacotherapy in successful prevention programmes. They disagreed about the association between relapse and being female, and there was some disagreement about the absence of an association between relapse and unsuccessful quit attempts.

After the third round, there were still some items on which no consensus had been reached. The researchers fell short of consensus on the importance of setting challenging goals for successful goal setting, gathering information about anticipatory cognitions as a function of implicit cognitions, the time span needed to successfully prevent relapse and the importance of intensive support and pharmacotherapy in successful smoking relapse programmes. The coaches fell short of consensus on the association between relapse and being younger/ not using pharmacological aids.

\section{Differences in consensus between the second and third rounds}

Compared with the second round, the third round showed an overall significant increase in consensus among both the researchers $(\mathrm{z}=-3.108 ; \mathrm{P}<0.01)$ and the coaches $(\mathrm{z}=-2.656 ; \mathrm{P} \leq 0.01)$. For each part of the questionnaire separately, both the researchers $(\mathrm{z}=-2.232 ; \mathrm{P}<0.05)$ and the coaches $(\mathrm{z}=-2.070 ; \mathrm{P}<0.05)$ showed a significant increase in consensus in the third round when only the first part of the questionnaire was considered. No significant changes were found in either group for the other parts.

\section{DISCUSSION}

Our first objective was to identify factors important for smoking relapse using expert opinions. Our findings correspond with those reported by Ockene et al. (Ockene et al., 2000). The experts associated being younger; smoking for many years and having a high addiction level, previous quit attempts, lack of motivation to quit and low self-efficacy with relapse. Comparable results were found among the coaches, although they did not reach consensus on the association between relapse and being younger. In addition, both expert groups reached consensus for stress, depression and NA; the literature, in contrast, is ambivalent regarding these factors. Our experts associated high stress levels with relapse, this time in line with previous studies (Kassel, Stroud and Paronis, 2003; Brown, Lejuez, Kahler, Strong and Zvolensky, 2005; Shaw and al'Absi, 2008). It has been reported that people with a history of depression are vulnerable to 
relapse (Covey, Glassman, Stetner and Becker, 1993), including because they experience more abstinence symptoms (Covey and Tam, 1990). Gilbert et al. (Gilbert, Crauthers, Mooney, McClernon and Jensen, 1999) demonstrated that some predictors of smoking relapse are also markers of NA. Furthermore, more cigarettes are smoked during NA periods (Pomerleau, Fertig and Shanahan, 1983), and NA has been positively associated with (re)lapse (Shiffman, Paty, Gnys, Kassel and Hickcox, 1996; Shiffman et al., 2007). Yet, the direct association between relapse and NA remains unclear and thus still requires further research (Shiffman, Kassel, Gwaltney and McChargue, 2005). In general, however, our findings are in line with the RP model of Marlatt and Gordon (Marlatt and Donovan, 2005) in terms of the importance of negative emotional states, selfefficacy, urges and overall stress levels.

Our second aim was to obtain an overview of expert opinions of relatively new, but potentially important, factors concerning relapse. Both expert groups reached strong consensus on the importance of goal setting and action planning in relapse prevention. This supports a previous study which showed that abstinence was related to high levels of sub-goal achievement (as the latter fostered increased self-efficacy) and that abstainers set fewer goals but achieved more of them than smokers (Borrelli, 1994). Our findings also support an earlier Dutch study in which action planning was shown to protect against relapse (Hoving, Mudde and de Vries, 2006). Still, despite the consensus on action plans, more research is needed to investigate which plans and goals can feasibly or should be set (Borrelli (Borrelli, 1994), for example, suggests that setting many goals may be counterproductive). Consensus was also reached on the importance of implicit cognitions in relapse prevention, yet their working mechanisms were not fully understood by either group: $3-12 \%$ of coaches and $20-35 \%$ of researchers answered 'I don't know' to this question. The fact that implicit cognition is a broad construct may have caused some confusion here, and the high percentage of researchers answering 'I don't know' might be explained by their being more aware of the issues surrounding its definition.

Our third aim was to identify key factors to include in prevention programmes. Both expert groups confirmed the importance of training in coping and other skills, developing emergency plans to deal with lapses and identifying risky situations. Unlike the researchers, however, the coaches were keen to include intensive support in cessation programmes. They also estimated that 1 year is needed to quit successfully, whereas the researchers did not reach consensus on a time span. Future research could thus examine the contribution of intensive support and the approximate time needed to quit. Furthermore, the researchers fell short of consensus on the importance of pharmacotherapy in relapse prevention programmes but reached consensus on the association between relapse and not using pharmacological aids (whereas the coaches indicated precisely the reverse). These differing viewpoints might result from coaches focusing more on prevention programmes rather than relapse predic- 
tors. Stead et al. (Stead, Perera, Bullen, Mant and Lancaster, 2008) conclude that nicotine replacement therapies (NRT) help smokers to quit but that relapse rates might rise after the treatment. NRT as well as non-nicotine pharmacotherapy (e.g. Bupropion) (Ockene et al., 2000; Strasser, Pickworth, Patterson and Lerman, 2004; Hoving, Mudde and de Vries, 2006) has been associated with higher smoking abstinence. However, reviews call for more research into the role of NRT in smoking relapse given that NRT has to date mostly been studied in small samples and usually as an add-on to Bupropion (Stead, Perera, Bullen, Mant and Lancaster, 2008; Hajek, Stead, West, Jarvis and Lancaster, 2009).

Although the Delphi method yielded useful information on the experts' opinions of the factors and the consensus reached by each group, it has some methodological limitations. First, the number of experts consulted was necessarily limited; their opinions are thus not necessarily representative. Second, we only invited first authors for participation, who might not always have been the 'expert'. To ameliorate this, we asked the participants to inform us if they felt they did not have enough expertise to answer the questions. Similarly, the researchers were selected based on their participation in relapse prevention studies. This may have introduced bias and thus potentially threaten the generalizability of the results. Third, the comparison between the researchers and coaches might be confounded by the fact that the coaches were a more homogenous (as they all received the same training) national group, while the researchers were a more international and potentially more heterogeneous group. Moreover, we did not have any information with regard to the practical experience of the coaches, the time that has lapsed since they were trained and the differences in experience between the coaches. Nevertheless, this study yields an impression of the similarities and differences of opinion between experts from the practicebased versus 'theoretical' fields. Another limitation may be the low response rates, which could have biased the results. However, the response rates mentioned represent the percentage of experts who responded to our first invitation, not the experts we lost to follow-up. Moreover, these rates increased progressively, rising to $80 \%$ in the third round. This indicates that we lost few experts to follow-up, which is an important precondition for the success of Delphi studies (Hsu and Sandford, 2007). Additionally, other Delphi studies have showed comparable response rates in the second round (De Vet, Brug, De Nooijer, Dijkstra and Vries, 2005; Crutzen et al., 2008). On a different note, another possible limitation may be that the inclusion of questions on relatively new factors, such as implicit cognitions, may have prompted experts to respond more positively. Yet this study nevertheless gives a preliminary overview of the experts' opinions with regard to these factors. Next, it may also be seen as a limitation that only researchers participated in the first round. The inclusion of coaches could have resulted in a different list; yet in the second round, the coaches did not indicate that they felt any items were lacking. Finally, the opin- 
ions of highly experienced experts might have been underestimated, as the opinions of all experts were equally weighted in the analyses.

Despite these limitations, the present study shows that experts from the scientific- and practice-based fields of smoking relapse agree on the role of smoking many cigarettes per day and for many years; being female; having a high addiction level, previous attempts to quit, having a low motivation to quit and low self-efficacy, and depression, NA and stress. However, the coaches did not reach consensus on the role of being younger or the use of pharmacological aids. Second, relatively new factors like goal setting, action planning and implicit cognitions were seen by both groups as important for smoking relapse prevention. Hence, although some of these have already been incorporated into relapse prevention programmes, the lack of evidence-based interventions emphasizing their importance implies a need to further develop and test these strategies. Third, both experts groups agreed on the importance for relapse prevention programmes of training coping and other skills, developing emergency plans to deal with lapses and identifying risky situations. Further promising factors were also identified via open-ended questions: anger management for male smokers, weight management for female smokers and relaxation training, multiple sensory modalities and visually attractive information for low-SES smokers. This may imply a need for future research to test the impact of these factors. More research should also examine the role of pharmacotherapy in relapse prevention, as neither the literature nor the experts were clear on its effects. Fourth, the two groups displayed far more similarities of opinion than differences, suggesting that knowledge transfer between them is reasonably successful. The most apparent differences concerned the roles of being younger and of not using pharmacological aids as predictors of relapse, as well as the importance of pharmacological aids and social support in relapse prevention programmes. This suggests that the translation of research findings to practice regarding these factors may not be optimal and/or findings from practice are not optimally communicated to researchers and that more attention and/or research is needed to demonstrate the effects of these factors. Finally, although not within the scope of this study, more research should analyse the effects of combining various strategies. Dismantling studies will help show which components are most effective and for whom.

\section{Acknowledgements}

We would like to thank the experts who participated in this study, our project advisory board for sharing its knowledge and the Dutch Foundation for a Smoke-Free Future for recruiting the coaches. 



\section{CHAPTER 3}

\section{The role of self-efficacy, recovery self- efficacy, and preparatory planning in predicting short-term smoking relapse}

This chapter is published ${ }^{3}$ as:

Elfeddali, I, Bolman, C., Candel, M. J. J. M., Wiers, R. W. and de Vries, H. (2012). The role of self-efficacy, recovery self-efficacy, and preparatory planning in predicting short-term smoking relapse, British Journal of Health Psychology, 17: 185-201.

${ }^{3}$ Note that this chapter is written in British English conform the guidelines of the journal 


\section{ABSTRACT}

Objectives. This study aims to identify the role of self-efficacy, recovery selfefficacy, and preparatory planning with regard to short-term smoking relapse. We also assessed whether the importance of these variables differed for smokers quitting individually and without help (self-quitters) and smokers quitting with the help of a smoking cessation course (group quitters). Design. A longitudinal quasi-experimental study with follow-ups at 1 and 3 months after the quit attempt was conducted in order to assess the role of baseline self-efficacy, recovery self-efficacy, and preparatory planning on short-term relapse. Methods. The recruitment included adult daily smokers $(N=121)$, quitting in a smoking cessation course $(N=57)$ and self-quitters $(N=64)$. Respondents received Internet-based questionnaires 2 weeks before quitting (baseline) and 1 and 3 months after the quit attempt. Predictors of relapse were analysed using logistic regression analyses. Results. Relapse at 1 and 3 months after the quit attempt was predicted by low levels of baseline self-efficacy. Simple slope analyses revealed that less preparatory planning significantly predicted relapse at 1 month after the quit attempt among group quitters, but not among self-quitters. Recovery self-efficacy was only predictive of relapse after 1 month when self-efficacy was excluded from the analyses. Moreover, among group quitters, the results indicated a borderline significant curved relation between recovery self-efficacy and relapse after 1 month. Conclusions. Our results suggest that more research is needed on the role of preparatory planning and recovery self-efficacy. Moreover, we recommend incorporating self-efficacy increasing techniques in relapseprevention interventions. 


\section{INTRODUCTION}

Worldwide, smoking is the largest preventable behavioural cause of mortality and disability, and a risk factor for six of the eight leading causes of death (WHO, 2001; Danaei et al., 2010). In 2010, approximately 28\% of the Dutch population smoked (STIVORO, 2010), while smoking prevalence in the United States is about $20 \%$ (CDC, 2002). Although $70 \%$ of the smokers worldwide want to quit smoking and $45 \%$ try to quit each year, most quit attempts result in a relapse (CDC, 2002). A review regarding relapse curves showed that most relapse occurs in the first days or weeks after the quit attempt, with relapse rates of 49$76 \%$ in the first week after the quit attempt, and $80-90 \%$ after 3 months (Hughes, Keely and Naud, 2004). Multiple quit attempts are often needed in order to quit successfully (CTUMS, 2001; ACS, 2010). Resuming smoking after a quit attempt is referred to as smoking relapse. The Russell Standard's definition of relapse is smoking at least five cigarettes after the quit attempt (West, Hajek, Stead and Stapleton, 2005). To increase the likelihood of successful quitting, insight into the factors that predict smoking relapse among smokers with a high intention to quit smoking is necessary.

In general, intention is postulated as the most proximal predictor of behaviour, such as smoking cessation, according to classic social cognitive theories such as the Theory of Reasoned Action (Ajzen and Fishbein, 1980; Fishbein and Ajzen, 2010), Theory of Planned Behaviour (Ajzen, 1988; Ajzen, 1991), Social Cognitive Theory (Bandura, 1986), and Precaution Motivation Model (Rogers, 1983). Meta-analyses of the predictive value of intention as proximal antecedent of behaviour have pointed out, however, that intention only explains $28 \%$ of the variance in behaviour, so a considerable amount remains unexplained (Sheeran, 2002; Webb and Sheeran, 2006). Recent studies have therefore focused on factors that can predict behaviour beyond intention, including the I-Change Model (e.g., de Vries et al., 2003; Hoving, Mudde and de Vries, 2006; de Vries, Kremers, Smeets, Brug and Eijmael, 2008) that emphasizes the role of self-efficacy and preparatory planning as post-intentional predictors of behavioural change (see Figure 3.1).

Self-efficacy is a widely studied concept defined as the confidence a person has to perform certain behaviour successfully in high-risk situations (Bandura, 1997). In accordance with the assumptions of classical social cognitive theories, the I-Change Model accentuates the role of self-efficacy as a direct predictor of behaviour. Self-efficacy is incorporated as the immediate antecedent in the Relapse Prevention Model by Marlatt (Marlatt and Gordon, 1985; Marlatt and Donovan, 2005; Allen, Bade, Hatsukami and Center, 2008). Empirical testing of the role of self-efficacy on smoking relapse showed that low self-efficacy predicts relapse (Mudde, Kok and Strecher, 1995; Dijkstra and de Vries, 2000; Dijkstra and Borland, 2003; Gwaltney, Metrik, Kahler and Shiffman, 2009). An important component of self-efficacy for smoking cessation is recovery self- 
efficacy (Bandura, 1986; Marlatt, Baer and Quigley, 1995; Dijkstra and de Vries, 2000). With regard to smoking, this is aimed at the belief that one will be able to resume the quit attempt after a lapse (Dijkstra and de Vries, 2000). The social cognitive theory assumes that recovery self-efficacy should be high enough to trigger a smoker to resume a quit attempt, but not too high as that could lead to experimenting with lapses (Bandura, 1986). A study testing the role of recovery self-efficacy in smoking cessation confirmed this assumption and pointed out that quitters with moderate levels of recovery self-efficacy were significantly more often abstinent one year later, compared with those with low and high levels of recovery self-efficacy (Haaga and Stewart, 1992).

Preparatory plans (also referred to as 'goal intentions' in the literature; (Gollwitzer and Moskowitz, 1996; de Vries et al., 2003)) are defined as sub-goals identified in the process of behavioural change, in which thoughts, feelings, and actions are directed by systematic effort towards the attainment of goals (Zimmermann, 2000; de Vries et al., 2003). According to the I-Change Model, preparatory plans are one of the most important factors that translate intention into behaviour. Appropriate preparatory plans have been shown to foster successful behavioural change and maintenance of behaviour in non-smokingrelated studies (Abraham et al., 1999; Jones, Abraham, Harris, Schulz and Chrispin, 2001; Luszczynska and Schwarzer, 2003; Rise, Thompson and Verplanken, 2003) as well as smoking-related studies (Hilberink, Jacobs, Schlosser, Grol and De Vries, 2006; Hoving, Mudde and de Vries, 2006). The specific role of preparatory plans in smoking relapse was recently identified in a Dutch study (Hoving, Mudde and de Vries, 2006).

Further, Sun and colleagues compared the cognitive, affective, and effective experimental processes of change used by successful quitters, relapsers, and non-quitters, and speculated that those who relapse may lack adequate preparation for effective cessation (Sun, Prochaska, Velicer and Laforge, 2007). The previous studies assessed individual factors such as self-efficacy in relation to relapse. Yet, little data are presented that assesses how the combination of selfefficacy, recovery self-efficacy, and preparatory plans relates to relapse. 


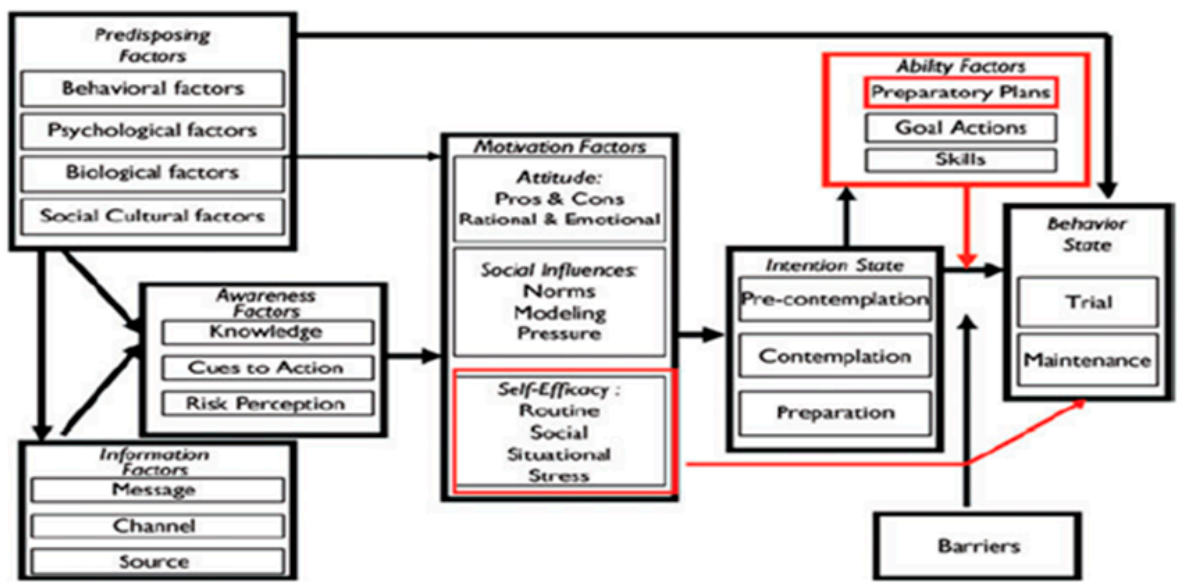

Figure 3.1 The I-Change Model 1.3, de Vries et al. Note. The red path represents the postmotivational factors of preparatory planning and self-efficacy

Furthermore, studies have shown that quitting with help increases the likelihood of success, although effective smoking relapse prevention programmes remain scarce (Zhu et al., 1996; Willemsen, Wagema and Schayck van, 2003; Hajek, Stead, West and Jarvis, 2005; Lancaster and Stead, 2005; Fiore, 2008; CBO, 2009). In addition, only a small percentage of smokers seek help to quit smoking. About $70 \%$ of smokers still try to quit without help, and this indicates that smokers use different modalities to quit smoking (Zhu, Melcer, Sun, Rosbrook and Pierce, 2000; Cokkinides, Ward, Jemal and Thun, 2005; Nagelhout, de Korte, Zeegers, van der Meer and Willemsen, 2010). Several studies have already indicated factors that determine participation in a smoking cessation group programme (Pohl, Martinelli and Antonakos, 1998; Hublet, Maes and Csincsak, 2002). These studies indicated that low levels of self-efficacy combined with high intentions to quit smoking determine participation in a group. This might suggest that group quitters and self-quitters differ in their cognitions. Group processes are characterized by social influences such as social modelling and social support (Bandura, 1986). According to social learning theories, these social influences play a role in changing cognitions such as selfefficacy (Bandura, 1986). Moreover, most smoking cessation courses explicitly use strategies (e.g., social modelling) to increase self-efficacy and motivate respondents to engage in planning in order to reach successful quitting. This suggests that smokers participating in cessation courses are exposed to intensive and interactive strategies, which play a role in changing their baseline cognitions. Consequently, it can be expected that the effect of concepts such as selfefficacy and planning, measured at baseline, can be moderated by group participation. Consequently, baseline levels of self-efficacy, for example, may then be less predictive of relapse for group quitters. They will be subject to positive 
changes due to social influences associated with group participation as well as specific strategies used to increase self-efficacy and planning. The same process applies to the role of planning. Insight into baseline differences between selfquitters and group quitters as well as whether the strength of these predictors differs for smokers using different quitting modalities, is essential to better understand potential differences in pathways of change between smokers who quit individually or in a group.

The first aim of this study is, therefore, to assess baseline differences between group and self-quitters. Based on previous studies (Pohl, Martinelli and Antonakos, 1998; Hublet, Maes and Csincsak, 2002), we expected group quitters to have lower levels of self-efficacy and to engage in more preparatory planning than self-quitters (hypothesis 1). Moreover, we aim to assess differences in relapse rates between self-quitters and group quitters. The second and main objective of the present study is to assess the role of self-efficacy, recovery selfefficacy, and preparatory planning in relapse among smokers who are motivated to quit smoking within 2 weeks. The I-Change Model is used as the research model, with a focus on post-motivational factors. We expect low levels of selfefficacy, low levels of recovery self-efficacy, and less preparatory planning to predict smoking relapse (hypothesis 2). Third, insight into the differences in predictors of relapse per quitting modality will be valuable in optimising smoking counselling for smokers wishing to quit on their own without guidance (self quitters) or through a smoking cessation course (group quitters). Therefore, the last goal of the study aims to assess whether the role of baseline self-efficacy, recovery self-efficacy, and preparatory plans differs per quitting modality. As group quitters are motivated to plan and prepare their quit attempt and are provided with strategies to increase (recovery) self-efficacy, we expect low levels of self-efficacy and recovery self-efficacy as well as less preparatory planning to predict relapse in self-quitters but not in group quitters (hypothesis 3).

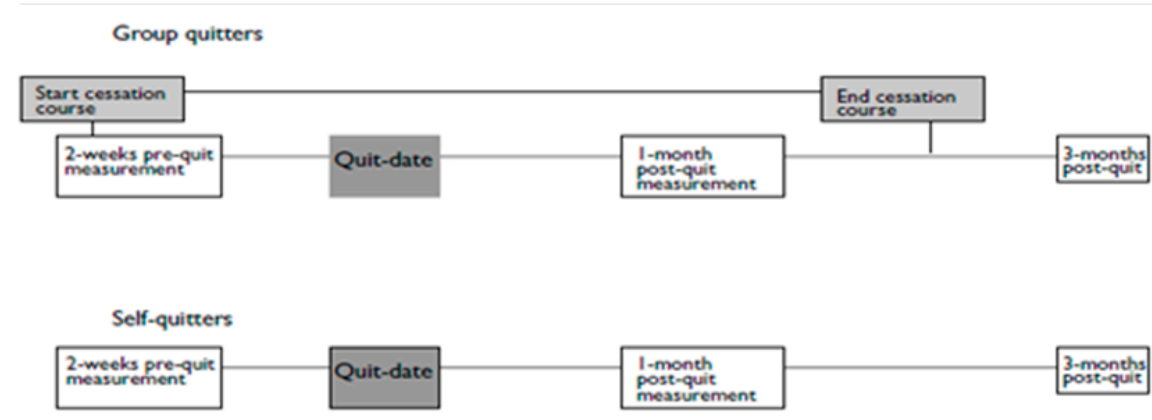

Figure 3.2 Design of the study 


\section{METHODS}

Ethical approval for this study was obtained from the Medical Ethics Committee.

\section{Study design, respondents, and recruitment}

Respondents $(N=121)$ were daily smokers between the ages of 18 and 65 who were willing to quit smoking within 2 weeks. The design of the study was quasiexperimental. Respondents were recruited from two groups: (1) Self-quitters and (2) group quitters. The self-quitters $(n=64)$ stopped smoking on their own without help from a structured smoking cessation course. They were recruited through advertisements in local newspapers. The group quitters $(n=57)$ were participants of a national smoking cessation course offered by The Dutch Foundation for a Smoke-Free Future (STIVORO) (see next section for more information on the course). The group quitters were recruited through flyers sent to course trainers asking them to participate in the study upon starting the course. Both advertisements and flyers contained information about the purpose of the study, the relevant website, and indicated how respondents could register for participation. All respondents needed to give consent for participation. They were told that participation involved filling in the baseline questionnaire 2 weeks before the quit attempt and 2 follow-up questionnaires at 1 and 3 months afterwards. The detailed design of the study is shown in Figure 3.2.

\section{Smoking cessation course}

One of the smoking cessation courses in the Netherlands, is called Pak je Kans (Grab your Chance), and is organized by STIVORO. The course consists of nine meetings each lasting an hour and a half. The meetings took place over 3 months and aim to help smokers quit successfully by keeping them motivated to quit, helping them to prepare their quit attempt, and deal with difficult situations and lapses. The meetings address four phases of the quitting process: (1) Preparation; (2) Action; (3) Maintenance; and (4) Emergency Plans (aimed at dealing with possible lapses). The first session focuses on nicotine dependence and stages of change. In the second session, participants are asked to identify their perceived pros and cons of smoking and a balance is made. In this session, the participants also need to make the decision to quit smoking and to make a quit attempt during the next week with a deadline of the third session. The third session focuses entirely on the quit attempt and what it will be like to be a nonsmoker. In this session, the participants are asked to identify difficult situations and strategies to help them remain smoke free in order to increase self-efficacy. The participant is supposed to quit at the end of this session. The fourth session 
focuses on the effects of non-smoking on the body and health and on dealing with withdrawal symptoms and difficult situations. Sessions five to eight focus on dealing with difficult situations, lapses and relapse prevention, and thus maintaining/increasing (recovery) self-efficacy to remain smoke free. The last session includes an evaluation session. In this session, the course targets recovery self-efficacy and the participants again make an emergency plan to deal with possible lapses in the future. The groups consist of an average of 10-12 participants. The meetings are led by coaches who are trained and professionally licenced to give smoking cessation courses by STIVORO. Approximately $85 \%$ of the coaches had a higher vocational educational background in nursing; a few had a Master degree in psychology. The course is packaged as a workshop with information sessions (e.g., regarding nicotine uptake in the brains), intensive assignments (e.g., to deal with possible smoking-related high-risk situations), and possibilities to learn from and exchange experiences with fellow group participants.

\section{Pre-quit measurement}

Demographic Variables were assessed with questions on age, gender, and social economical status (SES). We used income (low compared to the middle income in the Netherlands was coded as low SES and average and high income were coded as high SES) as a SES measure.

Self-Efficacy (SE) was measured with 14 items. Respondents were asked whether they thought they would be able to refrain from smoking in various difficult situations (at a party, with friends). The scale had already been successfully used in several other studies (Dijkstra, de Vries and Bakker, 1996; Dijkstra and de Vries, 2000; Te Poel, Bolman, Reubsaet and de Vries, 2009). Answers were given on a 7-point scale from totally disagree (1) to totally agree (7), with a high score representing high self-efficacy. The mean of the 14 items was used as the scale score in the analysis $(\alpha=.97)$.

Recovery Self-Efficacy (RSE) was measured with the five-item scale composed by Dijkstra and de Vries (Dijkstra and de Vries, 2000) (e.g., 'Do you think you could quit again if you smoked for 1 day after not smoking for a month?'). Respondents were asked to rate the extent to which they felt confident they could quit smoking again after a lapse. Answers were given on a 7-point scale from totally disagree (1) to totally agree (7), with a high score representing a high level of recovery self-efficacy. The mean of the five items was used as the scale score in the analyses $(\alpha=.92)$.

Preparatory Plans were assessed using 18 items asking respondents to indicate whether they planned to perform preparatory behaviour (e.g., 'I plan to remove all smoking materials from my home'). The scale composed for this study was based on previous preparatory planning scales (Hilberink, Jacobs, 
Schlosser, Grol and De Vries, 2006; Hoving, Mudde and de Vries, 2006; Te Poel, Bolman, Reubsaet and de Vries, 2009). Answers were given on a 5-point scale from totally disagree (1) to totally agree (5), with a high score indicating a strong intention to perform preparatory behaviour. The mean score of the 18 items was used as the scale score in the analysis $(\alpha=.88)$.

\section{Post-quit measurements after 1 and 3 months}

Continued abstinence was measured by asking whether the respondent had smoked more or fewer than five cigarettes after the initial quit attempt (see Figure 2 for information about the quit attempt). Smoking more than five cigarettes was coded as 'relapse' (1) and smoking fewer than five was coded as 'abstinent' (0). This definition of relapse conforms to the Russell Standard (West, Hajek, Stead and Stapleton, 2005).

\section{Analysis}

Differences at the pre-quit measurement between self-quitters and group quitters were assessed using chi-square tests for categorical variables and $t$-tests for continuous variables. A correlation matrix for self-efficacy, recovery selfefficacy, preparatory plans, and the outcome variables was made by calculating correlations between these variables. The role of self-efficacy, recovery selfefficacy, and preparatory planning in predicting smoking relapse was analysed using logistic regression taking these factors in one block. We corrected for quitting modality (self-quitters or group quitters), gender, age, and SES. In order to assess the differential effects of preparatory plans, self-efficacy, and recovery self-efficacy, we added the interaction terms (group $\times$ self-efficacy, group $\times$ recovery self-efficacy, group $\times$ preparatory plans) in the second block and used the BACKWARD method to assess their influence. We used this complete model (including the significant interaction terms) as the end model in this study. In the case of a differential effect of a variable, we conducted simple slope analysis using the method proposed by Aiken and West (Aiken and West, 1991). We checked for multicollinearity and centred the continuous variables used in the interaction terms. The analysis was a complete case analysis (using list-wise deletion with regard to the independent variables) as we omitted respondents with missing scores on the dependent variables. The dependent variables were relapse at 1 and 3 months. Finally, chi-square tests were used to assess the difference in relapse rates at 1 and 3 months after the quit attempt between the self-quitters and group quitters. 


\section{RESULTS}

\section{Sample characteristics}

A total of 121 (of whom 114 filled out the follow-ups, see 'missing data' below) respondents made a successful quit attempt and were included in this study. Table 3.1 shows the baseline characteristics. The mean age of the respondents was 37 years and $51.2 \%$ were female. On average, the respondents smoked 15 cigarettes a day and $81 \%$ had made previous attempts to quit. Analysis showed no significant differences at baseline in demographical variables and variables related to smoking behaviour between the self-quitters and group quitters. In our first hypothesis, we expected that group quitters would have lower levels of self-efficacy and would engage in more preparatory planning than self-quitters at baseline. The results pointed out significant differences in the level of selfefficacy between group quitters and self-quitters. The group quitters had higher levels of self-efficacy at baseline. No differences were found regarding recovery self-efficacy and planning.

Table 3.1 Means and differences between self-quitters and group quitters in demographic variables, smoking related variables, and post-motivational factors.

\begin{tabular}{|c|c|c|c|c|}
\hline Variables & $\begin{array}{c}\text { Overall } \\
(\mathrm{N}=121)\end{array}$ & $\begin{array}{l}\text { Self-quitters } \\
\quad(\mathrm{N}=64)\end{array}$ & $\begin{array}{l}\text { Group quitters } \\
(\mathrm{N}=57)\end{array}$ & t-test $/ \chi^{2}$ \\
\hline Gender (\% female) & 51.2 & 54.7 & 47.4 & 0.646 \\
\hline Age (mean [SD]) & $37.13(6.34)$ & $36.22(6.13)$ & $38.16(6.46)$ & -1.693 \\
\hline SES (\% high ses) & 21.8 & 16.1 & 28.1 & 2.480 \\
\hline $\begin{array}{l}\text { Number of cigarettes smoked per } \\
\text { day (mean [SD]) }\end{array}$ & $15.06(6.72)$ & $15.24(7.15)$ & $14.86(6.28)$ & 0.307 \\
\hline $\begin{array}{l}\text { Number of years of smoking } \\
\text { (mean [SD]) }\end{array}$ & $21.46(6.72)$ & $21.89(6.94)$ & $20.98(6.46)$ & 0.742 \\
\hline Previous quit attempts (\% yes) & 81.0 & 82.8 & 78.9 & 1.435 \\
\hline Self-efficacy & $3.91(1.96)$ & $3.44(1.70)$ & $4.43(2.11)$ & $-.2 .808^{*}$ \\
\hline Recovery self-efficacy & $3.89(2.05)$ & $3.86(1.99)$ & $3.92(2.13)$ & -0.142 \\
\hline Preparatory planning & $2.42(.80)$ & $2.33(.70)$ & $2.53(.89)$ & -1.364 \\
\hline
\end{tabular}

Note.: ${ }^{*} p<.05$.

\section{Missing data}

Seven respondents were ineligible for the follow-up and were not included in the analyses. One respondent was omitted from the analyses as they missed scores on one of the independent variables. 


\section{Relapse rates}

Table 3.2 presents the relapse rates for both self-quitters and group quitters and the total sample at 1 and 3 months after the quit attempt. Chi-square analysis showed significantly higher relapse rates among self-quitters compared to group quitters at both 1 and 3 months. Table 3.2, however, only includes raw percentages and takes no other predictors of smoking relapse into account.

Table 3.2 Relapse rates at 1- and 3-month follow-ups for the self-quitters and the group quitters

\begin{tabular}{lcc}
\hline $\begin{array}{l}\text { Group } \\
\text { Relapse Rates }(\%)\end{array}$ & $\begin{array}{c}\text { 1-month } \\
\text { Relapse rates }\end{array}$ & $\begin{array}{c}\text { 3-months } \\
\text { Relapse rates }\end{array}$ \\
\hline Self quitters $(\mathrm{N}=59)$ & $42(71.2 \%)$ & $54(91.5 \%)$ \\
Group quitters $(\mathrm{N}=55)$ & $24(43.6 \%)$ & $37(67.3 \%)$ \\
Total sample $(\mathrm{N}=114)$ & $66(57.9 \%)$ & $91(79.8 \%)$ \\
$\chi^{2}$ & $8.86^{*}$ & $10.40^{*}$ \\
\hline
\end{tabular}

Note.: ${ }^{*} p<.05$

\section{The role of post-motivational factors in predicting smoking relapse at 1 and 3 months after a quit attempt}

Table 3.3 shows the correlations between post-motivational factors (selfefficacy, recovery self-efficacy, and preparatory planning) and relapse at 1 and 3 months after the quit attempt - stratified by quitting modality. In both selfquitters and group quitters, we found moderate positive significant correlations between relapse at the 1 month measurement and relapse at the third month measurement.

Table 3.3 Correlations among relapse at 1 and 3 months and the post-motivational variables - selfefficacy, recovery self-efficacy, and preparatory planning -stratified by quit modality.

\begin{tabular}{|c|c|c|c|c|c|}
\hline & & $\begin{array}{c}\text { Relapse at } \\
1 \text { month }\end{array}$ & $\begin{array}{l}\text { Relapse at } \\
3 \text { months }\end{array}$ & Self-efficacy & $\begin{array}{c}\text { Recovery } \\
\text { self-efficacy }\end{array}$ \\
\hline \multirow[t]{5}{*}{ Self-quitters } & Relapse at 1 month & & & & \\
\hline & Relapse at third month & $.478^{*}$ & & & \\
\hline & Self-efficacy & $-.325^{*}$ & $-.295^{*}$ & & \\
\hline & Recovery Self-efficacy & -.206 & -.051 & .205 & \\
\hline & Preparatory planning & .048 & -.113 & .184 & .008 \\
\hline \multirow[t]{5}{*}{ Group quitters } & Relapse at one month & & & & \\
\hline & Relapse at third month & $.614^{*}$ & & & \\
\hline & Self-efficacy & $-.485^{*}$ & $-.228^{+}$ & & \\
\hline & Recovery Self-efficacy & -.190 & -.169 & .201 & \\
\hline & Preparatory planning & $-.298^{*}$ & $-.262^{+}$ & -.008 & $.331^{*}$ \\
\hline
\end{tabular}

Note. ${ }^{*} p<.05{ }^{+} p<.10$. 
In self-quitters, we found weak but significant negative correlations between relapse at the 1 as well as the third month measurement and self-efficacy. At the 1 month measurement in group quitters, we found a moderate but significant negative correlation between relapse and self-efficacy and a weak but significant correlation between preparatory planning and relapse. Moreover, we found weak negative correlations of borderline significance between relapse at the third month measurement, and self-efficacy and preparatory planning. Finally, in group quitters, the correlation matrix showed weak but significant positive associations between recovery self-efficacy and planning, suggesting that respondents with higher recovery self-efficacy also make more preparatory plans. The low correlations indicate that preparatory planning, self-efficacy, and recovery self-efficacy measure separate constructs.

In our second hypothesis, we expected low levels of self-efficacy, low levels of recovery self-efficacy, and less preparatory planning to predict smoking relapse. Moreover, as group quitters are motivated to plan and prepare their quit attempt and are provided with strategies to increase (recovery) self-efficacy, in our third hypothesis, we expected low levels of self-efficacy and recovery selfefficacy as well as less preparatory planning to predict relapse in self-quitters but not in group quitters. Table 3.4 shows the results of logistic regression analysis for relapse 1 month after the quit attempt. The results show a significant effect of self-efficacy $(\mathrm{OR}=0.57 ; p<.05)$ and preparatory plans $(\mathrm{OR}=0.40 ; p<$ $.05)$ and a borderline significant effect of age (OR $=0.93 ; p=.07)$, indicating that having a lower level of self-efficacy, making fewer plans, and younger age increases the risk of relapse at 1 month after the quit attempt. However, the influence of preparatory planning is not interpretable as this factor significantly interacts with the quitting modality (group). The analyses showed a significant effect of interaction between group and preparatory plans (OR = 4.26; $p=.045$ ), indicating a differential effect of preparatory planning per quitting modality. Simple slope analysis revealed that less preparatory planning predicted relapse among group quitters ( $\mathrm{OR}=0.40 ; p=.043$ ), but not among the self-quitters (OR $=1.69 ; p=.333$ ). Overall, the model predicted $44 \%$ of the explained variance. 
Table 3.4 Regression relapse at one month in the variables group - demographical variables, postmotivational variables (self-efficacy, recovery self-efficacy and preparatory planning) and the interaction terms $(\mathrm{N}=113)$.

\begin{tabular}{|c|c|c|c|c|c|}
\hline & & & & CI $95 \%$ & \\
\hline & Variables & B & OR & Lower & Upper \\
\hline STEP 1 & Group (group quitters ${ }^{1}$ ) & 661 & 1.937 & .733 & 5.119 \\
\hline (ENTER) & Gender $\left(\right.$ male $\left.^{1}\right)$ & 680 & 1.973 & .734 & 5.305 \\
\hline & Age & $-.076^{+}$ & .927 & .854 & 1.006 \\
\hline & SES $\left(\right.$ high $\left.^{1,2}\right)$ & .769 & 2.158 & .626 & 7.438 \\
\hline & Self efficacy (SE) & $-.555^{*}$ & .574 & 439 & .751 \\
\hline & Recovery self efficacy & -.112 & .894 & .711 & 1.125 \\
\hline & Preparatory plans & $-.926^{*}$ & .396 & 161 & .972 \\
\hline STEP 2 & Group x Self-efficacy & & & & \\
\hline (BACK-WARD) & Group x Recovery self-efficacy & & & & \\
\hline & Group x Preparatory plans & $1.449^{*}$ & 4.257 & 1.030 & 17.586 \\
\hline & $\chi^{2}$ & $44.109 *$ & & & \\
\hline & Nagelkerke $\mathrm{R}^{2}$ & .435 & & & \\
\hline & Percentage correct prediction & 77.0 & & & \\
\hline
\end{tabular}

Note. ${ }^{*} p<.05 ;{ }^{+} p<.10$. The model $\chi^{2}$ is significant $(p<.05)$ for all models. ${ }^{1}$ reference category, ${ }^{2}$ SES was divided into two groups, high and low SES.

Table 3.5 shows the results for relapse at 3 months with a significantly higher likelihood of relapse among self-quitters (OR=3.56; $p<.05)$.Next, the results point out that relapse was significantly more likely when respondents had low self-efficacy at the baseline measurement $(\mathrm{OR}=0.71 ; p<.05)$. The results for preparatory planning showed a borderline significant effect $(\mathrm{OR}=0.55 ; p=$ .079 ), indicating that less planning at baseline predicted smoking relapse 3 months after the quit attempt. Finally, none of the interaction terms were of significance in this model, implying that no differences in the effect of preparatory planning, self-efficacy, and recovery self-efficacy for self-quitters and group quitters were found at 3-month follow-up. Overall, this model explained 34\% of the variance. 
Table 3.5 Regression relapse at three months on the variables group - demographical variables, post-motivational variables (self-efficacy, recovery self-efficacy and preparatory planning) and the interaction terms $(\mathrm{N}=113)$.

\begin{tabular}{llllll}
\hline & & \multicolumn{3}{c}{ CI 95 \% } \\
& Variables & B & OR & Lower & Upper \\
\hline STEP 1 & Group (group quitters ${ }^{1}$ ) & $1.269^{*}$ & 3.559 & 1.006 & 12.588 \\
(ENTER) & Gender (male ${ }^{1}$ ) & .220 & 1.246 & .403 & 3.851 \\
& Age & -.077 & .926 & .844 & 1.016 \\
& SES (high ${ }^{1,2}$ ) & .919 & 2.508 & .688 & 9.139 \\
& Self efficacy (SE) & $-.337^{*}$ & .714 & .527 & .968 \\
& Recovery self efficacy & -.092 & .912 & .695 & 1.197 \\
& Preparatory plans & $-.593^{+}$ & .553 & .285 & 1.072 \\
STEP 2 & Group * Self-efficacy & & & & \\
(BACK-WARD) & Group * Recovery self-efficacy & & & & \\
& Group * Preparatory plans & & & & \\
& $\chi^{2}$ & $27.104^{*}$ & & & \\
& Nagelkerke R ${ }^{2}$ & .340 & & & \\
& Percentage correct prediction & 80.5 & & & \\
\hline
\end{tabular}

Note. ${ }^{*} p<.05 ;{ }^{+} p<.10$. The model $\chi^{2}$ is significant $(p<.05)$ for all models. ${ }^{1}$ reference category, ${ }^{2}$ SES was divided into two groups, high and low SES.

\section{Additional analyses on the role of recovery self-efficacy}

Two additional analyses were conducted regarding the role of recovery selfefficacy in predicting smoking relapse. First we assessed whether the nonsignificance of recovery self-efficacy could be due to intercorrelation between self-efficacy and recovery self-efficacy. We checked whether the effects of recovery self-efficacy were suppressed by self-efficacy by running the analyses (complete model as presented in Tables 3.4 and 3.5) without (1) the interaction term self-efficacy by group and (2) self-efficacy (main-effect). The first step did not result in a significant effect of recovery self-efficacy, while removal of selfefficacy in the second step revealed that low levels of recovery self-efficacy then significantly predicted relapse at the 1 month post measurement only. The interaction between group and recovery self-efficacy remained non-significant. Second, since moderate levels of recovery self-efficacy lead to more smoking abstinence than low and high levels of recovery self-efficacy (Bandura, 1986; Haaga and Stewart, 1992), we assessed whether the relationship between relapse and recovery self-efficacy could be a non-linear (curved) relationship. This was done by replacing the initial recovery self-efficacy term by a squared term of the same construct. The results pointed out a differential effect of recovery self-efficacy per group ( $p=.064)$ at the first month measurement. Simple slope analyses aimed at assessing the role of recovery self-efficacy per group revealed a borderline significant effect (OR $=1.192 ; p=.095)$ - indicating an association between low and high levels of recovery self-efficacy and relapse among group 
quitters and a non-significant effect (OR $=.914 ; p=.371)$ in self-quitters. The effect of recovery self-efficacy at the third month measurement was nonsignificant $(\mathrm{OR}=1.030 ; p=.704)$.

\section{DISCUSSION}

The main goal of this study was to identify the role of (low) baseline levels of (recovery) self-efficacy and (less) preparatory planning with regard to smoking relapse among smokers who are motivated to quit smoking. Our findings regarding self-efficacy showed that low levels of self-efficacy predict relapse and confirm the results of previous studies (Mudde, Kok and Strecher, 1995; Dijkstra and de Vries, 2000; Ockene et al., 2000; Dijkstra and Borland, 2003; Amodei and Lamb, 2005; Gwaltney, Shiffman, Balabanis and Paty, 2005; Gwaltney, Metrik, Kahler and Shiffman, 2009). Regarding recovery self-efficacy, however, our study did not reveal a significant effect on relapse at 1 and 3 months. This might have been due to the intercorrelation between self-efficacy and recovery selfefficacy. We tested this assumption and the results indicated that removing selfefficacy revealed that low levels of recovery self-efficacy then significantly predicted relapse at the 1 month post measurement, but not at the 3 months post measurement. The interaction term between recovery self-efficacy and group remained non-significant. Yet, these effects of recovery self-efficacy are likely to be attributed to the general efficacy-related aspect of recovery self-efficacy instead of specific relapse-related aspects of the construct. Moreover, this finding suggests that the effects of general self-efficacy were greater than the effects of recovery self-efficacy. Finally, since moderate levels of recovery self-efficacy lead to more smoking abstinence than low and high levels of recovery selfefficacy (Bandura, 1986; Haaga and Stewart, 1992), we conducted additional analyses to test whether a non-linear association existed between recovery selfefficacy and relapse. Our additional analyses, however, indicated non-significant effects of recovery self-efficacy for both the first and the third month. Yet, the first month results were of borderline significance in group quitters, a finding that supports the role of both low as well as high levels of recovery self-efficacy on relapse. Our borderline significant effect may be the result of a relatively small sample size. Therefore, more research regarding the role of recovery selfefficacy in smoking relapse is needed.

Regarding planning, our findings are in line with those of an earlier Dutch study revealing that less preparatory planning predicts smoking relapse (Hoving, Mudde and de Vries, 2006). Our study indicates that less planning predicted relapse at 1 month after the quit attempt. However, only a borderline significant effect of planning was found 3 months after the quit attempt. The latter might be due to the possibly limited power of the study since the sample size was small. Moreover, the results for the main effect of preparatory planning 
at the 1 month measurement are not interpretable, as we found a significant interaction effect of planning by group, indicating differential effects of preparatory planning per group at the 1-month follow-up. Contrary to our expectations, the simple slope analysis revealed that low levels of planning were predictive of relapse in group quitters, but not in self-quitters. As far as we know, there are no previous studies on this issue. A possible explanation for this effect may be that planning needs to be combined with actual practice. This would imply that group quitters who made preparatory plans (high levels of planning) actually carried out these plans more frequently as they may have received more encouragement and support to prepare and carry out plans to quit. However, we had no data to test this assumption. We hypothesized that the amount of planning at baseline would not be predictive for group quitters as we expected them to learn and to be stimulated to form and carry out plans (as a result of group processes and the intervention aims), this contradictory finding prompts further research into the effects of the intervention and group processes on immediate outcomes such as planning.

With regard to the influence of demographic variables and quitting modality (self-quitters or group quitters) on relapse, our results indicate that those who quitted without the help of a smoking cessation course had the highest risk of relapse at 3 months. These findings are line with studies regarding the efficacy of group help in the process of smoking relapse (Willemsen, Wagema and Schayck van, 2003; Lancaster and Stead, 2005). However, as our study was nonrandomized, it remains difficult to interpret the findings regarding quitting modality. No significant effects were found regarding age, gender, and SES. Overall, the model explained $44 \%$ and $34 \%$ of the variance, 1 and 3 months after the quit attempt, respectively, suggesting that this model was better at predicting immediate relapse than later relapse.

Next, we assessed differences between self-quitters and group quitters at the pre-quit measurement. Our results showed higher levels of baseline selfefficacy among group respondents. The literature however, suggests that respondents who decide to participate in a smoking cessation intervention have lower levels of self-efficacy (and therefore seek help with their quit attempt) (Pohl, Martinelli and Antonakos, 1998; Hublet, Maes and Csincsak, 2002). A possible explanation for our contradictory finding might be that group quitters are often referred to the courses by their general practitioner or their employer, which may overrule the role of self-efficacy. Furthermore, it is worth mentioning that the average levels of self-efficacy in the group quitters were (although somewhat higher than those of self-quitters) still not very high (mean around four implying neutral regarding self-efficacy). Finally, although caution is needed because of our quasi-experimental study design, our findings support the conclusions of the Cochrane Review which found individual counselling to be more effective than no counselling (Lancaster and Stead, 2005) by showing 
significantly large differences in relapse rates between self-quitters and group quitters at 1 and 3 months after the quit attempt.

The last goal of the study was to gain in-depth information on the differences between self-quitters and group quitters by assessing whether the role of selfefficacy, recovery self-efficacy, and preparatory planning differed between the groups. Besides the previous mentioned differential effect of preparatory planning, no differential effects were found for self-efficacy and recovery selfefficacy at both the 1- and 3-month follow-up.

This study is subject to limitations. First, measurements of smoking abstinence were based on self-reports, which were not verified with biochemical validation. However, previous studies have suggested that the difference between self-reported results and verified results is negligible (Velicer, Prochaska, Rossi and Snow, 1992; Patrick et al., 1994). Second, the respondents' answers regarding the quit attempt were also based on self-reports. However, this is an inevitable limitation of self-report studies. Third, we used a dichotomous outcome variable. Studies have shown that dichotomizing a continuous primary outcome may result in loss of information (Moser and Coombs, 2004; Bakhshi, Eshraghian, Mohamed and Seifi, 2008). In smoking-related studies, the use of a dichotomous-dependent outcome measure (relapse vs. abstinence) is standard (Hall et al., 2001; Hughes, Keely and Niaura, 2003; West, Hajek, Stead and Stapleton, 2005). Fourth, the study design was quasi-experimental. This, however, is of less importance in our study since the main goal was to identify the determinants of smoking relapse and not to show the effectiveness of an intervention per se. Fifth, we measured preparatory planning only, while it would have been useful to have information about the realization of intended plans. Therefore, we suggest conducting this information in future studies. Sixth, we did not assess changes in cognitions (self-efficacy and planning) due to group participation. Measuring this, however, would have been useful as it would have helped us to gain insight into possible mediation processes. Seventh, we only assessed income as an indicator for SES, whereas additional information about education and occupation may have given a more complete picture of the SES status of our respondents. Finally, our study measured only short-term relapse at 3 months, while research shows that short-term (within 6 months) abstinence does not always accurately predict long-term abstinence (more than 1 year) (Fiore, 2008). However, as preliminary research our short-term findings are still valuable for future studies and interventions.

To our knowledge, this is the first study to show a differential effect of preparatory planning and indicates that planning is a significant predictor of relapse for group quitters, but not for self-quitters. An explanation might be that group quitters (who engage in more planning) are motivated by the course trainers to carry out their plans. Participating in a smoking cessation course can therefore encourage quitters to carry out their plans. It should also encourage the development of planning. As these are only preliminary results and the lat- 
ter issue remains unclear, more research is needed into the efficacy of making and carrying out preparatory plans for group quitters as well as for self-quitters. In addition, we suggest for the future, researching how to motivate smokers to carry out their plans, without participating to cessation courses. Future research could also investigate how group interventions could influence respondents who are not preparing their quit attempt by making preparatory plans, such as moving smokers' requisites. In line with other studies, we found that low levels of self-efficacy at the pre-quit measurement are of great importance in the smoking relapse process. Finally, the results showed that self-quitters, quitting without help, are at higher risk of smoking relapse at 3 months compared to group quitters. In general, our study shows that low self-efficacy and, to a lesser extent, a low level of planning is consistent predictors of relapse. The role of recovery self-efficacy remains unclear and needs further research. Finally, we recommend dismantling experimental studies with regard to the effects of selfefficacy, preparatory planning, and recovery self-efficacy in relapse prevention programmes.

\section{Acknowledgements}

This study was funded by ZonMw, the Netherlands Organization for Health Research and Development. We would like to thank the trainers of the smoking cessation courses held by STIVORO, the Dutch Foundation for a Smoke-Free Future, for helping to recruit participants. Finally, we would like to thank all the people who participated in the study. 


\section{CHAPTER 4}

\section{SQ4U - A computer tailored smoking relapse prevention program incorporating planning strategy assignments and multiple feedback time points after the quit-attempt: development and design protocol}

This chapter is published as:

Elfeddali, I., Bolman, C., and de Vries, H. (2012). SQ4U - A computer tailored smoking relapse prevention program incorporating planning strategy assignments and multiple feedback time points after the quit-attempt: Development and design protocol, Contemporary Clinical Trials, 33:151-158. 


\section{ABSTRACT}

Background. The SQ4U (Stay Quit for You)-study aims to test the efficacy of two computer tailored smoking relapse prevention programs which incorporate planning strategy assignments and provide tailored feedback at multiple time points after the quit-attempt. The programs differ in the support provided after the quit-attempt. This paper aims to describe the development and design of SQ4U. Methods/design. SQ4U-respondents were daily smokers in the 18-65 years age group, who were motivated to quit smoking and willing to make a quit-attempt within 1 month of registration. The study is a randomized controlled trial with three conditions: 1. Control group, 2. Action planning (AP) program, 3. Action planning plus (AP+) program. Respondents in the control group only filled out questionnaires. The AP program consisted of computer tailored baseline feedback based on the I-Change Model and six planning strategy assignments. The AP+ program provided the same program elements as the AP program, but was extended with tailored feedback at eleven time points after the quit-attempt. The feedback targeted (recovery) self-efficacy, planning and negative affect. There were two follow-up measurements at 6 and 12 months after baseline. User experiences and the efficacy of the programs in fostering seven-day point prevalence ${ }^{4}$ and continued abstinence were examined using a process evaluation and logistic regression analyses. Discussion. The present paper outlines the development and design of the SQ4U study. This study has the potential to provide a new effective computer tailored smoking relapse prevention program as well as insight into effective smoking relapse prevention strategies.

\footnotetext{
${ }^{4}$ Note that this dissertation only reports on continued smoking abstinence
} 


\section{INTRODUCTION}

Smoking relapse is an evident problem in the process of smoking cessation. A systematic review shows relapse rates of $49-76 \%$ in the first week and $80-90 \%$ in the first three months after the quit-attempt (Hughes, Keely and Naud, 2004).

Several factors are associated with smoking relapse. The Relapse Prevention (RP) Model (Marlatt and Gordon, 1985; Marlatt and Donovan, 2005) accentuates the role of covert (e.g. lifestyle imbalances and cravings) and immediate (e.g. high-risk situations) factors in the process of relapse. A range of empirical studies demonstrated the role of self-efficacy and identified a low level of selfefficacy as a reliable predictor of smoking relapse (Ockene et al., 2000; Dijkstra and Borland, 2003; Amodei and Lamb, 2005; Gwaltney, Shiffman, Balabanis and Paty, 2005; Segan, Borland and Greenwood, 2006; Gwaltney, Metrik, Kahler and Shiffman, 2009; Herd, Borland and Hyland, 2009). Furthermore, studies identified associations between smoking relapse and negative outcome expectancies of smoking (Dijkstra and Borland, 2003; Gwaltney, Shiffman, Balabanis and Paty, 2005), lack of social support (Roski, Schmid and Lando, 1996; Lawhon, Humfleet, Hall, Reus and Muñoz, 2009), physical dependence (Kenford et al., 2002; Hyland et al., 2006; Zhou et al., 2009), high craving levels (Killen and Fortmann, 1997; Shiffman et al., 1997; Herd, Borland and Hyland, 2009), negative affect and stress (Shiffman, Paty, Gnys, Kassel and Hickcox, 1996; Kassel, Stroud and Paronis, 2003; Brown, Lejuez, Kahler, Strong and Zvolensky, 2005; Shiffman et al., 2007; Shaw and al'Absi, 2008). A number of relapse prevention programs incorporating strategies to change these factors have been developed and tested. Many of these programs prevent relapse by utilizing behavioral approaches, mainly skill trainings aimed at identifying and coping with high-risk situations (Hajek, Stead, West, Jarvis and Lancaster, 2009). Other programs use pharmacological therapy. Yet, two literature reviews concluded that the efficacy of current smoking relapse prevention programs remains limited (Lancaster, Hajek, Stead, West and Jarvis, 2006; Hajek, Stead, West, Jarvis and Lancaster, 2009). The alarming relapse rates combined with the lack of effective prevention programs suggest the need for new approaches. We conducted the SQ4U study and developed and tested a new relapse prevention approach consisting of three main elements.

First, planning strategies - which consist of preparatory planning and coping planning according to the Integrated Change Model - have recently shown their importance in fostering smoking cessation (de Vries, Eggers and Bolman, submitted) and smoking abstinence (Hoving, Mudde and de Vries, 2006; O'Connell, Hosein and Schwartz, 2007; van Osch, Lechner, Reubsaet, Wigger and de Vries, 2008; Elfeddali, Bolman, Candel, Wiers and de Vries, 2012). However, little attention has been given to the possible efficacy of combining these planning strategies in smoking relapse prevention programs. We incorporated preparatory and coping planning strategy assignments. The second element is the 
delivery mode of the prevention program. This needs to be modified for the needs of the quitter. Computer tailoring is a very personalized approach and computer feedback is assessment-based, focuses on the respondent and only addresses aspects that are relevant to the respondent (Dijkstra and De Vries, 1999; Kreuter, Strecher and Glassman, 1999). Moreover this strategy has been shown to meet the needs and interests of the respondent, to be more likely to be read and remembered and to have a high reach with relatively low costs (Dijkstra, De Vries and Roijackers, 1998; Strecher, 1999; Brug, Oenema and Campbell, 2003; de Vries, Kremers, Smeets, Brug and Eijmael, 2008). Computer tailored programs have shown to be promising tools in the field of smoking cessation (Dijkstra, De Vries and Roijackers, 1998; Etter, 2005; Lancaster and Stead, 2005; Strecher, Shiffman and West, 2005; Te Poel, Bolman, Reubsaet and de Vries, 2009). Third, providing tailored feedback at multiple time points has shown to be more effective than a single tailoring point (Brug, Kok, van Breukelen, Glanz and van Assema, 1998; Dijkstra, De Vries, Roijackers and van Breukelen, 1998; Smeets, Brug and De Vries, 2008). Yet, as far as we know, no specific computer tailored smoking relapse prevention program incorporating planning strategy assignments and multiple feedback points has been developed and/or tested.

The SQ4U study aims to fulfill these needs by developing and testing the efficacy of two computer tailored smoking relapse prevention programs incorporating planning strategy assignments and providing tailored feedback at multiple time points after the quit-attempt. The programs differ in the support provided after the quit-attempt. This paper describes the development of the SQ4U program, the program elements and the design of the SQ4U study.

\section{METHODS}

Ethical approval for this study was obtained from the Medical Ethics Committee of the Maastricht Academic Hospital and Maastricht University (MEC 08-3-003; NL21414.068.08). The study is registered with the Dutch Trial Register (NTR1892).

\section{Target population and inclusion criteria}

Only daily smokers, in the 18-65 years age group, who were motivated to quit smoking and willing to make a quit-attempt between 8 days and 1 month from the moment of registration, were allowed to participate in the study. In addition, all respondents needed to give consent for participation. 


\section{Study design}

The SQ4U study was a randomized controlled study (RCT) with a control condition and two experimental conditions. Respondents were randomly allocated to one of the three following programs:

1. Control group: respondents only filled out questionnaires.

2. Action Planning (AP) program: provides single tailored feedback prior to the quit-date and three planning strategy assignments before and three after the quit-date.

3. Action Planning Plus (AP+) program: is an extended version of the AP program that additionally provides tailored feedback at multiple time points after the quit-date.

Fig. 4.1 shows the flow chart of the randomized controlled trial.

\section{Procedure}

\section{Recruitment}

Smokers were recruited by ads in local newspapers; online ads on websites of national health funds (Dutch Cancer Society and Dutch Asthma Foundation), a national news page (Telegraaf Online) and the Dutch Foundation for a Smokefree Future; as well as by distribution of 10,000 flyers. These recruitment strategies were partly based on good experiences with comparable strategies used in previous studies conducted in our department (Dijkstra, De Vries and Roijackers, 1998; Te Poel, Bolman, Reubsaet and de Vries, 2009). The ads referred the respondents to our research website (www.sq4u.nl) for more information. The website explained that we had developed a new smoking relapse prevention program and that we were testing the efficacy of three different versions of the program. The respondents were notified that the versions of the program differed in their intensity and that they would be randomly allocated to one of the versions after signing up for participation. All respondents were told that they could participate in the most effective version for free (after the end of the study) if they were assigned to a less effective version of the program. Moreover, the website clarified the inclusion criteria for participation, explained that respondents were eligible to win €250 after completing all parts of the version they were assigned to, and that biochemical validations would be conducted in order to verify self-reported abstinence.

\section{Randomization}

After signing up for participation respondents were assigned to one of the three programs (1. control condition, 2. AP program, 3. AP+ program). Randomization took place automatically by means of a software randomization mode. 


\section{Study course}

The course of the study is depicted simply in Fig. 4.1 and is explained below. The core elements of the AP and AP+ programs are described in detail in the 'Materials' section.

After being assigned to one of the three programs respondents filled out questions assessing the inclusion criteria. Respondents who did not meet the inclusion criteria received a message on the computer screen explaining why they could not participate in the study. All other respondents continued with the baseline questionnaire. The respondents were instructed to choose a quit-date (between 8 days and 1 month from baseline) in the baseline questionnaire. Respondents in the control group were finished after completing the baseline questionnaire (they did not receive tailored feedback). They received a short message on their computer screen which explained that they would be invited for the next part (verifying quit-attempt) of the program 2 days after the chosen quit-date. Respondents in the AP and AP+ programs received computer tailored baseline feedback immediately after the baseline questionnaire. Afterwards they also received a short message on screen which explained that they would be invited for the next part (planning strategy assignments) of the program 6 days before their quit-date. Respondents in both experimental conditions (AP and AP+ programs) were invited for three planning strategy assignments at 6, 4 and 2 days before the quit-date. All respondents (including those in the control group) were invited 2 days after their chosen quit-date to confirm their quitattempt. Additionally, the respondents in the AP and AP+ programs were invited for the last three planning strategy assignments after the quit-attempt. The last planning strategy assignment formed the end of the AP program. Respondents in the AP+ program, additionally, were invited for the last part of the AP+ program which consisted of filling out eleven short questionnaires after the quitattempt (daily during the first three days, once a week during the rest of the first month and once per two weeks until the third month) followed by tailored feedback. Finally, all respondents were invited to fill out follow-up questionnaires at 6 and 12 months after baseline. All invitations for participation were sent by email and SMS (optional), with a reminder after 1 week in the case of non-response. At the follow-up measurements, respondents were called when they did not respond to the invitation and reminder. All tailored messages were displayed on the computer screen, sent by email and could be printed. 


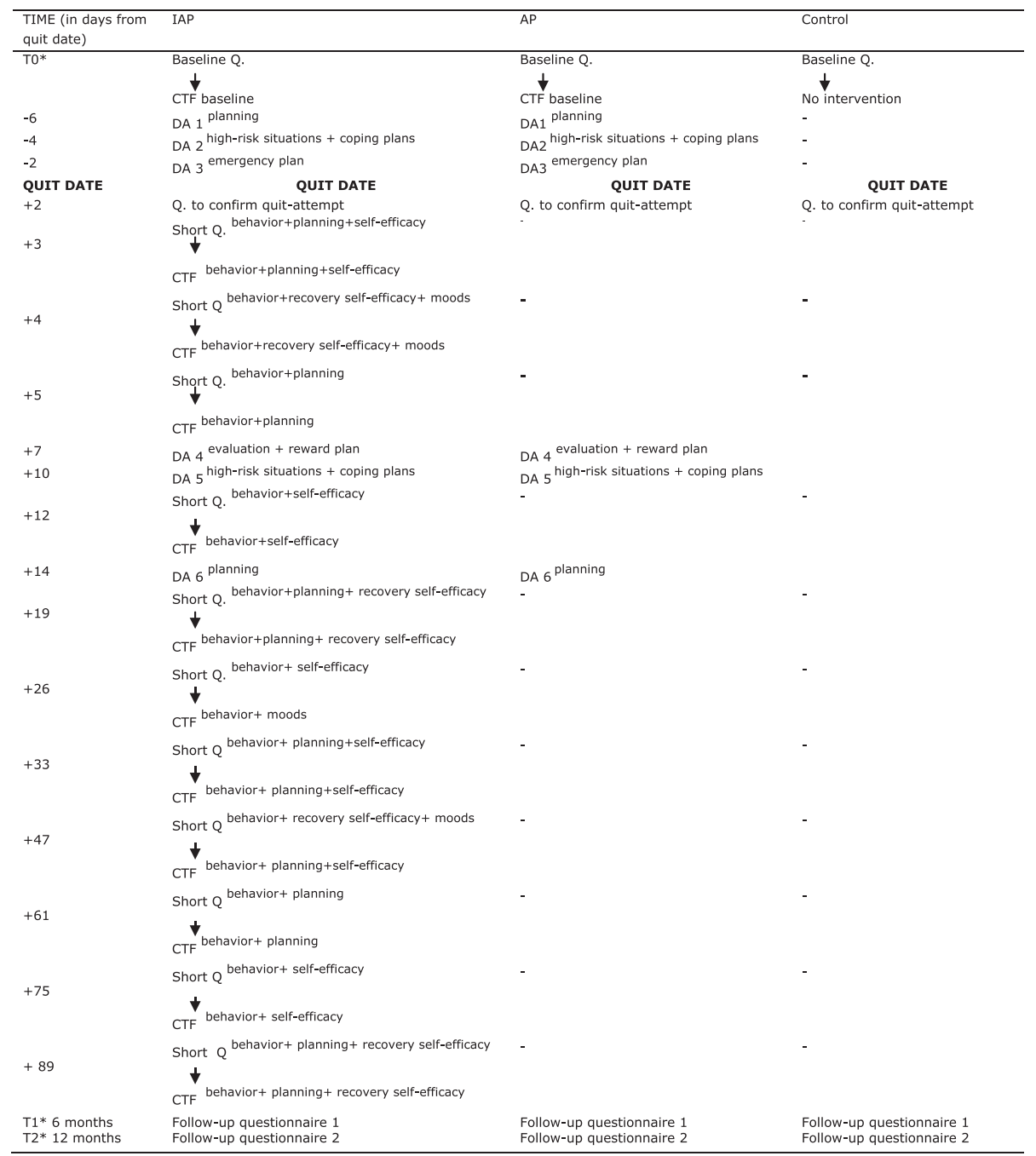

Figure 4.1 Flowchart of the randomized controlled trial of SQ4U. * T0, T1 and T2 are not based on the quit-date, but on baseline. $\mathrm{Q}=$ questionnaire, $\mathrm{CTF}=$ computer tailored feedback; $\mathrm{DA}=$ diary assignment

\section{Biochemical validation}

Biochemical validations using cotinine assessments were conducted in a sub sample of the participants who reported to be abstinent. This verified the nonsmoking status of the respondents as indicated in their self-reported answers at the twelve month follow-up measurement. Validations needed to be conducted 4 days after the self-report assessment. After the respondents reported that 
they were abstinent they were contacted to set an appointment for the biochemical validation. The assessments were conducted by a research assistant who visited the respondent at a convenient place (e.g. at home or at work). The assistant collected saliva from the respondent using a swab stick. After the saliva was collected, it was applied to a test strip on which the results appeared within 20 min. To minimize the time consumption of the validation tests for the respondent the assistant left immediately after the saliva was collected (and therefore before the results appeared on the test strip). Respondents could, however, ask for their results later on by email or phone. Results were either negative (no cotinine detected in the saliva) or positive (cotinine detected in the saliva). The results were registered by the assistant and reported to the research team. When biochemical validations could not be conducted reasons for this (of the respondents as well as of the assistant) were also registered.

Table 4.1 Description of the concepts on which tailored feedback was provided before (baseline feedback) and after the quit-attempt (short feedback messages).

\begin{tabular}{|c|c|c|c|}
\hline \multirow[b]{2}{*}{ Construct } & \multirow{2}{*}{$\begin{array}{l}\text { Before the quit-attempt (at baseline) } \\
\text { description }\end{array}$} & \multicolumn{2}{|c|}{ After the quit-attempt } \\
\hline & & Level ${ }^{*}$ description & Level * \\
\hline Introduction & $\begin{array}{l}\text { The introduction contained short information } \\
\text { about the upcoming tailored feedback and the } \\
\text { chosen quit-date. Name and gender were used } \\
\text { to personalize the Introduction. }\end{array}$ & 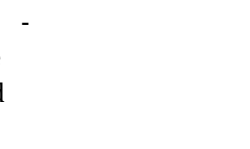 & - \\
\hline $\begin{array}{l}\text { Pros of non- } \\
\text { smoking }\end{array}$ & $\begin{array}{l}\text { Feedback was given on the respondent's } \\
\text { scores on nine items measuring the ad- } \\
\text { vantages of non-smoking. The feedback fo- } \\
\text { cused on confirming advantages of non- } \\
\text { smoking such as health improvements and } \\
\text { financial savings. }\end{array}$ & Item & Item \\
\hline $\begin{array}{l}\text { Cons of non- } \\
\text { smoking }\end{array}$ & $\begin{array}{l}\text { Feedback was given on the respondent's } \\
\text { scores on nine items measuring the disad- } \\
\text { vantages of non-smoking. The feedback fo- } \\
\text { cused on invalidating and/or considering } \\
\text { perceived disadvantages of non-smoking (e.g. } \\
\text { weight gain) in perspective. }\end{array}$ & Item & Item \\
\hline $\begin{array}{l}\text { Pros of } \\
\text { relapse }\end{array}$ & $\begin{array}{l}\text { Feedback was given on the respondents scale } \\
\text { score for perceived pros of relapse. The feed- } \\
\text { back focused on the disadvantages of relapse } \\
\text { and the role of the nicotine dependence in } \\
\text { perceiving advantages of smoking again. }\end{array}$ & Scale & Scale \\
\hline $\begin{array}{l}\text { Cons of } \\
\text { relapse }\end{array}$ & $\begin{array}{l}\text { Feedback was given on the respondents scale } \\
\text { score for perceived cons of relapse. The feed- } \\
\text { back focused on confirming the disadvantages } \\
\text { of relapse and motivating the respondent to } \\
\text { prevent relapse and therefore the disad- } \\
\text { vantages of it. }\end{array}$ & Scale & Scale \\
\hline
\end{tabular}




\begin{tabular}{|c|c|c|c|c|}
\hline \multirow[b]{2}{*}{ Construct } & \multirow{2}{*}{$\begin{array}{l}\text { Before the quit-attempt (at baseline) } \\
\text { description }\end{array}$} & \multicolumn{3}{|c|}{ After the quit-attempt } \\
\hline & & Level * & description & Level * \\
\hline $\begin{array}{l}\text { Smoking and } \\
\text { diseases }\end{array}$ & $\begin{array}{l}\text { The feedback was given on the respondents' } \\
\text { answers regarding suffering from heart dis- } \\
\text { eases, COPD, diabetes and/or cancer. The } \\
\text { feedback explained the importance and ad- } \\
\text { vantages of smoking cessation in the light of } \\
\text { the disease in question. }\end{array}$ & Item & & Item \\
\hline Self-efficacy & $\begin{array}{l}\text { Feedback was given on the respondent's level } \\
\text { of self-efficacy regarding non-smoking in } \\
\text { fourteen difficult situations (e.g. at a party, in } \\
\text { the morning, when being angry). The feed- } \\
\text { back focused on increasing self-efficacy per } \\
\text { situation. }\end{array}$ & Item & $\begin{array}{l}\text { Feedback was given on } \\
\text { the respondents scale } \\
\text { score on self-efficacy. } \\
\text { The feedback aimed at } \\
\text { increasing self-efficacy } \\
\text { by giving tips and using } \\
\text { textual modeling strat- } \\
\text { egies. }\end{array}$ & Item \\
\hline $\begin{array}{l}\text { Recovery } \\
\text { self-efficacy }\end{array}$ & $\begin{array}{l}\text { Feedback was given on the respondents scale } \\
\text { score for recovery self-efficacy. The feedback } \\
\text { explained nicotine dependence, the possibil- } \\
\text { ity of lapses and the importance of resuming } \\
\text { a quit-attempt after a lapse. }\end{array}$ & Scale & $\begin{array}{l}\text { Feedback was given on } \\
\text { the respondents scale } \\
\text { score on recovery self- } \\
\text { efficacy. The feedback } \\
\text { aimed at increasing } \\
\text { recovery self-efficacy } \\
\text { by giving tips and using } \\
\text { textual modeling strat- } \\
\text { egies. }\end{array}$ & Scale \\
\hline $\begin{array}{l}\text { Preparatory } \\
\text { planning }\end{array}$ & $\begin{array}{l}\text { Feedback was given on the level of engage- } \\
\text { ment in planning measured with eighteen } \\
\text { items. First, feedback was given on a scale } \\
\text { level and continued with discussing the } \\
\text { importance of each plan (e.g. informing } \\
\text { relevant others about the quit attempt, } \\
\text { quitting together with someone, moving } \\
\text { smokers' requisites) }\end{array}$ & $\begin{array}{l}\text { Scale } \\
\text { and } \\
\text { item }\end{array}$ & $\begin{array}{l}\text { Feedback was given on } \\
\text { the level of engagement } \\
\text { in planning measured } \\
\text { with five items. }\end{array}$ & $\begin{array}{l}\text { Scale } \\
\text { tand } \\
\text { Item }\end{array}$ \\
\hline $\begin{array}{l}\text { Perceived } \\
\text { stress }\end{array}$ & $\begin{array}{l}\text { Feedback was given on the scale score of the } \\
\text { respondents regarding perceived stress. The } \\
\text { feedback contained information about how } \\
\text { to perform relaxation exercises in stressful } \\
\text { situations. }\end{array}$ & Scale & & Scale \\
\hline $\begin{array}{l}\text { Negative } \\
\text { affect }\end{array}$ & - & & $\begin{array}{l}\text { Feedback focused on } \\
\text { the mood state of the } \\
\text { respondent, explained } \\
\text { the importance of a } \\
\text { good mood and provid- } \\
\text { ed tips on how to keep } \\
\text { or reach a good mood } \\
\text { using rational emotive } \\
\text { therapy strategies } \\
\text { (recognize, accept, } \\
\text { react) }\end{array}$ & Scale \\
\hline
\end{tabular}




\begin{tabular}{|c|c|c|c|c|}
\hline \multirow[b]{2}{*}{ Construct } & \multirow{2}{*}{$\begin{array}{l}\text { Before the quit-attempt (at baseline) } \\
\text { description }\end{array}$} & \multicolumn{3}{|c|}{ After the quit-attempt } \\
\hline & & Level * & description & Level * \\
\hline $\begin{array}{l}\text { Smoking } \\
\text { behavior }\end{array}$ & - & & $\begin{array}{l}\text { Feedback on reported } \\
\text { smoking behavior was } \\
\text { given. We included the } \\
\text { smoking behavior of } \\
\text { the last three meas- } \\
\text { urements and provided } \\
\text { ipsative feedback } \\
\text { reporting progress, } \\
\text { maintenances or de- } \\
\text { cline. Tips were given } \\
\text { on how to remain } \\
\text { smoke-free or to re- } \\
\text { sume the quit-attempt. }\end{array}$ & Item \\
\hline
\end{tabular}

Feedback was provided on item or scale level. The item level contained feedback per item of the scale, while feedback provided on scale level was based on the mean scores of all items of a scale.

Table 4.2 Overview of the list of preparatory plans and risky situations used in the planning strategy assignments

\begin{tabular}{ll}
\hline $\begin{array}{l}\text { Planning strategy assignment } 1 \text { and 6: } \\
\text { Preparatory planning }\end{array}$ & $\begin{array}{l}\text { Planning strategy assignment } 2 \text { and 5: } \\
\text { Risky situations }\end{array}$ \\
\hline \begin{tabular}{ll} 
I plan to.... & $\begin{array}{l}\text { Situations in which it is difficult for me to } \\
\text { remain smoke free }\end{array}$ \\
avoid difficult situations & When I am sad \\
change habits to prevent smoking at certain moments or & When I am drinking tea or coffee \\
places & \\
do something else when I desire a cigarette & When I see someone enjoying a cigarette \\
make non-smoking pacts with friends & When I am stressed \\
make plans to reward myself when I abstain from smok- & When I gain weight \\
ing & \\
move all my smokers requisites & When I desire a cigarette \\
quit smoking cold turkey & When I am with others and I do not know \\
quit together with someone else & how to act \\
tell my environment that I am going to quit smoking & When I am at a party, visiting, or in a cafe \\
think about difficult situations in advance & When I am with friends \\
think about how to prevent weight gain & When I wake up in the morning \\
use smoking cessation aids & When I am very angry \\
\hline & When I am having a break \\
& When someone offers me a cigarette \\
After dinner
\end{tabular} \\
\hline
\end{tabular}




\section{Materials}

\section{Questionnaires}

The baseline questionnaire was based on the I-Change Model and was experimentally tested in previous studies. The questionnaire included intention to quit, pros and cons of non-smoking, pros and cons of relapse, self-efficacy, recovery self-efficacy, social influence and preparatory planning (Dijkstra, de Vries and Bakker, 1996; Dijkstra, De Vries and Roijackers, 1998; Dijkstra and de Vries, 2000; Hilberink, Jacobs, Schlosser, Grol and De Vries, 2006; Hoving, Mudde and de Vries, 2006; Mudde, Willemsen, Kremers and de Vries, 2006; Te Poel, Bolman, Reubsaet and de Vries, 2009). Finally, we measured demographics, level of nicotine dependence (Fagerstrom, Heatherton and Kozlowski, 1990; Heatherton, Kozlowski, Frecker and Fagerstrom, 1991), perceived stress (Cohen and Williamson, 1988) and depression (Cole, Rabin, Smith and Kaufman, 2004). The questionnaire at the six and twelve month measurements assessed sevenday point prevalence, and continued abstinence (see descriptions in the section 'outcome measures'). Moreover, we assessed planning and level of self-efficacy in these follow-up questionnaires.

\section{Intervention elements of AP and AP+ programs}

\section{Computer tailored baseline feedback (before the quit attempt)}

The computer tailored baseline feedback provided in the SQ4U programs aimed to increase respondents' motivation to quit smoking, to stimulate the respondent to make a quit-attempt and to prepare the respondent for the period after the quit-attempt. The feedback focused on respondents' characteristics, conforms to the I-Change Model and was based on previous tested effective computer tailoring programs (Dijkstra, De Vries and Roijackers, 1998; Te Poel, Bolman, Reubsaet and de Vries, 2009). The computer tailored feedback targeted the pros and cons of not smoking and relapse, aimed at enhancing or increasing (recovery) self-efficacy, how to deal with social influence, the importance of preparatory planning and how to make plans and to deal with stress. The feedback was in the form of a letter with an average of 4-5 pages. Animations were used to make the messages attractive for the respondents. Table 4.1 gives an overview and description of the concepts and feedback at baseline.

\section{Planning strategy assignments}

Both experimental programs (AP and $\mathrm{AP}+$ ) consisted of three planning strategy assignments before and three after the quit date. The planning assignments consisted of preparatory and coping planning strategies (see Fig. 4.1 for an overview per assignment). After each planning assignment the respondents received an overview of their plans by email. Two assignments focused on preparatory planning by stimulating respondents to make and carry out preparato- 
ry plans. Preparatory plans have shown to be protective of smoking relapse (Hoving, Mudde and de Vries, 2006; Elfeddali, Bolman, Candel, Wiers and de Vries, 2012) and to foster cessation (Te Poel, Bolman, Reubsaet and de Vries, 2009). The respondents were instructed to choose three preparatory plans from a list of plans (see Table 4.2) and to carry them out. The list of plans was based on earlier studies (Hilberink, Jacobs, Schlosser, Grol and De Vries, 2006; Hoving, Mudde and de Vries, 2006; Te Poel, Bolman, Reubsaet and de Vries, 2009). Two other assignments focused on coping planning. Coping plans aim to help respondents realize their intentions (e.g. not to smoke) by targeting barriers and preparing respondents to deal with them (Gollwitzer, 1999). In our study the respondents were instructed to choose three high-risk situations from a list (see Table 4.2). Next, the respondents were instructed to make coping plans in order to deal with the high-risk situations. The coping plans needed to be formulated as 'if ..... then' plans (e.g. if I feel the urge to smoke among smoking friends, then I will tell my friends about my quitting and ask them not to smoke in my presence). Finally, one assignment focused on a specific coping plan namely making an emergency plan to deal with a possible lapse and one on a specific preparatory plan namely planning a reward. Table 4.2 gives an overview of the list of preparatory plans and high-risk smoking related situations we provided.

\section{Intervention element for AP+ program only}

\section{Tailored feedback after the quit-attempt}

As mentioned before, multiple tailoring has shown to be more effective than single tailoring (Brug, Kok, van Breukelen, Glanz and van Assema, 1998; Dijkstra, De Vries, Roijackers and van Breukelen, 1998; Smeets, Brug and De Vries, 2008). Furthermore, studies using ecological momentary assessments to gain in-depth information from day-to-day pointed out that low self-efficacy and negative affect preceded the first lapse (Shiffman, Paty, Gnys, Kassel and Hickcox, 1996; Shiffman et al., 1997; Gwaltney, Shiffman, Balabanis and Paty, 2005; Shiffman et al., 2007). Therefore, we provided multiple tailored feedback time points after the quit-attempt targeting negative affect and two variants of self-efficacy 1 . standard self-efficacy and 2 . recovery self-efficacy. The latter type has been emphasized as important in resuming quit-attempts after a lapse (Haaga and Stewart, 1992; Dijkstra and de Vries, 2000). Additionally, we included feedback about the level of planning. Feedback was given daily in the first three days after the quit-attempt, once a week during the rest of the first month and once per two weeks until the third month. This resulted in eleven feedback time points after the quit-attempt. Each measurement targeted two of the mentioned four concepts (see Fig. 4.1 for an overview). Respondents filled out a short questionnaire about the concepts in question and received tailored feedback immediately after completing the questionnaire. The feedback did not only concern the respondents' present state, but also provided ipsative feedback by 
referring to earlier states (reporting positive or negative changes). Additionally, all feedback points targeted self-reported smoking behavior of the last three measurements and again provided ipsative feedback by reporting progress maintenance or decline over those three measurements. Table 4.1 gives an overview and description of the concepts and feedback provided after the quitattempt.

\section{Statistical analyses}

\section{Primary outcome variables}

The outcome variables in this study were seven-day point-prevalence and continued abstinence at 6 and 12 months after baseline. The outcome variables were measured conforming to the definitions in Hughes et al. (Hughes, Keely and Niaura, 2003). The respondents were asked whether they had smoked during the last 7 days (from follow-up) and since the quit-date to measure respectively seven-day point-prevalence and continued abstinence. Smoking during the last 7 days and after the quit-date was coded as relapse (0) and non-smoking was coded as abstinence (1) for respectively seven-day point prevalence and continued abstinence.

\section{Secondary outcome measures}

Secondary outcome measures include the cognitive behavioral determinants self-efficacy and preparatory planning. As the main focus of the SQ4U study was behavior change, we did not measure the other cognitive determinants at the follow-up measurements. Moreover, all respondents were asked to complete a process evaluation at the six month follow-up measurement in order to assess user experiences and to improve the program for implementation. Respondents in the control condition, however, did not fill out questions targeting experiences with the intervention, but only process questions (e.g. how they were attended on our research etc.).

\section{Hypotheses, required sample size and analyses}

We expect that the AP+ program will be most effective with $30 \%$ of the respondents being abstinent at the twelve - month measurement versus $15 \%$ in the AP program and 5\% in the Control program. Sample size estimations were based on these expectations. This implies that 132 smokers were needed to find significant differences between the AP and the control group and 118 to find differences between $\mathrm{AP}$ and $\mathrm{AP}+$ programs. Taking into account attrition rates of $20 \%, 175$ respondents per program needed to be recruited for participation. Logistic regression analyses will be conducted to assess the effect of the SQ4U programs on the dichotomous outcome measures of abstinence. Moreover, linear regression analyses will be conducted to assess the effects of the program on 
the secondary outcome measures (e.g. planning and self-efficacy). Analyses will be performed on complete cases only as well as on all cases by including missing follow-up outcomes as treatment failures (relapse). A correction for baseline variables will be made in the analyses.

\section{DISCUSSION}

This paper describes the development of the SQ4U programs, the program elements and the design of the SQ4U study. The SQ4U study aims to test the efficacy of the two described internet based smoking relapse prevention programs. Both programs include planning strategies. The two programs differ in the support provided after the quit-attempt $(\mathrm{AP}+$ provided tailored feedback at multiple time points after the quit-attempt, while AP did not) and will be compared to a control program.

The SQ4U study has several strengths. First, this study addresses the efficacy of a computer tailored approach with multiple tailored feedback points to prevent smoking relapse specifically. Although, previous programs have fostered smoking cessation using computer tailored approaches (Dijkstra, De Vries and Roijackers, 1998; Etter, 2005; Lancaster and Stead, 2005; Strecher, Shiffman and West, 2005; Te Poel, Bolman, Reubsaet and de Vries, 2009), few (see e.g., Borland, Balmford and Hunt, 2004) have focused on relapse prevention specifically and provided multiple feedback time points after the quit-attempt. In the process of successful smoking cessation, focusing on the period after the quitattempt is imperative as studies have identified factors predicting lapses and smoking during this period from day to day (Shiffman, Paty, Gnys, Kassel and Hickcox, 1996; Shiffman et al., 1997; Gwaltney, Shiffman, Balabanis and Paty, 2005; Shiffman et al., 2007). Second, to our knowledge, the SQ4U program is the first to include planning strategies in a computer tailored smoking relapse prevention program. Our decision to include these strategies and their potential strength is supported by recent studies testing the association between preparatory planning and smoking relapse (Hoving, Mudde and de Vries, 2006; Elfeddali, Bolman, Candel, Wiers and de Vries, 2012). A third strength of this study is the randomized controlled design. Randomization excludes potential biases with regard to the assignment of subjects to the control or experimental conditions and tends to generate comparable groups (Scherstén, 1986). A final strength of the SQ4U study is the measurement of a range of factors at baseline providing an extensive assessment of possible covariates. Covariate adjustment is considered as important in randomized controlled trials (Hernández, Steyerberg and Habbema, 2004).

The SQ4U study may be subject to limitations. First, our control program only included pointing to a quit date with no further feedback. However, previous studies indicated no difference in smoking cessation rates between a control 
program consisting of a standard non-tailored message and no intervention (Strecher et al., 1994). A second limitation may be that the SQ4U-respondents were not obliged to complete all parts of the programs, which may result in differences in support received between respondents from the same program. Corrections for level of implementation (intervention dose) in the analyses can help to overcome this limitation. Finally, the intensity of the AP and AP+ programs might form a limitation by leading to more drop-outs in these programs. However, intensive support has been found to increase abstinence rates (Fiore, 2008), suggesting that multiple sessions are needed in order to prevent smoking relapse successfully.

\section{CONCLUSION}

The SQ4U study has the potential to provide a new effective computer tailored smoking relapse prevention program and to help us to gain insight into effective prevention strategies in the field of smoking relapse prevention. The behavioral effects of SQ4U will be reported in other papers.

\section{ACKNOWLEDGMENTS}

This study was funded by the Dutch Organisation for Health Research and Innovation (grant number 6130-0030). We would like to thank Verina Servranck and Claire Jeukens for their contribution to the development and piloting of the SQ4U intervention materials. Finally, we would like to thank the respondents for their participation in the study. 



\section{CHAPTER 5}

\section{Preventing Smoking Relapse via Web- Based Computer-Tailored Feedback: A Randomized Controlled Trial}

This chapter is based on:

Elfeddali, I, Bolman, C, Candel, M., Wiers, R.W. \& de Vries, H. (2012). Preventing Smoking Relapse via Web-Based Computer-Tailored Feedback: A Randomized Controlled Trial, Journal of Medical Internet Research, 14 e109 


\section{ABSTRACT}

Background. Web-based computer-tailored approaches have the potential to be successful in supporting smoking cessation. However, the potential effects of such approaches for relapse prevention and the value of incorporating action planning strategies to effectively prevent smoking relapse have not been fully explored. The Stay Quit for You (SQ4U) study compared two Web-based computer-tailored smoking relapse prevention programs with different types of planning strategies versus a control group. Objectives. To assess the efficacy of two Web-based computer-tailored programs in preventing smoking relapse compared with a control group. The action planning (AP) program provided tailored feedback at baseline and invited respondents to do 6 preparatory and coping planning assignments (the first 3 assignments prior to quit date and the final 3 assignments after quit date). The action planning plus $(\mathrm{AP}+$ ) program was an extended version of the AP program that also provided tailored feedback at 11 time points after the quit attempt. Respondents in the control group only filled out questionnaires. The study also assessed possible dose-response relationships between abstinence and adherence to the programs. Methods. The study was a randomized controlled trial with three conditions: the control group, the AP program, and the AP+ program. Respondents were daily smokers $(\mathrm{N}=2031)$, aged 18 to 65 years, who were motivated and willing to quit smoking within 1 month. The primary outcome was self-reported continued abstinence 12 months after baseline. Logistic regression analyses were conducted using three samples: (1) all respondents as randomly assigned, (2) a modified sample that excluded respondents who did not make a quit attempt in conformance with the program protocol, and (3) a minimum dose sample that also excluded respondents who did not adhere to at least one of the intervention elements. Observed case analyses and conservative analyses (considering dropouts at follow-up as relapsers) were conducted. Results. In the observed case analysis of the randomized sample, abstinence rates were $22 \%(45 / 202)$ in the control group versus 33\% (63/190) in the AP program and 31\% (53/174) in the $\mathrm{AP}+$ program. The AP program (odds ratio $1.95, P=.005$ ) and the AP+ program (odds ratio $1.61, P=.049$ ) were significantly more effective than the control condition. In the conservative analysis of the randomized sample, abstinence rates were $7 \%(45 / 636)$ in the control group versus $9 \%(63 / 698)$ in the AP program and $8 \%(53 / 697)$ in the $\mathrm{AP}+$ program: the $\mathrm{AP}$ and $\mathrm{AP}+$ programs were no longer significantly more effective than the control condition. Abstinence rates and effects further differed per sample. Moreover, the results suggest a dose-response relationship between abstinence and the number of intervention elements completed by the respondents. Conclusion. Abstinence rates and effects differed per sample and per analytic strategy (observed case or conservative) used precluding unequivocal conclusions. The observed case analyses suggest that Web-based computer-tailored programs combined with planning 
strategy assignments and feedback after the quit attempt can be effective in preventing relapse 12 months after baseline. However, two of the three conservative analyses conducted do not support this suggestion. Since the study was subject to high study drop-out rates (72.1\%) that hindered drawing firm conclusions, improvements of the SQ4U-program aimed at preventing study dropout at follow-up measurements are required. Finally, more research is needed to assess the optimum intervention dose since adherence to the intervention seems critical for effectiveness. 


\section{INTRODUCTION}

Smoking relapse rates can be extremely high (up to $90 \%$ in the first 3 months), and only 3\%-5\% of quitters maintain their quit attempt for 6 months or longer (Hughes, Keely and Naud, 2004). The role of risk factors for relapse (eg, low selfefficacy, the expectation of negative outcomes from quitting, negative affect, stress, and physical dependence) is quite well documented (see for examples, Marlatt and Gordon, 1985; Killen et al., 1996; Kenford et al., 2002; Dijkstra and Borland, 2003; Shiffman and Waters, 2004). However, a Cochrane review concluded that current smoking relapse prevention programs are not effective (Hajek, Stead, West, Jarvis and Lancaster, 2009). This ineffectiveness, combined with the alarming relapse rates, underlines the need for new, effective smoking relapse prevention strategies and programs. One potential explanation for these programs' lack of effectiveness is that quitters are not fully prepared for their cessation attempt and lack sufficient coping strategies to maintain their attempts successfully (Hoving, Mudde and de Vries, 2006; O'Connell, Hosein and Schwartz, 2007; Elfeddali, Bolman, Candel, Wiers and de Vries, 2012).

Adding action planning components to programs may be a promising strategy for improving smoking relapse prevention programs (Hoving, Mudde and de Vries, 2006; O'Connell, Hosein and Schwartz, 2007; van Osch, Lechner, Reubsaet, Wigger and de Vries, 2008; Te Poel, Bolman, Reubsaet and de Vries, 2009; Elfeddali, Bolman, Candel, Wiers and de Vries, 2012). Planning strategies are already incorporated into many face-to-face and telephone smoking cessation counseling sessions (eg, smoking cessation courses provided by the Dutch Foundation for a Smoke-free Future in the Netherlands) (Plas, Hilberink, Hermans and Breteler, 2001). Furthermore, the role of action planning strategies is acknowledged by integrative social cognitive models, such as the Integrated Change (I-Change) Model (de Vries et al., 2003; de Vries, Kremers, Smeets, Brug and Eijmael, 2008). The I-Change Model distinguishes between two essential planning components: (1) preparatory plans as actions designed to prepare for the behavior change, and (2) coping plans as actions designed to maintain the new behavior by coping with challenging or difficult situations. Yet, as far as we know, these planning strategies have received little emphasis in Web-based prevention programs.

The Internet has proven to be a promising delivery mode for healthpromoting and lifestyle-changing interventions (for instance, Brug, Campbell and van Assema, 1999; Walters, Wright and Shegog, 2006; Vandelanotte, Spathonis, Eakin and Owen, 2007; Te Poel, Bolman, Reubsaet and de Vries, 2009). Since 91\% of Dutch households have access to the Internet, it could potentially be used to reach large numbers of people (CBS, 2011). Additionally, interactive, personalized Internet-based delivery modes, such as computer tailoring, have already demonstrated their potential to support smoking cessation (Dijkstra, De Vries and Roijackers, 1998; Etter, 2005; Strecher, Shiffman and 
West, 2005; Shahab and McEwen, 2009; Te Poel, Bolman, Reubsaet and de Vries, 2009). These highly personalized approaches are assessment based and adapt their messages to the needs of the respondent (Dijkstra and De Vries, 1999; Kreuter, Strecher and Glassman, 1999). Compared with nontailored messages, tailored messages are evaluated more positively, attract more attention, and are more likely to be read (Brug, Campbell and van Assema, 1999; Dijkstra and De Vries, 1999; Brug, Oenema and Campbell, 2003; Te Poel, Bolman, Reubsaet and de Vries, 2009). Computer-tailored health programs have shown to be promising tools for promoting healthy behavior in general (Bandura, 1998; Kreuter and Wray, 2003; Kreuter, Caburnay, Chen and Donlin, 2004; Kroeze, Werkman and Brug, 2006; Noar, Benac and Harris, 2007; Smeets, Brug and De Vries, 2008) and smoking cessation specifically (Dijkstra, De Vries and Roijackers, 1998; Etter, 2005; Strecher, Shiffman and West, 2005; Shahab and McEwen, 2009; Te Poel, Bolman, Reubsaet and de Vries, 2009), with multiple tailoring moments being more effective than a single tailoring moment (Brug, Kok, van Breukelen, Glanz and van Assema, 1998; Dijkstra, De Vries, Roijackers and van Breukelen, 1998; Smeets, Brug and De Vries, 2008). Few computer-tailored programs have explicitly targeted smoking relapse (see Borland et al (Borland, Balmford and Hunt, 2004) for an example). In line with earlier studies (Brug, Kok, van Breukelen, Glanz and van Assema, 1998; Dijkstra, De Vries, Roijackers and van Breukelen, 1998; Noar, Benac and Harris, 2007), Borland's study also indicated the surplus value of multiple tailoring moments and suggested a dose-response relationship between the number of feedback letters and smoking abstinence. Moreover, no studies have assessed the effects of using planning strategies in combination with multiple tailored feedback time points after the quit attempt.

In sum, the main goal of the Stay Quit for You (SQ4U) study was to assess the efficacy of two relapse prevention programs: (1) an action planning (AP) program that provided tailored feedback based on the baseline questionnaire and 6 preparatory and coping planning assignments, and (2) an action planning plus $(\mathrm{AP}+)$ program that extended the AP program by providing tailored feedback at 11 time points after the quit date. The efficacy of the programs was compared with that of a control group (with no intervention). Moreover, we aimed to assess possible dose-response relationships between abstinence and adherence to the number of program elements. First, we expected both programs to be more effective than the control condition in fostering continued abstinence 12 months after the start of the study (hypothesis 1). We expected the $\mathrm{AP}+$ program to be the most effective. Moreover, we expected to find a doseresponse relationship between continued abstinence and intervention dose (hypothesis 2). Finally, we will provide an overview of the respondents' program evaluations. 


\section{METHODS}

Ethics approval was obtained from the Medical Ethics Committee of Maastricht Academic Hospital and Maastricht University (MEC 08-3-003; NL21414.068.08). The study is registered with the Dutch Trial Register (NTR1892).

\section{Respondents and Recruitment}

We recruited smokers by placing ads in local newspapers, distributing 10,000 flyers in the city of Maastricht, and placing online ads on the websites of national health funds, a national news page, and the Dutch Foundation for a Smokefree Future. The ads referred the respondents to our research website for more information. All data were gathered via the Web and there was no face-to-face contact between respondents and the study team. A software program randomly assigned a total of 2681 respondents to one of the three conditions using a simple randomization type (see design below). The enrollment and inclusion of respondents is presented in Figure 5.1. Respondents were eligible for participation when they met the baseline inclusion criteria (aged 18-65 years, smoked daily, willing to set a quit date within 1 month, and motivated to quit smoking) and agreed with the informed consent. The final sample consisted of 2031 respondents, of whom $566(27.98 \%)$ responded to the 12-month follow-up measurement. 
Registered for participation $(\mathrm{N}=2697)$

Randomly assigned to one of the three conditions $(n=2681)$

Note: 16 respondents were excluded from the sample because they also participated in one of the other programs

Control
$(\mathrm{n}=888)$

Exduded (total): $252(28.4 \%)$
-Did not meet ariteria: 68
-No baseline quit-date: 113
-Inconsistent answers: 14
-Bug in control program: 57

Sample $1^{2}: 636$

Additional exclusion criteria

-No quit attempt: 94

- Dose $=0:$ NA.

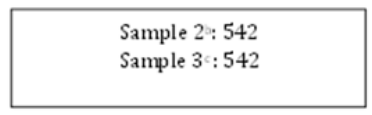

Lost to follow-up Sample 1: $434(68.2 \%)$

Sample 2: $408(75.3 \%)$

Sample 3: $408(75.3 \%)$

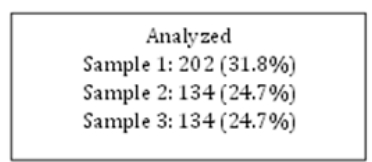

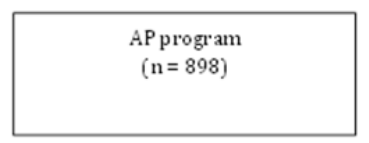

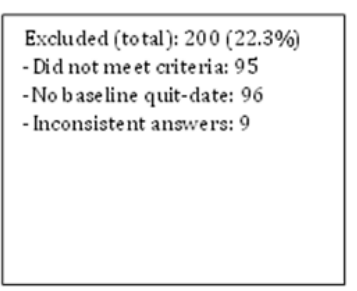

Sample 1:698

Additional exclusion criteria

-No quit attempt: 76

- Dose $=0: 177$

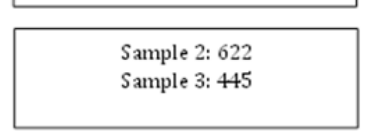

Lost to follow-up Sample 1: $508(72.8 \%)$

Sample 2: $480(77.2 \%)$

Sample 3: $315(70.8 \%)$

Analyzed

Sample 1: $190(27.2 \%)$

Sample 2: $142(22.8 \%)$

Sample 3: $130(29.2 \%)$

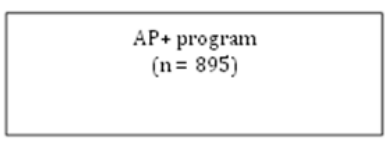

Excluded (total): $198(22.1 \%)$

-Did not meet criteria: 83

-No baseline quit-date: 102

-Inconsistent answers: 13

Sample $1 \div 697$

Additional exdusion criteria

-No quit attempt: 49

- Dose $=0: 311$

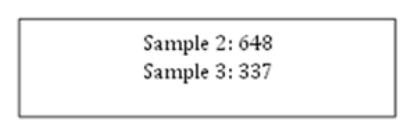

Lost to follow-up Sample 1: $523(75.0 \%)$

Sample 2: $506(78.1 \%)$

Sample 3: $212(62.9 \%)$

\section{Analyzed}

Sample 1: $174(25.0 \%)$

Sample 2: $142(21.9 \%)$

Sample 3: $125(37.1 \%)$

Figure 5.1 Enrollment and inclusion of respondents. NA = not applicable. a All respondents as randomly assigned, ${ }^{\mathrm{b}}$ modified sample excluding respondents who indicated after their quit-date as well as at follow-up that they did not make a quit-attempt during the study and respondents who quitted too close to follow-up (see Analyses section in the Methods), c minimum dose sample additionally excluding respondents who did not adhere to at least one intervention element. 


\section{Design and Procedure}

The SQ4U study was a randomized controlled study with a control condition and two experimental conditions. Respondents registered via the research website and made their own login account (each time they were invited for participation they received this account in the invitation mail). After registration, respondents were randomly assigned to one of the three programs outlined in the Introduction. Respondents in the intervention groups were invited by email or text message (optional) to perform intervention tasks (eg, filling out a planning assignment). The same procedure was used to invite all respondents for the 12-month follow-up measurement. Reminder emails were sent when respondents did not respond to the follow-up measurement, which asked them to report on their smoking behavior using self-assessed questionnaires. Respondents who reported that they were abstinent were asked to take biochemical validation tests (see below). Respondents who completed all parts of their assigned SQ4U variant (including those in the control group) were eligible to win 1 of 20 prizes of $€ 250$. A more detailed description of the development, design, study course, biochemical validation, and intervention elements can be found elsewhere (Elfeddali, Bolman and de Vries, 2012).

\section{Biochemical Validation}

We used cotinine assessments to validate reports of abstinence in a subsample $(n=70)$ of the respondents. This verified the nonsmoking status self-reported by respondents at the 12-month follow-up measurement. Only $1(1 \%)$ respondent showed positive cotinine results and admitted to having smoked. Another respondent admitted to smoking when invited for biochemical validation. The smoking status for these $2(3 \%)$ respondents was changed to relapse.

\section{Intervention Materials}

Baseline Computer-Tailored Feedback Before the Quit Attempt (AP and AP+ programs)

Feedback focused on respondents' perceptions of smoking and quitting and was based on previously tested effective computer tailoring programs that used the I-Change Model (Dijkstra, De Vries and Roijackers, 1998; Te Poel, Bolman, Reubsaet and de Vries, 2009). The feedback was intended to increase the respondents' motivation to quit smoking and to prepare them for the period after the quit attempt. It targeted the pros and cons of not smoking and relapses, provided tips to enhance or increase self-efficacy, offered suggestions for dealing 
with social influences, explained the importance of preparatory planning, and gave ideas for preparing for the quit attempt and dealing with stress.

Planning Strategy Assignments Before and After the Quit Attempt (AP and AP+ programs)

Since planning assignments have proven to be promising strategies to foster cessation and prevent relapse, the SQ4U programs incorporated assignments designed to motivate respondents to use these strategies to make a quit attempt (first 3 assignments, prior to quit date) and to prevent relapse (final 3 assignments, after quit date). Two assignments focused on making and carrying out preparatory plans; 2 more assignments addressed coping planning. Finally, 1 assignment focused on a specific coping plan (making an emergency plan for coping in case of a lapse) and 1 assignment required making a specific preparatory plan (planning a reward for abstaining from smoking for some time).

\section{Tailored Feedback After the Quit Attempt (AP+ program only)}

Studies that use ecological momentary assessments to gain in-depth, day-to-day information on the process of quitting have noted that low self-efficacy and negative affect preceded lapsing (Shiffman, Paty, Gnys, Kassel and Hickcox, 1996; Ferguson, Bauld, Chesterman and Judge, 2005; Gwaltney, Shiffman, Balabanis and Paty, 2005; Shiffman et al., 2007). Therefore, we targeted selfefficacy, recovery self-efficacy, and negative affect in the feedback moments after the quit attempt. We also included feedback about the level of planning. Each measurement after the quit attempt targeted two of the four concepts mentioned. Tailored feedback about each of the four concepts was provided daily during the first 3 days (after the quit date), once a week during the rest of the first month, and once every 2 weeks until the third month. The feedback not only addressed the respondents' present state but was also ipsative, referring to earlier states (reporting changes in a positive or negative direction). Finally, all feedback targeted self-reported smoking behavior for the last three measurements and reported the progress of maintenance or decline over those three measurements.

\section{Baseline Questionnaire}

The following basic information was collected about each respondent:

Demographic variables assessed age, gender, and educational level $(1=$ low [no education or only primary or primary-level vocational education], 2 = medium [secondary or secondary-level vocational education], and $3=$ high [higher education]).

Perceived stress was assessed by 5 items based on the Perceived Stress Scale (Cohen and Williamson, 1988) and was rated on a 5-point scale ( $1=$ never, $5=$ 
very often). The mean scale score was included in the analyses (Cronbach alpha $=.75$ ).

Level of depression was measured by 10 items (eg, "I feel anxious") using the Center for Epidemiologic Studies Depression scale (Cole, Rabin, Smith and Kaufman, 2004). The answers were given on a 4 -point scale $(1=$ never, $4=$ all the time). The mean scale score was included in the analyses (alpha $=.83$ ).

Level of dependence was assessed by 5 items (eg, the time when tobacco is smoked after awakening) based on an abbreviated Fagerström test (Fagerstrom, Heatherton and Kozlowski, 1990; Heatherton, Kozlowski, Frecker and Fagerstrom, 1991). The sum score was used in the analyses $(0=$ not dependent, $9=$ very dependent).

The following questions about intention and motivational factors were based on questions used in previous studies (Dijkstra, De Vries and Roijackers, 1998; Dijkstra and de Vries, 2000; Hilberink, Jacobs, Schlosser, Grol and De Vries, 2006; Hoving, Mudde and de Vries, 2006; Mudde, Willemsen, Kremers and de Vries, 2006; Te Poel, Bolman, Reubsaet and de Vries, 2009):

Attitudes were measured on a 4-point scale ( $1=$ no, $2=$ yes, a bit, $3=$ yes, $4=$ yes, a lot/very) with four subscales measuring the following: (1) pros of not smoking, expressed by 9 statements representing positive expected outcomes (eg, "not smoking will save me money") (alpha = .73), (2) cons of not smoking, expressed by 9 statements representing negative expected outcomes (eg, "not smoking will cause me more stress") (alpha $=.71$ ), (3) pros of relapse, expressed by 4 statements representing positive expected outcomes (eg, "relapse will make me feel relieved") (alpha $=.82$ ), and (4) cons of relapse, expressed by 6 statements representing negative expected outcomes (eg, "relapse will make me feel weak") (alpha $=.85$ ).

Social support was measured by 5 items that asked about the support received from significant others (partner, children, other family members, friends, or colleagues) on a 4-point scale ( $1=$ no, $2=$ yes, some, $3=$ yes, moderate, and 4 = yes, a lot). A "not applicable" response was coded as missing. We created an index and used these scores in the analyses.

Modeling was assessed by 5 items that measured the smoking status of the partner (yes, no, not applicable) and residential children, parents, colleagues, and friends (all, the majority, half, a minority, none, not applicable). The items were coded into three category scales $(-1=$ not smoking, $0=$ not applicable, $1=$ smoking). The items were summed and formed an index that we used in the analyses; smoking status of the partner was included separately in the analyses.

Self-efficacy was assessed by 13 items that asked whether respondents thought they would be able to refrain from smoking in various smoking-related high-risk situations such as parties (alpha $=.88$ ). Recovery self-efficacy was assessed by 7 items that asked whether respondents thought they would be able to resume a smoking cessation program after a lapse (eg, after a week of absti- 
nence) (alpha $=.92)$. Answers were given on a 5-point scale ( 1 = totally disagree, $5=$ totally agree) and the mean score was used in the analyses. Preparatory planning was assessed by 12 items (based on previous studies (Hilberink, Jacobs, Schlosser, Grol and De Vries, 2006; Hoving, Mudde and de Vries, 2006; Te Poel, Bolman, Reubsaet and de Vries, 2009; Elfeddali, Bolman, Candel, Wiers and de Vries, 2012)) asking respondents to indicate whether they had plans to perform preparatory behaviors, such as removing all smoking materials, on a 5point scale ( $1=$ totally disagree, $5=$ totally agree) (alpha $=.72)$. The mean scale scores were used in the analyses.

\section{Follow-up Measurements}

Continued abstinence at 12 months after baseline was the primary outcome. In line with the definitions provided by Hughes et al (Hughes, Keely and Niaura, 2003), we defined continued abstinence as not smoking at all after the quit attempt. We measured it by asking whether the respondent had smoked since the quit date. Continued abstinence was coded as $0=$ relapse and nonsmoking as $1=$ abstinence.

\section{Analyses}

The most common approach to analyzing the effects of interventions is to include all respondents randomly assigned to the programs. The advantage to this approach is that it reflects the situation as it is likely to occur in practice (where low adherence levels and not following program protocols will also be common). This strategy also maintains the balance between randomly assigned groups and preserves sample sizes (Wertz, 1995; Heritier, Gebski and Keach, 2003). On the other hand, including all randomly assigned respondents is a very conservative approach that may be susceptible to type II errors (Wertz, 1995; Heritier, Gebski and Keach, 2003) and may say little about the efficacy of a treatment, since respondents who did not receive the treatment or did not follow the protocol are still included (Hollis and Campbell, 1999; Heritier, Gebski and Keach, 2003). A modified approach (which has been used more frequently in the last decades (Abraha and Montedori, 2010)) seems to be more suitable for gaining insight into the effects of programs among those who actually followed them. However, excluding respondents after randomization may threaten the randomization balance and neglect the fact that nonadherence (and even making or not making a quit attempt) may also be a result of the treatment (Wertz, 1995). Therefore, both approaches have their advantages and disadvantages. To provide a complete overview of our results, we analyzed three samples and report on the above-mentioned modified approach. This resulted in three different analytic approaches with three different samples: 
Sample 1 is the sample as randomized, including all respondents. Since this study focused on relapse prevention and therefore on continued abstinence, we also report on smaller samples:

Sample 2, referred to as the modified sample, excluded respondents who indicated after their quit date as well as at follow-up that they did not make a quit attempt, and those who reported that they had quit less than 320 days before the follow-up measurement (this is after about 2 weeks after the first month in which they were supposed to make an attempt). We excluded the latter group because one of the inclusion criteria was that respondents needed to set a quit date within 1 month after inclusion. Including respondents who explicitly stated that they made their quit attempt much later or even too close to the follow-up measurement would result in differences between respondents in the time frame from the quit attempt to the follow-up measurement.

Sample 3, referred to as the minimum dose sample, excluded respondents who did not adhere to at least one element of the program they were assigned to (ie, did not complete the prequit and postquit assignments) in addition to meeting the exclusion criteria in the modified sample.

For all three samples, we conducted an observed case analysis (only including respondents with follow-up data) and a conservative analysis in which we assumed that participants missing at follow-up had relapsed to smoking. We used a logistic regression analysis to compare the efficacy of the control condition and the SQ4U programs to foster continued smoking abstinence after 12 months. Differences in baseline factors (demographics, smoking-related factors, perceived stress, depression, intention strength, social influence, attitude, selfefficacy, recovery self-efficacy, and preparatory planning) were assessed using chi-square tests for categorical variables and analysis of variance for continuous variables. Attrition was analyzed by logistic regression and included baseline factors. To preserve power, we included only baseline factors on which the three conditions significantly differed at baseline as well as the factors that significantly predicted study dropout at follow-up as covariates in the effect analyses. Listwise deletion with regard to missing values was used. Finally, chisquare tests were used to assess the existence of dose-response relationships within the SQ4U programs using the observed cases in sample 2 (the modified sample) to conform to the methods used by Borland et al (Borland, Balmford and Hunt, 2004). 


\section{RESULTS}

\section{Sample Characteristics and Attrition Check}

Table 5.1 presents the demographic and smoking-related characteristics at baseline and shows no significant differences between these variables in the three conditions. The mean age of the respondents was 41 (SD 11.80) years, and 1265 of the 2031 (62.28\%) respondents were female. On average, respondents smoked 20 (SD 8.73) cigarettes per day, and 1887 (92.91\%) had made previous attempts to quit. Furthermore, we found no significant $(P>.05)$ differences between the three conditions on the baseline measurements of perceived stress, depression, intention strength, social influence, attitude, self-efficacy and recovery self-efficacy, and preparatory planning. (Table 1 shows only demographics and smoking-related factors.)

In the control condition, 434 of $636(68.2 \%)$ were lost to follow-up versus 508 of 698 (72.8\%) in the AP program and 523 of 697 (75.0\%) in the AP+ program (Figure 5.1). Attrition analysis proved that study dropout was more likely among respondents in the AP (odds ratio [OR] 1.26, $P=.06)$ and $\mathrm{AP}+(\mathrm{OR} 1.44, P$ $=.004$ ) programs and respondents who were younger (OR 0.98, $P<.001,95 \%$ confidence interval [CI] 0.97-0.99), were male (OR 1.32, $P=.02,95 \%$ CI 1.051.66), had a lower education level (OR 2.00, $P=.001,95 \%$ CI 1.33-3.00), perceived fewer advantages to relapse (OR 0.80, $P=.02,95 \%$ CI 0.67-0.97), and had low levels of self-efficacy (OR 0.78, $P=.001,95 \%$ CI 0.67-0.91). 
Table 5.1 Means and baseline differences between the three programs in demographic and smoking-related variables.

\begin{tabular}{|c|c|c|c|c|c|c|}
\hline Characteristic & $\begin{array}{l}\text { Overall } \\
(\mathrm{N}=2031)\end{array}$ & $\begin{array}{l}\text { Control } \\
(\mathrm{n}=636)\end{array}$ & $\begin{array}{l}\mathrm{APa}^{\mathrm{a}} \\
(\mathrm{n}=698)\end{array}$ & $\begin{array}{l}\mathrm{AP}+\mathrm{b} \\
(\mathrm{n}=697)\end{array}$ & $\begin{array}{l}F \\
\text { value } / \chi^{2}\end{array}$ & $\begin{array}{l}P \\
c \text { value }\end{array}$ \\
\hline Female gender, n (\%) & $1265(62.3 \%)$ & $381(59.9 \%)$ & $442(63.3 \%)$ & $442(63.4 \%)$ & 2.2 & .33 \\
\hline Age (years), mean (SD) & $40.88(11.80)$ & $40.68(11.81)$ & 40.75 & $41.18(12.12)$ & 0.36 & .70 \\
\hline Educational level, n (\%) & & & & & 6.4 & .17 \\
\hline Low & 207 (10.2\%) & $57(9 \%)$ & $86(12 \%)$ & $64(9 \%)$ & & \\
\hline Medium & $1130(55.6 \%)$ & $357(56.1 \%)$ & $371(53.2 \%)$ & $402(57.7 \%)$ & & \\
\hline High & $694(34.2 \%)$ & $222(34.9 \%)$ & $241(34.5 \%)$ & $231(33.1 \%)$ & & \\
\hline $\begin{array}{l}\text { Cigarettes smoked per } \\
\text { day, mean (SD) }\end{array}$ & $19.85(8.73)$ & $19.85(8.39)$ & $19.89(9.36)$ & $19.80(8.41)$ & 0.02 & .98 \\
\hline $\begin{array}{l}\text { Smoking duration } \\
\text { (years), mean (SD) }\end{array}$ & $24.81(11.96)$ & $24.61(11.90)$ & $24.79(11.58)$ & $25.01(12.41)$ & 0.19 & .83 \\
\hline $\begin{array}{l}\text { Previous quit attempts } \\
\text { (yes), n (\%) }\end{array}$ & $1887(92.9 \%)$ & $588(92.5 \%)$ & $654(93.7 \%)$ & $645(92.5 \%)$ & 1.0 & .61 \\
\hline $\begin{array}{l}\text { Nicotine dependence } \\
\text { mean }(S D)^{\mathrm{d}}\end{array}$ & $4.53(2.18)$ & $4.57(2.21)$ & $4.48(2.13)$ & $4.55(2.19)$ & 0.26 & .77 \\
\hline
\end{tabular}

${ }^{a}$ Action planning.

${ }^{\mathrm{b}}$ Action planning plus.

${ }^{c}$ Degrees of freedom (DF) $=2$ for all except for educational level $(D F=4)$.

d Sum score of abbreviated Fagerström test $(0=$ not dependent, $9=$ very dependent $)$.

\section{Abstinence Rates 12 Months After Baseline}

Table 5.2 presents the abstinence rates for samples 1,2, and 3 when using observed cases alone, as well as when conducting conservative analyses and considering dropouts at follow-up as relapsers. When using the observed case analysis strategy on sample 1, abstinence rates in the control group, the AP program, and the $\mathrm{AP}+$ program were $22 \%, 33 \%$, and $31 \%$, respectively (see Table 5.2 ). Conservative analyses - in which dropouts at follow-up were considered as relapsers - on sample 1 resulted in abstinence rates of $7 \%, 9 \%$, and $8 \%$, respectively. 
Table 5.2 12-month abstinence rates per program for the three samples using observed and conservative analyses.

\begin{tabular}{|c|c|c|c|c|c|c|c|c|}
\hline \multirow[t]{3}{*}{ Sample } & \multicolumn{4}{|c|}{ Observed } & \multicolumn{4}{|c|}{ Conservative } \\
\hline & \multirow{2}{*}{$\begin{array}{l}\mathrm{n} \\
\text { Total }\end{array}$} & \multicolumn{3}{|c|}{$\mathrm{n}(\%)$ abstinent } & & \multicolumn{3}{|c|}{ n (\%) abstinent } \\
\hline & & Control & $\mathrm{APa}$ & $\mathrm{AP}+\mathrm{b}$ & & Control & $\mathrm{AP}$ & $\mathrm{AP}+$ \\
\hline $1^{\mathrm{c}}$ & 566 & $45(22 \%$ & $63(33 \%)$ & $53(31 \%)$ & 2031 & $45(7 \%)$ & $63(9 \%)$ & $53(8 \%)$ \\
\hline $2^{\mathrm{d}}$ & 418 & $45(34 \%$ & $63(44 \%)$ & $53(37 \%)$ & 1812 & $45(8 \%)$ & $63(10 \%)$ & $53(8 \%)$ \\
\hline $3^{e}$ & 389 & $45(34 \%$ & $60(46 \%)$ & 49 (39\%) & 1324 & 45 (8\%) & $60(14 \%)$ & $49(15 \%)$ \\
\hline
\end{tabular}

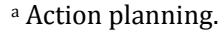

${ }^{\mathrm{b}}$ Action planning plus.

c Including all respondents as randomly assigned.

d Modified sample excluding respondents who indicated after their quit date as well as at follow-up that they did not make a quit attempt during the study and respondents who quit too close to followup (see Analyses section in the Methods).

e Minimum dose sample additionally excluding those who adhered to none of the intervention elements of their SQ4U variant.

\section{Main Effects of the AP and AP+ Programs With Correction for Covariates}

Table 5.3 presents the main effects of the AP and AP+ programs compared with the control condition, while controlling for covariates (factors that predicted dropout according to the attrition analysis). The table shows these findings for observed case analyses as well as conservative analyses for sample 1 (including all respondents as randomly assigned), sample 2 (modified sample), and sample 3 (minimum dose sample). The AP program was significantly more effective in fostering abstinence than was the control condition in sample 1 (OR 1.95, $P=$ .005 ), sample 2 (OR 1.71, $P=.04$ ), and sample 3 (OR 1.84, $P=.02$ ) when including observed cases only. The AP+ program was, however, only significant in sample 1 (OR 1.61, $P=.049$ ). In the conservative analyses, both programs were significantly more effective than the control condition only in sample 3 (AP: OR $1.72, P=.01 ; \mathrm{AP}+:$ OR $1.76, P=.01$ ). The program effects in sample 1 (AP: OR $1.38, P=.12$; AP+: OR 1.12, $P=.61$ ) and sample 2 (AP: OR 1.29, $P=.23$; AP+: OR $.99, P=.98)$ were non-significant when considering dropouts as relapsers. Finally, having high levels of self-efficacy was the only consistent predictor of continued abstinence in all these analyses. 
Table 5.3 Regression 12-month continued abstinence on the APa and AP+b program in sample 1 (observed cases, $n=559$; conservative analysis, $n=1974$ ), sample 2 (observed cases, $n=412$; conservative analysis, $n=1757$ ), and sample 3 (observed cases, $n=383$; conservative analysis, $n=$ 1297).

\begin{tabular}{|c|c|c|c|c|c|c|}
\hline \multirow[t]{2}{*}{ Variable } & \multicolumn{3}{|c|}{ Observed case analysis ${ }^{c}$} & \multicolumn{3}{|c|}{ Conservative analysis $^{d}$} \\
\hline & $\mathrm{OR}^{\mathrm{e}}$ & $95 \% \mathrm{Cl}^{\mathrm{f}}$ & $\begin{array}{l}P \\
\text { value }\end{array}$ & OR & $95 \% \mathrm{CI}$ & $\begin{array}{l}P \\
\text { value }\end{array}$ \\
\hline \multicolumn{7}{|l|}{ Sample $1^{\mathrm{g}}$} \\
\hline Gender & 1.15 & $0.77-1.71$ & .50 & .91 & $0.64-1.29$ & .59 \\
\hline Age & 1.01 & $0.99-1.03$ & .26 & 1.02 & $1.01-1.04$ & .002 \\
\hline Low education level (high $\left.{ }^{\mathrm{h}}\right)$ & 1.61 & $0.75-3.43$ & .22 & .76 & $0.40-1.43$ & .40 \\
\hline Pros of relapse & 0.87 & $0.63-1.20$ & .39 & 1.00 & $0.76-1.32$ & .98 \\
\hline Self-efficacy & 1.51 & $1.14-1.99$ & .004 & 1.64 & $1.29-2.07$ & $<.001$ \\
\hline AP program (control $\left.{ }^{\mathrm{h}}\right)$ & 1.95 & $1.23-3.11$ & .005 & 1.38 & $0.92-2.08$ & .12 \\
\hline $\mathrm{AP}+$ program (control $\left.{ }^{\mathrm{h}}\right)$ & 1.61 & $1.00-2.60$ & .049 & 1.12 & $0.73-1.70$ & .61 \\
\hline \multicolumn{7}{|l|}{ Sample $2^{\mathrm{i}}$} \\
\hline Gender & 1.12 & $0.73-1.73$ & .59 & .88 & $0.62-1.25$ & .48 \\
\hline Age & 1.01 & $0.99-1.03$ & .28 & 1.03 & $1.01-1.04$ & .001 \\
\hline Low education level $\left(\mathrm{high}^{\mathrm{h}}\right)$ & 1.69 & $0.73-3.95$ & .22 & .71 & $0.37-1.34$ & .29 \\
\hline Pros of relapse & 0.81 & $0.57-1.15$ & .23 & 1.00 & $0.76-1.32$ & .99 \\
\hline Self-efficacy & 1.39 & $1.03-1.89$ & .03 & 1.62 & $1.28-2.06$ & $<.001$ \\
\hline AP program (controlh) & 1.71 & $1.03-2.83$ & .04 & 1.29 & $0.86-1.95$ & .23 \\
\hline $\mathrm{AP}+$ program $\left(\right.$ control $\left.^{\mathrm{h}}\right)$ & 1.22 & $0.73-2.03$ & .44 & .99 & $0.65-1.52$ & .98 \\
\hline \multicolumn{7}{|l|}{ Sample $3^{j}$} \\
\hline Gender & 1.17 & $0.75-1.83$ & .49 & .87 & $0.61-1.26$ & .47 \\
\hline Age & 1.01 & $0.99-1.03$ & .31 & 1.02 & $1.01-1.04$ & .005 \\
\hline Low education level $\left(\mathrm{high}^{\mathrm{h}}\right)$ & 1.95 & $0.81-4.72$ & .14 & .87 & $0.45-1.68$ & .68 \\
\hline Pros of relapse & 0.86 & $0.60-1.23$ & .41 & 1.06 & $0.80-1.42$ & .68 \\
\hline Self-efficacy & 1.43 & $1.04-1.96$ & .03 & 1.53 & $1.19-1.97$ & .001 \\
\hline AP program (control ${ }^{\mathrm{h}}$ ) & 1.84 & $1.10-3.07$ & .02 & 1.72 & $1.13-2.61$ & .01 \\
\hline 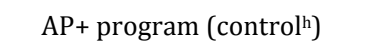 & 1.36 & $0.80-2.29$ & .26 & 1.76 & $1.13-2.73$ & .01 \\
\hline
\end{tabular}

a Action planning.

${ }^{\mathrm{b}}$ Action planning plus.

c Sample including only respondents with follow-up data.

d Sample including missing data at follow-up as treatment failures.

e Odds ratio.

${ }^{\mathrm{f}}$ Confidence interval.

$\mathrm{g}$ Including all respondents as randomly assigned.

h Reference category.

${ }^{i}$ Modified sample excluding respondents who indicated after their quit date as well as at follow-up that they did not make a quit attempt during the study and respondents who quit too close to followup (see Analyses section in the Methods).

j Minimum dose sample excluding those who did not adhere to at least one of the SQ4U elements. 


\section{Abstinence Rates per Program Stratified to Intervention Dose}

Table 5.4 shows the 12-month continued abstinence rates per intervention dose for the modified sample (sample 2). As posed in hypothesis 2, the results revealed significant relationships between abstinence and the number of planning assignments using linear by linear association chi-square tests (AP: $\chi^{2}=7.4, P<$ .007; $\left.\mathrm{AP}+: \chi^{2}=14.7, P<.001\right)$ and feedback moments $\left(\mathrm{AP}+: \chi^{2}=24.5, P<.001\right)$ and confirmed higher abstinence rates when more planning assignments or questionnaires after the quit attempt were completed. On average, respondents in the program groups adhered to 4 out of 6 planning assignments and 6 out of 11 feedback questionnaires.

Table 5.4 12-month continued abstinence rates stratified by the number of planning assignments and feedback moments in the modified sample (sample 2).

\begin{tabular}{llllll}
\hline & & \multicolumn{3}{c}{$\mathrm{AP}^{\mathrm{a}}$} & \multicolumn{2}{c}{$\mathrm{AP+b}$} \\
Stratification & Dose & $\mathrm{n}^{\mathrm{c}}$ & $\begin{array}{l}\mathrm{n}(\%) \\
\text { abstinent }\end{array}$ & $\mathrm{n}^{\mathrm{c}}$ & $\begin{array}{l}\mathrm{n}(\%) \\
\text { abstinent }\end{array}$ \\
\hline Per number of assignments & $0-1$ & 27 & $6(22 \%)$ & 23 & $4(17 \%)$ \\
& $2-4$ & 53 & $24(45 \%)$ & 49 & $13(27 \%)$ \\
& $5-6$ & 62 & $33(53 \%)$ & 70 & $36(51 \%)$ \\
& Total, mean (SD) & & $3.71(2.00)$ & & $3.95(1.93)$ \\
& $\chi^{2}$ & & 7.4 & & 14.7 \\
Per number of feedback moments & $P$ value & & .007 & & $<.001$ \\
& $0-5$ & NAd & NA & 66 & $10(15 \%)$ \\
& $6-7$ & NA & NA & 12 & $4(33 \%)$ \\
& $8-9$ & NA & NA & 31 & $19(61 \%)$ \\
& $10-11$ & NA & NA & 33 & $20(61 \%)$ \\
& Total, mean (SD) & & NA & & $5.77(3.83)$ \\
& $\chi^{2}$ & & NA & & 24.5 \\
$P$ value & & NA & & $<.001$ \\
\hline
\end{tabular}

a Action planning.

b Action planning plus.

c Only observed cases.

d Not applicable, as the AP program did not provide tailored feedback after the quit date.

\section{Program Evaluation of the AP and AP+ Programs}

Table 5.5 presents the program evaluation that was conducted 6 months after baseline. Respondents from the AP and AP+ programs gave the baseline-tailored feedback a positive evaluation. However, significantly more respondents in the $\mathrm{AP}+$ program remembered the content of the baseline-tailored feedback and perceived the feedback as relevant and helpful for making the quit attempt. The 
planning assignments were perceived as useful by 87 of 164 (53\%) respondents. Moreover, 724 (44\%) of the respondents rated them as helpful for making a quit attempt and 51 (31\%) agreed they were helpful in maintaining a quit attempt. Respondents from the AP and AP+ programs did not differ significantly on the evaluation of the planning assignments. The feedback after the quit attempt (short feedback moments) was rated as useful by 66 of 104 (63\%) respondents, as helpful for making a quit attempt by 49 (47\%), and as helpful for maintaining the quit attempt by 50 (48\%).

Table 5.5 Program evaluation (conducted 6 months after baseline) by respondents from the $\mathrm{AP}^{\mathrm{a}}$ and the $\mathrm{AP}+\mathrm{b}$ programs.

\begin{tabular}{|c|c|c|c|c|c|}
\hline Evaluation item & $\begin{array}{l}\text { Total } \\
(\mathrm{n}=248)\end{array}$ & $\begin{array}{l}\text { AP } \\
(n=137)\end{array}$ & $\begin{array}{l}\mathrm{AP}+ \\
(\mathrm{n}=111)\end{array}$ & $\chi^{2}$ & $P$ value \\
\hline \multicolumn{6}{|l|}{ Baseline feedback } \\
\hline Remembered the content & & & & 9.7 & .008 \\
\hline Yes & $142(57.3 \%)$ & $72(53 \%)$ & $70(63 \%)$ & & \\
\hline Neutral & $63(25 \%)$ & $32(23 \%)$ & $31(28 \%)$ & & \\
\hline No & $43(17 \%)$ & $33(24 \%)$ & $10(9 \%)$ & & \\
\hline Perceived feedback as useful & & & & 4.4 & .111 \\
\hline Yes & $156(62.9 \%)$ & $79(58 \%)$ & $77(69 \%)$ & & \\
\hline Neutral & $68(27 \%)$ & $41(30 \%)$ & $27(24 \%)$ & & \\
\hline No & $24(10 \%)$ & $17(12 \%)$ & $7(6 \%)$ & & \\
\hline Perceived feedback as relevant & & & & 8.8 & .012 \\
\hline Yes & $121(48.8 \%)$ & $56(41 \%)$ & $65(59 \%)$ & & \\
\hline Neutral & $98(40 \%)$ & $60(44 \%)$ & $38(34 \%)$ & & \\
\hline No & $29(12 \%)$ & $21(15 \%)$ & $8(7 \%)$ & & \\
\hline Perceived feedback as understandable & & & & 3.8 & .152 \\
\hline Yes & $208(83.9 \%)$ & $110(80.3 \%)$ & $98(88 \%)$ & & \\
\hline Neutral & $34(14 \%)$ & $24(18 \%)$ & $10(9 \%)$ & & \\
\hline No & $6(2 \%)$ & $3(2 \%)$ & $3(3 \%)$ & & \\
\hline Recognized own situation in feedback & & & & 0.2 & .92 \\
\hline Yes & $117(47.2 \%)$ & $63(46 \%)$ & $54(49 \%)$ & & \\
\hline Neutral & $101(40.7 \%)$ & $57(42 \%)$ & $44(40 \%)$ & & \\
\hline No & $30(12 \%)$ & $17(12 \%)$ & $13(12 \%)$ & & \\
\hline Perceived feedback as credible & & & & 3.6 & .16 \\
\hline Yes & $170(68.5 \%)$ & $87(64 \%)$ & $83(75 \%)$ & & \\
\hline Neutral & $67(27 \%)$ & $43(31 \%)$ & $24(22 \%)$ & & \\
\hline No & $11(4 \%)$ & $7(5 \%)$ & $4(4 \%)$ & & \\
\hline Feedback helped to make a quit attempt & & & & 6.7 & .04 \\
\hline Yes & $107(43.1 \%)$ & $51(37 \%)$ & $56(50 \%)$ & & \\
\hline Neutral & $73(29 \%)$ & $49(36 \%)$ & $24(22 \%)$ & & \\
\hline No & $68(27 \%)$ & $37(27 \%)$ & 31 (28\%) & & \\
\hline
\end{tabular}




\begin{tabular}{|c|c|c|c|c|c|}
\hline Evaluation item & $\begin{array}{l}\text { Total } \\
(\mathrm{n}=248)\end{array}$ & $\begin{array}{l}\text { AP } \\
(n=137)\end{array}$ & $\begin{array}{l}\text { AP+ } \\
(n=111)\end{array}$ & $\chi^{2}$ & $P$ value \\
\hline Feedback helped to maintain quit attempt & & & & 3.7 & .16 \\
\hline Yes & $72(29 \%)$ & $33(24 \%)$ & $39(35 \%)$ & & \\
\hline Neutral & $65(26 \%)$ & $38(28 \%)$ & $27(24 \%)$ & & \\
\hline No & $111(44.8 \%)$ & $66(48 \%)$ & $45(41 \%)$ & & \\
\hline Planning assignments & $\mathrm{n}=164$ & $\mathrm{n}=93$ & $\mathrm{n}=71$ & & \\
\hline Perceived feedback as useful & & & & 4.0 & .14 \\
\hline Yes & $87(53 \%)$ & $49(53 \%)$ & $38(54 \%)$ & & \\
\hline Neutral & $62(38 \%)$ & $32(34 \%)$ & $30(42 \%)$ & & \\
\hline No & $15(9 \%)$ & $12(13 \%)$ & $3(4 \%)$ & & \\
\hline Feedback helped to make a quit attempt & & & & 5.6 & .06 \\
\hline Yes & $72(44 \%$ & $37(40 \%)$ & $35(49 \%)$ & & \\
\hline Neutral & $57(35 \%)$ & $30(32 \%)$ & $27(38 \%)$ & & \\
\hline No & $35(21 \%)$ & $26(28 \%)$ & $9(13 \%)$ & & \\
\hline Feedback helped to maintain quit attempt & & & & 5.1 & .08 \\
\hline Yes & $51(31 \%)$ & $27(29 \%)$ & $24(34 \%)$ & & \\
\hline Neutral & $56(34 \%$ & 27 (29\%) & $29(41 \%)$ & & \\
\hline No & 57 (35\%) & $39(42 \%)$ & $18(25 \%)$ & & \\
\hline
\end{tabular}

Feedback moments after quit attempt $(\mathrm{n}=104)$

Perceived feedback as useful

$\begin{array}{llll}\text { Yes } & 66(63 \%) & N^{c} & 66(63 \%) \\ \text { Neutral } & 26(25 \%) & \text { NA } & 26(25 \%) \\ \text { No } & 12(12 \%) & \text { NA } & 12(12 \%)\end{array}$

Feedback helped to make a quit attempt

$\begin{array}{llll}\text { Yes } & 49(47 \%) & \text { NA } & 49(47 \%) \\ \text { Neutral } & 32(31 \%) & \text { NA } & 32(31 \%) \\ \text { No } & 23(22 \%) & \text { NA } & 23(22 \%)\end{array}$

Feedback helped to maintain quit attempt

$\begin{array}{llll}\text { Yes } & 50(48 \%) & \text { NA } & 50(48 \%) \\ \text { No } & 54(52 \%) & \text { NA } & 54(52 \%)\end{array}$

action planning.

b Action planning plus.

c Not applicable.

\section{DISCUSSION}

The main goal of this study was to evaluate the efficacy of two Web-based smoking relapse prevention programs (AP and AP+) in the SQ4U study with regard to 12-month continued smoking abstinence. Furthermore, we aimed to assess dose-response associations. Despite the potential of the Internet, a recurrent 
problem in Internet trials is low adherence to the programs (Wangberg, Bergmo and Johnsen, 2008). These low levels of adherence may lead to underestimations of intervention effects. This impression is strengthened by the fact that most studies of Internet interventions have shown dose-response relationships (see, for instance, Eysenbach, 2002; Borland, Balmford and Hunt, 2004; Cobb, Graham, Bock, Papandonatos and Abrams, 2005; An et al., 2006; Japuntich et al., 2006; Steele, Mummery and Dwyer, 2007). Hence, an alternative strategy in which nonadherent respondents are excluded may be needed. Recently, a systematic review has discussed an increase in the literature of randomized controlled trials that report on a modified strategy (Abraha and Montedori, 2010). To provide a complete overview of our results, we employed both approaches and reported on three samples: (1) the sample as randomly assigned, including all respondents, (2) a sample excluding those who did not make a quit attempt (modified sample), and (3) a sample additionally excluding those who did not adhere to at least one of the intervention elements (minimum dose sample). Observed case analyses (only including respondents with follow-up data) and conservative analyses (including all cases and coding respondents who were missing at follow-up as smoking relapsers) were conducted on all samples.

The results of all three observed case analyses (samples 1, 2, and 3) revealed significant effects in favor of the AP program and support our first hypothesis that planning strategies can be effective in preventing relapse among smokers who are motivated to quit smoking. The AP+ program, on the other hand, only proved to be significantly more effective than the control condition in the randomized sample (sample 1). The approach for sample 2 seems to have created a bias against the AP+ program by excluding respondents who did not make a quit attempt during the study, which resulted in more exclusions of relapsers (since nonquitters cannot be considered to be continued abstinent at follow-up) in the control condition than in the AP+ program (which consisted of elements designed to foster making a quit attempt). This approach may therefore have been too conservative. Furthermore, additional power analyses showed that 2623 respondents would have been needed to find significant differences in abstinence rate between the control group (45/134, 34\%) and the $\mathrm{AP}+$ program group $(53 / 142,37 \%)$. Therefore, the lack of significance in sample 2 may be due to power issues. Another possible explanation for lack of significant effect for the AP+ program in sample 2 and sample 3 may be that the program was too intensive and therefore resulted in an overload for the respondents that negatively influenced its efficacy. A comparable result was found in an earlier study conducted among vocational students, which tested the efficacy of a standard in-school program, a computer-tailored program, and a combined program (Ausems, Mesters, van Breukelen and De Vries, 2004). This study found that the combined strategy did not have a surplus value. The authors suggested that combining strategies may lead to an overload of information, which may produce more negative effects. Although this may also account for our find- 
ings, program evaluation data do not support this suggestion because the AP+ and AP programs both received a positive evaluation. A final explanation may be that the planning assignments and the feedback provided after the quit attempt may not have been an ideal combination to foster abstinence after all.

When conducting conservative analyses, we found the AP and AP+ programs to be only significantly more effective than the control condition in the minimum dose sample (sample 3). The program effects in sample 1 and 2 were non-significant. However, given the large dropout rate at follow-up, this conservative approach (coding dropouts as relapsers) may be too conservative. Additional descriptive analyses indicated that about $60 \%$ of the respondents who dropped out at follow-up were nonsmokers at their last visit, indicating that interpreting all missing cases as treatment failures may be too conservative, a finding also supported by others (Lachin, 1999). Moreover, the significant results from the conservative analysis in the minimum dose sample (sample 3 ) may be biased in favor of the experimental conditions by the exclusion of respondents who adhered to none of the intervention elements (whose follow-up data are generally missing). Excluding these nonadherers results in fewer imputations of relapsers in the experimental conditions than in the control condition, because these respondents are already excluded because they did not adhere to the programs.

The abstinence rate of $22 \%$ in the control group is another notable finding, since self-quitters generally reach abstinence rates of only 3\%-5\% (Hughes, Keely and Naud, 2004). A possible explanation for this high abstinence rate may be that respondents in our control condition, who were highly motivated to quit smoking, sought additional help themselves when they did not receive the help they expected from our program. Since not all respondents reported on their use of additional help, we were not able to test this assumption with the available data. Moreover, the high motivation of these respondents may have played a role in their high abstinence rates. It should, however, be noted that this abstinence rate was based on observed cases and that the abstinence rate in the control group of the sample as randomized was only $7 \%$ when considering dropouts as relapsers.

Finally, the dose-response relationship between abstinence and the number of intervention elements suggests that a dose-response association may exist. This is because abstinence rates increased by up to $53 \%(33 / 62)$ in the AP program and $51 \%(36 / 70)$ in the AP+ program when doing 5 to 6 planning assignments, and up to $61 \%(20 / 33)$ in the AP+ program when filling out 10-11 feedback questionnaires (on which feedback was provided). These findings suggest, in line with hypothesis 2 , that the efficacy of the programs depends on adherence to the program, also found in previous studies (Borland, Balmford and Hunt, 2004; Fiore, 2008). Our findings regarding dose-response relationships may, however, be attributed to the fact that respondents who relapsed after a few sessions discontinued the program, resulting in the finding that those who 
continued with the program were more successful. Caution is, therefore, needed when interpreting dose-response relationships: these relationships can be subject to selection biases, since the respondents are not randomly assigned to different doses (McGowan, Nix, Murphy and Bierman, 2010). Additional research that tests the assumption of a dose-response relationship in this context is needed in the form of an experimental design in which respondents are randomly assigned to groups with different doses.

The SQ4U study was subject to limitations. The first limitation is that the planning assignments and feedback moments were provided at fixed times, while the varying levels of adherence found in our study suggest that programs should perhaps provide support when the respondent needs it most (ie, by realtime support in difficult situations). Research is needed to explore the potential additional efficacy of such an approach. Second, the cut-off point for the minimum dose sample (sample 3) is not based on empirical findings and needs to be explored in additional studies. Third, because of medical ethics guidelines, we could not prevent respondents from using additional help to quit smoking. The use of additional help, however, may interfere with the effects of the programs and may be beneficial or counterproductive. Further research is needed to explore which additional aids may have positive or negative effects. Fourth, our study had a high rate of loss to follow-up (1465/2031, 72.1\%), an issue that is very common in comparable studies (Tate and Zabinski, 2004; Etter, 2005; Eysenbach, 2005; Te Poel, Bolman, Reubsaet and de Vries, 2009). Attrition may have been caused by factors such as spam filters or invalid email accounts or because people who have quit smoking do not want to be reminded of their past smoking behavior (Strecher, 2007). The latter is partly supported by our data, which showed that about $60 \%$ of the respondents who dropped out of the experimental programs were nonsmokers at their last visit. High dropout rates hinder an unequivocal interpretation of the results of the observed case analyses as well as the conservative analyses. This study presented the results of both analyses as the true impact of the interventions probably lies somewhere between the results of the observed case analyses and the conservative analyses. With regard to the latter, it should further be noted that the conservative analyses (in which missing answers at follow-up were regarded as relapse) may be too conservative, as our data showed that about $60 \%$ of the respondents who dropped out of the experimental programs were nonsmokers at their last visit. Furthermore, attrition analyses indicated that dropout at follow-up was more likely in the experimental programs. Consequently, the conservative analyses can be subject to biases strengthening the relation between the experimental programs and relapse, while the actual relation is one between the programs and dropout. Therefore, caution is needed with interpreting these results.

Aside from these limitations, our SQ4U study is the first to test the efficacy of incorporating planning assignments in a Web-based computer-tailored relapse prevention program and of combining planning assignments with multiple 
tailored feedback moments after the quit date. The study reflected on the findings from different samples, and the results pointed out the importance of using planning strategies and tailored feedback moments after the quit date for smokers who are motivated to quit (based on observed cases). Previous studies indicated that a lack of preparatory planning is associated with smoking relapse (Hoving, Mudde and de Vries, 2006; Elfeddali, Bolman, Candel, Wiers and de Vries, 2012). Our current study further illuminates the role of planning by suggesting that managing behavior using action planning strategies in relapse prevention programs fosters abstinence. Two of the three conservative analyses conducted (in sample 1 and 2), however, did not support this suggestion. Yet, it should be noted that the conservative analysis conducted in the sample excluding respondents who did not adhere to at least one of the intervention elements (sample 3) showed significant effects of the programs. The latter suggests that the programs are effective when people adhere at least to one session, a finding also suggested by our dose-response analysis. Nevertheless, caution is needed with interpreting these results since dropout rates were very high and the observed case analyses as well as conservative analyses may be subject to biases. Since study dropout (at follow-up) was high and some of the respondents in the experimental programs did not adhere to even one intervention element, insight into how to foster participation in Web-based internet interventions, into the predictors of adherence to the intervention elements and into strategies to facilitate adherence is needed. Finally, additional research is needed to determine the optimum dose for reaching best effects and which planning strategies are most effective for which groups.

\section{Acknowledgements}

This study was funded by the Dutch Organization for Health Research and Innovation (grant number 6130-0030). We would like to thank Claire Jeukens and Verina Servranck for their contribution to the development and piloting of the SQ4U program materials. We would also like to thank Stivoro for their help in recruiting respondents, as well as the respondents for their participation in the study. 



\section{CHAPTER 6}

\section{The role of adherence in a computer tailored smoking relapse prevention program: six months results of the SQ4U study}

This chapter is under review as:

Elfeddali, I, Bolman, C, Candel, M.J.J.M, Wiers, R.W. and de Vries, H. The role of adherence in a computer tailored smoking relapse prevention program: six months results of the SQ4U study. 


\section{ABSTRACT}

Background. Web-based computer-tailored approaches have the potential to be successful in supporting smoking cessation. The SQ4U study compares two webbased computer-tailored smoking relapse prevention programs with different types of planning strategies with a control group. Objectives. The study aimed to assess the efficacy of two web-based computer-tailored programs in preventing smoking relapse compared to a control group. The action planning (AP) program provided tailored feedback at baseline and invited respondents to make six preparatory and coping planning assignments (first three assignments prior to quit-date and final three assignments after quit-date). The action planning plus (AP+) program was an extended version of the AP program that also provided tailored feedback at eleven time points after the quit-attempt. Respondents in the control group only filled out questionnaires. Furthermore, the study focused on the role of adherence to the programs. Methods. The study was a randomized controlled trial with three conditions: the control group, the AP program and the AP+ program. Respondents were daily smokers aged 18 to 65 years, who were motivated and willing to quit smoking within one month. The primary outcome was self-reported continued abstinence six months after baseline. Data were analyzed using logistic regression analyses, conducting observed case as well as conservative analyses. Results. The abstinence rates of the $\mathrm{AP}$ and $\mathrm{AP}+$ programs seemed highly dependent on adherence to program elements. The programs were not significantly more effective in fostering shortterm abstinence compared to the control group when adherence was not taken into account. This accounted for observed case as well as for conservative analyses. Furthermore, the study was subject to high study drop-out rates (69\%) at the follow-up measurement. Conclusion. Making action planning assignments and receiving tailored feedback after the quit-attempts seems non-effective in fostering short-term abstinence compared to a control group. However, drawing firm conclusions based on the results from the observed case analyses and the conservative analyses is hindered by high study drop-out rates (69\%). Improvements of the SQ4U-programs aimed at preventing study drop-out are therefore essential in order to gain a better insight into the program effects. Finally, adherence to the intervention seems critical for effectiveness and more research is needed to gain insight into the optimum intervention-dose and how to increase adherence. 


\section{INTRODUCTION}

Smoking causes serious harm to one's health (2008) and many smokers want to quit smoking (CDC, 2002; Dijkstra, 2005; STIVORO, 2011). Relapse prevention programs have often modest effects, underlining the need for new approaches (Hajek, Stead, West, Jarvis and Lancaster, 2009), since smoking cessation is hindered by several barriers (Garvey and Bliss, 1992; Hughes et al., 1992; Zhu et al., 1996; Hughes, Keely and Naud, 2004).

Smokers need strategies that foster the execution of their quit-attempt. Preparatory and coping planning strategies - as postulated in the I-Change Model (de Vries et al., 2003; Hughes, Keely and Naud, 2004; de Vries, Kremers, Smeets, Brug and Eijmael, 2008) - pertain to actions needed to prepare (preparatory plans) and maintain a behavior by coping with risk situations (coping plans). Preparatory planning has been associated with smoking cessation and abstinence (Hoving, Mudde and de Vries, 2006; Elfeddali, Bolman, Candel, Wiers and de Vries, 2012; de Vries, Eggers and Bolman, submitted) and coping planning with promoting abstinence (O'Connell, Hosein and Schwartz, 2007; van Osch, Lechner, Reubsaet and de Vries, 2010).

Personalized approaches, such as computer tailoring, have demonstrated to be more effective in fostering healthy behaviors compared to no feedback and usual care (Brug, Kok, van Breukelen, Glanz and van Assema, 1998; Dijkstra, De Vries and Roijackers, 1998; Etter, 2005; Oenema, Tan and Brug, 2005; Strecher, Shiffman and West, 2005; Kroeze, Werkman and Brug, 2006). Providing tailored messages at multiple time points is more effective than a single tailoring moment (Brug, Kok, van Breukelen, Glanz and van Assema, 1998; Dijkstra, De Vries, Roijackers and van Breukelen, 1998; Smeets, Brug and De Vries, 2008), for smoking cessation (Dijkstra, De Vries and Roijackers, 1998; Etter, 2005; Lancaster and Stead, 2005; Strecher, Shiffman and West, 2005; Te Poel, Bolman, Reubsaet and de Vries, 2009) and relapse prevention (Borland, Balmford and Hunt, 2004).

The SQ4U (Stay Quit for You)-study assessed the effects of two computer tailored relapse prevention programs (1. action planning (AP) program with a single tailoring moment; 2 . action planning plus (AP+) program with multiple tailoring sessions) incorporating six planning assignments in comparison with a control group on six month continued smoking abstinence. Since effects are more optimal if one adheres to a program (Wangberg, Bergmo and Johnsen, 2008), we expect that program effects will be greatest when adhering to program elements and when receiving multiple tailored moments. 


\section{METHODS}

The study is registered with the Dutch Trial Register (NTR1892) and ethical approval was obtained (MEC 08-3-003; NL21414.068.08). A detailed description of the recruitment, procedure, intervention elements and questionnaires is provided elsewhere (Elfeddali, Bolman, Candel, Wiers and de Vries, 2012; Elfeddali, Bolman and de Vries, 2012).

\section{Respondents and design}

Dutch smokers were recruited by flyers and (online) ads; all referring to our research website. Respondents were daily smokers aged 18-65 years, motivated and willing to quit within one month, gave consent for participation and set a quit-date at baseline. Respondents who indicated after their quit-date as well as at follow-up that they did not make a quit-attempt during the study or those who made a quit-attempt less than 135 days (which means within about two weeks after the first month in which they were supposed to make an attempt) before the follow-up measurement were excluded. The latter was done because one of the inclusion criteria was that respondents needed to set a quit-date within one month after inclusion and including respondents who made their quit-attempt much later or even too close to the follow-up measurement would result in differences between respondents in the time frame from the quitattempt to the follow-up measurement, especially as we focus on continued abstinence. The study was a randomized controlled trial with a control condition and two experimental conditions (AP and AP+ program). Respondents were randomly allocated to one of the conditions. Figure 6.1 presents the enrolment and inclusion of respondents. 


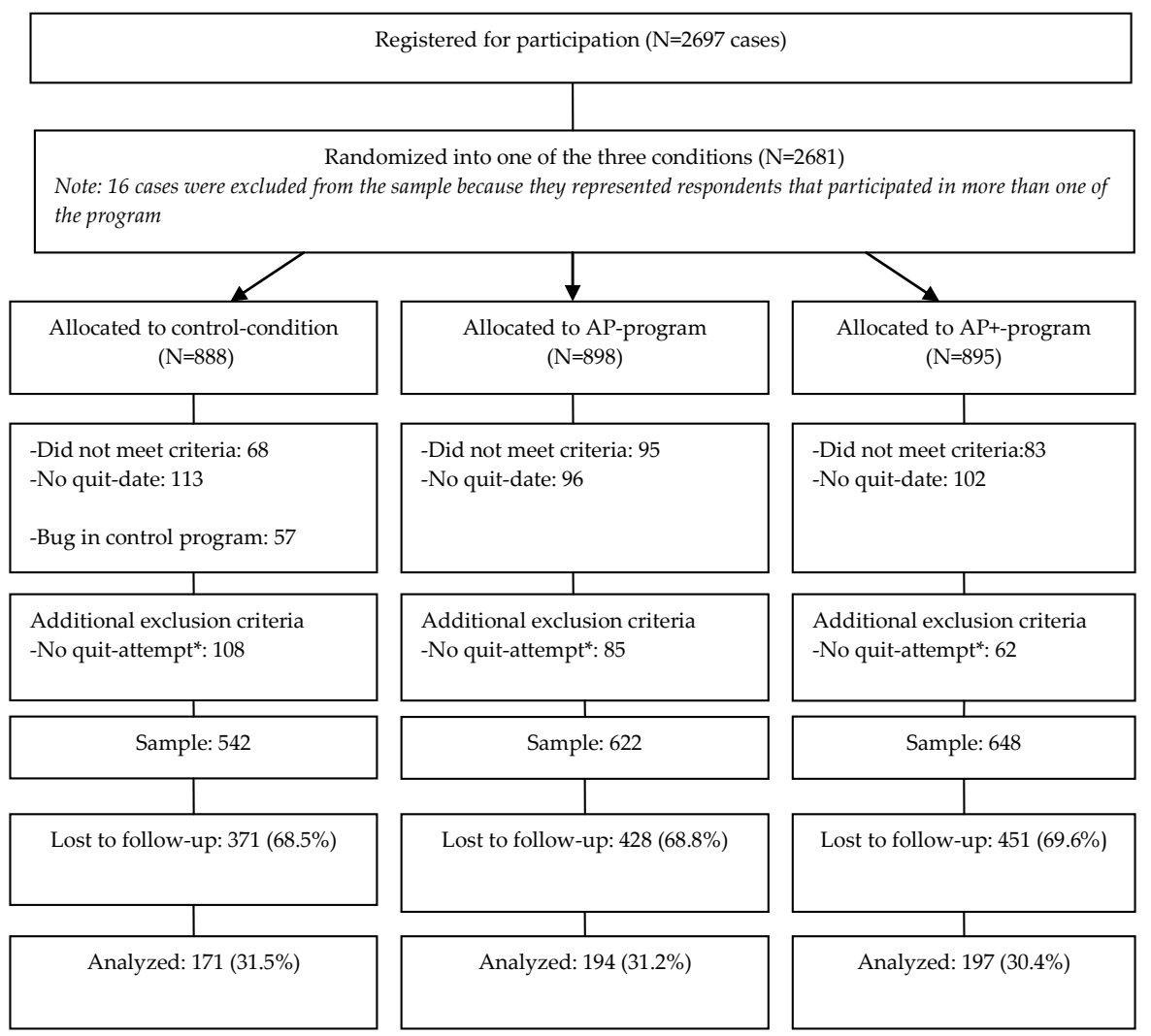

Figure 6.1 Enrollment and inclusion of respondents, *Note: these are respondents who indicated after their quit-date as well as at follow-up that they did not make a quit-attempt during the study and respondents who quitted too close to follow-up (see Methods section)

\section{Intervention materials}

Both programs (AP and AP+) used tailored feedback messages developed in previously tested effective computer tailoring programs using the I-Change Model to increase respondents' motivation to quit smoking and to remain abstinent (Dijkstra, De Vries and Roijackers, 1998; Te Poel, Bolman, Reubsaet and de Vries, 2009). Both programs invited respondents at six times to make planning assignments as to motivate respondents to make and realize preparatory plans, identify personal risk-situations and make coping plans. Only in the AP+ program eleven additional feedback messages were provided after the quit-attempt targeting (recovery) self-efficacy, preparatory planning and negative affect; all feedback moments also targeted self-reported smoking behaviour. 


\section{Questionnaires}

The baseline questionnaire was based on questionnaires tested in previous studies (Dijkstra, de Vries and Bakker, 1996; Dijkstra, De Vries and Roijackers, 1998; Dijkstra and de Vries, 2000; Hilberink, Jacobs, Schlosser, Grol and De Vries, 2006; Hoving, Mudde and de Vries, 2006; Te Poel, Bolman, Reubsaet and de Vries, 2009). All scales had good reliability (Cronbach's Alpha>.70) and the mean scores were used in analyses (except for level of dependence, social support and modeling: for which index scores were included). A detailed description of the scales and items is provided elsewhere (see, Elfeddali, Bolman, Candel, Wiers and de Vries, 2012; Elfeddali, Bolman and de Vries, 2012).

The questionnaire assessed age, gender, education level, perceived stress, level of depression, pros and cons of non-smoking and relapse, intention to quit smoking, self-efficacy, recovery self-efficacy, social influence and preparatory planning.

Continued abstinence after six months was measured by asking whether one had smoked since the quit-date conforming to the definitions of Hughes et al (Hughes, Keely and Niaura, 2003). Smoking was coded as $0=$ 'relapse' and nonsmoking as 1='abstinence'.

\section{Analyses}

Baseline differences were assessed using chi $^{2}$-tests for categorical and ANOVAtests for continuous variables. A three-step logistic regression analysis was conducted to assess 1 . main effect of the programs on continued abstinence; 2 . the effects of the number of planning assignments made by including an interaction term between condition (AP or AP+) and adherence to assignments; 3 . the effects of the number of feedback questionnaires completed after the quit-date, by including an interaction term between the AP+ program and the number of completed questionnaires. The interaction terms represent the effects of intervention-dose per program. The analyses excluded main effects of the assignments/feedback moments as these intervention elements were not provided in all conditions. Baseline variables predicting drop-out or differing between conditions were included as covariates. Observed case analyses (including only respondents with follow-up data) and conservative analyses coding missing cases as smokers were conducted. 


\section{RESULTS}

\section{Characteristics and attrition check}

Table 6.1 presents the baseline characteristics; differences between conditions were non-significant. In the control condition $68.5 \%$ was lost to follow-up versus $68.8 \%$ in the AP-program versus $69.6 \%$ in the AP+ program; the differences were non-significant $\left(\chi^{2}=.195 ; P=.907\right)$. Study drop-out was more likely among respondents with a lower age (OR=.98, $P<.001, \mathrm{CI}=.97-.99)$, lower education level (OR=1.77; $P=.005 ; \mathrm{CI}=1.18-2.64)$, lower intention to quit ( $\mathrm{OR}=.89, P=.012$, $\mathrm{CI}=.81-98)$, lower self-efficacy (OR=.82, $P=.008, \mathrm{CI}=.70-.95)$ and less preparatory planning at baseline $(\mathrm{OR}=.75, P=.002, \mathrm{CI}=.62-.90)$.

Table 6.1 Baseline characteristics and differences between the three conditions

\begin{tabular}{|c|c|c|c|c|c|c|}
\hline Characteristics & $\begin{array}{c}\text { Overall } \\
(\mathrm{N}=1812)\end{array}$ & $\begin{array}{c}\text { Control } \\
(\mathrm{N}=542)\end{array}$ & $\begin{array}{c}\text { AP } \\
(\mathrm{N}=622)\end{array}$ & $\begin{array}{c}\mathrm{AP}+ \\
(\mathrm{N}=648)\end{array}$ & $\begin{array}{c}\text { F-value/ } \\
X^{2}\end{array}$ & $\begin{array}{c}P- \\
\text { value }\end{array}$ \\
\hline \multicolumn{7}{|l|}{ Gender } \\
\hline \% Female & 61.9 & 59.8 & 62.5 & 63.1 & 1.549 & .461 \\
\hline \multicolumn{7}{|l|}{ Age } \\
\hline Mean age (SD) & $40.70(11.88)$ & $40.39(11.92)$ & $40.73(11.48)$ & $40.93(12.22)$ & .311 & .733 \\
\hline \multicolumn{7}{|l|}{ Educational level a } \\
\hline \% low educated & 10.4 & 9.2 & 12.7 & 9.3 & 5.582 & .233 \\
\hline$\%$ high educated & 33.7 & 34.9 & 33.1 & 33.3 & & \\
\hline \multicolumn{7}{|l|}{ Cigarettes smoked per day } \\
\hline Mean consumption (SD) & $19.97(8.78)$ & $19.99(8.47)$ & $20.20(9.42)$ & $19.75(8.41)$ & .399 & .671 \\
\hline \multicolumn{7}{|l|}{ Years one has been smoking } \\
\hline \multicolumn{7}{|l|}{ Previous quit attempts } \\
\hline$\%$ Yes & 92.8 & 91.9 & 94.0 & 92.4 & 2.249 & .325 \\
\hline \multicolumn{7}{|l|}{ Nicotine dependence } \\
\hline Mean level (SD) & $4.57(2.16)$ & $4.55(2.22)$ & $4.60(2.08)$ & $4.54(2.19)$ & .154 & .857 \\
\hline
\end{tabular}

a Educational level was divided in three groups (low, medium and high level of education).

\section{Main effects and dose-response associations}

Table 6.2 presents the results from the three-step logistic regression analyses corrected for gender, age, education, intention, self-efficacy and preparatory planning. The first step of the analyses (not taking into account the role of adherence) showed no positive significant effects of the AP-program (OR=.96; $\mathrm{CI}=.63-1.55 ; \mathrm{p}=.99)$ and $\mathrm{AP}+$ program $(\mathrm{OR}=.57 ; \mathrm{CI}=.48-1.18 \mathrm{p}=.22)$ compared to the control condition. Descriptive analyses showed abstinence rates of $60 / 171=35.1 \%$ in the control group versus $70 / 194=36.1 \%$ in the AP program 
versus $58 / 197=29.4 \%$ in the $A P+$, depending on observed cases. The second step (including the effects of adherence to the planning assignments in the AP and $\mathrm{AP}+$ program) revealed positive significant effects of the number of planning assignments on abstinence in the $\mathrm{AP}(\mathrm{OR}=1.36$; $\mathrm{CI}=1.14-1.62 ; \mathrm{P}=.001)$ and $\mathrm{AP}+(\mathrm{OR}=1.34 ; \mathrm{CI}=1.12-1.60 ; \mathrm{P}=.002)$ programs. In-depth descriptive analyses showed that the abstinence rates reach up to $47 \%$ in the AP and $39.6 \%$ in the $\mathrm{AP}+$ program when filling out more than half (three) planning assignments ( $\mathrm{N}=100$ in $\mathrm{AP}$ and $\mathrm{N}=106$ in $\mathrm{AP}+$ program). The third step (including an interaction term between the $\mathrm{AP}+$ program and the number of feedback questionnaires completed after the quit-date) demonstrated a positive significant ( $\mathrm{OR}=1.37$; $\mathrm{CI}=1.19-1.58 ; \mathrm{P}<.001$ ) effect of the number of feedback moments on abstinence in the $\mathrm{AP}+$ program. The effects of planning assignments in the $\mathrm{AP}+$ program became non-significant. Abstinence rates reached 50.6\% when respondents completed more than half (five) feedback questionnaires $(\mathrm{N}=85)$ in the $\mathrm{AP}+$ program. Over all steps, intention and self-efficacy were the only significant covariates. Conservative analyses - also presented in Table 6.2 - revealed comparable results. 
Table 6.2 Regression 6-months continued abstinence on the SQ4U programs and dose-response measures for observed cases only $(\mathrm{N}=558)$ and all cases $(\mathrm{N}=1739)$

\begin{tabular}{|c|c|c|c|c|c|c|c|c|c|c|}
\hline & & STEP 1 & & & STEP 2 & & & STEP 3 & & \\
\hline & Variables & OR & CI $95 \%$ & $\mathrm{P}$ & OR & CI $95 \%$ & $\mathrm{P}$ & OR & CI $95 \%$ & $\mathrm{P}$ \\
\hline 1 & Observed cases only & & & & & & & & & \\
\hline & Gender & .942 & $.634-1.400$ & .768 & 1.028 & $.684-1.545$ & .893 & 1.059 & $.700-1.603$ & .786 \\
\hline & Age & 1.003 & $.987-1.020$ & .693 & .996 & $.979-1.014$ & .672 & .994 & $.977-1.012$ & .530 \\
\hline & Education & .532 & $.233-1.218$ & .135 & .614 & $.262-1.440$ & .262 & .654 & $.277-1.544$ & .333 \\
\hline & Intention & 1.362 & $1.150-1.612$ & .000 & 1.357 & $1.143-1.612$ & .001 & 1.370 & $1.149-1.634$ & .000 \\
\hline & Self efficacy & 1.529 & $1.188-1.966$ & .001 & 1.525 & $1.178-1.974$ & .001 & 1.490 & $1.145-1.939$ & .003 \\
\hline & Action planning & .911 & $.666-1.247$ & .562 & .903 & $.656-1.242$ & .530 & .885 & $.638-1.227$ & .465 \\
\hline & AP program & .989 & $.630-1.552$ & .961 & .313 & $.138-.709$ & .005 & .307 & $.136-.697$ & .005 \\
\hline & $\mathrm{AP}+$ program & .751 & $.477-1.184$ & .218 & .241 & $.101-.576$ & .001 & .232 & $.095-.569$ & .001 \\
\hline 2 & $\mathrm{AP} *$ assignments & & & & 1.358 & $1.140-1.618$ & .001 & 1.361 & $1.143-1.622$ & .001 \\
\hline & $\mathrm{AP}+*$ assignments & & & & 1.336 & $1.117-1.599$ & .002 & .862 & $.660-1.125$ & .275 \\
\hline 3 & $\mathrm{AP}+*$ feedback moments & & & & & & & 1.369 & $1.190-1.575$ & .000 \\
\hline 1 & Conservative analysis ${ }^{1}$ & & & & & & & & & \\
\hline & Gender & .901 & $.645-1.259$ & .542 & .972 & $.686-1.379$ & .876 & .945 & $.661-1.350$ & .755 \\
\hline & Age & 1.016 & $1.003-1.030$ & .020 & 1.009 & $.955-1.024$ & .222 & 1.009 & $.994-1.024$ & .255 \\
\hline & Education & .383 & $.184-.794$ & .010 & .405 & $.191-.859$ & .018 & .408 & $.191-.872$ & .021 \\
\hline & Intention & 1.349 & $1.170-1.554$ & .000 & 1.292 & $1.115-1.497$ & .001 & 1.301 & $1.119-1.512$ & .001 \\
\hline & Self efficacy & 1.586 & $1.280-1.966$ & .000 & 1.588 & $1.265-1.994$ & .000 & 1.572 & $1.248-1.980$ & .000 \\
\hline & Action planning & 1.104 & $.854-1.428$ & .541 & 1.048 & $.798-1.376$ & .735 & 1.025 & $.776-1.354$ & .860 \\
\hline & AP program & .956 & $.656-1.392$ & .813 & .209 & $.105-.414$ & .000 & .209 & $.106-.414$ & .000 \\
\hline & $\mathrm{AP}+$ program & .759 & $.514-1.120$ & .164 & .136 & $063-.291$ & .000 & .148 & $.069-.319$ & .000 \\
\hline 2 & $\mathrm{AP} *$ assignments & & & & 1.595 & $1.380-1.843$ & .000 & 1.595 & $1.381-1.843$ & .000 \\
\hline & $\mathrm{AP}+*$ assignments & & & & 1.673 & $1.430-1.958$ & .000 & .960 & $.757-1.218$ & .737 \\
\hline 3 & $\mathrm{AP}+*$ feedback moments & & & & & & & 1.473 & $1.296-1.674$ & .000 \\
\hline
\end{tabular}

${ }^{1}$ missings at follow-up were considered as relapsers; effects of the AP and AP+ program in step 1 represent the main effects compared to the control group; main effects of the $\mathrm{AP}$ and $\mathrm{AP}+$ program in step 2 and 3 represent the effects of the programs when zero intervention elements are completed

\section{DISCUSSION}

This research suggests the importance of program adherence with regard to continued abstinence in two computer tailored smoking relapse prevention programs (AP and $\mathrm{AP}+$ ).

As expected the effects of AP and the AP+ programs appear to be understated when adherence to the intervention elements is not taken into account, a phenomenon quite common in internet-trials (Wangberg, Bergmo and Johnsen, 2008). Consequently, most of these studies report dose-response relationships (see, for instance Eysenbach, 2002; Borland, Balmford and Hunt, 2004; Cobb, Graham, Bock, Papandonatos and Abrams, 2005; An et al., 2006; Japuntich et al., 2006; Steele, Mummery and Dwyer, 2007). Corresponding to these findings, our results demonstrated a significant dose-response relation between abstinence 
and adherence to the planning assignments (in AP and AP+ program) and feedback questionnaires (in AP+ program). However, the effects of the planning assignments became non-significant in the AP+ program after inclusion of adherence to the feedback questionnaires; implying that the effect of the assignments may be suppressed by that of the feedback moments after the quitattempt and that the latter may be more important in the process of preventing smoking relapse. In terms of abstinence rates (using observed cases only), an increase up to $47 \%$ in the AP-program and $39.6 \%$ in the AP+ program was found when filling out more than three assignments, while completing more than five feedback questionnaires resulted in $50.6 \%$ abstinence. Finally, there are additional explanations for the high abstinence rates in the control condition and the lack of effects when excluding the role of dose. As our sample consisted of smokers highly motivated to quit, control condition respondents may have sought additional help which lead to short-term abstinence; unfortunately we have no valid data on this issue. Next, this high motivation may have helped the respondents in the control group to reach short-term abstinence, but may be insufficient to reach longer term abstinence. Data on the longer-term effects of the SQ4U programs revealed support for this suggestion (Elfeddali, Bolman, Candel, Wiers and de Vries, 2012). Furthermore, those who quit smoking may have dropped-out not feeling the need to continue the program. Additional analyses to test this assumption showed that $64 \%$ of those who dropped-out were non-smokers at their last visit to the program. This finding, furthermore, suggests that conservative (in which missing answers at follow-up were considered as relapse) analyses may be too conservative; a finding also supported by others (Lachin, 1999).

The SQ4U study is subject to limitations. First, dose-response relationships can be subject to selection biases as the subjects are not randomized into different dosages (McGowan, Nix, Murphy and Bierman, 2010). Additional research in the form of an experimental design is needed to test dose-response associations in this context. Second, the intervention elements were provided at fixed times, while providing support when needed by respondents may be a more optimal strategy. Third, because of medical ethical guidelines, we could not prevent respondents from using additional help to quit smoking. Fourth, our study had a high lost to follow-up rate (69\%), an issue which is very common in comparable studies (Tate and Zabinski, 2004; Etter, 2005; Eysenbach, 2005; Te Poel, Bolman, Reubsaet and de Vries, 2009). Attrition may have been caused by factors such as spam filters or invalid email accounts or because people who have quit smoking do not want to be reminded of their past smoking behavior (Strecher, 2007). The latter is partly supported by our data, which showed that about $64 \%$ of the respondents who dropped out of the experimental programs were non-smokers at their last visit. The latter also indicates that the conservative analyses are probably too conservative. 
In conclusion, our SQ4U program-effects seem to be dependent on adherence to the intervention, in accordance with previous studies (Borland, Balmford and Hunt, 2004; Fiore, 2008). Moreover, it can be concluded that the interpretation of the results from the observed as well as the conservative analyses is hindered by high study drop-out rates. Hence, insight into the factors that determine participation and adherence in web-based interventions such as SQ4U is required. Finally, more research on the role of adherence to intervention elements, strategies on how to foster adherence and the optimum intervention dose is needed.

\section{Acknowledgements}

This study was funded by the Dutch Organization for Health Research and Innovation (grant number 6130-0030). We would like to thank Claire Jeukens and Verina Servranck for their contribution to the development and piloting of the SQ4U program materials. Finally, we would like to thank Stivoro for their help in recruiting respondents and the respondents for their participation in the study. 



\section{CHAPTER 7}

\section{Situational and affective risk situations of relapse and the quality of implementation intentions in an e-health smoking relapse prevention programme}

This chapter ${ }^{5}$ is in press as:

Elfeddali, I., Bolman, C., and de Vries, H. (in press). Situational and affective risksituations of relapse and the quality of implementation intentions in an e-health smoking relapse prevention program. Substance Use and Misuse.

${ }^{5}$ Note that this chapter is written in British English conform the guidelines of the journal 


\section{ABSTRACT}

Objectives. This study aims to provide an overview of the situational and affective risk situations of smoking relapse, and to assess the plan quality (instrumentality and specificity) of the implementation intentions formulated by smokers to deal with these risk situations (distinguishing between situational and affective risk situations). Additionally, the study aims to assess the impact of plan quality on continued smoking abstinence. Design. This study was part of a larger randomised controlled trial with two experimental conditions and a control group. Both experimental conditions involved forming implementation intentions at four days before the quit date. Methods. The respondents had participated in these two experimental conditions and completed an implementation intention assignment $(\mathrm{N}=563)$. Plan quality and continued smoking abstinence at six and twelve months after baseline were the main outcome measures. The results were analysed using descriptive and logistic regression analyses. Results. Feeling stressed and craving for a cigarette were most often selected as risk situations. Most quitters formulated instrumental implementation intentions. Moreover, the specificity of implementation intentions formed to deal with affective situations was significantly lower than the specificity of plans formed to cope with situational risk situations. Finally, plan specificity had a behavioural impact on continued smoking abstinence at six and twelve months after baseline. Conclusions. Stress and craving are important risk factors for relapse. Programmes inviting quitters to make specific implementation intentions to cope with these situations are promising for preventing relapse. These programmes also need to target the difficulties that quitters have with specifying plans for dealing with affective triggers. 


\section{INTRODUCTION}

Smoking is the largest preventable behavioural cause of mortality and disability worldwide, and is a risk factor for six of the eight leading causes of death (WHO, 2008). It is therefore important to foster smoking cessation in general and to prevent smoking relapse in particular. Although many smokers want to quit smoking (about 70\% worldwide), only very few (3-5\%) succeed. Furthermore, relapse rates after a quit attempt are extremely high, reaching up to $90 \%$ in the first three months (CDC, 2002; Hughes, Keely and Naud, 2004). The importance of risk factors for relapse, such as low self-efficacy, negative outcome expectancies of quitting, lack of preparatory planning, negative affect, stress and physical dependence are well-documented with regard to their role in the process of smoking relapse (Marlatt and Gordon, 1985; Killen et al., 1996; Kenford et al., 2002; Dijkstra and Borland, 2003; Shiffman and Waters, 2004). Relapse prevention theories and empirical studies postulate that certain situations trigger the urge to smoke after a quit attempt and that these situations form evident barriers in preventing relapse in smoking cessation (Shiffman, 1982; Marlatt and Gordon, 1985; Shiffman, 1987; Shiffman, Paty, Gnys, Kassel and Hickcox, 1996; Marlatt and Donovan, 2005). These risk situations can be situational as well as affective. Depression, stress and negative moods are examples of affective risk situations that have already shown to be associated with smoking relapse (Shiffman, Paty, Gnys, Kassel and Hickcox, 1996; Shaw and al'Absi, 2008). One study has also shown that quitters were likely to lapse due to situational risk situations such as when smoking was permitted, cigarettes were easily available and others around them were smoking (Shiffman, Paty, Gnys, Kassel and Hickcox, 1996). Consequently, it is important to identify risk situations that prompt relapse and to develop more effective relapse prevention programmes (Marlatt and Donovan, 2005; Hajek, Stead, West, Jarvis and Lancaster, 2009). To help quitters cope with these risk situations, studies have suggested selfregulative coping planning as a strategy to overcome barriers in performing tasks or reaching goals such as remaining abstinent after a quit attempt (Gollwitzer, 1996; van Osch, Lechner, Reubsaet and de Vries, 2010). Coping planning involves planning actions that can be undertaken to cope with difficult situations and to maintain the new behaviour (Sniehotta, Schwarzer, Scholz and Schüz, 2005). A specific technique for making effective coping plans is to form implementation intentions, which involves identifying a response that can be initiated when a certain situation occurs in the form of 'if ... then' plans (e.g. 'If situation X occurs, then I will do Y') (see e.g., Gollwitzer, 1993; Gollwitzer, 1996; Gollwitzer, 1999; Gollwitzer and Sheeran, 2006; Sniehotta, 2009). Forming implementation intentions has already shown to be a successful strategy for promoting health-related behaviours in general (Luszczynska, 2006; Sniehotta, Scholz and Schwarzer, 2006; Kwak, Kremers, van Baak and Brug, 2007; Armitage, 2009; Luszczynska and Haynes, 2009; Chatzisarantis and Hagger, 
2010) as well as fostering smoking cessation and abstinence (Armitage, 2007; Armitage, 2008; van Osch, Lechner, Reubsaet, Wigger and de Vries, 2008). However, while substantial attention has been paid to the effects of implementation intentions in fostering health behaviours, only a small number of studies (Ziegelmann, Lippke and Schwarzer, 2006; van Osch, Lechner, Reubsaet and de Vries, 2010; de Vet et al., 2011; de Vet, Oenema and Brug, 2011) have assessed the role of the quality of implementation intentions in fostering healthy behaviour, and only one has focused on smoking abstinence in particular (van Osch, Lechner, Reubsaet and de Vries, 2010). Most of these studies focused on the level of a plan's completeness and precision, also referred to in a recent study by Van Osch and colleagues on smoking abstinence as 'plan specificity' (van Osch, Lechner, Reubsaet and de Vries, 2010). This study indicated that the level of specificity with which implementation intentions were formulated had significant effects on point prevalence smoking abstinence and borderline significant effects on continued smoking abstinence at seven months after baseline (van Osch, Lechner, Reubsaet and de Vries, 2010). Plan specificity was only assessed for respondents who made instrumental plans, meaning that all specific plans were unconditionally instrumental plans. Plan instrumentality formed another component of plan quality and was defined as whether the plan sufficed the goal (in this case smoking abstinence). This factor, however, had no significant impact on abstinence (van Osch, Lechner, Reubsaet and de Vries, 2010). The study revealed high abstinence rates among those who made non-instrumental plans, and furthermore showed that respondents who made non-instrumental plans mostly wrote down nonsense plans. This finding may suggest that these respondents were not involved in plan formulation, either because they did not see the need of plan formulation or because they were not involved in the study. Moreover, the authors attributed the high abstinence rates among those who made non-instrumental plans to the possibility that these respondents shared characteristics associated with high levels of self-regulation and experienced no additional benefits from the planning intervention. As far as we know, this study by van Osch and colleagues is the first to report on the role of plan instrumentality and specificity with regard to smoking abstinence. Yet, their study did not outline the risk situations that are considered to trigger smoking after a quit attempt, nor did it distinguish between situational and affective risk situations. Furthermore, respondents were asked to formulate implementation intentions as a part of an intervention about one month before the planned quit date. This relatively long time in between the intervention and the quit date may have been responsible for the total lack of significant effects of plan instrumentality as well as the borderline significant effects of plan specificity with regard to continued abstinence. Finally, the study assessed short-term abstinence only. The present study was, therefore, conducted among smokers who had planned a quit date and were asked to formulate implementation intentions four days 
before that quit date. This task was part of an e-health smoking relapse prevention programme (called SQ4U, see Methods).

The present study aims to 1) provide an overview of the personal situational and affective risk situations as perceived by smokers; 2) assess whether the number of selected situational and affective risk situations is related to abstinence at six and twelve months after baseline; 3) provide an overview of the overall plan instrumentality of the implementation intentions, distinguishing between implementation intentions made for situational and affective risk situations; 4) provide an overview of the plan specificity of the implementation intentions, distinguishing between implementation intentions made for situational and affective risk situations; and 5) assess the role of plan instrumentality and specificity with regard to smoking abstinence at six and twelve months after baseline.

\section{METHODS}

\section{Respondents, design and procedure}

The data for this study were obtained from respondents who participated in the SQ4U study (Elfeddali, Bolman, Candel, Wiers and de Vries, 2012; Elfeddali, Bolman and de Vries, 2012), a randomised controlled trial that tested the effects of planning techniques on preventing smoking relapse. The programme provided tailored feedback based on individuals' answers on the baseline questionnaire as well as six planning assignments. The coping planning assignment took place four days before the quit attempt, the programmes were identical until the quit-date. After the quit date, the programmes used two slightly different strategies (see, Elfeddali, Bolman, Candel, Wiers and de Vries, 2012; Elfeddali, Bolman and de Vries, 2012)/chapter 4 and 5 of this dissertation) for a more detailed overview of the recruitment of respondents, the design, the study course and the procedure of the SQ4U study).

\section{Measurements}

The questionnaire was based on versions used in previous studies (Dijkstra, de Vries and Bakker, 1996; Dijkstra, De Vries and Roijackers, 1998; Dijkstra and de Vries, 2000; Hilberink, Jacobs, Schlosser, Grol and De Vries, 2006; Hoving, Mudde and de Vries, 2006; Mudde, Willemsen, Kremers and de Vries, 2006; Te Poel, Bolman, Reubsaet and de Vries, 2009; Elfeddali, Bolman, Candel, Wiers and de Vries, 2012) and assessed the following constructs. 
It assessed the demographic variables age, gender and educational level $(1=$ low: no education, primary [vocational] education, 2 = medium: secondary education; and 3 = high: college and university).

Perceived stress was assessed with five items based on the Perceived Stress Scale (Cohen and Williamson, 1988) and was rated on a five-point scale ( $1=$ never; to $5=$ very often). The mean scale score was included in the analyses (Cronbach's $\alpha=.74$ ).

Level of depression was measured with ten items (e.g. 'I feel anxious') using the CES-D depression scale (Cole, Rabin, Smith and Kaufman, 2004), the answers were given on a four-point scale $(1=$ never; to $4=$ all the time). The mean scale score was included in the analyses $(\alpha=.83)$.

The level of dependence was assessed with five items (e.g. the time when tobacco is smoked after wakening up) based on the abbreviated Fagerstrom test (Fagerstrom, Heatherton and Kozlowski, 1990; Heatherton, Kozlowski, Frecker and Fagerstrom, 1991), and used the sum score in the analyses $(0=$ not dependent, 9 = very dependent). Furthermore, we measured other smoking-related factors such as daily consumption of cigarettes, number of years a person had been smoking and previous quit attempts.

Attitudes were measured on a four-point scale (1=no, 2=yes, a bit, 3=yes, $4=y e s$, a lot/very) with two subscales measuring 1 . Pros of non-smoking with nine statements representing positive outcome expectancies; for instance 'nonsmoking will save me money' ( $\alpha=.73), 2$. cons of non-smoking with nine statements representing negative outcome expectancies of non-smoking; for instance 'non-smoking will cause me more stress' $(\alpha=.71)$,

Modeling was assessed with five items measuring the smoking status of the partner (yes, no, not applicable) and residential children, parents, colleagues and friends (all, the majority, half, a minority, none, not applicable). The items were coded into 3 category scales: not-smoking (-1), not applicable (0) and smoking (1). The items were summed and formed an index which was used in the analyses.

The intention strength to quit smoking was measured with one item ('how strong is your intention to quit smoking'?) on a ten-point scale ( $0=$ very weak, 9 = very strong).

Self-efficacy was assessed with thirteen items asking whether the respondent thought they would be able to refrain from smoking in various high-risk situations such as parties $(\alpha=.89)$. Answers were given on a seven-point scale ( 1 = totally disagree, $7=$ totally agre e), and the mean score was used in the analyses.

Finally, preparatory planning was assessed with twelve items asking respondents to indicate whether they had plans to perform preparatory behaviors such as 'removing all smoking materials' on a five-point scale (1=totally disagree, to $5=$ totally agree; $\alpha=.72$ ). The mean scale scores were used in the analyses. 


\section{Coping planning assignment}

The coping planning assignment was part of the SQ4U intervention and took place four days before the quit date. In this assignment, respondents were instructed to choose from a list of situations which three they felt created the highest smoking-related risk (see Table 7.1 for an overview). Next, the respondents were instructed to formulate their coping responses for dealing with these situations in the format of implementation intentions. They received instructions to formulate these implementations as 'If ..... then' plans together with an example (e.g. If I feel the urge to smoke when I am among smoking friends, then I will tell my friends that I have quit and ask them not to smoke in my presence). Respondents in both experimental conditions received this assignment after having been exposed to similar intervention elements.

\section{Outcome measures}

Continued abstinence (primary outcome). At six and twelve months after baseline, continued abstinence was measured with the definitions of Hughes and colleagues (Hughes, Keely and Niaura, 2003) by asking respondents whether they had smoked since the quit date. Smoking after the quit date was coded as 'relapse' (score =0); not smoking was coded as 'abstinence (score $=1$ ).

Instrumentality. The implementation intentions formulated by the respondents were evaluated for instrumentality by two researchers independently $(0=$ non-instrumental and 1 = instrumental), following a procedure used in an earlier study (van Osch, Lechner, Reubsaet and de Vries, 2010). Researchers were instructed to rate the implementation intentions as instrumental if they helped the respondent abstain from smoking (e.g. If I feel stressed, then I will take a walk with my dog to calm down and stop myself from smoking). The researchers were instructed to rate the plans as non-instrumental if they explicitly led to smoking (e.g. If I feel stressed, then I will have to smoke a cigarette). Furthermore, implementation intentions that were missing, incomplete or noninterpretable were rated as non-instrumental (and scored with 0). Cohen's Kappa interrater reliability for instrumentality was .95; when no consensus was reached a third researcher was consulted. A sum score of instrumentality was calculated by adding the scores of the three implementation intentions. This total score represented the number of instrumental plans, which ranged from 0 to 3 , and was used as the scale score in the analyses.

Specificity. The implementation intentions were also evaluated for specificity by the two researchers independently 0 = non-specific; $1=$ medium specific; 2 = very specific). The researchers were instructed to only rate a plan for specificity if the plan was instrumental; others were defined as missing (van Osch, Lechner, Reubsaet and de Vries, 2010). Implementation intentions were coded 
as non-specific (scored as 0 ) when they were vague (e.g. do something else); as medium specific (scored as 1) when they contained a certain amount of details (e.g. exercise) and as highly specific (scored as 2) when they gave enough details to be carried out when the specific situation occurred (e.g. take a walk with my dog for an hour). Cohen's Kappa interrater reliability was 0.79; when no consensus was reached a third researcher was consulted. A mean score for specificity over the three implementation intentions, ranging from 0 to 2 , was calculated and was used as the scale score in the analyses.

\section{Analyses}

Descriptive analyses were performed to describe the sample characteristics, to give an overview of the selected situational and affective risk situations and to describe the quality (instrumentality and specificity) of the implementation intentions. Next, $\chi^{2}$-tests were conducted to assess the relationship between abstinence and the number of selected situational and affective risk situations. Moreover, logistic regression analyses were conducted to assess the role of plan instrumentality and plan specificity in predicting short term (six months after baseline) and longer term (twelve months after baseline) smoking abstinence. To preserve power there was only corrected for condition (variant of the SQ4U programme), post-motivational factors (self-efficacy, preparatory planning and intention to quit) and factors that predicted attrition. We conducted observed case analyses including only respondents with follow-up data.

\section{RESULTS}

\section{Sample characteristics}

In this study we used data from smokers who had completed the coping planning assignment in the experimental conditions $(\mathrm{N}=563)$. Of these respondents, $250(44.4 \%)$ and 194 (34.5\%) completed the six and twelve month follow-up measurements, respectively. In this sample $(\mathrm{N}=563)$, most respondents $(95 \%)$ had already made previous quit attempts. The majority (about 65\%) were women. Respondents had a mean age of 42 years (SD $=11.34)$, consumed an average of 20 cigarettes per day (SD $=9.04$ ), had smoked for 26 years on average $(S D=11.45)$ and had a mean score of $4.65(S D=2.10)$ on the nicotine dependence scale. 


\section{Attrition analyses}

Drop-out at six as well as at twelve months after baseline was predicted by making plans with a low level of specificity ( 6 months $\mathrm{OR}=.62 ; \mathrm{CI}=.44-.86 ; P=.005$; 12 months $\mathrm{OR}=.61 ; \mathrm{CI}=.42-.87 ; \mathrm{P}=.007)$. Furthermore, drop-out at twelve months was predicted by lower age $(\mathrm{OR}=.97 ; \mathrm{CI}=.96-99 ; P=.003)$, higher levels of nicotine dependence $(\mathrm{OR}=1.10 ; \mathrm{CI}=1.00-1.21 ; P=.042)$, perceiving more pros of non-smoking (OR=1.84; $\mathrm{CI}=1.13-2.99 ; P=.014)$.

\section{Perceived situational and affective risk situations of smoking after a quit attempt}

Our first goal was to provide an overview of situational and affective risk situations of smoking after a quit attempt as perceived by smokers who are highly motivated to quit smoking. Table 7.1 gives an overview of the risk situations selected by the respondents $(\mathrm{N}=563)$. Being stressed was most often selected as a personal risk situation (43\% of the respondents selected this as a trigger for smoking), followed by desiring a cigarette (36.8\%), waking up in the morning (33.0\%), being angry or frustrated $(32.5 \%)$ and visiting a party $(30.6 \%)$. The two most frequently selected risk situations concerned affective triggers. Of the following three risk situations selected by respondents, one was affective and two were situational.

Table 7.1 Overview of selected situational and affective risk situations among all assignment completers $(\mathrm{N}=563)$

\begin{tabular}{lccc}
\hline & Sort of situation & $\begin{array}{c}\text { Respondents who } \\
\text { selected the risk situation }\end{array}$ \\
\hline Situational (S) and affective (A) risk situations & $\mathrm{S}$ & $\mathrm{A}$ & $\mathrm{N}(\%)$ \\
When I am stressed & & $\mathrm{X}$ & $242(43.0 \%)$ \\
When I desire a cigarette & & $\mathrm{X}$ & $207(36.8 \%)$ \\
When I wake up in the morning & $\mathrm{X}$ & $\mathrm{X}$ & $186(33.0 \%)$ \\
When I feel angry or frustrated & & & $183(32.5 \%)$ \\
When I am at a party, visiting, or in a café & $\mathrm{X}$ & $172(30.6 \%)$ \\
When I am with my friends & $\mathrm{X}$ & $\mathrm{X}$ & $93(16.5 \%)$ \\
When I see someone enjoying a cigarette & & $\mathrm{X}$ & $89(15.8 \%)$ \\
When if feel depressed & $\mathrm{X}$ & $69(12.3 \%)$ \\
After diner & $\mathrm{X}$ & $60(10.7 \%)$ \\
When I gain weight & $\mathrm{X}$ & $48(8.5 \%)$ \\
When someone offers me a cigarette & $\mathrm{X}$ & & $45(8.0 \%)$ \\
When I drink coffee or tea & $\mathrm{X}$ & & $39(6.9 \%)$ \\
When I am having a break & & $\mathrm{X}$ & \\
When I feel awkward when with others & & &
\end{tabular}




\section{Abstinence and the number of selected situational and affective risk situations}

The second study goal was to assess the relationship between continued abstinence (after six and twelve months) and the number of situational and affective risk situations. Table 7.2 gives an overview of the number of situational and affective situations selected and shows no significant relationship between the number of situational risk situations selected and abstinence at $\operatorname{six}\left(\chi^{2}=5.53 ; P\right.$ $=.14)$ or at twelve months $\left(\chi^{2}=.64 ; P=.89\right)$ after baseline. The associations between the number of affective triggers and abstinence at six $\left(\chi^{2}=4.12 ; P=\right.$ $.25)$ and twelve $\left(\chi^{2}=.53 ; P=.91\right)$ months after baseline were also nonsignificant.

Table 7.2 Association between the number of selected situational and affective situations and abstinence at $\operatorname{six}(\mathrm{N}=250)$ and twelve $(\mathrm{N}=194)$ months after baseline.

\begin{tabular}{lcccclc}
\hline & $\begin{array}{l}\text { Total } \\
\text { (N=563) }\end{array}$ & $\begin{array}{l}\text { 6-months } \\
(\mathrm{N}=250)\end{array}$ & \multicolumn{2}{l}{$\begin{array}{l}\text { 12-months } \\
\text { (N=194) }\end{array}$} \\
& $\mathrm{N}(\%)$ & $\mathrm{N}$ & $\mathrm{N}(\%$ abstinent $)$ & $\mathrm{N}$ & $\mathrm{N}(\%$ abstinent) \\
\hline Situational triggers & 0 & $44(7.8 \%)$ & 16 & $8(50.0 \%)$ & 17 & $7(41.2 \%)$ \\
& 1 & $179(31.8 \%)$ & 86 & $27(31.4 \%)$ & 69 & $27(39.1 \%)$ \\
& 2 & $260(46.2 \%)$ & 105 & $32(30.5 \%)$ & 74 & $32(43.2 \%)$ \\
& 3 & $80(14.2 \%)$ & 43 & $20(46.5 \%)$ & 34 & $16(47.1 \%)$ \\
$\chi 2$ & & & 5.533 & & .635 & \\
P-value & & & .137 & & .888 & \\
Affective triggers & 0 & $87(15.5 \%)$ & 46 & $20(43.5 \%)$ & 37 & $16(43.2 \%)$ \\
& 1 & $253(44.9 \%)$ & 102 & $32(31.4 \%)$ & 71 & $32(45.1 \%)$ \\
& 2 & $179(31.8 \%)$ & 86 & $27(31.4 \%)$ & 69 & $27(39.1 \%)$ \\
$\chi 2$ & 3 & $44(7.8 \%)$ & 16 & $8(50.0 \%)$ & 17 & $7(41.2 \%)$ \\
P-value & & 4.124 & & .530 & \\
\hline
\end{tabular}

\section{Plan instrumentality of implementation intentions: overall overview and stratification by sort of situation (situational and affective)}

The third goal was to gain insight into the plan instrumentality of the implementation intentions made by respondents and to distinguish between implementation intentions made to deal with situational risk situations and those made to deal with affective risk situations. Table 7.3 gives an overview of the plan instrumentality. 
Most (86.0\%) of those who completed our implementation intentions assignment $(\mathrm{N}=563)$ made three instrumental plans. Considerably less respondents made two $(8.3 \%)$, one $(2.0 \%)$ or no instrumental plan (3.7\%). For the situational risk situations, all implementation intentions were rated as instrumental for $92.7 \%$ of those who selected only one situational risk situation, for $87.3 \%$ of those who selected two situational situations and for $92.5 \%$ of those who selected three situational risk situations. This resulted in $92.9 \%$ of instrumental implementation intentions over all situational risk situations. Concerning affective risk situations, all implementation intentions were also rated as instrumental for $89.7 \%$ of the cases in which one affective risk situation was identified, for $88.8 \%$ of the cases in which two affective situations were identified and for $86.4 \%$ of the cases in which three affective situations were identified. This resulted in $91.4 \%$ of instrumental implementation intentions formed for all affective risk situations. The difference between the instrumentality of implementation intentions formed to cope with situational risk situations and those formed to cope with affective risk situations was not significant $\left(\chi^{2}=1.26 ; P=.15\right)$.

Table 7.3 Plan instrumentality including stratification by the number of selected situational and affective risk situations

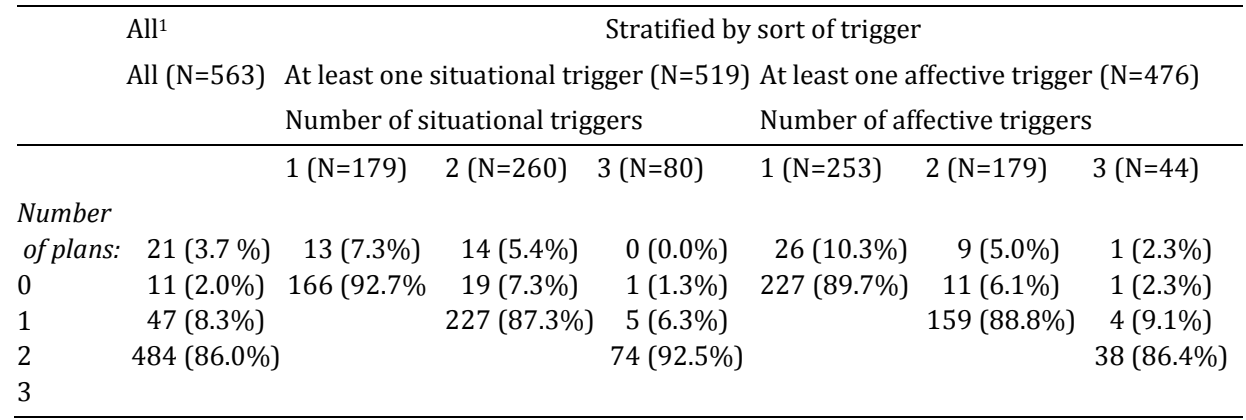

${ }^{1}$ All assignment completers

\section{Plan specificity of implementation intentions: overall overview and stratification by sort of risk situation (situational and affective)}

The fourth goal was to gain insight into the level of the plan specificity of the implementation intentions that respondents made and to assess whether plan specificity differed for plans dealing with situational and affective risk situations. Table 7.4 shows that the average level of specificity over all implementation intentions was high among about a half (53.9\%) of the respondents, medium for about one third (31.4\%) and low for the rest (14.8\%). The mean score over all respondents was $1.47(\mathrm{SD}=.54)$, indicating that on average respondents made reasonably specific plans. 
Of the respondents $(\mathrm{N}=491)$ who selected at least one situational risk situation, $69 \%$ made highly specific plans, $20.2 \%$ made medium-specific plans and $10.8 \%$ made plans with very few specifics. The specificity of the implementation intentions for dealing with affective risk situations was high among 59.1\% of the respondents $(\mathrm{N}=440)$ who selected at least one affective risk situation, medium among $19.5 \%$ and low among $21.4 \%$. Specificity differed significantly between situational and affective risk situations $(\mathrm{t}=3.99 ; \mathrm{P}<.001)$, revealing significantly higher levels of specificity for the implementation intentions formed to cope with situational risk situations $(\mathrm{M}=1.56$; $\mathrm{SD}=.61)$ than for affective risk situations $(\mathrm{M}=1.38 ; \mathrm{SD}=.77)$

Table 7.4 Level of plan specificity among instrumental plan makers ( $N=542)$ including stratification by sort of situation (situational or affective)

\begin{tabular}{lccc}
\hline & \multicolumn{1}{l}{ All } & \multicolumn{2}{c}{ Stratified by sort of triggers } \\
& All & At least 1 situational trigger & \multicolumn{1}{c}{$\begin{array}{l}\text { At least 1 emotional trigger } \\
(\mathrm{N}=440)\end{array}$} \\
\hline Specificity & & & \\
Low specificity & $80(14.8 \%)$ & $53(10.8 \%)$ & $94(21.4 \%)$ \\
Medium specificity & $170(31.4 \%)$ & $99(20.2 \%)$ & $86(19.5 \%)$ \\
High specificity & $292(53.9 \%)$ & $339(69.0 \%)$ & $260(59.1 \%)$ \\
Mean (SD) & $1.47(.54)$ & $1.56(.61)$ & $1.38(.77)$ \\
\hline
\end{tabular}

${ }^{1}$ All assignment completers; ${ }^{2} 492$ of those who selected at least one situational risk situation made one instrumental plans, but in one of the cases the specificity could not be rated.

\section{Plan quality of implementation intentions: influence of specificity and instrumentality on short and longer term abstinence}

Logistic regression analyses were conducted in order to answer our final goal to assess the role of plan instrumentality and specificity in fostering smoking abstinence. Assessing these effects in a logistic regression analysis (using a complete case analysis strategy) while correcting for demographics (gender, age, education), level of dependence, pros of non-smoking, self-efficacy, preparatory planning, intention to quit smoking, and condition revealed that plan specificity significantly predicted continued smoking abstinence at the six $(O R=2.02$; $\mathrm{CI}=1.11-3.66 ; P=.021)$ and twelve (OR=2.23; $\mathrm{CI}=1.14-4.36 ; P=.019$ ) month follow-up measurements. Plan instrumentality showed no significant relation with abstinence at the six $(\mathrm{OR}=1.11 ; \mathrm{CI}=.48-2.54 ; P=.810)$ nor at the twelve $(\mathrm{OR}=.82$; $\mathrm{CI}=.35-1.94 ; P=.653)$ month follow-ups. Finally, none of the covariates were significantly associated with abstinence at six or twelve months after baseline in case the factor implementation intention was included. 


\section{DISCUSSION}

Our study aimed to provide an overview of situational and affective risk situations of smoking after a quit attempt as perceived by smokers shortly before their planned quit date; to gain insight into the instrumentality and specificity of the implementation intentions formed to deal with these situational and affective risk situations; and to assess the role of plan instrumentality and specificity in fostering smoking abstinence at six and twelve months after baseline.

First, our study pointed out that affective risk situations, namely being stressed and desiring a cigarette, were most often perceived as a relapse risk. These risk situations correspond with those in earlier studies that consistently indicated that stress (Kassel, Stroud and Paronis, 2003; Brown, Lejuez, Kahler, Strong and Zvolensky, 2005; Shaw and al'Absi, 2008) and high craving levels (Killen and Fortmann, 1997; Shiffman et al., 1997; Shiffman, 2004) predict smoking relapse. Of secondary importance were the affective risk situation of feeling angry or frustrated and the situational risk situations of waking up in the morning and attending a party. Previous studies also indicated these situations as risky: negative affect states such as being angry as well as positive events such as being at a party have shown to precede smoking relapse (Zinser, Baker, Sherman and Cannon, 1992; Shiffman and Waters, 2004). Furthermore, studies have demonstrated that a shorter time span between waking up and the first cigarette can be seen as an indicator of nicotine dependence (Baker et al., 2007), and is associated with higher cotinine levels and even relapse (Muscat, Stellman, Caraballo and Richie, 2009). In sum, our results show that smokers who want to quit smoking are highly aware of these risk situations before their quit attempt. Identifying personal risk situations is an important first step in dealing with them (Marlatt and Donovan, 2005). Our in-depth analyses -conducted in order to reach our second goal of the study- did not reveal the importance of the number of selected situational and affective relapse risk situations. Yet, we did not assess whether and which anticipated triggers actually occurred and the extent to which a mix of risk situations (affective and situational) took place. Another explanation for this finding may be that it is not the perceived risk that is of importance, but whether a person manages to cope with the situation.

In order to assess the quality of the coping strategies our third, fourth and fifth goal pertained to assess the level of plan instrumentality and specificity of the implementation intentions that were formed to cope with the selected situational and affective risk situations as well as the behavioral impact of this plan quality. Our findings pointed out that most respondents (86\%) made three instrumental implementation intentions. The level of the instrumentality of the implementation intentions did not differ significantly for situational and affective risk situations. This finding may imply that the type of risk situation (situational or affective) does not hinder the process of making instrumental plans. In line with an earlier study (van Osch, Lechner, Reubsaet and de Vries, 2010), our 
results did not reveal a significant effect with regard to plan instrumentality on smoking abstinence at six and twelve months after baseline. This finding may be due to the fact that most of the respondents made three instrumental plans. A final explanation may be that selected risk situations for which noninstrumental plans were made did not actually occur during the study and therefore did not negatively influence the abstinence rates. More insight into whether or not respondents actually faced the situations for which they made coping responses is therefore needed. With regard to plan specificity, our findings confirmed the results of Van Osch and colleagues (van Osch, Lechner, Reubsaet and de Vries, 2010). However, their respondents were asked to form their implementation intentions at baseline one month before the quit attempt, while ours were asked to form them four days before their quit date. This may have contributed to our significant effects regarding continued abstinence as well as our longer term effects. More research is therefore needed to assess whether the time point of making implementation intentions matters. Finally, in-depth analyses indicated that specificity of implementation intentions made by the respondents to cope with affective risk situations was significantly lower compared to the specificity of implementation intentions made to deal with situational risk situations. This difference may be due to the fact that affective states (such as stress, depressive feelings, moods) are determined by multiple factors such as chemical brain imbalances, the use of medicine, life events, social demographic factors, personality traits, diseases and work and family influences (Mroczek and Kolarz, 1998; Flaa, Ekeberg, Kjeldsen and Rostrup, 2007; Gruenewald, Mroczek, Ryff and Singer, 2008; OSUMC, 2012). Furthermore, the respondents may not be aware of the underlying factors of their affective states, which may have resulted in difficulties making specific plans to target the relapse risk situation appropriately. As far as we know, no earlier studies have assessed or compared the plan quality of implementation intentions formulated for affective and situational relapse risk situations. More research is needed to gain insight into the exact difficulties when it comes to dealing with affective risk situations, and in turn to improve interventions to prevent smoking relapse and provide people with assistance in the coping process.

This study was subject to limitations. First, the sample consisted of respondents from two different versions of the SQ4U programme (although these were comparable to a large degree, the $\mathrm{AP}+$ was more intensive in the period after the quit date). We targeted this limitation by correcting for the effects of condition (variant of the SQ4U programme) in all logistic regression analyses. Second, drop-out rates were high - as is common in internet-based studies (Wangberg, Bergmo and Johnsen, 2008). Conservative analyses (in which missing answers at follow-up are considered as relapse) could have helped us to gain insight into the effects of a worst case scenario (where all drop-outs are considered relapsers). However, this study contained predictive analyses and one of the included 
predictors namely plan specificity was significantly associated with drop-out after six and twelve months. Consequently, the conservative analyses would be subject to biases strengthening the relation between not making specific plans and relapse, while the actual relation is one between not making quality plans and drop-out. Finally, respondents where explicitly asked to select only three relapse risk situations. Although respondents were not obligated to do so, additional research may be needed to assess the influence of the number of plans in a context where smokers are not restricted to a specific number of plans.

Despite these limitations, this study is the first to provide an overview of the situational and affective risk situations of smoking after a quit attempt as perceived by smokers who participated in an e-health smoking relapse prevention programme just a few days before their quit date. Another novel finding is that the implementation intentions formed to deal with affective risk situations were of a significantly lower specificity level compared to implementation intentions made to cope with situational risk situations. Finally, our findings support the importance of formulating specific plans for preventing relapse, and revealed that specificity influences smoking abstinence positively up to twelve months after baseline. It is, therefore, recommended that future interventions stress the importance of plan specificity, explain when a plan is specific enough to be helpful and target the difficulties related to making implementation intentions for affective risk situations.

\section{Acknowledgements}

This study was funded by the Dutch Organization for Health Research and Innovation (grant number 6130-0030). We would like to thank Stivoro for their help in recruiting respondents and the respondents for their participation in the study. 



\section{CHAPTER 8}

\section{Preventing smoking relapse among smokers via a Web-based multiple- session attentional bias modification training: a randomized controlled trial}

This chapter is in preparation as:

Elfeddali, I., de Vries, H. and Wiers, R.W. Preventing short-term smoking relapse among smokers via a Web-based multiple-session attentional bias modification training: a randomized controlled trial. 


\section{ABSTRACT}

Aims Smoking relapse prevention programs - mostly targeting explicit processes of behavior change - have shown only modest behavioral effects. Recent studies have associated implicit cognitive processes such attentional and approach biases with smoking behavior. This study aimed to assess the efficacy of an attentional bias modification (ABM) training in modifying attentional and approach biases and fostering continued abstinence. Differential effects of the training were assessed for regular smokers ( $>15$ cigarettes per day) and nonregular smokers (not $>15$ cigarettes per day). Participants Daily current smokers ( $>5$ cigarettes per day), aged between 18 and 65 years, who were motivated to quit smoking within one month and made a quit-attempt. Design The study was a randomized controlled trial with two conditions: 1. a control group, 2 an ABM-training. Both conditions consisted of a pre- and post-training assessment, six intervention sessions and a follow-up measurement after six months. The intervention sessions were either training sessions or assessments only (in the control condition). Group allocation was randomized. Measurements Pre- and post-training assessments consisted of subjective measures of smoking-related cognitions (e.g., self-efficacy) and implicit measures of attentional bias (Visual Probe (VP) task) and approach bias (Stimulus Response Compatibility (SRC) task). The VP-task taken at post-training included untrained pictures to assess whether the effects of the training generalize to new pictures. Follow-up measurements assessed self-reported continued abstinence. Findings The ABMtraining had only moderate effects with regard to attentional bias and no effects on approach bias. The training significantly fostered continued abstinence compared to the control group, but only for regular smokers. Conclusions This study is the first to show significant effects of an ABM-training in fostering continued smoking abstinence among regular smokers who made a quit-attempt. The modest effects with regard to attentional bias may be due to poor reliability of the VP-task. The manuscript further provides recommendations for future research. 


\section{INTRODUCTION}

Smoking relapse refers to the fallback into smoking after a quit-attempt and forms a serious barrier to successful smoking cessation (Hughes, Keely and Naud, 2004). Furthermore, a Cochrane systematic literature review concluded that current smoking relapse prevention programs, which mainly use behavioral techniques such as skill trainings, are not effective for smoking relapse prevention and that alternative strategies are needed to target smoking relapse (Hajek, Stead, West, Jarvis and Lancaster, 2009).

Up until now, smoking relapse prevention programs have mostly targeted explicit cognitions (for review, see; Hajek, Stead, West, Jarvis and Lancaster, 2009). However, dual-process models (see examples in, Strack and Deutsch, 2004; Bechara, 2005; Deutsch and Strack, 2006; Wiers and Stacy, 2006; Wiers et al., 2007) propose the existence of two different systems that determine a person's motivation and behavior: 1) a reflective system, which is slow, controlled, rule-based and relates behavior to a decision process, and 2) an impulsive system, which is fast, associative, often unconscious and in which behavior may take place without intention. The latter is sensitive to the incentive salience of cues that results in implicit cognitive biases such as attentional bias (Robinson and Berridge, 2003; Wiers, van de Luitgaarden, Van den Wildenberg and Smulders, 2005; Field and Cox, 2008; Robinson and Berridge, 2008) and approach bias (Field, Kiernan, Eastwood and Child, 2008; Robinson and Berridge, 2008; Wiers, Rinck, Dictus and van den Wildenberg, 2009). Consequently, in recent years researchers in the field of addictive behaviors have started to use implicit measures to assess substance-related implicit cognitions and to study the associations between these implicit cognitive biases and behavior (Stacy, 1997; Wiers, van Woerden, Smulders and de Jong, 2002; Wiers and Stacy, 2006; Stacy and Wiers, 2010). Attentional bias implies that a person's attention is drawn by attractive cues (in addictive behaviors, substance-related cues), while approach bias can be defined as the tendency to approach these attractive cues faster than avoiding them: both have been demonstrated in smokers (see e.g., Mogg, Bradley, Field and De Houwer, 2003; Waters, Shiffman, Bradley and Mogg, 2003; Cox, Fadardi and Pothos, 2006; Watson, de Wit, Hommel and Wiers, 2012). It should be noted that implicit cognitive processes are not measured by self-report assessments of feelings and thoughts, but indirectly using most often Reaction Time (RT) paradigms.

Importantly, implicit cognitive processes can not only be assessed, but can also be directly manipulated, often referred to as Cognitive Bias Modification (CBM). In their pioneering study, MacLeod and colleagues (2002) adapted a version of the Visual Probe (VP) task (an assessment instrument for attentional bias) in order to modify attentional bias towards threat-related stimuli in students with medium levels of anxiety. The VP task normally presents two pictures on a screen (one disorder/substance-related and one control (neutral) 
picture) followed by a probe (e.g., an arrow pointing up or down). Participants' task is to react to the probe, for example by indicating the direction of the arrow. In the assessment version of the task, the arrow appears equally often behind the disorder/substance-related picture and the neutral picture: attentional bias is calculated by subtracting the response times on the disorder/substancerelated pictures from the RTs on the neutral pictures. In the adapted version that was developed to modify attentional bias, a contingency was introduced with the probe appearing more often behind the neutral stimulus to modify the attention away from the anxiety-related pictures (or behind the anxiety-related picture in order to modify the bias towards the threat-related picture).

Following this attentional bias modification (ABM) in anxiety studies (MacLeod, Rutherford, Campbell, Ebsworthy and Holker, 2002), studies in the field of addiction involved a single-session of ABM training and showed a very similar pattern: an attentional bias for alcohol (Field et al., 2007; Schoenmakers, Wiers, Jones, Bruce and Jansen, 2007) or smoking (Attwood, O'Sullivan, Leonards, Mackintosh and Munafo, 2008; Field, Duka, Tyler and Schoenmakers, 2009) could be modified towards or away from the substance-related stimulus. These single-session studies, however, did not provide evidence for 'close generalization effects' (decreased bias towards substance-related pictures when measured with the same task, but with new/untrained pictures), since the effects only took place in reaction to pictures that were used in the task. 'Close generalization' is important because it indicates that the respondents' attention is modified away from substance-related stimuli in general and not only for the task-specific stimuli. More encouragingly, the first two studies using a multiplesession ABM training for problem drinkers (Fadardi and Cox, 2009) and alcoholdependent patients in treatment (Schoenmakers et al., 2010) both found generalized positive effects (decreased bias when measured with new/untrained stimuli) and reduced drinking. Given that both studies concern alcohol, a first important open question is whether multiple sessions of ABM training also induce generalized effects on new/untrained stimuli (using the same task) and positive behavioral effects with respect to smoking.

A second important question in current CBM research concerns the specificity of training. For example, in alcoholism, retraining an approach bias for alcohol has also generated positive effects, including increased abstinence a year after retraining was added to standard treatment (Wiers, Eberl, Rinck, Becker and Lindenmeyer, 2011). Approach biases have also been demonstrated in smokers (Mogg, Bradley, Field and De Houwer, 2003); it is unknown whether ABM training also influences an approach bias. This kind of generalization effect to other measures of implicit cognition is referred to as 'further generalization' and forms an important question in current research on CBM trainings (see for a review, Wiers, Gladwin, Hofmann, Salemink and Ridderinkhof, in press). 'Further generalization' is important because it shows that an ABM program can 
also result in positive effects with regard to approach biases and vice versa. For that reason, a measure of approach bias has been included in this study.

Third, substance-related attentional bias has been shown to be associated with the quantity and frequency of use among alcohol users, with heavy drinkers having a significantly greater bias (Townshend and Duka, 2001; Field, Mogg, Zetteler and Bradley, 2004). A similar finding has been found in smokers (Mogg and Bradley, 2002), suggesting that heavier smokers may benefit more from ABM training. The different training effects deserve further investigation and will, therefore, be tested in this study. It should be noted that different definitions of moderate/heavy smoking exist and that the present study defined moderate/heavy smoking (referred to as regular smoking) as smoking more than 15 cigarettes per day (conform (Killen, Fortmann, Telch and Newman, 1988).

A final important question concerns the delivery method. Since ABM training is computerized, it can be delivered online. Studies have found that the Internet is a promising delivery mode for health-promoting and lifestyle-changing interventions (see, for instance Brug, Campbell and van Assema, 1999; Walters, Wright and Shegog, 2006; Vandelanotte, Spathonis, Eakin and Owen, 2007; Te Poel, Bolman, Reubsaet and de Vries, 2009; ACS, 2010). In the Netherlands, 91\% of households have Internet access, so it could potentially reach large numbers of people (CBS, 2011). However, a recent study found no effects of Internetdelivered ABM training in social anxiety (Carlbring et al., 2012), which contrasted with more positive findings for $\mathrm{ABM}$ strategies delivered in a clinical setting for the same disorder (Amir, Beard, Burns and Bomyea, 2009; Schmidt, Richey, Buckner and Timpano, 2009). In addition, controlled alcoholism studies have reported positive effects for repeated ABM training when it is added to more traditional cognitive motivational interventions. Hence, an interesting third question is whether repeated ABM training over the Internet alone can help smokers remain abstinent after a quit-attempt.

To recap, this is the first study to test a Web-based multiple-session ABM training program called 'Train Yourself Smoke-free' for smokers who are motivated to quit smoking within one month. We hypothesized that the program would: 1) result in a significantly larger reduction of attentional bias regarding new/untrained smoking-related materials (close generalization); 2) generalize to an approach bias, which is another implicit cognitive bias (further generalization); and 3) significantly foster continued smoking abstinence compared to the control group. For all outcomes we expected the ABM training to have differential effects with stronger effects among regular smokers.

\section{METHODS}

Ethical approval was obtained from the Medical Ethics Committee of the Maastricht Academic Hospital and Maastricht University (MEC 08-3-003; 
NL21414.068.08). The study is registered with the Dutch Trial Register (NTR2312).

\section{Design}

This was a randomized controlled study with an experimental condition (ABM training program) and a control condition (placebo training with assessments only). Both conditions consisted of a pre-training assessment (referred to as 'pre-training'), six training/placebo sessions, a post-training assessment shortly after the final training/placebo session (referred to as 'post-training') and a follow-up measurement six months after baseline in order to assess the smoking status of the respondents.

\section{Respondents and recruitment}

Smokers were recruited by placing ads in local newspapers and online ads on the website of a national news page and the website of the Dutch Foundation for a Smoke-free Future. The ads referred the respondents to our research website (www.trainjezelfrookvrij.nl) for more information on the study and the criteria for participation. Furthermore, it was explained that the respondents had a $50 \%$ change of being assigned to a control condition. A total of 2,302 respondents signed up to participate.

Smokers were defined as people who smoke more than five cigarettes per day, in accordance with another study (Attwood, O'Sullivan, Leonards, Mackintosh and Munafo, 2008). Inclusion criteria included giving consent for participation, being between 18 and 65 years old, reporting that they had smoked on a daily basis for at least a year and not having made their quitattempt yet (thus respondents who had already quit smoking - had not smoked in the previous week and/or previous 24 hours - were excluded from the analyses). Furthermore, respondents needed to select a quit-date at baseline (all the following program elements were based on this date). Respondents who reported that they met one of the following conditions did not meet the baseline inclusion criteria and were excluded from the analyses: they did not understand the Dutch language well, they consumed more than 16 glasses of alcohol per week, they were unable to refrain from alcohol use during a whole day, they used drugs or calming medicines, they had a psychological disorder or they were color blind and/or vision impaired (even with glasses). Moreover, respondents needed to confirm their quit-attempt after their quit-date; otherwise, they were excluded from further participation in the study (the program did not continue to the next program element). Many respondents had to be excluded because 
they had either already quit smoking or did not make or confirm their quitattempt. The enrollment and inclusion of respondents is presented in Figure 8.1.

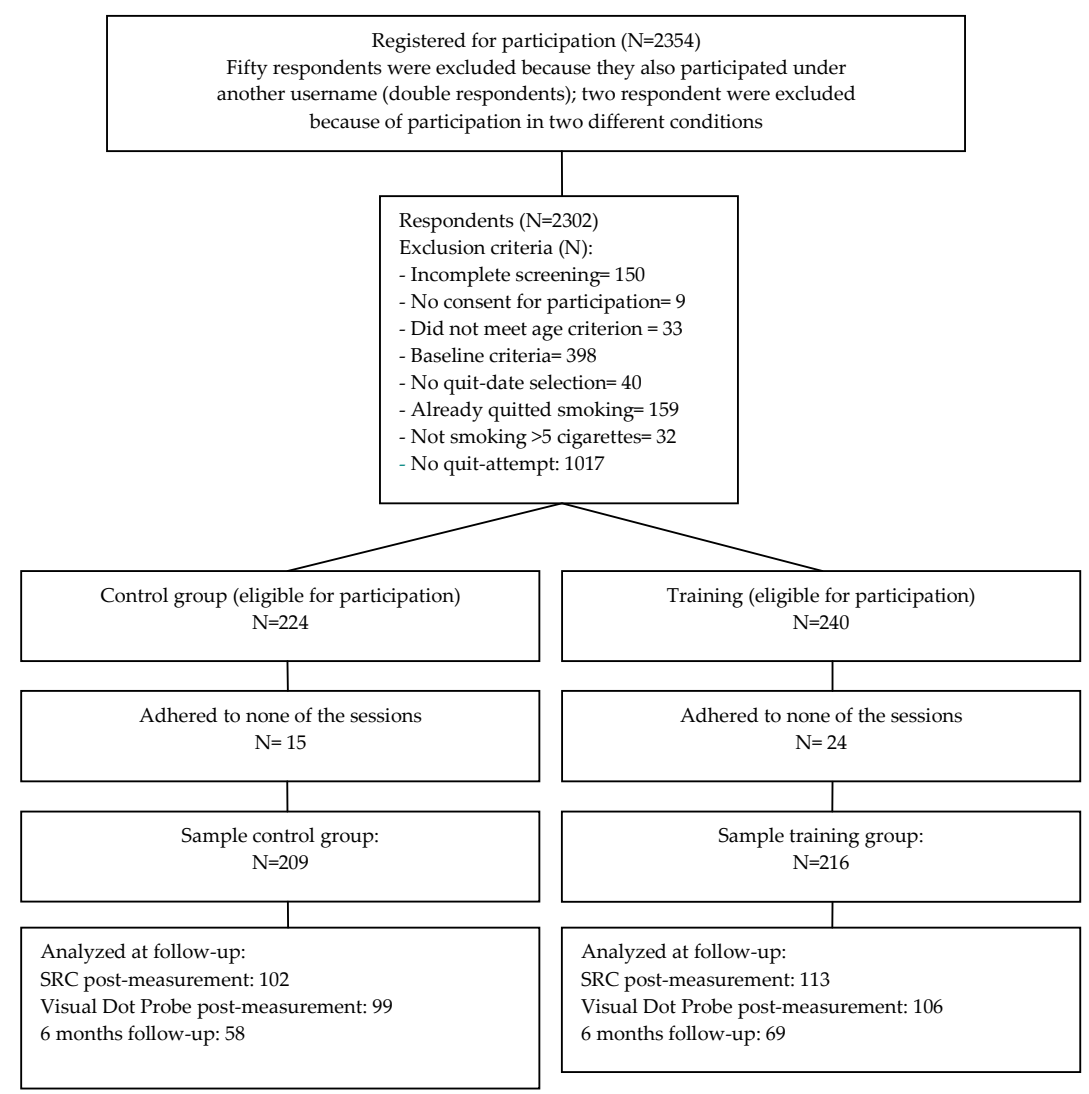

Figure 8.1. Enrollment and inclusion of respondents.

\section{Procedure}

After entering the program via the research website, the respondents created user accounts by choosing their own usernames and passwords; the user account was used for participating in all sessions. Since we recruited a very general sample of smokers who were motivated to quit smoking, the study started with a screening to assess whether they met the baseline criteria (see previous section). Respondents who did not meet the criteria for participation received a message on the computer screen explaining why they were not eligible for participation.

Following screening, all remaining respondents were asked to select a quit-date within one month and then continued with the pre-training, which consisted of 
a self-report questionnaire, a Stimulus Response Compatibility (SRC) task to measure approach-avoidance biases and a VP task to measure attentional biases (see the 'Pre- and post-training' section for the set-up of the tasks). The respondents were randomized into one of the two conditions by means of a software randomization mode when they entered the VP task. All respondents (including those in the control group) were invited to confirm their quit-attempt two days after their chosen quit-date. The program only continued for those who confirmed they had made a quit-attempt: they started with the first session of the intervention (training or placebo) directly after confirming their quitattempt.

Each of the following sessions (training/placebo sessions 2-7 and the posttraining) started 18 hours after the respondents entered the previous session. Respondents were given 60 hours (two-and-a-half days) to complete each session; after 60 hours, the session closed. Finally, respondents were invited to complete the self-report questionnaires about their smoking behavior six months after the pre-training. All invitations for participation were sent by email directly at the start of each session. For the six months follow-up, two reminders were sent if the respondent did not respond: one after one week and another after two weeks.

\section{Materials}

The materials for the VP task consisted of 96 smoking-related pictures and 96 neutral pictures. Smoking-related pictures represented smoking by showing items such as smoking people, cigarettes, cigarette packages, lighters and ashtrays. Neutral pictures lacked any smoking-related content and showed, for instance, non-smoking people, pencils and pencil packages. Eight sets of 12 matched smoking-related/neutral picture pairs were created. Sets 1 and 2 were used in the pre-training and sets 2-8 were used in the intervention (training/placebo) sessions. Each session consisted of an old and a new set of picture pairs. The post-training presented set 1 (untrained pictures). Finally, an additional eight neutral/neutral picture pairs were created for practice and filler trials. Each picture had a dimension of 425 by 282 pixels.

The materials for the SRC task consisted of a set of 14 matched smokingrelated and neutral picture pairs. Another four picture pairs were used as practice trials. Each picture had a dimension of 352 by 288 pixels. 


\section{Pre- and post-training}

\section{The SRC task}

The trials in the SRC task presented either a smoking-related picture or a neutral picture on the computer screen, with a manikin appearing above or below the picture. Before the start of the task, respondents received instructions: they were either instructed to move the manikin towards the smoking-related picture or away from the smoking-related picture using the letters I (to move the manikin up) and V (to move the manikin down) on their keyboard. They were instructed to respond quickly but to try to make as few mistakes as possible. The instruction was followed by a practice session with eight trials in which four smoking-related and four neutral pictures were used. When the correct response was given, the manikin moved towards or away from the picture and then the next picture was shown (with an inter-trial interval of 1,500 milliseconds (ms)). When an incorrect response was given, a red cross appeared on the screen followed by the same picture again. The practice session was followed by two main blocks: an 'approach' block and an 'avoid' block. In the 'approach' block the respondents were instructed to move towards the smoking-related picture; in the 'avoid' block they were instructed to move away from the smoking-related picture. The order of the blocks was counterbalanced across respondents. Each block presented 28 trials using a set of 14 pictures pairs, with all pictures presented once in the approach block and once in the avoid block. The manikin appeared above the picture in $50 \%$ of the trials. RTs were logged for all respondents.

\section{The VP task}

All trials used in the pre-training for the VP task started with a fixation cross for $500 \mathrm{~ms}$. Each trial presented a matched picture pair for $500 \mathrm{~ms}$ : practice and filler trials presented neutral/neutral pairs and critical trials presented smoking-related/neutral picture pairs. The picture pairs were then replaced by an arrow probe pointing up or down. Respondents were instructed to identify the direction of the arrow as quickly as possible by using the letters $S$ (arrow is pointing up) and L (arrow is pointing down) on their keyboard and to try to make as few mistakes as possible. Error responses were followed by an identical trial to ensure serious task performance, as is often done with RT tasks over the Internet (Greenwald, Nosek and Banaji, 2003).

The pre-training started with a practice block of eight trials with neutral/neutral picture pairs that were repeated until the right response was given in all eight trials. The practice block was followed by two blocks that both consisted of 48 critical trials and 12 filler trials (neutral/neutral picture pairs). Two sets of 12 pictures were used for the critical trials: each set was repeated four times. In the critical trials of the pre-training, the probe had a $50 \%$ probability of appearing behind the smoking-related picture and a 50\% probability of appear- 
ing behind the neutral picture. The post-training procedure was identical to the pre-training procedure and included untrained pictures.

\section{Self-report questionnaires}

Demographic variables were assessed, including age, gender and educational level ( 1 = low: no education or primary (vocational) education; 2 = medium: secondary (vocational) education; and 3 = high: higher education).

Smoking-behavior-related information was gathered by asking about the number of cigarettes smoked per day, the number of years the respondent had been smoking and whether the respondent had made previous quit-attempts.

Level of dependence was measured by six items based on the abbreviated Fagerström Test for Nicotine Dependence (FTND) (Fagerstrom, Heatherton and Kozlowski, 1990; Heatherton, Kozlowski, Frecker and Fagerstrom, 1991). The questionnaire included questions about "the amount of tobacco smoked" (more than 31 cigarettes (3) , 21 to 30 cigarettes (2), 11 to 20 cigarettes (1), 10 or fewer cigarettes (0)), "the amount of time that occurs between getting out of bed and first smoking tobacco" (within 5 minutes (3), between 6 and 30 minutes (2) 31 and 60 minutes and (1) after 60 minutes (0)), "the cigarette that is most difficult to give up" (the morning cigarette (1) or another (0)) and three other questions: "do you smoke in places where smoking is prohibited", "do you smoke more in the morning" and "do you even smoke when you are ill in bed" (answered with yes (1) or no (0)). An index score was made of the answers and the sum score was used in the analyses ( $0=$ not dependent, $10=$ very dependent).

Craving was assessed by six items (Dijkstra and Borland, 2003) asking about the frequency of looking forward to a cigarette, thinking of a cigarette, missing a cigarette and longing for a cigarette (e.g., "I desire smoking a cigarette" and "I miss smoking a cigarette"). The items were rated on a five-point scale from never (1) to very often (5) and the mean score was used as the scale score in the analyses (Cronbach's alpha $(\alpha)=.84$ ).

The following questions with regard to intention and self-efficacy were derived from previous studies (Dijkstra, de Vries and Bakker, 1996; Dijkstra, De Vries and Roijackers, 1998; Dijkstra and de Vries, 2000; Hilberink, Jacobs, Schlosser, Grol and De Vries, 2006; Hoving, Mudde and de Vries, 2006; Mudde, Willemsen, Kremers and de Vries, 2006; Te Poel, Bolman, Reubsaet and de Vries, 2009).

Intention strength to quit smoking was measured by one item ("how strong is your intention to quit smoking?") that was scored on a ten-point scale from very weak (1) to very strong (10).

Self-efficacy was assessed by 14 items asking whether the respondent thought they would be able to refrain from smoking in various high-risk smoking-related situations (e.g., "do you think that you will be able to refrain from smoking when you are at a party?"). The questions were rated on a seven-point 
scale from totally disagree (1) to totally agree (7) and the mean score was used in the analyses $(\alpha=.92)$.

Attention Control Task. The Attention Control Scale (ATTC) is a self-report questionnaire that measures two components of attention (attention focusing and attention shifting). It consists of 20 items (e.g., "even when I am working very hard, I get distracted by things that happen in my environment" and "I can switch very fast from one task to another"). The questions were rated on a fourpoint Likert scale from almost never (1) to always (4) and the mean score was used in the analyses $(\alpha=.87)$.

\section{Follow-up measurement after six months}

In line with the definitions provided by Hughes et al. (Hughes, Keely and Niaura, 2003), continued abstinence was defined as not smoking at all after the quitattempt and was measured by asking whether the respondent had smoked since the quit-attempt.

\section{Intervention}

The intervention (training or placebo) was based on the VP task (the set-up of the task was explained earlier). The intervention included a practice block with eight trials and six sessions, each with six blocks. The first block of each session presented 48 assessment trials (the probe appeared behind the smoking-related cue in $50 \%$ of the trials). Blocks $2-5$ consisted of 48 critical trials and 12 intermeasure trials. Block 6 was formed of 48 critical trials. In the assessment version of the task (as provided in the control condition), the probe appears equally often behind the smoking-related picture and the neutral picture; attentional bias was calculated by subtracting the response times on the smoking-related pictures from the RTs on the neutral pictures. In the ABM training (as provided in the experimental condition), a contingency was introduced with the probe appearing behind the neutral picture in all critical trials, in $50 \%$ of the Block 1 trials (continued assessment) and in $50 \%$ of the inter-measure trials. This meant that the probe appeared behind the neutral picture in $91 \%$ of the trials over Block 2-6.

\section{Analyses}

Baseline differences were assessed using $\chi^{2}$-tests for categorical variables and $t$ tests for continuous variables. Attrition analysis was conducted by means of logistic regression analyses and included all factors described in the questionnaire section. To preserve power, only factors on which the respondents from the control group and the ABM training program significantly differed and the 
factors that significantly predicted drop-out were included as covariates in the effect analyses.

This study assessed close generalization using VP data, further generalization using SRC data and behavioral effects using the six month follow-up data. Five outcomes were central to this study: 1) the change in attentional bias from pre- to post-training, 2) attentional bias at post-training, 3) the change in approach bias from pre- to post-training, 4) approach bias at post-training, and 5) continued smoking abstinence after six months.

Attentional bias was calculated by using the VP data. Median RTs were calculated for each respondent when they identified the probe when it appeared behind the neutral picture as well as when it appeared behind the smokingrelated picture: this resulted in two median scores per respondent. Medians are often used in RTs research because they are less sensitive to outliers than means (see e.g., MacLeod, Rutherford, Campbell, Ebsworthy and Holker, 2002; Schoenmakers, Wiers, Jones, Bruce and Jansen, 2007). Pre- and post-training attentional bias was calculated by subtracting the median RTs for identifying the direction of the arrow when it appeared behind the smoking-related picture from the median RTs for identifying the direction when the arrow appeared behind the neutral picture. A positive score indicated a bias towards smokingrelated pictures, while a negative score indicated a bias towards neutral pictures. The change in bias from the pre- to post-training was calculated by subtracting the bias at the pre-training measurement from the bias at the posttraining measurement: a positive score represented an increase in bias, while a negative score represented a decrease.

Approach/avoidance biases were calculated using data from the SRC task and calculating the median RTs per respondent in approaching and avoiding smoking-related pictures: this resulted in two median RTs per respondent. Approach/avoidance bias on the pre- and post-training measurement was calculated by subtracting the median approach RTs from the median avoidance RTs: a positive score indicated a faster RT when approaching the smoking-related picture and thus an approach bias. The change from pre- to post-training was calculated by subtracting the bias at the pre-training from the bias at the posttraining: a positive score indicated an increase in bias and a negative score indicated a decrease in approach bias.

Paired sample t-tests were conducted to assess the pre-training biases and independent sample t-tests were conducted to assess the differences between the pre-and post-measurements. Linear regression analyses were conducted to assess the effects of the training with regard to attentional and approach/avoidance biases. As implicit cognitive biases tend to decrease after repeated measurements (see, for instance, Wiers, van de Luitgaarden, Van den Wildenberg and Smulders, 2005), we conducted the analyses on all respondents as well as on a sample excluding those who repeatedly filled out the pre- or post-training. Logistic regression analyses were conducted to assess behavioral 
effects after six months: complete case analyses as well as conservative analyses (including drop-outs as treatment failures) were conducted. The interaction term of condition (training or placebo) by consumption (being a regular smoker or not) was included in all analyses to assess the differential effects of the training for regular smokers and non-regular smokers. A significance level of $20 \%$ was used for interaction terms; all other hypotheses were tested at the twosided 5\% significance level.

\section{RESULTS}

\section{Sample characteristics}

The mean age of the respondents was 41 years $(S D=11.01)$ and $69 \%$ of the sample was female. On average, respondents consumed 18 (SD = 7.22) cigarettes per day, had smoked for 25 (SD = 11.12) years and had a FTND score of 4.45 (SD = 2.23). Furthermore, $92 \%$ had made previous attempts to quit. There were no statistically significant differences between the control group and the $\mathrm{ABM}$ training group with respect to these demographic and smoking-related variables. As the difference in FTND scores between the groups was of borderline significance, the variable was included as a covariate in the regression analyses presented below. Table 8.1 presents the demographic and smoking-related characteristics at the pre-training.

Table 8.1 Demographics and smoking-related characteristics per condition

\begin{tabular}{|c|c|c|c|c|c|}
\hline Characteristics & Overall $(\mathrm{N}=225)$ & Control $(\mathrm{N}=209)$ & $\mathrm{ABM}(\mathrm{N}=216)$ & $\mathrm{T}$-value/ $\mathrm{Chi}^{2}$ & $P$-value \\
\hline Gender & & & & & \\
\hline$\%$ Female & $68.9 \%$ & $69.9 \%$ & $68.1 \%$ & .16 & .75 \\
\hline Age & & & & & \\
\hline Mean age (SD) & $40.80(11.01)$ & $40.37(11.41)$ & $41.22(10.62)$ & -.80 & .43 \\
\hline $\begin{array}{l}\text { Educational level } \\
\text { \% low educated } \\
\% \text { medium educated } \\
\% \text { high educated }\end{array}$ & $\begin{array}{l}8.7 \% \\
52.9 \% \\
38.4 \%\end{array}$ & $\begin{array}{l}8.6 \% \\
54.1 \% \\
37.3 \%\end{array}$ & $\begin{array}{l}8.8 \% \\
51.9 \% \\
39.4 \%\end{array}$ & .22 & .90 \\
\hline $\begin{array}{r}\text { Cigarettes smoked per day } \\
\text { Mean consumption (SD) }\end{array}$ & $18.32(7.22)$ & $18.52(6.47)$ & $18.14(7.89)$ & .54 & .59 \\
\hline $\begin{array}{l}\text { Years one had been smoking } \\
\text { Mean number of years (SD) }\end{array}$ & 25.37 (11.12) & $24.78(11.54)$ & $25.95(10.68)$ & -1.09 & .28 \\
\hline $\begin{array}{l}\text { Previous quit-attempts } \\
\quad \% \text { Yes }\end{array}$ & $91.8 \%$ & $93.3 \%$ & $90.3 \%$ & 1.29 & .30 \\
\hline $\begin{array}{l}\text { FTND score } \\
\text { Mean level (SD) }\end{array}$ & $4.45(2.23)$ & $4.66(2.05)$ & $4.25(2.38)$ & 1.90 & .06 \\
\hline $\begin{array}{l}\text { Craving } \\
\quad \text { Mean level (SD) }\end{array}$ & $3.04(.69)$ & $3.07(.64)$ & $3.02(.73)$ & .66 & .51 \\
\hline
\end{tabular}




\section{Attrition check}

Drop-out rates were calculated separately for the SRC task, the VP task and the behavioral follow-up after six months. Drop-out rates were $51.2 \%$ in the control group versus $47.7 \%$ in the training group when using SRC data, 52.6\% versus $50.9 \%$ when using VP data and $72.2 \%$ versus $68.1 \%$ after six months. Differences in drop-out rates between the control group and the training group were non-significant $(P$-values $>.35)$. Attrition analyses using SRC and VP data showed that drop-out was related to low craving levels, lower education levels and being male. After six months, study drop-out was related to being younger, lower craving levels and being male.

\section{Attentional bias}

\section{Data preparation}

Data from six respondents $(0.38 \%$ of the data) were excluded because an error occurred during their sessions or because they closed the task; three of them tried again and those data were included. Twenty-nine respondents filled out the pre- or post-training measurement multiple times; the first measurement was included in the analyses while the data from the other measurements (4.6\%) was excluded. Data from error trials, identical trials following the error trial and trials with RTs under $200 \mathrm{~ms}$ and over $2000 \mathrm{~ms}$ were excluded from the analyses (6.6\% of the data). Univariate outliers in attentional bias scores were evaluated; one respondent was excluded for this reason (this respondent had a bias score of more than nine standard deviations lower than the respondents in the experimental group and would bias the results in favor of the training).

Attentional bias at pre- and post-training

At the pre-training, the sample of smokers $(\mathrm{N}=424)$ was shown to be significantly biased towards smoking-related cues ( $\mathrm{t}(423)=-2.03, P=.04)$ : differences in bias between the control and ABM training groups were non-significant $(\mathrm{t}(422)=.38, P=.71)$.

Bias differences between the control and the ABM training groups at the post-training were non-significant when including all respondents $(\mathrm{t}$ (182) = $1.12, P=.27$ ). Table 8.2 presents the RTs and attentional bias at the pre- and post-training for the control and ABM training groups. 
Table 8.2 Pre- and post-training attentional bias scores (in milliseconds) by condition

\begin{tabular}{cllll}
\hline & $\begin{array}{l}\text { Control } \\
\text { Median (SD) }\end{array}$ & $\begin{array}{l}\text { ABM training } \\
\text { Median (SD) }\end{array}$ & T-test & $P$-value \\
\hline $\begin{array}{l}\text { Pre-training } \\
\text { RT for smoking pictures }\end{array}$ & $681.83(120.02)$ & $676.00(103.93)$ & .54 & .59 \\
RT for neutral pictures & $685.72(123.99)$ & $678.68(102.93)$ & .64 & .53 \\
Attentional bias & $3.89(34.25)$ & $2.68(31.59)$ & .38 & .71 \\
& & & & \\
Post-training & & & & .29 \\
RT for smoking stimuli & $567.95(82.15)$ & $571.28(80.54)$ & .74 & .89 \\
RT for neutral stimuli & $574.53(90.10)$ & $572.86(80.28)$ & 1.12 & .27 \\
Attentional bias & $6.57(35.84)$ & $1.58(26.93)$ & & \\
\hline
\end{tabular}

Descriptive analyses for non-regular and regular smokers separately pointed out that the bias difference between the control and ABM training groups at post-training was non-significant for the group of non-regular smokers and of borderline significance ( $\mathrm{t}(109)=1.81, P=.07$ ) for the group of regular smokers, with a lower bias in the ABM training group.

Finally, the exclusion of the respondents who filled out the pre- or posttraining multiple times $(\mathrm{N}=29)$ resulted in a non-significant difference between the control group and the ABM-training group in the whole sample $(\mathrm{t}(166)=$ $1.40, P=.16)$, a non-significant differences in the sample of non-regular smokers only ( $\mathrm{t}(85)=-.03, P=.98)$ and a significant difference (thus a lower bias in the ABM-training group compared to the control group) in the sample of regular smokers $(\mathrm{t}(98)=2.04, P=.04)$.

Main and differential effects of the ABM training with correction for covariates The results from linear regression analysis (adjusting for the effects of gender, education level, FTND score and craving levels) indicated that compared to the control group, the training did not result in a significant decrease in attentional bias towards smoking-related pictures from pre- to post-training $(\mathrm{B}=.82, P=$ .89). The interaction term between condition and consumption added in the second step was also non-significant $(\mathrm{B}=6.22, P=.62)$, implying that the training had no differential effect on non-regular and regular smokers with regard to the decrease in bias from pre- to post-training. The effects remained nonsignificant when the respondents who filled out the pre- and post-training measurements multiple times $(\mathrm{N}=29)$ were excluded. Table 8.3 presents these effects. 
Table 8.3 Regression bias reduction on condition for the general sample ( $N=204)$ and the sample excluding respondents who revisited the pre- or post-training $(\mathrm{N}=187)$

\begin{tabular}{|c|c|c|c|c|c|c|c|}
\hline & & STEP & & & STEP & & \\
\hline & Variables & $\mathrm{B}$ & SE B & $P$ & $\mathrm{~B}$ & SE B & $P$ \\
\hline & Original sample & & & & & & \\
\hline \multirow[t]{5}{*}{ BLOCK 1} & Condition & .82 & 6.14 & .89 & -1.99 & 8.39 & .81 \\
\hline & Gender & 7.74 & 6.94 & .27 & 7.19 & 7.12 & .31 \\
\hline & Education level & -3.74 & 5.08 & .46 & -3.62 & 5.12 & .48 \\
\hline & FTND score & .10 & 1.50 & .95 & .16 & 1.68 & .93 \\
\hline & Craving & 4.58 & 4.71 & .33 & 4.67 & 4.77 & .33 \\
\hline \multirow[t]{3}{*}{ BLOCK 2} & Consumption & & & & -3.27 & 9.58 & .73 \\
\hline & Condition * Consumption & & & & 6.22 & 12.58 & .62 \\
\hline & Sample II* & & & & & & \\
\hline \multirow[t]{5}{*}{ BLOCK 1} & Condition & -2.05 & 6.49 & .75 & -6.23 & 8.95 & .49 \\
\hline & Gender & 6.10 & 7.36 & .41 & 5.45 & 7.59 & .47 \\
\hline & Education level & -3.19 & 5.38 & .55 & -3.08 & 5.43 & .57 \\
\hline & FTND score & .37 & 1.53 & .81 & .50 & 1.73 & .77 \\
\hline & Craving & 5.29 & 4.91 & .28 & 5.47 & 4.96 & .27 \\
\hline \multirow[t]{2}{*}{ BLOCK 2} & Consumption & & & & -4.13 & 10.13 & .68 \\
\hline & Condition * Consumption & & & & 9.01 & 13.24 & .50 \\
\hline
\end{tabular}

*Sample excluding respondents who filled out the pre- or post-training multiple times.

When analyzing the effects on post-training bias, the results again showed no main effect of the training $(B=-5.03 ; P=.26)$. However, the interaction term between consumption and condition included in the next step suggests that the training had a differential effect on regular and non-regular smokers: simple analyses found that the ABM training had a borderline significant effect on posttraining bias among regular smokers $(\mathrm{B}=-10.64 ; P=.08)$, and a non-significant effect on non-regular smokers $(B=1.67 ; P=.80)$. The latter suggests that in the group of regular smokers the bias after the training was significantly lower than the bias in the control group. The exclusion of respondents $(\mathrm{N}=29)$ who completed the pre- or post-training multiple times further strengthened this effect in the group of regular smokers $(B=-13.10, P=.046)$. Table 8.4 presents the regression on post-training bias. 
Table 8.4 Regression bias at the post-training measurement on condition for the general sample (N $=204)$ and the sample excluding respondents who revisited the pre- or post-training $(\mathrm{N}=187)$

\begin{tabular}{|c|c|c|c|c|c|c|c|}
\hline & & STEP 1 & & & STEP 2 & & \\
\hline & Variables & B & SE B & $P$ & $\mathrm{~B}$ & SE B & $P$ \\
\hline & Original sample & & & & & & \\
\hline \multirow[t]{6}{*}{ BLOCK 1} & Condition & -5.03 & 4.45 & .26 & -10.64 & 6.06 & .08 \\
\hline & Gender & 3.22 & 5.02 & .52 & 2.31 & 5.13 & .65 \\
\hline & Education level & -5.17 & 3.67 & .16 & -5.02 & 3.68 & .18 \\
\hline & Bias at pre-measurement & .04 & .07 & .62 & .03 & .07 & .67 \\
\hline & FTND score & .00 & 1.08 & 1.00 & .25 & 1.21 & .84 \\
\hline & Craving & 5.10 & 3.40 & .14 & 5.38 & 3.43 & .12 \\
\hline \multirow[t]{3}{*}{ BLOCK 2} & Consumption & & & & -4.99 & 6.89 & .47 \\
\hline & Condition $*$ Consumption & & & & 12.31 & 9.05 & .18 \\
\hline & Sample II* & & & & & & \\
\hline \multirow[t]{6}{*}{ BLOCK 1} & Condition & -6.76 & 4.76 & .16 & -13.10 & 6.53 & .046 \\
\hline & Gender & 2.47 & 5.38 & .65 & 1.73 & 5.52 & .76 \\
\hline & Education level & -5.45 & 3.93 & .17 & -5.39 & 3.95 & .17 \\
\hline & Bias at pre-measurement & .04 & .08 & .63 & .03 & .08 & .68 \\
\hline & FTND score & .09 & 1.12 & .94 & .43 & 1.26 & .73 \\
\hline & Craving & 4.97 & 3.59 & .17 & 5.34 & 3.61 & .14 \\
\hline \multirow[t]{2}{*}{ BLOCK 2} & Consumption & & & & -4.71 & 7.37 & .52 \\
\hline & Condition $*$ Consumption & & & & 13.65 & 9.63 & .16 \\
\hline
\end{tabular}

*Sample excluding respondents who filled out the pre- or post-training multiple times. Note that the main effect of condition in STEP 2 presents the effect for the variant when consumption is coded as zero (i.e., the regular smokers group).

\section{Approach bias}

\section{Data preparation}

Data about 16 respondents (1.3\% of the data) was excluded because an error occurred during their session or because they closed the task; 12 of them tried again (these data were included). Thirty respondents filled out the pre- or posttraining multiple times; the first measurement was included in the analyses while the data from the other measurements (4.7\%) were excluded. Data from error trials, identical trials following the error trial (10.3\%) and trials with RTs under $200 \mathrm{~ms}$ and over $2000 \mathrm{~ms}$ (8.0\%) were excluded from analyses. Univariate outliers in approach/avoidance bias scores were evaluated; one control group respondent was excluded for this reason (this respondent had a bias score of 4.5 SD's lower than the other respondents).

\section{Approach bias at the pre- and post-training and main effects of the ABM training}

At the pre-training measurement, the sample $(\mathrm{N}=424)$ showed a significant approach bias towards smoking-related cues $(\mathrm{t}(423)=6.25, P<.001)$. The re- 
sults from linear regression analysis (adjusting for the effects of gender, education level, FTND score, craving levels, and approach bias at baseline) indicated that the training did not result in a significant decrease in approach bias towards the smoking-related pictures group ( $\mathrm{B}=-.25, P=.99)$. The interaction term between the consumption of cigarettes and condition was also nonsignificant $(B=-66.13 ; P=.33)$, indicating that the training did not have a differential effect for regular and non-regular smokers in decreasing the bias from the pre- to post-measurement. The effects remained non-significant after excluding respondents who filled out the pre- and post-training multiple times.

The effect of the training on the post-training bias was also non-significant $(\mathrm{B}=-10.41 ; P=.65)$ and the non-significant interaction term indicated that the training did not have differential effects for regular and non-regular smokers ( $B$ $=-29.48 ; P=.53$ ). The effects remained non-significant after the exclusion of respondents who repeatedly filled out the pre- and post-training.

\section{Abstinence rates six months after the pre-training}

When including complete cases only, abstinence rates after six months were $29.3 \%$ in the control group versus $36.2 \%$ in the ABM training group. Logistic regression analysis (adjusting for the effects of age, gender, FTND score and craving levels) indicated that the training had a non-significant effect $(\mathrm{OR}=$ $1.62 ; P=.23$; $\mathrm{CI}=.74-3.55$ ) on abstinence. However, the interaction term between consumption and condition included in the second block was significant $(\mathrm{OR}=.18 ; P=.04 ; \mathrm{CI}=.04-.90)$, indicating that the training had a differential effect on regular and non-regular smokers. Simple analyses conducted to assess this differential effect showed that the ABM training was significantly more effective in fostering abstinence than the control group in regular smokers (OR $=3.46 ; \mathrm{P}=.03 ; \mathrm{CI}=1.15-10.38)$, but not in non-regular smokers. Abstinence rates for regular smokers were $22.6 \%$ in the control group versus $50.0 \%$ in the ABM group.

Conservative analysis in which all drop-outs were coded as relapses showed abstinence rates of $8.1 \%$ in the control group versus $11.6 \%$ in the ABM training group. Logistic regression analysis (adjusting for the effects of age, gender, FTND score and craving levels) indicated that the training had non-significant main effects with regards to continued abstinence after six months $(\mathrm{OR}=1.46$; $P$ $=.26$; $\mathrm{CI}=.76-2.81$ ). The interaction term between consumption and condition included in the second block again suggested a differential effect: simple analyses again demonstrated that the training was significantly better in fostering abstinence than the control group was for regular smokers $(\mathrm{OR}=2.68 ; P=.04$; $\mathrm{CI}=1.06-6.76$ ) but not for non-regular smokers. Abstinence rates for regular smokers were $5.9 \%$ in the control group and $14.9 \%$ in the ABM group. 


\section{DISCUSSION}

This study evaluated the effects of a Web-based multiple-session ABM training with regard to close generalization, further generalization and fostering continued smoking abstinence after six months. The study further tested whether the training had differential effects for regular and non-regular smokers. The results of this study only partly supported our expectations about the effects of a multiple-session ABM training on attentional and approach biases, but were promising with respect to the behavioral effects on continued smoking abstinence.

First, in line with other studies (for review see, Cox, Fadardi and Pothos, 2006), our results demonstrated a significant bias towards smoking-related pictures in our sample of smokers. Yet, in contrast to our expectations, the multiple-session ABM training did not result in a significant decrease of attentional bias compared to the control group; the training did, however, predict a lower bias score at post-training when compared to the control group. These results were only found in regular smokers and they were only significant after the exclusion of respondents who revisited the pre- or post-training. The latter may have been the result of learning effects caused by repeated participation in the pre- and post-training. This is referred to as task-specific learning and is common in CBM studies (Field et al., 2007). Task-specific learning usually happens because the implicit task on which the training was based was also used as postmeasurement; in general, the use of untrained stimuli is proposed to demonstrate whether cognitive biases have actually changed and to correct for learning effects (Field et al., 2007). However, although our program did include untrained stimuli to correct for the possibility of task-specific learning, some of our respondents repeatedly visited the pre- and post-training sessions, which may have biased their results in those measurement sessions.

The lack of significant effects in decreasing attentional bias can, furthermore, be due to the fact that the reliability of the dot probe task has still not been established in non-clinical samples (Schmukle, 2005). A study testing the reliability of the dot probe found that the task showed no internal consistency or one-week test-retest reliability and suggests that this may form the reason for the negative findings in studies using the task (Schmukle, 2005). It was, however, stated that this may not be applicable to studies with experimental designs (Schmukle, 2005) and that the test may be reliable for assessing between-subject differences (Staugaard, 2009). The latter may explain why the results did not show a significant decrease (from pre- to post-measurement) within the Train Yourself Smoke-free program, but did show that the ABM program resulted in a significantly lower bias (in regular smokers, when excluding those who repeatedly filled out the pre- or post-training) after the intervention when compared to the control group.

Another explanation may be the different design compared to other attentional retraining studies targeting smoking. Up until now, smoking-related ABM 
studies have only used a single-session of retraining and were not Web-based but conducted in a lab. One of these studies failed to find a significant decrease in attentional bias when compared to a control group (McHugh, Murray, Hearon, Calkins and Otto, 2010), while another study resulted in significant alterations in bias (Attwood, O'Sullivan, Leonards, Mackintosh and Munafo, 2008). The latter, however, compared the approach training to avoidance training instead of to a control group: this creates a large difference between the two conditions and increases the possibility of finding an effect. Furthermore, the study assessed the bias directly after the training session, while in our design the posttraining took place at least 18 hours after the start of the last training session.

Second, our study confirmed the literature (see ,for instance, Mogg, Bradley, Field and De Houwer, 2003; Watson, de Wit, Hommel and Wiers, 2012) by pointing out a significant approach bias among smokers at pre-training. The present study, however, found that the ABM training had no significant effect on modifying this approach bias. These findings suggest that ABM training does not generalize to other measures of implicit bias such as approach bias and that the inclusion of other training strategies such as approach-avoidance trainings may be needed to reach optimal effects with regard to smoking relapse prevention. In this context, it is also interesting to refer to a study that found no correlation between attentional bias and approach bias after placebo, but a strong correlation after two drinks (Schoenmakers, Wiers and Field, 2008); perhaps also in smoking, the two get synchronized only in a "hot" (craving) state.

Third, this study is the first to demonstrate the potential of a Web-based multiple-session ABM training for fostering continued smoking abstinence among regular smokers who made a quit-attempt. The effects remained significant after conducting conservative analyses in which drop-outs at follow-up were coded as treatment failures. These behavioral effects were non-significant for non-regular smokers. An explanation for the differential behavioral effects of the ABM training for regular and non-regular smokers may be that attentional bias is more evident in smokers who consume more cigarettes per day (Mogg and Bradley, 2002). The latter suggests that these smokers suffer more of the real-life consequences of being biased and thus reap more beneficial effects from ABM training.

The present study is subject to limitations. First, the study applied a wide range of inclusion and exclusion criteria. This may impede the generalizability of the results since a study that includes a wide range of respondents is thought to be more representative (Britton et al., 1998). Second, the respondents selfreported their smoking statuses. Previous studies have, however, suggested that the difference between self-reported results and verified results is sometimes negligible (Velicer, Prochaska, Rossi and Snow, 1992; Patrick et al., 1994). The SRNT (Society for Research on Nicotine and Tobacco) Subcommittee on Biochemical Verification, for instance, has stated that biological verification is not required in large-scale population-based studies with limited face-to-face contact 
and studies where the data is collected by mail, telephone or Internet (SRNT, 2002). Third, this study did not assess whether the respondents were aware of the condition to which they were assigned. A previous study (Schoenmakers et al., 2010) showed that, in general, respondents think they are assigned to a control group, which consequently may impede their motivation to participate. The latter may also be related to the high drop-out rates that also formed a limitation in the present study. Although high drop-out rates are common in Internet trials (Tate and Zabinski, 2004; Etter, 2005; Eysenbach, 2005; Te Poel, Bolman, Reubsaet and de Vries, 2009), drop-out can bias the results of analyses and therefore needs to be prevented. Further studies should aim at including strategies to prevent study drop-out.

Despite the limitations, this is, as far as we know, the first study to assess the effects of a Web-based multiple-session ABM training on continued smoking abstinence and to show positive behavioral effects on continued smoking abstinence. These findings are an important first step towards successful smoking relapse prevention since up until now, behavioral smoking relapse prevention programs have shown only modest effects (Hajek, Stead, West, Jarvis and Lancaster, 2009) while relapse rates are extremely high (Garvey and Bliss, 1992; Hughes et al., 1992; Zhu et al., 1996; Hughes, Keely and Niaura, 2003).

Several challenges for future research remain. Most importantly, future research should aim at disentangling the working mechanisms of ABM trainings in order to understand how the behavioral effects are reached and how the training can be improved, especially since the findings from this study only partly supported our expectations about effects of the training on the attentional and approach biases to which smokers are subject. Moreover, understanding the surplus value of the ABM training in fostering continued smoking abstinence compared to smoking relapse prevention programs utilizing explicit behavioral strategies to prevent relapse is important in order to gain insight into the best method for targeting smoking relapse.

\section{Acknowledgements}

This study was funded by the Dutch Organization for Health Research and Innovation (grant number 6130-0030). We would like to thank Thomas Pronk and Wouter Boendermaker for their valuable contributions to the development and piloting of the Train Yourself Smoke-free program materials. We would also like to thank Stivoro for their help in recruiting respondents, as well as the respondents for their participation in the study. 

CHAPTER 9

General discussion 


\section{ABSTRACT}

This final chapter discusses the findings on smoking relapse prevention as derived from the results of the studies presented in the previous chapters. The main aim was to develop and test the smoking relapse prevention programs SQ4U (which targeted explicit cognitions) and Train Yourself Smoke-free (which targeted implicit cognitions) in order to improve the current practice of smoking relapse prevention. This chapter will start with the current findings and recommendations for future directions. Next, the strengths of the studies conducted and the challenges to meet in the future will be discussed. The chapter will end with general conclusions. The discussion of the mentioned sections will be based on the two themes as outlined in the introduction (prediction and prevention) and the following seven research questions:

\section{Predicting smoking relapse}

$\rightarrow$ In the opinion of researchers and coaches working in the area of smoking cessation and relapse prevention, what are the factors that predict and prevent smoking relapse?

○ Do post-motivational factors predict smoking relapse among smokers who are highly motivated to quit smoking?

\section{Preventing smoking relapse}

$\rightarrow$ Can a computer-tailored program combined with multiple action planning assignments prevent smoking relapse?

$\Rightarrow$ What is the role of making instrumental and specific plans in the process of smoking relapse prevention?

○ Can an attentional bias modification program reduce smoking-related attentional bias?

$\rightarrow$ Can an attentional bias modification program also influence another implicit cognitive bias (i.e., approach bias)?

- Can an attentional bias modification program prevent smoking relapse? 


\section{CURRENT FINDINGS \& FUTURE DIRECTIONS}

\section{PREDICTING SMOKING RELAPSE}

The purpose of the studies concerning the prediction of smoking relapse was: 1 . to study the opinions of researchers (investigating smoking cessation processes and interventions) and coaches (who provide smoking cessation courses and thusly guide smokers in practice) on factors that predict and prevent smoking relapse and 2 . to assess the relation between post-motivational factors and smoking relapse among smokers who are motivated to quit smoking.

\section{Current findings}

The findings from the Delphi-study (chapter 2) demonstrated much congruence and few differences in opinions of researchers and coaches on the topic of smoking relapse prevention.

Both researchers and coaches suggested associations between relapse and smoking related factors (i.e., the number of years one has been smoking, craving, addiction level, the number of quit-attempts), negative emotional states, personality, high stress levels, depression, psychosocial problems, having other smokers in one's environment, low levels of self-efficacy, having positive outcome expectancies of smoking, lack of motivation to quit smoking and not having adequate coping strategies. With regard to prevention programs researchers as well as coaches perceived training in coping and other skills, the development of emergency plans, the identification of risk-situations and recognition of earlyrelapse warning signs as strategies that need to be incorporated in smoking relapse prevention programs. Moreover, the expert opinions underlined the potential importance of less studied concepts such as action planning components and implicit cognitions for smoking relapse prevention.

Researchers and coaches also differed in opinions regarding some factors. Researchers associated relapse with being younger and not using pharmacological aids respectively: coaches did not. Coaches, however, did emphasize the role of pharmacological therapy in prevention programs. Coaches also emphasized the importance of intensive support, while in the researchers' panel no consensus was researched about the need to provide intensive support to quitters.

Finally, the results of the quasi-experimental longitudinal study among smokers (chapter 3) confirmed the importance of post-motivational factors in the process of smoking relapse by indicating that self-efficacy was a consistent predictor of relapse, and that preparatory planning was also related to relapse (but only for group-quitters). 


\section{Recommendations for future directions (research \& practice)}

Based on the findings from the Delphi-study (chapter 2) and the quasiexperimental longitudinal study (chapter 3), recommendations concern the transition from theory to practice and promising strategies that need further testing with regard to smoking relapse prevention.

\section{The transition from research to practice}

The Delphi-study demonstrated large similarities between the opinions of researchers and coaches respectively. Nevertheless, the study revealed notable differences concerning the importance of intensive support and pharmacological aids in prevention programs as well as with regard to the association between relapse and being younger and not using pharmacological aids. This discrepancy may imply that these factors are not yet fully understood and that more research on their importance for relapse prevention is needed. It may also indicate that the transfer form theory to practice and vice versa is not yet optimal. The transition from theory to practice is a recurrent problem over all fields (Stephan, 2006; Belli, 2010), including the area of substance use (MarinelliCasey, Domier and Rawson, 2002). Experts from the research field and those from the practice field are posed to differ from each other in culture, background and expertise (Marinelli-Casey, Domier and Rawson, 2002; Stephan, 2006). Researchers are assumed to be cognitively-oriented and to value theory, research and objectivity (Stephan, 2006). Experts from the practice field, on the other hand, are assumed to be action-oriented and comfortable with subjectivity (Stephan, 2006). Based on these differences it can be stated that experimental evidence forms the base of the researchers' opinions, while coaches tend to depend on sound judgment derived from experience rather than scientific evidence.

In the case of providing intensive support, for instance, one can assume that coaches' opinions were based on the positive feedback that coaches may receive from clients who get intensive support, while researchers may be led by literature pointing out that intensive support is not always successful (Lancaster and Stead, 2005). A similar conclusion can be drawn concerning the influence of using pharmacological aids: researchers may be driven by research underlining the substantial potential of pharmacological aids in fostering smoking cessation (for review on the use of pharmacological therapy for smoking cessation, see; Stead, Perera, Bullen, Mant and Lancaster, 2008), while this evidence for the importance of using pharmacological aids may not be clear in practice. A possible explanation for the latter is that most research on the success of pharmacological aids has been done in samples with mainly males (Feigenbaum, 2010), while coaches are mostly confronted with women as they are more likely to participate in cessation courses (Zhu, Melcer, Sun, Rosbrook and Pierce, 2000; NHS, 2012). Among women pharmacological aids have proven to be less suc- 
cessful (see e.g., Feigenbaum, 2010), which may on its turn explain the coaches' opinion concerning the lack of an association between relapse prevention and the use of pharmacological aids.

Collaboration between experts from the research field and those from the practice field may be hindered by these different perspectives of the two communalities (Stephan, 2006). It is, therefore, recommended to gain more insight into the transition process from theory to practice (and vice versa) in the smoking cessation and relapse prevention domain. This insight is needed in order to narrow the gap between the two communalities and to foster collaborations, because even though the Delphi-study revealed the opinions of experts working in the research field as well as those working in practice, the study did not address these transitions from theory to practice and vice versa. Furthermore, we recommend involving coaches more directly in the research process and vice versa as this may contribute to steps forward towards the development as well as the dissemination, adoption and implementation of successful smoking relapse prevention programs.

\section{Promising strategies for successful smoking relapse prevention}

In addition to the recommendation for further understanding of the transition from theory to practice, the following recommendations relate to potential promising relapse prevention strategies (derived from the findings of the Delphi-study and the longitudinal quasi-experimental study).

First, the results from the Delphi-study as well as the literature underline the importance of pharmacological therapy. Therefore, it is recommended that smoking relapse prevention programs at least motivate respondents to use pharmacological aids. These programs should specifically explain how the aids should be used, because lack of this knowledge has shown to be an important reason for non-compliance to pharmacological aids (Shiffman, 2007).

Second, researchers and coaches perceived training in coping and other skills, the development of emergency plans and the identification of risksituations to be successful strategies to prevent relapse. On the other hand, a review on the effects of relapse prevention programs states that these strategies have only limited effects and recommends the use of combined strategies and new approaches (Hajek, Stead, West, Jarvis and Lancaster, 2009). The Delphistudy itself already explicitly assessed opinions on new relatively less studies factors that can be utilized for smoking relapse prevention (i.e. action planning components and implicit cognitions) and researchers as well as coaches agreed on their importance in the process of smoking relapse prevention. In relation to this, the findings from the quasi-experimental study among smokers (presented in chapter 3) suggest that preparatory planning needs to be combined with actual practice. With regard to action planning components, previous studies conducted have already taken initial steps in indicating the importance of action planning strategies with regard to smoking cessation (Te Poel, Bolman, 
Reubsaet and de Vries, 2009) and abstinence (Hoving, Mudde and de Vries, 2006; van Osch, Lechner, Reubsaet, Wigger and de Vries, 2008). Following all these findings (the experts' opinions, the results of the quasi-experimental study and the review on smoking relapse prevention programs), it can be recommended to combine different planning components altogether in one program. First steps into meeting this recommendation have already been set in the SQ4U study as this study tested two programs that incorporated coping plans together with other action planning approaches (i.e. preparatory planning strategies) and computer-tailored strategies. The effect and implications of the program is further discussed in the next section of this chapter.

Concerning implicit cognitions studies in the field of addictive behaviors have demonstrated that implicit tendencies predict a unique variance in behavior even after controlling for explicit tendencies, and suggest that explicit and implicit tendencies predict behavior independently (Stacy, 1997; Wiers et al., 2002; Strack and Deutsch, 2004). Although the researchers' panel as well as the coaches' panel reached a consensus on the importance of implicit cognitions, a substantial high percentage of the experts answered the questions with 'I don't know'. This may either imply that the working mechanisms of implicit cognitions on relapse are not fully understood or that the experts did not know precisely what was meant by the concept and possibilities to influence it. Further research on the importance of implicit cognitions in the process of smoking relapse prevention is, therefore, needed to foster further understanding of implicit cognitions in the process of relapse prevention. First steps to testing this approach were taken in this dissertation by testing the effects of an attentional bias modification training (ABM) program called Train Yourself Smoke-free. The results and implications will be discussed in the next section of this chapter.

A final recommendation for prevention programs - that can be given based on the findings of the Delphi-study - relates to the factors that were associated with smoking relapse (by the expert groups). These findings are in line with theoretical assumptions of the Relapse Prevention Model of Marlatt and Gordon (Marlatt and Gordon, 1985; Marlatt and Donovan, 2005) in terms of the importance of negative emotional states, self-efficacy, urges and overall stress levels. Likewise, the opinions of the researchers and coaches fit the findings from empirical studies with regard to associations between relapse and wellstudied factors such as being younger, smoking for many years, having a high addiction level, previous quit attempts, lack of motivation to quit and lack of adequate coping strategies (Dijkstra and Borland, 2003; Kassel, Stroud and Paronis, 2003; Amodei and Lamb, 2005; Brown, Lejuez, Kahler, Strong and Zvolensky, 2005; O'Connell, Hosein and Schwartz, 2007; Shaw and al'Absi, 2008). The recurrent importance of these factors implies that smoking relapse prevention programs should at least target these factors. The fact that most current smoking relapse prevention programs have only modest effects (Hajek, Stead, West, Jarvis and Lancaster, 2009) may imply that these factors are not all 
addressed in current prevention programs or that they have been addressed but not with the appropriate behavior change techniques. In general, a clear description of the program content is often missing (Michie, Fixsen, Grimshaw and Eccles, 2009), and this also applies to computer-tailored programs (Noar, Benac and Harris, 2007). The necessity for categorizing intervention elements can, however, be derived from reviews of behavioral interventions (Webb and Sheeran, 2006), and it is therefore recommended to document more precisely which factors in a relapse prevention programs are addressed and how. This makes it possible to gain insight into the working mechanisms of an intervention, which elements may be lacking in a program and which steps may be needed to improve a program.

\section{PREVENTING SMOKING RELAPSE}

\section{Current findings}

Overall, this dissertation has pointed out that tailored strategies as utilized in the SQ4U study (chapter 4, 5, 6 and 7) as well as an attentional bias modification (ABM) training as used in the Train Yourself Smoke-free study (chapter 8) may form promising tools for smoking relapse prevention (measured by continued abstinence rates).

Interpretation of the SQ4U-results should, however, occur in the light of the sample and analytic strategy (observed case or conservative analyses) used to analyze the data. Long-term results were analyzed using a standard intentionto-treat ${ }^{6}$ approach and a modified approach in which respondents were excluded after randomization (chapter 5). These two approaches resulted in three samples: (1) the sample as randomized including all respondents; (2) a sample excluding those who did not make a quit-attempt (modified sample); and (3) a sample additionally excluding those who did not adhere to at least one of the intervention elements (minimum dose sample). These samples were analyzed according to the observed case procedure and the conservative analyses procedure in which drop-outs at follow-up were coded as relapsers (thus the term 'intention-to-treat' refers to the inclusion of all respondents as randomized, but not per se to the conservative analyses since also observed case analyses were conducted for the 'intention-to-treat' approach). In these three samples (observed cases only) the AP program (in which respondents received tailored feedback at baseline and six planning assignments) was consistently significant-

\footnotetext{
${ }^{6}$ In this dissertation the term 'intention-to-treat' refers to the inclusion of all respondents as randomized, but not per se to the conservative analyses (considering dropouts as relapsers) since also complete case analyses were conducted for the 'intention-to-treat' approach.
} 
ly more effective in fostering continued abstinence compared to the control group. The AP+ program (extended AP program) only resulted in significant results in the sample as randomized (sample 1). Short-term effects (six months after baseline) of the programs were assessed using a modified strategy only (sample 2 analyses, excluding those who did not make a quit-attempt during the study) and revealed that the AP nor the AP+ program outperformed the control group in fostering short-term abstinence (chapter 6). Conservative analyses on both short as well as longer-term data lacked finding significant program effects, except in the sample excluding respondents who did not adhere to at least one of the intervention elements (sample 3, longer-term data). Moreover, short as well as longer-term data suggested that effects were dependent on adherence to the programs. Furthermore, in-depth analyses pointed out that making specific plans fostered abstinence and that respondents found it more difficult to make implementation intentions for emotional situations compared to situational situations (chapter 7).

The results of the Train Yourself Smoke-free study showed that smokers were biased towards smoking related pictures by indicating that they had significantly more attention for smoking-related pictures and were significantly faster at approaching smoking-related pictures instead of avoiding them. The ABM training, however, did not significantly decrease this bias compared to the control group, but it was associated with a lower bias after participation to the training. More promising was the effect of the training on continued abstinence after six months: the ABM training was compared to the control group significantly more effective in fostering continued abstinence among regular smokers, even when conducting conservative analyses in which drop-outs at follow-up were coded as smokers (chapter 8).

\section{Recommendations for future directions (research \& practice)}

\section{The SQ4U program}

Our analyses on short and longer-term data do not yield unambiguous conclusions with regard to the efficacy of the SQ4U programs. The positive findings were merely related to observed case analyses on longer-term data (continued abstinence after twelve months) and not to analyses on short-term data (continued abstinence after six months) or conservative analyses. It should, however, be noted that the longer-term conservative analysis conducted on sample 3 (the sample excluding respondents who did not adhere to at least one of the intervention elements) did support the efficacy of the programs. These findings and the findings from the longer-term observed case analyses in all three samples yield us to conclude that especially the AP-program can be effective, in particular among those who adhere to the program. Yet, high study drop-out rates may have biased the results obtained from observed case as well as from con- 
servative analyses. Hence, improvements and more research on the effects and program adherence are needed.

Subsequently, recommendations in this section concern the need for more insight into the current short- and longer-term results of the SQ4U programs as well as the improvement of the SQ4U programs.

\section{More insight into the current short and longer-term effects of the SQ4U programs}

The matter of the lacking short-term effects can be partly explained by results from other computer-tailored programs. While an older smoking cessation computer-tailored program did manage to reach beneficial effects after six months (Te Poel, Bolman, Reubsaet and de Vries, 2009), a more recent study on the effects of a computer-tailored program called PAS (Personal Advice for Smoking cessation) - in line with the SQ4U-results - lacked finding substantial effects after six months (Smit, de Vries and Hoving, 2012). In the SQ4U and PASprograms respondents (also the respondents in the control condition) needed to select a quit-date as part of the program and also as a prerequisite in the study: this was not needed in the program developed by Te Poel et al (2009).

The selection of a quit-date is a preparatory plan that on its own has the strength to influence smoking for instance by means of an increase of motivation due to the explicit commitment made or because specifying and concretizing intentions fosters enactment (see, for instance, Hallaq, 1976; Gollwitzer and Sheeran, 2006; Balmford and Borland, 2008). This strategy may have contributed to the non-substantial difference in abstinence rates (after six months) between the control group and the experimental conditions in the PAS and the SQ4U study. It should be noted, however, that the PAS-study demonstrated significant effects after six weeks and that the PAS-study as well as the study by te Poel (2009) used other behavioral outcomes than the SQ4U study (namely point prevalence and prolonged abstinence instead of continued abstinence).

Besides setting a quit-date as part of the program, respondents in the control group of the SQ4U study may have sought additional help (as they were highly motivated to quit smoking) when they did not receive the help they expected from the SQ4U programs. Yet, setting a quit-date and the possible sought additional help does not seem adequate for maintaining abstinence on longerterm; the SQ4U data showed a decrease in relative and absolute abstinence from six to twelve months in the control group. Based on these findings, it is recommended for future studies - in which control group respondents will probably seek additional help - to assess in detail the strategies used in both conditions to analyze more thoroughly which strategies were used and which strategies may impact on the behavioral outcomes.

In relation to the above, the SQ4U data pointed out that abstinence rates (in the experimental conditions using observed cases) were higher after twelve months than after six months. This is remarkable, as often a decrease of abstinence over time is reported. Yet, our results can be explained by inspecting the 
absolute number (reported in chapter 5 and 6 ) of respondents at both measurements. The data show a small decrease (from six to twelve months) of the absolute number of abstinent respondents and a larger decrease of the total number of respondents per condition: this resulted in a higher relative number of abstinent respondents after twelve months. Based on this it can be assumed that those who dropped-out from six to twelve months are likely to be those who were smokers at the six months measurement and consequently, that a conservative analysis in which drop-outs are coded as relapsers would be a reliable approach for analyzing the results. On the other hand, it should be noted that respondents who completed the twelve months follow-up measurement were not all respondents who also completed the measurement after six months, and that data have indicated that about $60 \%$ of those who dropped-out were non-smokers at their last participation in the intervention elements. The latter suggests that coding all absents as treatment failure would be too conservative; this is a finding that is supported by others (Hollis and Campbell, 1999; Lachin, 1999). Consequently, efforts should be made to bring forth adequate ways to identify the smoking status of respondents who dropped-out from the study (their follow-up data are missing) in order to analyze results correctly and to draw adequate conclusions on program effects. It is therefore highly recommended to conduct further research on how to obtain information about the smoking status of drop-outs since not knowing the status makes the interpretation of the results a very complicated puzzle (because dealing with drop-out was also relevant for the other studies presented in this dissertation, it is discussed in more detail under the section 'challenges to meet in the future').

\section{Improving the SQ4U programs}

Further recommendations for research also concern the potential improvement of the SQ4U programs and are formed by themes that need additional testing in order to facilitate the actual implementation of the SQ4U programs in practice. The SQ4U-results support the findings from previous research on the potential beneficial effects of computer-tailored approaches in the area of smoking cessation and relapse prevention (Dijkstra, De Vries and Roijackers, 1998; Borland, Balmford and Hunt, 2004; Te Poel, Bolman, Reubsaet and de Vries, 2009; Smit, de Vries and Hoving, 2012). Additionally, the SQ4U study puts action planning components on the map as essential elements that need to be incorporated in smoking relapse prevention programs for smokers who are highly motivated to quit smoking. These promising findings, however, also raised new questions for which we will provide recommendations for future directions.

A first recommendation is to gain insight into the functional relationship between the SQ4U program elements and the outcomes. Although our experimental approach made it possible to gain insight into the main effects, the programs were complex and consisted of multiple strategies provided in the form of computer-tailored advice and in open-ended interactive assignments that 
were on their turn based on different action planning components (preparatory planning and coping planning). Consequently, a detailed analysis concerning the actual active ingredients of the program was not possible. Yet, unraveling the active ingredients is necessary for designing more effective interventions and applying them properly (Michi and Abraham, 2004). This is essential because successful implementation in practice is dependent on the level of understanding of the effective key components of an intervention (Bauman, Stein and Ireys, 1991; Winter and Szulanski, 2001) and future initiatives that aim to gain insight into the working mechanisms of each of the SQ4U components are thus highly recommended.

Second, but in relation to the previous recommendation, it should be noted that a small first step to identify the working mechanisms of the planning assignments in the SQ4U program was made in this dissertation. In-depth analyses (presented in chapter 7) pointed out that forming specific implementation intentions when making coping plans in order to deal with risky situations was highly associated with short- and longer-term abstinence. Moreover, specificity of implementation intentions made by the respondents to cope with affective risk situations was significantly lower compared to the specificity of implementation intentions made to deal with situational risk situations. This finding can possibly be attributed to the fact that affective states (such as stress, depressive feelings, moods) are determined by multiple factors such as chemical brain imbalances, the use of medicine, life events, social demographic factors, personality traits, diseases and work and family influences (Mroczek and Kolarz, 1998; Flaa, Ekeberg, Kjeldsen and Rostrup, 2007; Gruenewald, Mroczek, Ryff and Singer, 2008; OSUMC, 2012), which may make it difficult to form specific plans. Based on these findings it can be recommended to stress the importance of specifying plans when participating to the SQ4U programs and in relapse prevention programs in general. Moreover, strategies in order to help respondents deal with affective situations and to form specific plans for these situations need to be identified in future studies. Still, it should be noted that although the results from these in-depth analyses can serve as an indication for the importance of specificity and the difficulties when dealing with emotional situations, the design of the study (respondents were participants in two different experimental conditions of a larger randomized controlled trial) and the sort of assignment (the list of situations and the number that could be chosen was predefined) make it difficult to draw firm conclusions. Consequently, studies testing the efficacy of plan specificity and the difficulties with regard to affective situations are therefore still required.

The third recommendation is based on the results of the extended SQ4U program $(\mathrm{AP}+)$ in which respondents received tailored feedback after their quitdate in addition to the six action planning assignments. At first sight, the results provide limited support for the surplus value of extending the combination of computer-tailoring and multiple planning assignments with tailored feedback 
after the quit attempt. Substantial effects of the AP+ program (compared to the control group) were only found in the sample as randomized (sample 1), after twelve months. Neither short-term effects nor longer-term effects from the modified samples - in which respondents who did not make a quit-attempt or those who did not adhere to at least one intervention element were excluded were found. Reasons for this lack of effects may be that modified intention-totreat approaches are subject to biases (Abraha and Montedori, 2010). Such a bias may have been created against the AP+ program, since applying a modified approach with post-randomization exclusions resulted in the exclusion of more relapsers in the control condition compared to the AP+ program (as the latter consisted of elements to foster making a quit-attempt). Findings from the intention-to-treat strategy (on observed cases) conducted after twelve months (sample 1 analyses) further support this suggestion by revealing significant effects of the AP+ program when respondents without a quit-attempt were not excluded from the analysis (while both modified approaches (sample 2 and sample 3 resulted in non-significant effects)). Other explanations that need to be considered in explaining the lack of effects of the AP+ program are that the program is too intensive or that the combination of planning assignments are not an ideal combination after all. Earlier studies have already pointed out that combined strategies can cause an overload for the respondents and negatively influence their participation (Ausems, Mesters, van Breukelen and De Vries, 2004). Furthermore, the results obtained from the six months follow-up data partly support the suggestion that planning assignments and feedback after the quitattempt are not an ideal combination: the effects of the planning assignments in the AP+ program disappeared when the feedback moments were included in the analyses. This suggests that only one of the intervention strategies (assignments or feedback moments) can be enough to foster abstinence. The sole effects of providing feedback moments after the quit-attempt were, however, not tested in our study. Additional testing on this is needed. Furthermore, the SQ4U programs provided support at fixed time points, while the varying levels of adherence found in our study suggest that programs should perhaps provide support when respondents may need it most (i.e., real-time support in difficult situations). Ecological momentary interventions are such real-time treatments as they are provided in one's everyday life and can be implemented effectively as interventions for a variety of health behaviors (Heron and Smyth, 2010). Additional research on the surplus value of imbedding these ecological momentary intervention strategies in a smoking relapse prevent program such as SQ4U is needed, especially since the support for the effect of providing tailored feedback after the quit-attempt (in the AP+ program) remained limited.

In the end, it is recommended to determine the optimal dose for the SQ4U programs. The short- as well as the longer-term results suggest that the effect of the programs depends on adherence to the program elements: such doseresponse associations are common in Internet-interventions (see, for instance, 
Eysenbach, 2002; Borland, Balmford and Hunt, 2004; Cobb, Graham, Bock, Papandonatos and Abrams, 2005; An et al., 2006; Japuntich et al., 2006). However, since the effect of dosages in the SQ4U study were not experimentally tested, selection biases may underlie the relationships found (McGowan, Nix, Murphy and Bierman, 2010). Caution is, therefore, needed when interpreting the relations found. Some of the effects found in this study can for instance be attributed to motivation or to the fact that respondents who relapsed after a few sessions discontinued the program. The latter means that those who continued with the program were the successful ones. Although we managed to conduct additional analyses to identify the smoking status of the respondents at their last visit - showing that about $60 \%$ were non-smokers - our data make it impossible to assess whether they relapsed afterwards and decided to discontinue the program. Additional research is recommended to test the assumption of a doseresponse relationship in this context and identify the optimum dose using an experimental design in which respondents are randomized into groups with different dosages. In connection with the previous, it is essential for actual implementation and adoption of the SQ4U programs to gain more insight into the factors that determine adherence to the program by smokers, into strategies on how to foster adherence and into what is needed in order to disseminate and adopt the program in practice (these recommendations form challenges for the future and also account for other studies presented in this dissertation; they will be further discussed in the section 'challenges to meet in the future').

\section{Train Yourself Smoke-free program}

In line with other studies (see e.g., Mogg, Bradley, Field and De Houwer, 2003; Waters, Shiffman, Bradley and Mogg, 2003), for review attentional bias see, Cox, Fadardi and Pothos, 2006 and for review approach bias see, Watson, de Wit, Hommel and Wiers, 2012) results from the Train Yourself Smoke-free study confirmed that smokers are biased towards smoking related stimuli. The ABMtraining that was provided in the Train Yourself Smoke-free study, however, had only modest effects with regard to modifying attentional bias and no effect on approach bias. Moreover, the results showed no behavioral effects of the ABMtraining when including all smokers, but did show differential effects of the training for regular and non-regular smokers: simple analyses indicated that the training significantly fostered abstinence among regular smokers. Although the latter behavioral effects are encouraging for taking next steps into Web-based prevention using ABM-strategies, the program needs to be improved.

\section{Improving the Train Yourself Smoke-free program}

The limited reliability (especially in non-clinical trials) of the dot probe task (Schmukle, 2005; Ataya et al., 2012) and task-specific learning effects (Field et al., 2007) formed important limitations for the Train Yourself Smoke-free study. These limitations may underlie the lack of a significant decrease in attentional 
bias (from pre to post-measurement in the ABM-training group) and the finding that the effect of the ABM-training on the post-training bias was only significant when respondents who filled out the pre- and post-training repeatedly were excluded from the analyses. The latter finding supports the assumption that the results were subject to learning effects. Future studies should target the low internal reliability of the dot probe task, develop and test alternative measures of attentional bias and rule out task-specific learning effects in order to limit biases.

The findings with regard to further generalization effects of the ABMtraining showed that the attentional bias modification training did not result in any significant effects on approach bias. A recent review on cognitive bias modification strategies in addiction concluded that the question on further generalization effects of implicit re-training tasks is central to current cognitive bias modification research and that further insight into whether a specific training can influence different implicit cognitive biases or each bias needs to be targeted separately is required (Wiers, Gladwin, Hofmann, Salemink and Ridderinkhof, in press). More research on this topic is thus recommended and should for instance assess whether the inclusion of separate approach bias modification strategies is effective for targeting approach bias in smokers and into whether these effects generalize to other biases (since attentional bias modification strategies did not show generalized effects with regard to approach bias). Alternatively, the measurement instrument used (the SRC) could be less sensitive to changes than another measure of approach-bias, the irrelevant feature approach avoidance test (cf. (Cousijn, Goudriaan and Wiers, 2011)). Further testing of this assumption is required.

Another topic that is worth investigation is whether implicit cognitive bias modification strategies (such as the ABM-training provided in the Train Yourself Smoke-free study) can be imbedded in a tailored format. Tailored formats for targeting explicit cognitions have shown their potential for fostering healthrelated behaviors (Brug, Kok, van Breukelen, Glanz and van Assema, 1998; Dijkstra, De Vries and Roijackers, 1998; Etter, 2005; Oenema, Tan and Brug, 2005; Strecher, Shiffman and West, 2005; Kroeze, Werkman and Brug, 2006; Noar, Benac and Harris, 2007; Shahab and McEwen, 2009). Following these findings with regard to explicit cognitions, it may be interesting to select respondents for a specific type of cognitive bias modification training. The earlier mentioned review on cognitive bias modification suggests that tailoring should be based on the bias strength at pre-test as trainings may be more effective for respondents with a stronger bias (Wiers, Gladwin, Hofmann, Salemink and Ridderinkhof, in press). But, for providing a tailored training it is essential that the variable that will be used for matching the training can be measured in a reliable way (Wiers, Gladwin, Hofmann, Salemink and Ridderinkhof, in press). The reliability of the dot probe that is commonly used for measuring attentional bias, however, is not yet optimal and can hinder the tailoring process. For future 
research it is, therefore, recommended to improve the assessment tools and to assess how cognitive bias modification strategies such as an ABM-training can be tailored towards the needs of an individual.

The ABM-training as provided in the Train Yourself Smoke-free study showed significant effects with regard to smoking relapse prevention on the short-term (after six months) for regular: the significance of the effects remained when conducting conservative analyses in which all drop-outs were coded as relapsers. Based on these findings it can be concluded that ABMstrategies have the potential to help smokers to remain smoke-free after a quitattempt and that prevention programs targeting smoking relapse should include such strategies. However, as explained earlier it is necessary to unravel the active ingredients of an intervention for designing more effective interventions and applying them properly (Michi and Abraham, 2004). Therefore, more research on the working mechanisms of the ABM-training is required. Furthermore, it should be noted that the Train Yourself Smoke-free program did not provide the ABM-training until after the quit-attempt and that many of the smokers who intended to make a quit-attempt eventually did not act on their intention (or did not return to confirm their attempt). The effects of starting the ABM-training before the quit-attempt are worth further investigation as such an approach may result in more smokers who make a quit-attempt.

Finally, future research on cognitive bias modification strategies should focus on facilitating acceptance of such approaches. A recent qualitative study on the attitudes towards cognitive bias modification strategies showed that the respondents did not understand how such a training can help them change their behavior (Beard, Weisberg and Primack, 2011): such attitudes may impede with the credibility of the training and hinder implementation in practice. Targeting these elements in future approaches is therefore recommended.

\section{Combining explicit and implicit prevention strategies}

Findings from the SQ4U study and the Train Yourself Smoke-free study raise questions with regard to the potential of combining these two strategies. However, in order to reach a combined strategy intervention there is still much research needed about how and when to use which strategy. For instance: should one start with an implicit cognition approach followed by an explicit cognition approach or vice versa? Furthermore, it can be suggested that implicit tendencies may be underlying explicit post-motivational factors. Bandura (Bandura, 1986; Bandura, 1997; Bandura, 1998) for instance claims in his social cognitive theory that persons with high self-efficacy are willing to master difficult tasks instead of avoiding them. Likewise, persons with low levels of self-efficacy are suggested to avoid difficult situations whenever possible. This approachavoidance bias can be measured using implicit approach-avoidance tasks in order to assess whether there are implicit tendencies underlying the explicit construct of self-efficacy. With regard to preparatory planning (even high inten- 
tions to engage in planning), studies demonstrated that planning does not necessarily lead to plan enactment (Gollwitzer and Sheeran, 2006). Two selfregulatory problems are pointed out as explanations for not translating preparatory plans into action plans: 1 . failing to get started, 2 . getting derailed along the way. One of the explanations given by Gollwitzer (2006) for getting derailed along the way is spontaneously attending to distracting stimuli. Attention for distracting stimuli can be measured implicitly in order to assess whether attentional biases may influence carrying out intended plans. We, therefore, currently started a new project to assess whether explicit cognitions such as self-efficacy and action planning are subject to implicit tendencies.

The findings derived from the studies presented in this dissertation also raise questions with regard to which of the strategies tested works best and for whom. Randomized controlled trails testing the explicit cognition approach used in the SQ4U programs against the implicit cognition approach used in the Train Yourself Smoke-free program are recommended for the future. Furthermore, both approaches may need further testing in other groups of smokers such as smokers who are not motivated to quit smoking. Smokers who are not motivated to quit smoking may be less receptive of persuasion because they avoid reading, talking and/or thinking about their risk-behavior (Prochaska, 2008): an interesting hypothesis to be tested is whether smokers unmotivated to quit may respond better to implicit approaches than to explicit approaches. Moreover, the implicit retraining technique may be more suitable for less educated groups as it has been shown that drug-related associations in memory predicted more strongly in individuals with lower levels of working memory capacity (Grenard et al., 2008) which in turn is associated with educational factors (Al-Ahmadi and Oraif, 2009; Packiam Alloway and Alloway, 2009). A study on anxiety in adolescents has already demonstrated stronger training effects among those with lower working memory capacity (Salemink and Wiers, 2012). Following these findings, we recommend more research on these assumptions in the field of smoking relapse prevention.

In sum, integrating principles of implicit and explicit strategies may yield ample possibilities for better understanding behavior change processes and may result in improved effectiveness of behavior change programs.

\section{STRENGTHS AND FUTURE CHALLENGES}

As described in the previous chapters, the findings from the studies conducted in this dissertation have several strengths which make them valuable for this dissertation. Other factors form limitations of the current studies and can be regarded as challenges for the future. 


\section{Strengths of the current studies}

\section{Randomization}

Both studies were randomized controlled trials. Randomization excludes potential biases with regard to the assignment of subjects to the control or experimental conditions and tends to generates comparable groups (Scherstén, 1986). Furthermore, both studies measured a range of factors at baseline that can form possible covariates. Covariate adjustment is considered important in randomized controlled trials, because they can take account for any baseline variables that may be related to the outcome (Hernández, Steyerberg and Habbema, 2004).

\section{Based on theory and empirical research}

The introduction of this dissertation explained that the I-Change Mode and neurobiological theories of addiction formed the theoretical base for the interventions developed and tested. Using theory-based approaches is highly recommended in the literature as interventions are likely to be more effective when they are theory-based and it facilitates further testing and development of theories (Michie, Johnston, Francis, Hardeman and Eccles, 2008).

\section{Intensity of the interventions/use of multiple sessions}

The SQ4U programs as well as the Train Yourself Smoke-free program provided intensive support by incorporating multiple intervention sessions. Providing intensive support in the form of multiple intervention sessions has demonstrated to increase smoking abstinence rates (Fiore, 2008). More specific, a metaanalyses on the efficacy of computer tailoring approaches as used in the SQ4U programs have pointed out that multiple feedback time points result in more behavioral change (Noar, Benac and Harris, 2007). The latter also accounts for attentional bias modification approaches since single-session programs have shown no effects where multiple sessions have shown to be more promising. The importance of multiple-session programs for smoking relapse prevention is partly supported by the results from the SQ4U study that suggested a doseresponse relation as well as by the Train Yourself smoke-free study that resulted in behavioral effects after six months. Yet, the effects of the AP+ program (one of the SQ4U programs) suggest that too much program elements can have a counterproductive effect.

\section{Limitations and future challenges}

\section{Defining smoking relapse}

One of the challenges in this dissertation was to choose the most appropriate strategy for assessing smoking relapse, because the literature shows substantial 
variation in the terminologies used to define relapse (Piasecki, 2006). Insight into these definitions is essential. Some studies differentiate between lapses and relapse. Lapses are commonly seen as isolated occasions that are followed by resumption of the quit-attempt or by relapse and have been defined as any smoking (Brandon, Tiffany, Obremski and Baker, 1990), smoking less than once per week (O'Connell and Martin, 1987), smoking at least one cigarette in the first month after the quit-attempt (Bliss, Garvey, Heinold and Hitchcock, 1989), and an episode of smoking followed by resuming the quit-attempt (Curry, Marlatt, Gordon and Bear, 1988; Bear, Kamarck, Lichtenstein and Ransom, 1989). In general, research has demonstrated that most lapses result in relapse (Kenford et al., 1994; Shiffman, Paty, Gnys, Kassel and Hickcox, 1996). Relapse typically refers to a period of continued smoking after a cessation attempt or a period of abstinence and has also been defined in various ways: as three consecutive days of smoking (Brandon, Tiffany, Obremski and Baker, 1990; Cohen and Lichtenstein, 1990), smoking five or more cigarettes in a period of three consecutive days (Morgan, Ashenberg and Fisher, 1988; Shiftman et al., 1996) and smoking more than five cigarettes (over a period of 30 days) (Stevens and Hollis, 1989; West, Hajek, Stead and Stapleton, 2005).

When targeting intervention outcomes, however, relapse is mostly termed as a binary outcome measure of abstinence (Piasecki, 2006) and continued abstinence and prolonged abstinence nowadays (Hughes, Keely and Niaura, 2003; Velicer and Prochaska, 2004) are the most common measures. Continued abstinence is defined as total abstinence between a quit day and a follow-up measurement. Prolonged abstinence is defined as total abstinence after an initial grace period (mostly one or two weeks). Prolonged abstinence has the advantage that this strategy has the potential to assess delayed positive treatment effects. Continued abstinence is the most conservative outcome measure and often seen as the golden standard as it requires total abstinence since the quit attempt (Hughes, Keely and Niaura, 2003). Yet, the fact that this strategy also considers a temporary lapse a final failure may also imply an increased risk of type II errors.

Deciding on the use of a certain outcome measure depends on the goals of the study or intervention. As lapsing is strongly associated with a total relapse, interventions may need to incorporate strategies to prevent any smoking after the quit attempt and foster continued abstinence, because this outcome eventually has the strongest association with total abstinence (Kenford et al., 1994; Shiffman, Paty, Gnys, Kassel and Hickcox, 1996). Therefore, we focused on continued abstinence (defined as no smoking at all after a quit-attempt) in the interventions studies. The challenge remains to report on the best fitting outcome measure to provide a complete view of the results. 


\section{Non-adherence and study drop-out}

Non-adherence to the program elements and study drop-out at the follow-up measurements formed limitations in the SQ4U study as well as the Train Yourself Smoke-free study. Although non-adherence and study drop-out have become very common in Internet studies (Tate and Zabinski, 2004; Etter, 2005; Eysenbach, 2005; Te Poel, Bolman, Reubsaet and de Vries, 2009), they do pose serious limitations and can bias the results. Low levels of adherence may for instance lead to underestimations of intervention effects and a range of Internet studies have therefore shown dose-response relationships (see, for instance, Eysenbach, 2002; Cobb, Graham, Bock, Papandonatos and Abrams, 2005; An et al., 2006; Japuntich et al., 2006). Moreover, when drop-outs rates are very high, conservative analyses in which drop-outs are interpreted as relapses may be too strict and subject to biases (Hollis and Campbell, 1999).

These limitations form two challenges: 1 . to gain insight into the best analyses approach for randomized controlled trials with high drop-out rates and 2. to foster adherence and prevent study drop-out. These two challenges are discussed further below.

\section{Analyzing the results of randomized controlled trials}

Although intention-to-treat approaches (in this study: including all respondents as randomized apart from whether observed case analyses or conservative analyses are conducted) are the gold standard and are recommended (Heritier, Gebski and Keach, 2003); reporting on alternative strategies may provide a more complete view of the results. Several analysis strategies are feasible, each with advantages and disadvantages.

Analyzing by intention-to-treat entails including all respondents as randomized regardless of whether or not the intervention was received, compliance to the protocol and withdrawal from the study (Hollis and Campbell, 1999; Heritier, Gebski and Keach, 2003). The advantage to this approach is that it maintains the balance of random treatment allocation and it reflects the situation as it is likely to occur in practice (where not following program protocols and withdrawal will also be common) (Wertz, 1995; Heritier, Gebski and Keach, 2003). Furthermore, applying the intention-to-treat approach protects research against biases introduced when drop-out is related to the outcome of the intervention (informative drop-outs) and conscious or unconscious attempts to influence the results. Reporting on this approach is therefore essential. The intention-to-treat approach is, however, a very conservative approach that may be susceptible to type II errors and may say little about the actual efficacy of a treatment since respondents who did not receive the treatment are still included (Hollis and Campbell, 1999; Heritier, Gebski and Keach, 2003), especially in Internet studies, as these often result in low adherence to the programs and high drop-out rates (Wangberg, Bergmo and Johnsen, 2008). In the last decades more studies have started to report on modified approaches including post- 
randomization exclusions (Abraha and Montedori, 2010). Yet, descriptions of these approaches are sometimes ambiguous and may include any type of exclusions varying from protocol deviations to missing data. Providing explicit information concerning post-randomization exclusions is, however, necessary when using such a modified intention-to-treat approach (Abraha and Montedori, 2010). Furthermore, it should be noted that although modified approaches have the potential to provide an answer on questions concerning the efficacy of a program when the protocol is followed correctly, caution is needed when interpreting the results because approaches in which respondents are excluded after randomization may threaten the randomization balance and neglect the fact that non-adherence (and even making or not making a quit-attempt) may also be a result of the treatment (Heritier, Gebski and Keach, 2003).

In sum, reporting on multiple approaches and providing a broader view on program effects may result in a better understanding of treatment effects and is, therefore, recommended for future studies.

\section{Fostering adherence and preventing study drop-out}

The best way to solve the limitation formed by non-adherence and study dropout is to foster adherence to the program elements and the follow-up questionnaires so that most respondents remain active in the programs; future studies should aim at increasing adherence. Crutzen et al (2008) suggest that the recruitment channels play an important role and that for instance respondents who are recruited via popular online places may be less involved in their participation (Crutzen, de Nooijer and de Vries, 2008). This notion should be taken into account when recruiting a target population in order to prevent low involvement en high drop-out.

A recently introduced Internet intervention model provides a framework of how the Internet can be used to promote behavior change (Ritterband, Thorndike, Cox, Kovatchev and Gonder-Frederick, 2009). The model identifies important factors for adoption and use of Internet programs. These factors are for instance: attractive appearance, clear personalized instructions, low burden (length of the programs, difficulty of use), clear and simple content, attractive mode of delivery (apps, animations, videos, illustrations), active involvement of visitors, assessing personal needs and the message (source and style). The importance of these factors is underlined by a recent Delphi-study assessing experts' and users' opinions with regard to the factors related to optimal development of health-related websites (Schneider, van Osch and de Vries, 2012).

Moreover, within this framework introduced by Ritterband, enjoyment is also regarded as an essential factor for loyalty to programs. A general feeling of pleasure or displeasure is an important evaluation outcome in experiences (Hassenzahl and Ullrich, 2007). This feeling is a constant factor that will always be part of an experience and will regulate behavior (Hassenzahl and Ullrich, 2007). It is this feeling that drives a person to continue or quit doing something, 
which makes it a very important factor to foster adherence. How to best increase the appeal of a Web-based health program remains a question for probably several studies. One example for making programs more attractive may be the use of gaming strategies. Games are becoming popular tools in the field of health related research. While most people perceive games as entertainment, the interest in using gaming strategies as educational/training tools has been growing in the last decades (Durkin, 2010). Games have been shown to fulfill an individual's need for autonomy, connectedness, and control and thusly satisfy significant psychological needs (Ryan, Rigby and Przybylski, 2006). It is, moreover, suggested that gaming strategies attract individuals and preserve their attention (Baranowski, Buday, Thomson and Baranowski, 2008). Moreover, games are claimed to have the ability to increase motivation (Kato, 2010), which in turn is a core predictor of behavior. Testing their efficacy in fostering adherence is highly recommended for future research. Since games may also result in participation for the sake of gaming only, a critical reflection is needed to assess their effects on behavior change.

A final note is that the studies described in this dissertation were Internetbased using computers and that access to programs was not tailored towards needs of respondents to use the program when they wanted or needed it the most. Increasing the flexibility of use is therefore recommended - via the Internet and/or via other means - in order to foster adherence and prevent study drop-out. Recent technological developments have resulted in an increase of the use of mobile internet devices such as smartphones and tablets. In the Netherlands, 50\% of all Internet-users utilize mobile devices (CBS, 2012). The use of these devices doubled from 2010 to 2011, indicating a strong positive trend in the utilization of mobile Internet. They can be used for a range of functions, including the delivery of health programs (Free et al., 2010). The use of these mobile devices in health care and public health (which is referred to as 'mobile health (m-health)') has the advantage to increase usage flexibility not only by being available during the whole day, but also at various places and at moments when support may be needed most: for instance in smoking related risksituations (Free et al., 2010). Making the SQ4U programs as well as the Train Yourself Smoke-free program available via tablets and smart phone is a logical next step in improving the programs in order to foster adherence as this step will result in increased flexibility of use. Yet, more research in the form of expert studies (e.g. a Delphi-study) and social marketing approaches is needed.

\section{Dissemination and adoption in practice}

Besides adoption among the target population (smokers), another challenge for the future is formed by the eventual implementation of the SQ4U and Train Yourself Smoke-free programs in practice. The earlier mentioned theorypractice divide does not only have consequences with regard to understanding of determinants and the development of programs, but also for the dissemina- 
tion and adoption of successful programs in practice (Noonan and Emshoff, 2011). Implementation of successful prevention programs is, however, essential in order to gain successes at a population level (Noonan and Emshoff, 2011) (Noonan \& Emshoff, 2011). Hence, the identification of factors within several organizations that facilitate or hinder implementation of the programs described according to experts from these organizations is required and research on this is highly recommended. Within this context, health promotion theories (e.g. Havelock's linkage theory which can be seen as a basic paradigm for communication interventions) as well as social marketing theories (e.g. Hastings) suggest to include all relevant stakeholders from the very beginning. This implies that a next phase in which we move from an efficacy trial to an effectiveness trial is needed: in this phase all relevant stakeholders should be included to assess how to disseminate the program into practice and which changes to the programs may be needed to achieve this.

\section{FINAL CONCLUSIONS}

Based on the studies reported in the present dissertation several main conclusions for the field of smoking relapse prevention can be drawn. First, more insight into the transition from theory to practice is essential for the development as well as the dissemination and adoption of new smoking relapse prevention programs. Second, computer-tailored approaches combined with multiple action planning assignments as utilized in the SQ4U programs have the potential to foster longer-term continued smoking abstinence. However, improvements to the program are needed in order to reach better results. Third, the support for providing short tailored feedback at various moments after the quit attempt over and above planning strategy assignments is limited. More research is needed in order to assess whether providing this feedback when most needed, for instance by using real-time interventions such as ecological momentary interventions, will result in better effects. Fourth, improvements of the SQ4U programs are essential in order to foster adherence among smokers and adoption among national health care institutes are required. Fifth, attentional bias modification strategies are successful in fostering short-term smoking abstinence and should therefore be included in prevention programs. Improving the assessment tools that are used for measuring implicit bias is, however, essential. Finally, new initiatives are required in order to assess the effects of combined strategies (explicit cognition and implicit cognition approaches altogether in one program), to assess the efficacy of the approaches as reported in this dissertation among other groups of smokers (e.g. smokers who are not motivated to quit smoking), and to test whether implicit tendencies underlie explicit cognitions such as self-efficacy and action planning. 


\section{REFERENCES}

ABRAHA, L. and MONTEDORI, A. (2010). Modified intention to treat reporting in randomised controlled trials: systematic review. British Medical Journal, 340, c2697.

ABRAHAM, C., SHEERAN, P., NORMAN, P., CONNER, M., DE VRIES, N. and OTTEN, W. (1999). When good intentions are not enough: modeling postdecisional cognitive correlates of condom use. Journal of Applied Social Psychology, 19, 2591-2612.

ACS (2010), The Great American Health Challenge: Helping a Smoker Quit: Dos and Don'ts. from http://www.cancer.org/docroot/subsite/greatamericans/content/Helping_a_Smoker_Quit.asp, American Cancer Society.

ADLER, M. and ZIGLIO, E. (1996). Gazing into the Oracle:The Delphi Method and its Application to Social Policy and Public Health. London, Jessica Kingsley Publishers.

AIKEN, L. and WEST, S. (1991). Multiple regression: Testing and interpreting interactions (New ed.). Newbury Park, Sage Publications.

AJZEN, I. (1988). Attitudes, personality and behavior. Milton Keynes, Open University Press.

AJZEN, I. (1991). The Theory of Planned Behavior. Organizational Behavior and Human Decision Processes, 50, 179-211.

AJZEN, I. and FISHBEIN, M. (1980). Understanding attitudes and predicting social behavior. Englewood-Cliff: New York, Prentice-Hall.

AL-AHMADI, F. and ORAIF, F. (2009). Working memory capacity, confidence and scientific thinking. Research in Science \& Technological Education, 27, 225-243.

ALLEN, S. S., BADE, T., HATSUKAMI, D. and CENTER, B. (2008). Craving, Withdrawal, and smoking urges on days immediately prior to smoking relapse. Nicotine and Tobacco Research, 10, 35-45.

AMIR, N., BEARD, C., BURNS, M. and BOMYEA, J. (2009). Attention modification program in individuals with generalized anxiety disorder. Journal of Abnormal Psychology, 118, 28-33.

AMODEI, N. and LAMB, R. J. (2005). Predictors of Initial Abstinence in Smokers Enrolled in a Smoking Cessation Program. Substance use and misuse, 40, 141-149.

AN, L., PERRY, C., LEIN, E., KLATT, C., FARLEY, D., BLISS, R., HENNRIKUS, D., PALLONEN, E., LANDO, H., AHLUWALIA, J. and EHLINGER, E. (2006). Strategies for increasing adherence to an online smoking cessation intervention for college students. Nicotine \& Tabacco Research, 8, 7-12.

ANDERSON, J. R. (1983). The architecture of cognition. Cambridge, MA, Harvard University Press.

ARMITAGE, C. J. (2007). Efficacy of a brief worksite intervention to reduce smoking: the roles of behavioral and implementation intentions. Journal of Occupational Health Psychology, 12, 376390.

ARMITAGE, C. J. (2008). A volitional help sheet to encourage smoking cessation: a randomized exploratory trial. Health Psychology, 27, 557-566.

ARMITAGE, C. J. (2009). Effectiveness of experimenter-provided and self-generated implementation intentions to reduce alcohol consumption in a sample of the general population: A randomized exploratory trial. . Health Psychology, 28, 545-553.

ARMITAGE, C. J. and CONNER, M. (2000). Social cognition models and health behaviour: A structured review. Psychology \& Health, 15, 173-189.

ATAYA, A. F., ADAMS, S., MULlingS, E., COOPER, R. M., ATTWOOD, A. S. and MUNAFO, M. R. (2012). Internal reliability of measures of substance-related cognitive bias. Drug and Alcohol Dependence, 121, 148-151.

ATTWOOD, A. S., O'SUlliVAN, H., LEONARDS, U., MACKINTOSH, B. and MUNAFO, M. R. (2008). Attentional bias training and cue reactivity in cigarette smokers. Addiction, 103, 1875-1882. 
AUSEMS, M., MESTERS, I., VAN BREUKELEN, G. and DE VRIES, H. (2004). Effects of in-school and tailored out-of-school smoking prevention among Dutch vocational school students. Health Education Research, 19, 51-63.

BAILLIE, A. J., MATTICK, R. P. and HALL, W. (1995). Quitting smoking: Estimation by meta-analysis of the rate of unaided smoking cessation. The Australian and New Zealand Journal of Public Health, 19, 129-131.

BAKER, T. B., PIPER, M. E., MCCARTHY, D. E., BOLT, D. M., SMITH, S. S., KIM, S.-Y., COLBY, S., CONTI, D., GIOVINO, G. A., HATSUKAMI, D., HYLAND, A., KRISHNAN-SARIN, S., NIAURA, R., PERKINS, K. A. and TOLL, B. A. (2007). Time to First Cigarette in the Morning as an Index of Ability to Quit Smoking: Implications for Nicotine Dependence. Nicotine \& Tobacco Research, 9, S555-S570.

BAKHSHI, E., ESHRAGHIAN, M., MOHAMED, K. and SEIFI, B. (2008). A comparison of two methods for estimating odds ratios: Results from the National Health Survey. BMC Medical Research Methodology, 8, doi: 10.1186/1471/-2288-1188-1178.

BALMFORD, J. and BORLAND, R. (2008). What does it mean to want to quit? Drug Alcohol Rev, 27, 21-27.

BANDURA, A. (1986). Social foundations of thought and action: A social cognitive theory. New York, Prentice-Hall.

BANDURA, A. (1997). Self-efficacy: The exercise of control. New York, Freeman.

BANDURA, A. (1998). Health promotion from the perspective of social cognitive theory. Psychology \& Health, 13, $623-649$.

BARANOWSKI, T., BUDAY, R., THOMSON, D. and BARANOWSKI, J. (2008). Playing for Real Video Games and Stories for Health-Related Behavior Change. American Journal of Preventive Medicine, 34, 74-82.

BARTHOLOMEW, L. K., PARCEL, G. S., KOK, G., GOTTLIEB, N. H. and FERNANDEZ, M. E. (2011). Planning Health Promotion Programs: An Intervention Mapping Approach, John Wiley \& Sons.

BAUMAN, L. J., STEIN, R. E. and IREYS, H. T. (1991). Reinventing fidelity: the transfer of social technology among settings. American JOurnal of Community Psychology, 19, 619-639.

BEAR, J., KAMARCK, T., LICHTENSTEIN, E. and RANSOM, C. (1989). Prediction of smoking relapse: Analyses of temtations and transgressions after intitial cessation. Journal of Consulting and Clinical Psychology, 57, 623-627.

BEARD, C., WEISBERG, R. B. and PRIMACK, J. (2011). Socially Anxious Primary Care Patients' Attitudes Toward Cognitive Bias Modification (CBM): A Qualitative Study. Behavioural and Cognitive Psychotherapy, 1-16.

BECHARA, A. (2005). Decision making, impulse control and loss of willpower to resist drugs: a neurocognitive perspective. Nat Neurosci, 8, 1458-1463.

BELLI, G. (2010). Bridging the researcher-scientist gap: Views from different fields. in C. Reading (Ed.). Data and context in statistics education: Proceedings of the Eight International Conference on Teaching Statistics. Ljubljana, Slovenia.

BERKE, J. D. and HYMAN, S. E. (2000). Addiction, dopamine, and the molecular mechanisms of memory. Neuron, 25, 515-532.

BLISS, R., GARVEY, A., HEINOLD, J. and HITCHCOCK, J. (1989). The influence of situation and coping on relapse crisis outcomes after smoking cessation. Journal of Consulting and Clinical Psychology, 57, 443-449.

BOHADANA, A., NILSSON, F., RASMUSSEN, T. and MARTINET, Y. (2003). Gender differences in quit rates following smoking cessation with combination nicotine therapy: Influence of baseline smoking behavior. Nicotine \& Tobacco Research, 5, 111-116.

BOLMAN, C., DE VRIES, H. and VAN BREUKELEN, G. (2002). Evaluation of a nurse-managed minimalcontact smoking cessation intervention for cardiac inpatients. Health Education Research, 17, 99-116.

BONNEUX, L. G., LOOMAN, C. W. and COEBERGH, J. W. (2003). Sterfte door roken in Nederland: 1,2 miljoen tabaksdoden tussen 1950 en 2015 [Mortality due to smoking in the Netherlands: 1.2 milion tobacco-related deaths between 1950 and 2015]. Nederlands Tijdschrift voor Geneeskunde 147, 917-921. 
BORLAND, R., BALMFORD, J. and HUNT, D. (2004). The effectiveness of personally tailored computer-generated advice letters for smoking cessation. Addiction, 99, 369-377.

BORRELLI, B. (1994). Goal setting and behavior change in a smoking cessation program. Cognitve therapy and research, 18, 69-83.

BRANDON, T. H., TIFFANY, S. T., OBREMSKI, K. M. and BAKER, T. B. (1990). Postcessation cigarette use: the process of relapse. Addictive Behaviors, 15, 105-114.

BRITTON, A., MCKEE, M., BLACK, N., MCPHERSON, K., SANDERSON, C. and BAIN, C. (1998). Choosing between randomised and non-randomised studies: a systematic review. Health Technology Assessment, 2, 1-124.

BROWN, R. A., LEJUEZ, C. W., KAHLER, C. W., STRONG, D. R. and ZVOLENSKY, M. J. (2005). Distress tolerance and early smoking lapse. Clinical Psychology Review, 25, 713-733.

BRUG, J., CAMPBELL, M. and VAN ASSEMA, P. (1999). The application and impact of computergenerated personalized nutrition education: A review of the literature. Patient Education and Counseling, 36, 145-156.

BRUG, J., KOK, G., VAN BREUKELEN, G. J., GLANZ, K. and VAN ASSEMA, P. (1998). The impact of computer-tailored feedback and iterative feedback on fat, fruit, and vegetable intake. Health Education and Behavior, 25, 517-531.

BRUG, J., OENEMA, A. and CAMPBELL, M. (2003). Past, present an future of computer-tailored nutrition education. The American Journal of Clinical Nutrition, 77, I028S-I034S.

CANADA, H. (2001). Smoking in Canada: an overview. CTUMS (Canadian Tobacco use Monitoring Survey).

CARlbring, P., APElSTRAND, M., SEHLiN, H., AMIR, N., ROUSSEAU, A., HOFMANN, S. G. and ANDERSSON, G. (2012). Internet-delivered attention bias modification training in individuals with social anxiety disorder - a double blind randomized controlled trial. BMC Psychiatry, 12, 66.

CBO (2009). Richtlijn behandeling van Tabaksverslaving herziening 2009 [[GUIDELINE Treatment of tobacco addiction revision 2009]. Alphen aan den Rijn.

CBS (2011). Statline: vrije tijd en cultuur; internet toegang huishoudens 2005-2010 [Statline: spare time and culture; internet access households 2005-2010]. The Hague/Heerlen, Centraal Bureau voor de Statistiek.

CDC (2002). Cigarette smoking among adults--United States, 2000. Morbidity and mortality weekly report, 51, Centers for Disease Control and Prevention.

CDC (2008). Smoking-Attributable Mortality, Years of Potential Life Lost, and Productivity LossesUnited States, 2000-2004. Morbidity and Mortality Weekly Report 2008, 57, 45, Centers for Disease Control and Prevention (CDC).

CDC (2011). Vital Signs: Current Cigarette Smoking Among Adults AGED 18 Years- United States, 2005-2010

(http://www.cdc.gov/mmwr/preview/mmwrhtml/mm6035a5.htm?s_cid=\%20mm6035a5.htm_w) Morbidity and Mortality Weekly Report 2011, 60, 33, Centers for Disease Control (CDC).

CHATZISARANTIS, N. L. D. and HAGGER, M. S. (2010). Effects of Implementation Intentions Linking Suppression of Alcohol Consumption to Socializing Goals on Alcohol-Related Decisions. Journal of Applied Social Psychology, 40, 1618-1634.

COBB, N., GRAHAM, A., BOCK, B., PAPANDONATOS, G. and ABRAMS, D. (2005). Initial evaluation of a real-world Internet smoking cessation system. Nicotine \& Tobacco Research, 7, 207-216.

COHEN, S. and LICHTENSTEIN, E. (1990). Perceived stress, quitting smoking, and smoking relapse. Health Psychology, 9, 466-478.

COHEN, S. and WILLIAMSON, G. M. (1988). Perceived stress in a probability sample of the United States. in Oskamp S. Spacapan S. (Ed.). The Social Psychology of Health. Beverly Hills, Calif Sage Publications: 31-67.

COKKINIDES, V. E., WARD, E., JEMAL, A. and THUN, M. J. (2005). Under-use of smoking-cessation treatments: results from the National Health Interview Survey, 2000. Am J Prev Med, 28, 119122.

COLE, J. C., RABIN, A. S., SMITH, T. L. and KAUFMAN, A. S. (2004). Development and validation of a Rasch-derived CES-D short form. Psychological Assessment, 61, 360-372. 
COUSIJN, J., GOUDRIAAN, A. E. and WIERS, R. W. (2011). Reaching out towards cannabis: approachbias in heavy cannabis users predicts changes in cannabis use. Addiction, 106, 1667-1674.

COVEY, L. S., GLASSMAN, A. H., STETNER, F. and BECKER, J. (1993). Effect of history of alcoholism or major depression on smoking cessation. The American Journal of Psychiatry, 150, 1546-1547.

COVEY, L. S. and TAM, D. (1990). Depressive mood, the single-parent home, and adolescent cigarette smoking. American Journal of Public Health, 80, 1330-1333.

COX, W. M., FADARDI, J. S. and POTHOS, E. M. (2006). The Addiction-Stroop test: Theoretical considerations and procedural recommendations. Psychological Bulletin, 132, 443-476.

CRUTZEN, R., DE NOOIJER, J., BROUWER, W., OENEMA, A., BRUG, J. and DE VRIES, N. K. (2008). Internet-delivered interventions aimed at adolescents: a Delphi study on dissemination and exposure. Health Education Research, 23, 427-439.

CRUTZEN, R., DE NOOIJER, J. and DE VRIES, N. K. (2008). How to reach a target group with Internetdelivered interventions? The European Health Psychologist, 10, 77-79.

CTUMS (2001). Smoking in Canada: an overview. Canadian Tobacco use Monitoring Survey.

CURRY, S., MARLATT, G., GORDON, J. and BEAR, J. (1988). A comparison of alternative theoretical approaches to smoking cessation and relapse. Health Psychology, 7, 545-556.

CUSTER, R. L., SCARCELLA, J. A. and STEWART, B. R. (1999). The Modified Delphi Technique - A Rotational Modification. Journal of Vocational and Technical Education, 15, 50-58.

DANAEI, G., RIMM, E. B., OZA, S., KULKARNI, S. C., MURRAY, C. J. L. and EZZATI, M. (2010). The Promise of Prevention: The Effects of Four Preventable Risk Factors on National Life Expectancy and Life Expectancy Disparities by Race and County in the United States. PLOS Medicine, 7, e1000248.

DE HOUWER, J., CROMBEZ, G., BAEYENS, F. and HERMANS, D. (2001). On the generality of the affective Simon effect. Cognition and emotion, 15, 189-206.

DE VET, E., BRUG, J., DE NOOIJER, J., DIJKSTRA, A. and VRIES, N. K. (2005). Determinants of forward stage transitions: a Delphi study. Health Education Research, 20, 195-205.

DE VET, E., GEBHARDT, W. A., SINNIGE, J., VAN PUFFELEN, A., VAN LETTOW, B. and DE WIT, J. B. F. (2011). Implementation intentions for buying, carrying, discussing and using condoms: the role of the quality of plans. Health Education Research, 26, 443-455.

DE VET, E., OENEMA, A. and BRUG, J. (2011). More or better: Do the number and specificity of implementation intentions matter in increasing physical activity? Psychology of Sport and Exercise, 12, 471-477.

DE VRIES, H., EGGERS, M. and BOLMAN, C. (submitted). Action planning theory to better understand smoking cessation.

DE VRIES, H., KREMERS, S. P., SMEETS, T., BRUG, J. and EIJMAEL, K. (2008). The effectiveness of tailored feedback and action plans in an intervention addressing multiple health behaviors. American Journal of Health Promotion, 22, 417-425.

DE VRIES, H., MUDDE, A., LEIJS, I., CHARLTON, A., VARTIAINEN, E., BUIJS, G., ClEMENTE, M. P., STORM, H., NAVARRO, A. G., NEBOT, M., PRINS, T. and KREMERS, S. (2003). The European Smoking prevention Framework Approach (EFSA): an example of integral prevention. Health Education Research, 18, 611-626.

DEUTSCH, R. and STRACK, F. (2006). Reflective and impulsive determinants of addictive behavior. in R.W. Wiers and A.W. Stacy (Ed.). Handbook of Implicit Cognition and Addiction. Thousand Oaks, CA., SAGE Publishers: 45-57.

DIJKSTRA, A. (2005). De psychology van roken en stoppen met roken [The psychology of smoking and smoking cessation]. in K. Knol (Ed.). Tabaksgebruik; gevolgen en bestrijding [Tobacco use: consequences and control]. Utrecht, Lemma BV: 301-311.

DIJKSTRA, A. and BORLAND, R. (2003). Residual outcome expectations and relapse in ex-smokers. Health Psychology 22, 340-346.

DIJKSTRA, A. and DE VRIES, H. (1999). The development of computer-generated tailored interventions Patient Education and Counseling, 36, 193-203.

DIJKSTRA, A. and DE VRIES, H. (2000). Self-efficacy expectation with regard to different tasks in smoking cessation. Psychology and Health, 15, 501-511. 
DIJKSTRA, A., DE VRIES, H. and BAKKER, M. (1996). Pros and cons of quitting, self-efficacy, and the stages of change in smoking cessation. Journal of Consulting and Clinical Psychology, 64, 758763.

DIJKSTRA, A., DE VRIES, H. and ROIJACKERS, J. (1998). Long-term effectiveness of computergenerated tailored feedback in smoking cessation. Health Education Research, 13, 207-214.

DIJKSTRA, A., DE VRIES, H., ROIJACKERS, J. and VAN BREUKELEN, G. J. (1998). Tailored information to enhance quitting in smokers with low motivation to quit: three basic efficacy questions. Health Psychology, 17, 513-519.

DORAN, N., SPRING, B., MCCHARGUE, D., PERGADIA, M. and RICHMOND, M. (2004). Impulsivity and smoking relapse. Nicotine and Tobacco Research, 6, 641-647.

DURKIN, K. (2010). Videogames and Young People With Developmental Disorders. Review of General Psychology, 14, 122-140.

EHRMAN, R. N., ROBBINS, S. J., BROMWELL, M. A., LANKFORD, M. E., MONTEROSSO, J. R. and O' BRIEN, C. P. (2002). Comparing attentional bias to smoking cues in current smokers, former smokers, and non-smokers using a dot-probe task. Drug and Alcohol Dependence, 67, 185-191.

ELFEDDALI, I., BOLMAN, C., CANDEL, M. J., WIERS, R. W. and DE VRIES, H. (2012). The role of selfefficacy, recovery self-efficacy and preparatory planning in predicting short-term relapse. British Journal of Health Psychology, 17, 185-201.

ELFEDDALI, I., BOLMAN, C., CANDEL, M. J. J. M., WIERS, R. W. and DE VRIES, H. (2012). Preventing smoking relapse via Web-based computer tailored feedback in the SQ4U-study: a randomized controlled trial. Journal of Medical Internet Research 14, e109.

ELFEDDALI, I., BOLMAN, C. and DE VRIES, H. (2012). SQ4U - a computer tailored smoking relapse prevention program incorporating planning strategies and multiple feedback moments after the quit-attempt: development and design protocol. Contemporary Clinical Trials, 33, 151-158.

ETTER, J. (2005). Comparing the efficacy of twe internet-based computer-tailored smoking cessation programs: a randomized trial. Journal of Medical Internet Research, 7, e2.

EUROPEAN-COMMISSION (2004). Tobacco or health in the European Union - Past, present and future <http://ec.europa.eu/health/ph_determinants/life_style/Tobacco/Documents/tobacco_fr_en.p df>. Luxembourg, Office for Official Publications of the European Communities.

EVERITT, B. J., DICKINSON, A. and ROBBINS, T. W. (2001). The neuropsychological basis of addictive behaviour. Brain Research Review, 36, 129-138.

EYSENBACH, G. (2002). Issues in evaluating health websites in an Internet-based randomized controlled trial. Journal of Medical Internet Research, 4, e17.

EYSENBACH, G. (2005). The law of attrition. . Journal of Medical Internet Research, 7, e11.

EZZATI, M., LOPEZ, A., RODGERS, A., VAN DER HOOM, S., MURRAY, C. and GROUP, T. C. R. A. C. (2002). Selected major risk factors and global and regional burden of disease. Lancet, 360, 1347-1360.

FADARDI, J. S. and COX, W. M. (2009). Reversing the sequence: reducing alcohol consumption by overcoming alcohol attentional bias. Drug and Alcohol Dependence, 101, 137-145.

FAGERSTROM, K. O., HEATHERTON, T. F. and KOZLOWSKI, L. T. (1990). Nicotine addiction and its assesment. . Ear Nose \& Throat journal, 69 763-765.

FAZIO, R. H. and OLSEN, M. A. (2003). Implicit measures in social cognition research: Their meaning and use. Annual Review of Psychology, 54, 297-327.

FEIGENBAUM, J. (2010). Pharmacological Aids to Promote Smoking Cessation. Journal of Addictions Nursing, 21, 87-97.

FERGUSON, J., BAULD, L., CHESTERMAN, J. and JUDGE, K. (2005). The English smoking treatment services: one-year outcomes. Addiction, 100, 59-69.

FERNANDEZ, E., SCHIAFFINO, A., BORRELL, C., BENACH, J., ARIZA, C., RAMON, J. M., TWOSE, J., NEBOT, M. and KUNST, A. (2006). Social class, education, and smoking cessation: Long-term follow-up of patients treated at a smoking cessation unit. Nicotine and Tobacco Research, 8, 29-36.

FIELD, M. and COX, W. M. (2008). Attentional bias in addictive behaviors: a review of its development, causes, and consequences. Drug Alcohol Depend, 97, 1-20. 
FIELD, M., DUKA, T., EASTWOOD, B., CHILD, R., SANTARCANGELO, M. and GAYTON, M. (2007). Experimental manipulation of attentional biases in heavy drinkers: Do the effects generalise? Psychopharmacology, 192, 593-608.

FIELD, M., DUKA, T., TYLER, E. and SCHOENMAKERS, T. (2009). Attentional bias modification in tobacco smokers. Nicotine and Tobacco Research, 11, 812-822.

FIELD, M., EASTWOOD, B., BRADLEY, B. P. and MOGG, K. (2006). Selective processing of cannabis cues in regular cannabis users. Drug and Alcohol Dependence, 85, 75-82.

FIELD, M., KIERNAN, A., EASTWOOD, B. and CHILD, R. (2008). Rapid approach responses to alcohol cues in heavy drinkers. J Behav Ther Exp Psychiatry, 39, 209-218.

FIELD, M., MOGG, K., ZETTELER, J. and BRADLEY, B. (2004). Attentional biases for alcohol cues in heavy and light social drinkers: the roles of initial orienting and maintained attention. Psychopharmacology, 176, 88-93.

FIORE, M., JEAN, CR., BAKER,TB., BAILEY, WC., BENOWITZ, NL., CURRY, SJ., ..., WEWERS, L. (2008). Treating tobacco use and dependence: update 2008. Rockville, MD, U.S. Department of Health and Human Services, Public Health Service.

FISHBEIN, M. and AJZEN, I. (1975). Belief, Attitude, Intention and Behavior: An Introduction to Theory and Research. Reading, MA, Addison-Wesley.

FISHBEIN, M. and AJZEN, I. (2010). Predicting and changing behavior: The reasoned action approach. New York, Psychology Press (Taylor and Francis).

FLAA, A., EKEBERG, O., KJELDSEN, S. E. and ROSTRUP, M. (2007). Personality may influence reactivity to stress. BioPsychoSocial medicine, 1, 5.

FREE, C., PHILLIPS, G., FELIX, L., GALLI, L., PATEL, V. and EDWARDS, P. (2010). The effectiveness of M-health technologies for improving health and health services: a systematic review protocol. BMC Research Notes, 3, 250.

GARVEY, A. J. and BLISS, R. E. (1992). Predictors of smoking relapse among self-quitters: a report from the normative aging study. Addictive Behaviors, 17, 367-377.

GELDER, B., POOS, M. and ZANTINGE, E. (2011) Wat zijn de mogelijke gezondheidsgevolgen van roken? [What are the possible health consequences of smoking? Volksgezondheid Toekomst Verkenning [Public Health Future Explorer], Nationaal Kompas Volksgezondheid, Bilthoven: RIVM <http://www.nationaalkompas.nl> Nationaal Kompas Volksgezondheid \Gezondheidsdeterminanten \Leefstijl\Roken [accessed 8 May 2012]

GILBERT, D. G., CRAUThERS, D. M., MOONEY, D. K., MCCLERNON, F. J. and JENSEN, R. A. (1999). Effects of Monetary Contingencies on Smoking Relapse: Influences of Trait Depression, Personality, and Habitual Nicotine Intake. Experimental and Clinical Psychopharmacology, 7, 174-181.

GLANZ, K. and BISHOP, D. (2010). The Role of Behavioral Science Theory in Development and Implementation of Public Health Interventions. Annual review of public health, 31, 399-418.

GOLLWITZER, P. (1999). Implementation intentions. Strong effects of simple plans. American Psychologist, 54, 493-503.

GOLLWITZER, P. and SHEERAN, P. (2006). Implementation intentions and goal achievement: A meta-analysis of effects and processes. Advances in Experimental Social Psychology, 38, 69-119.

GOLLWITZER, P. M. (1993). Goal achievement: The role of intentions. European Review of Social Psychology, 4, 141-185.

GOLLWITZER, P. M. (1996). The volitional benefits of planning. in P. M. Gollwitzer and J. Bargh (Ed.). The psychology of action: Linking cognition and motivation to behavior New York, Guilford Press: 287-312.

GOLLWITZER, P. M. and MOSKOWITZ, G. B. (1996). Goal Effects on Action and Cognition. in (Ed.). Handbook of basic principles. New York, Guilford: 361-399.

GREENWALD, A. G., NOSEK, B. A. and BANAJI, M. R. (2003). Understanding and using the implicit association test: I. An improved scoring algorithm. Journal of Personality and Social Psychology, 85, 197-216.

GRENARD, J. L., AMES, S. L., WIERS, R. W., THUSH, C., SUSSMAN, S. and STACY, A. W. (2008). Working Memory Capacity Moderates the Predictive Effects of Drug-Related Associations on Substance Use. Psychology of Addictive Behaviors, 22, 426-432. 
GRUENEWALD, T. L., MROCZEK, D. K., RYFF, C. D. and SINGER, B. H. (2008). Diverse pathways to positive and negative affect in adulthood and later life: an integrative approach using recursive partitioning. Developmental Psychology, 44, 330-343.

GWALTNEY, C., METRIK, J., KAHLER, C. and SHIFFMAN, S. (2009). Self-efficacy and smoking cessation: A meta-analysis. Psychology of addictive behaviors, 23, 56-66.

GWALTNEY, C. J., SHIFFMAN, S., BALABANIS, M. H. and PATY, J. A. (2005). Dynamic Self-Efficacy and Outcome Expectancies: Prediction of Smoking Lapse and Relapse. Journal of Abnormal Psychology, 114, 661-675.

HAAGA, D. and STEWART, B. (1992). Self-efficacy for recovery from lapse after smoking cessation. Journal of Consulting and Clinical Psychology, 60, 24-28.

HAJEK, P., STEAD, L. F., WEST, R. and JARVIS, M. (2005). Relapse prevention interventions for smoking cessation. Cochrane Database Syst Rev, 25.

HAJEK, P., STEAD, L. F., WEST, R., JARVIS, M. and LANCASTER, T. (2009). Relapse prevention interventions for smoking cessation. Cochrane Database Syst Rev, Issue 1. Art. No.: CD003999.

HALL, S., DELUCCHI, K., VELICER, W., KAHLER, C., RANGER-MOORE, J., HEDEKER, D., TSOH, J. and NIAURA, R. (2001). Statistical analysis of randomized trials in tobacco treatment: longitudinal designs with dichotomous outcome. Nicotine and Tobacco Research, 3, 193-202.

HALLAQ, J. (1976). The pledge as an instrument of behavioral change. The Journal of Social Psychology, 98, 147-148.

HASSENZAHL, M. and ULLRICH, D. (2007). To do or not to do: Differences in user experience and retrospective judgments depending on the presence or absence of instrumental goals. Interacting with Computers, 19, 429-437.

HEATHERTON, T. F., KOZLOWSKI, L. T., FRECKER, R. C. and FAGERSTROM, K. O. (1991). The Fagerstrom test for nicotine dependence: A revision of the Fagerstrom tolerance questionnaire. British Journal of Addiction, 86, 1119-1127.

HERD, N., BORLAND, R. and HYLAND, A. (2009). Predictors of smoking relapse by duration of abstinence: findings from the International Tobacco Control (ITC) Four Country Survey. Addiction, 104, 2088-2099.

HERITIER, S., GEBSKI, V. and KEACH, A. (2003). Inclusion of patients in clinical trail analysis: The intention-to-treat principle. The medical journal of Australia, 179, 438-440.

HERNÁNDEZ, A., STEYERBERG, E. and HABBEMA, J. (2004). Covariate adjustment in randomized controlled trials with dichotomous outcomes increases statistical power and reduces sample size requirements. Journal of Clinical Epidemiology, 57, 454-460.

HERON, K. E. and SMYTH, J. M. (2010). Ecological momentary interventions: incorporating mobile technology into psychosocial and health behaviour treatments. British Journal of Health Psychology, 15, 1-39.

HILBERINK, S., JACOBS, J., SCHLOSSER, M., GROL, R. and DE VRIES, H. (2006). Characteristics of patients with COPD in three motivational stages related to smoking cessation. Patient Education and Counseling, 61, 449-457.

HOLLIS, S. and CAMPBELL, F. (1999). What is meant by intention to treat analysis? Survey of randomised controlled trials. BMJ, 319, 670-674.

HOVING, E., MUDDE, A. and DE VRIES, H. (2006). Predictors of smoking relapse in a sample of Dutch adult smokers: the roles of gender and action plans. Addict Behav, 31, 1177-1189.

HSU, C. C. and SANDFORD, B. A. (2007). Minimizing non-response in The Delphi Process: How to respond to non-response. Practical assessment, research and evaluation, 12, 1-6.

HUBLET, A., MAES, L. and CSINCSAK, M. (2002). Predictors of participation in two different smoking cessation interventions at school. Health Education and Behavior, 29, 585-595.

HUGHES, J., KEELY, J. and NAUD, S. (2004). Shape of the relapse curve and long-term abstinence among untreated smokers. Addiction, 99, 29-38.

HUGHES, J., KEELY, J. and NIAURA, R. (2003). Measures of abstinence in clinical trials: issues and recommendations. Nicotine and Tobacco Research, 5, 13-25. 
HUGHES, J. R., GULLIVER, S. B., FENWICK, J. W., VALLIERE, W. A., CRUSER, K., PEPPER, S. L., SHEA, P. J., SOLOMON, L. J. and FLYNN, B. S. (1992). Smoking cessation among self-quitters. Health Psychology, 11, 331-334.

HYLAND, A., BORLAND, R., LI, Q., YONG, H. H., MCNEILL, A., FONG, G. T., O'CONNOR, R. J. and CUMMINGS, K. M. (2006). Individual-level predictors of cessation behaviours among participants in the International Tobacco Control (ITC) Four Country Survey. Tobacco Control, 15, iii83-iii94.

HYMAN, S. E., MALENKA, R. C. and NESTLER, E. J. (2006). Neural mechanisms of addiction: the role of reward-related learning and memory. Annual Review of Neuroscience, 29, 565-598.

JAPUNTICH, S., ZEHNER, M., SMITH, S., JORENBY, D., VALDEZ, J., FIORE, BAKER, T. and GUSTAFSON, D. (2006). Smoking cessation via the Internet: A randomized clinical trial of an Internet intervention as adjuvant treatment in a smoking cessation intervention. Nicotine \& Tabacco Research, 8, 59-67.

JONES, F., ABRAHAM, C., HARRIS, P., SCHULZ, J. and CHRISPIN, C. (2001). From knowledge to action regulation: Modeling the cognitive prerequisites of sun screen use in Australian and UK samples. Psychology and Health, 16, 191-206.

KASSEL, J. D., STROUD, L. R. and PARONIS, C. A. (2003). Smoking, stress, and negative affect: Correlation, causation, and context across stages of smoking. Psychological Bulletin, 129, 270-304.

KATO, P. M. (2010). Video Games in Health Care: Closing the Gap. Review of General Psychology, 14, 113-121.

KENFORD, S. L., FIORE, M. C., JORENBY, D. E., SMITH, S. S., WETTER, D. and BAKER, T. B. (1994). Predicting smoking cessation. Who will quit with and without the nicotine patch. The Journal of the American Medical Association, 271, 589-594.

KENFORD, S. L., SMITH, S. S., WETTER, D. W., JORENBY, D. E., FIORE, M. C. and BAKER, T. B. (2002). Predicting relapse back to smoking: Contrasting affective and physical models of dependence. Journal of Consulting and Clinical Psychology, 70, 216-227.

KILLEN, J. D. and FORTMANN, S. P. (1997). Craving is associated with smoking relapse: Findings from three prospective studies. Experimental and Clinical Psychopharmacology, 5, 137-142.

KILLEN, J. D., FORTMANN, S. P., KRAEMER, H. C., VARADY, A. N., DAVIS, L. and NEWMAN, B. (1996). Interactive effects of depression symptoms, nicotine dependence, and weight change on late smoking relapse. Journal of Consulting and Clinical Psychology, 64, 1060-1067.

KILLEN, J. D., FORTMANN, S. P., TELCH, M. J. and NEWMAN, B. (1988). Are Heavy Smokers Different From Light Smokers? A Comparison After 48 Hours Without Cigarettes. Journal of the American Medical Association, 260, 1581-1585.

KILLEN, J. D., FORTMANN, S. P., VARADY, A. and KRAEMER, H. C. (2002). Do men outperform women in smoking cessation trials? Maybe, but not by much. Experimental and Clinical Psychopharmacology, 10, 295-301.

KINNUNEN, T., DOHERTY, K., MILITElLO, F. S. and GARVEY, A. J. (1996). Depression and smoking cessation: Characteristics of depressed smokers and effects of nicotine dependence. Journal of Consulting and Clinical Psychology, 64, 791-798.

KREUTER, M. (2000). Tailoring: what's in a name? Health Education Research, 15, 1-4.

KREUTER, M., STRECHER, V. and GLASSMAN, B. (1999). One size does not fit all: the case for tailoring print materials. Annals of Behavioral Medicine, 21, 276-283.

KREUTER, M. and WRAY, R. (2003). Tailored and targeted health communication: strategies for enhancing information relevance. American Journal of Health Behavior, 27, 227-232.

KREUTER, M. W., CABURNAY, C. A., CHEN, J. J. and DONLIN, M. J. (2004). Effectiveness of individually tailored calendars in promoting childhood immunization in urban public health centers. American Journal of Public Health, 94, 122-127.

KROEZE, W., WERKMAN, A. and BRUG, J. (2006). A systematic review of randomized trials on the effectiveness of computer-tailored education on physical activity and dietary behaviors. Annals of Behavioral Medicine, 31, 205-223.

KWAK, L., KREMERS, S. P. J., VAN BAAK, M. A. and BRUG, J. (2007). Formation of Implementation Intentions Promotes Stair Use. American Journal of Preventive Medicine, 32, 254-255. 
LACHIN, J. (1999). Worst-rank score analysis with informatively missing observations in clinical trials. Controlled Clinical Trials, 20, 408-422.

LAI, H. K., HO, S. Y., WANG, M. P. and LAM, T. H. (2009). Secondhand Smoke and Respiratory Symptoms Among Adolescent Current Smokers. Pediatrics, 124, 1306-1310.

LAM, T. H., HO, L. M., HEDLEY, A. J., ADAB, P., FIELDING, R., MCGHEE, S. M., LEUNG, G. M. and AHARONSON-DANIEL, L. (2005). Secondhand smoke and respiratory ill health in current smokers. Tobacco Control, 14, 307-314.

LANCASTER, T., HAJEK, P., STEAD, L. F., WEST, R. and JARVIS, M. J. (2006). Prevention of Relapse After Quitting Smoking: A Systematic Review of Trials. Archives of Internal Medicine, 166, 828835.

LANCASTER, T. and STEAD, L. (2005). Self-help interventions for smoking cessation. Cochrane Database of Systematic Reviews, Issue 3. Art. No.: CD001118. , DOI: 10.1002/14651858.CD14001118.pub14651852.

LANCASTER, T. and STEAD, L. F. (2005). Individual behavioral counselling for smoking cessation. Cochrane Database of Systematic Reviews, CD001292. .

LATHAM, G. and LOCKE, E. (1991). Self-Regulation through Goal Setting. Organizational Behavior and Human Decision Processes, 50, 212-247.

LAWHON, D., HUMFLEET, G. L., HALL, S. M., REUS, V. I. and MUÑOZ, R. F. (2009). Longitudinal Analysis of Abstinence-Specific Social Support and Smoking Cessation. Health Psychology, 28, 465472.

LEONARDI-BEE, J., JERE, M. L. and BRITTON, J. (2011). Exposure to parental and sibling smoking and the risk of smoking uptake in childhood and adolescence: A systematic review and metaanalysis. Thorax, 66, 847-855.

LINSTONE, H. A. and TUROFF, M. (1975). The Delphi Method: Techniques and Applications. Reading, MA, Addison-Wesley.

LUSZCZYNSKA, A. (2006). An implementation intentions intervention, the use of a planning strategy, and physical activity after myocardial infarction. Social Science \& Medicine, 62, 900-908.

LUSZCZYNSKA, A. and HAYNES, C. (2009). Changing Nutrition, Physical Activity and Body Weight among Student Nurses and Midwives. Journal of Health Psychology, 14, 1075-1084.

LUSZCZYNSKA, A. and SCHWARZER, R. (2003). Planning and self-efficacy in the adoption and maintenance of breast self-examination: A longitudinal study on self-regulatory cogntions. Psychology and Health, 18, 93-108.

MACLEOD, C., MATHEWS, A. and TATA, P. (1986). Attentional bias in emotional disorders. Journal of Abnormal Psychology, 95, 15-20.

MACLEOD, C., RUTHERFORD, E., CAMPBELL, L., EBSWORTHY, C. and HOLKER, L. (2002). Selective attention and emotional vulnerability: assessing the causal basis of their association through the experimental manipulation of attentional bias. Journal of Abnormal Psychology, 111, 107-123.

MARINELLI-CASEY, P., DOMIER, C. and RAWSON, R. (2002). The Gap Between Research and Practice in Substance Abuse Treatment. Psychiatric Service, 53, 984-987.

MARLATT, G. A., BAER, J. S. and QUIGLEY, L. A. (1995). Self-efficacy and addictive behavior. in A Bandura (Ed.). Self-efficacy in cahnging societies. New York, Cambridge University Press: 289315.

MARLATT, G. A. and DONOVAN, D. M. (2005). Relapse Prevention, Maintenance Strategies in the Treatment of Addictive Behaviors. New York, Guilford Publications, Inc.

MARLATT, G. A. and GORDON, J. R. (1985). Relapse prevention: Maintenance strategies in the treatment of addictive behaviors. New York, Guilford Press.

MCGOWAN, H., NIX, R., MURPHY, S. and BIERMAN, K. (2010). Investigating the Impact of Selection Bias in Dose-Response Analyses of Preventive Interventions. Prevention Science, 11, 239-251.

MCHUGH, R. K., MURRAY, H. W., HEARON, B. A., CALKINS, A. W. and OTTO, M. W. (2010). Attentional Bias and Craving in Smokers: The Impact of a Single Attentional Training Session. Nicotine \& Tobacco Research, 12, 1261-1264.

MEYRICK, J. D. (2003). The Delphi method and health research. Health Education, 103, 7-16. 
MICHI, S. and ABRAHAM, C. (2004). Interventions to change health behaviours: evidence-based or evidence-inspired? . Psychology \& Health, 19, 29-49.

MICHIE, S., FIXSEN, D., GRIMSHAW, J. M. and ECCLES, M. P. (2009). Specifying and reporting complex behavior change interventions: the need for a scientific method. Implementation Science 4 (1): 40 Implementation Science, 4, 40.

MICHIE, S., JOHNSTON, M., FRANCIS, J., HARDEMAN, W. and ECCLES, M. (2008). From Theory to Intervention: Mapping Theoretically Derived Behavioural Determinants to Behaviour Change Techniques. Applied Psychology, 57, 660-680.

MILLER, G. A., GALANTER, E. and PRIBRAM, K. H. (1960). Plans and the structure of behavior. London, Holt.

MOGG, K., BRADLEY, B., FIELD, M. and DE HOUWER, J. (2003). Eye movements to smoking-related pictures in smokers: relationships between attentional biases and implicit and explicit measures of stimulus valence. Addiction, 98, 825-836.

MOGG, K. and BRADLEY, B. P. (2002). Selective processing of smoking-related cues in smokers: manipulation of deprivation level and comparison of three measures of processing bias. Journal of Psychopharmacology, 16, 385-392.

MOGG, K., BRADLEY, B. P., FIELD, M. and DE HOUWER, J. (2003). Eye movements to smoking-related pictures in smokers: relationship between attentional biases and implicit and explicit measures of stimulus valence. Addiction, 98, 825-836.

MORGAN, G., ASHENBERG, Z. and FISHER, E. (1988). Abstinence from smoking and the social environment. Journal of Consulting and Clinical Psychology, 56, 298-301.

MOSER, B. and COOMBS, L. (2004). Odds ratios for a continuous outcome variable without dichotomizing. Statistics in Medicine, 23, 1843-1860.

MROCZEK, D. K. and KOLARZ, C. M. (1998). The effect of age on positive and negative affect: a developmental perspective on happiness. Journal of Personality and Social Psychology, 75, 1333-1349.

MUDDE, A., KOK, G. and STRECHER, V. (1995). Self-efficacy as a predictor for the cessation of smoking: methodological issues and implications for smoking cessation programs. Psychology and Health, 10, 353-367.

MUDDE, A., WILLEMSEN, M., KREMERS, S. and DE VRIES, H. (2006). Meetinstrumenten voor onderzoek naar roken en stoppen met roken. [Measurements for studies about smoking and smoking cessation]. The Hague, STIVORO - The Dutch Foundation for a Smoke-free Future.

MUSCAT, J. E., STELLMAN, S. D., CARABALLO, R. S. and RICHIE, J. P. (2009). Time to first cigarette after waking predicts cotinine levels. Cancer Epidemiology, Biomarkers \& Prevention 18, 34153420 .

NAGELHOUT, G., DE KORTE, J., ZEEGERS, M., VAN DER MEER, R. and WILLEMSEN, M. (2010). THEMA PUBLICATIE Hulpmiddelen voor stoppen met roken 2001-2009 [THEME PUBLICATION Aids for smoking cessation 2001-2009]. Den Haag, STIVORO - The Dutch Foundation for a Smoke-free Future.

NHS (2012). Statistics on NHS Stop Smoking Services: England, April 2011 to December 2011 (Q3 Quarterly report). The NHS Information Centre for health and social care (2012)

NOAR, S., BENAC, C. and HARRIS, M. (2007). Does tailoring matter? Meta-analytic review of tailored print health behavior change interventions. Psychological Bulletin, 133, 673-693.

NOEL, X., COLMANT, M., VAN DER LINDEN, M., BECHARA, A., BULLENS, Q., HANAK, C. and VERBANCK, P. (2006). Time course of attention for acohol cues in abstinent alcohol patients: the role of initial orienting. Alcohol Clinical Experimental Research, 30, 1871-1877.

NOONAN, R. K. and EMSHOFF, J. G. (2011). Translating Research to Practice: Putting 'What Works' to Work. in R.J. DiClemente, L.F. Salazar and R.A. Crosby (Ed.). Health Behavior Theory For Public Health: Principles, Foundations and Applications. Burlington, Jones \& Bartlett Learning: 309-334.

O'CONNELL, K., HOSEIN, V. and SCHWARTZ, J. (2007). How does coping help people resist lapses during smoking cessation? Health Psychology, 26, 77-84.

O'CONNELL, K. A. and MARTIN, E. J. (1987). Highly tempting situations associated with abstinence, temporary lapse, and relapse among participants in smoking cessation programs. J Consult Clin Psychol, 55, 367-371. 
OCKENE, J., EMMONS, K., MERMELSTEIN, R., PERKINS, K., BONOLLO, D. and VOORHEES, C. (2000). Relapse and Maintenance Issues for Smoking Cessation. Health Psychology, 19, 17-31.

OENEMA, A., TAN, F. and BRUG, J. (2005). Short-term efficacy of a web-based computer-tailored nutrition intervention: main effects and mediators. Annals of Behavioral Medicine, 29, 54-63.

OSUMC (2012), Mood Disorders. Retrieved March 14, 2012, from http://medicalcenter.osu.edu/patientcare/healthcare_services/mental_health/mental_health_about/mood/Pages/index.aspx, The Ohio State University Medical Centre.

PACKIAM ALLOWAY, T. and ALLOWAY, R. (2009). The efficacy of working memory training in improving crystallized intelligence. Available from Nature Precedings http://hdl.handle.net/10101/npre.2009.3697.1

PATRICK, D. L., CHEADLE, A., THOMPSON, D. C., DIEHR, P., KOEPSELL, T. and KINNE, S. (1994). The validity of self-reported smoking: a review and meta-analysis. Am J Public Health, 84, 10861093.

PATTEN, C. A. and MARTIN, J. E. (1996). Does nicotine withdrawal affect smoking cessation? Clinical and theoretical issues. . Annals of behavioral medicine, 18, 190-200.

PIASECKI, T. (2006). Relapse to smoking. Clinical Psychology Review, 26, 196-215.

PIETERSE, M. E., SEYDEL, E. R., DEVRIES, H., MUDDE, A. N. and KOK, G. J. (2001). Effectiveness of a minimal contact smoking cessation program for Dutch general practitioners: a randomized controlled trial. Prev Med, 32, 182-190.

PILL, J. (1971). The Delphi Method: Substance, Context, a Critique and an Annotated Bibliography. Socio-economic planning sciences, 5, 57-71.

PISINGER, C., AADAHL, M., TOFT, U. and JøRGENSEN, T. (2011). Motives to quit smoking and reasons to relapse differ by socioeconomic status. Preventive Medicine, 52, 48-52.

PLAS, A. G. M. V. D., HILBERINK, S. R., HERMANS, M. H. and BRETELER, M. H. M. (2001). De regionale cursussen 'stoppen met roken' / Regional smoking cessation courses. Nijmegen.

POHL, J. M., MARTINELLI, A. and ANTONAKOS, C. (1998). Predictors of participation in a smoking cessation intervention group among low-income women. Addictive Behaviors, 23, 699-704.

POMERLEAU, O. F., FERTIG, J. B. and SHANAHAN, S. O. (1983). Nicotine dependence in cigarette smoking: an empirically-based, multivariate model. Pharmacol Biochem Behav, 19, 291-299.

POMERLEAU, O. F., POMERLEAU, C. S., MEHRINGER, A. M., SNEDECOR, S. M., NINOWSKI, R. and SEN, A. (2005). Nicotine dependence, depression, and gender: Characterizing phenotypes based on withdrawal discomfort, response to smoking, and ability to abstain. Nicotine \& Tobacco Research, 7, 91-102.

PROCHASKA, J. O. (2008). Decision Making in the Transtheoretical Model of Behavior Change. Medical Decision Making, 28, 845-849.

PROCHASKA, J. O. and DICLEMENTE, C. C. (1983). Stages and processes of self-change of smoking: Toward an integrative model of change. Journal of Consulting and Clinical Psychology, 51, 390395.

PROCHASKA, J. O. and VELICER, W. F. (1997). The Transtheoretical Model of health behavior change. . American Journal of Health Promotion, 12, 38-48.

RISE, J., THOMPSON, M. and VERPLANKEN, B. (2003). Measuring implementation intentions in the context of the theory of planned behavior. Scandinavian Journal of Psychology, 44, 87-95.

RITTERBAND, L. M., THORNDIKE, F. P., COX, D. J., KOVATCHEV, B. P. and GONDER-FREDERICK, L. A. (2009). A behavior change model for internet interventions. Ann Behav Med, 38, 18-27.

ROBERT WEST, P. H. L. S. J. S. (2005). Outcome criteria in smoking cessation trials: proposal for a common standard. Addiction, 100, 299-303.

ROBINSON, T. and BERRIDGE, K. (1993). The neural basis of drug craving: a incentive-sensitization theory of addiction. Brain Research Review, 18, 247-291.

ROBINSON, T. E. and BERRIDGE, K. C. (2003). Addiction. Annual Review of Psychology, 54, 25-53.

ROBINSON, T. E. and BERRIDGE, K. C. (2008). Review. The incentive sensitization theory of addiction: some current issues. Philos Trans R Soc Lond B Biol Sci, 363, 3137-3146. 
ROGERS, R. W. (1983). Cognitive and physiological processes in fear appeals and attitude change: A revised theory of protection motivation. in J.T. Cacioppo and R.E. Petty (Ed.). Social Psychophysiology - A source-book. New York, Guilford Press.

ROOKE, S. E., HINE, D. W. and THORSTEINSSON, E. B. (2008). Implicit cognition and substance use: a meta-analysis. Addictive Behaviors, 33, 1314-1328.

ROSKI, J., SCHMID, L. A. and LANDO, H. A. (1996). Long-term associations of helpful and harmful spousal behaviors with smoking cessation. Addictive Behaviors, 21, 173-185.

RYAN, R., RIGBY, C. and PRZYBYLSKI, A. (2006). The Motivational Pull of Video Games: A SelfDetermination Theory Approach. Motivation and Emotion, 30, 344-360.

SALEMINK, E. and WIERS, R. W. (2012). Adolescent threat-related interpretive bias and its modification: the moderating role of regulatory control. Behaviour Research and Therapy, 50, 40-46.

SCHERSTÉN, T. (1986). Some Reflections on Randomized Controlled Trials. International Journal of Technology Assessment in Health Care, 2, 39-42.

SCHMIDT, N. B., RICHEY, J. A., BUCKNER, J. D. and TIMPANO, K. R. (2009). Attention training for generalized social anxiety disorder. Journal of Abnormal Psychology, 118, 5-14.

SCHMUKLE, S. C. (2005). Unreliability of the dot probe task. European Journal of Personality, 19, 595605.

SCHNEIDER, F., VAN OSCH, L. and DE VRIES, H. (2012). Identifying factors for optimal development of health-related websites: a delphi study among experts and potential future users. J Med Internet Res, 14.

SCHOENMAKERS, T., DE BRUIN, M., LUX, I. F., GOERTZ, A. G., VAN KERKHOF, D. H. and WIERS, R. W. (2010). Clinical effectiveness of attentional bias modification training in abstinent alcoholic patients. Drug and Alcohol Dependence, 109, 30-36.

SCHOENMAKERS, T., WIERS, R. and FIELD, M. (2008). Effects of a low dose of alcohol on cognitive biases and craving in heavy drinkers. Psychopharmacology, 197, 169-178.

SCHOENMAKERS, T., WIERS, R. W., JONES, B. T., BRUCE, G. and JANSEN, A. T. M. (2007). Attentional re-training decreases attentional bias in heavy drinkers without generalization. Addiction, 102, 399-405.

SCHWARZER, R. (2001). Social-Cognitive Factors in Changing Health-Related Behaviors. Current Directions in Psychological Science, 10, 47-51.

SEGAN, C. J., BORLAND, R. and GREENWOOD, K. M. (2006). Can transtheoretical model measures predict relapse from the action stage of change among ex-smokers who quit after calling a quitline? Addictive Behaviors, 31, 414-428.

SHAHAB, L. and MCEWEN, A. (2009). Online support for smoking cessation: a systematic review of the literature. Addiction, 104, 1792-1804.

SHAPIRO, D., JAMNER, L., DAVYDOV, D. and PROCHASKA, J. (2002). Situations and moods associated with smoking in everyday life. Psychology of Addictive Behaviors, 16, 342-345.

SHAW, D. and AL'ABSI, M. (2008). Attenuated beta endorphin response to acute stress is associated with smoking relapse. Pharmacol biochem Behav, 90, 357-362.

SHEERAN, P. (2002). Intention-behavior relations: a conceptual and empirical review. in W. Strobe and M. Hewstone (Ed.). European review of Social Psychology, Volume 12. Chichester, UK, Wiley: $1-30$.

SHIFFMAN, S. (1982). Relapse following smoking cessation: A situational analysis. J Consult Clin Psychol, 50, 71-86.

SHIFFMAN, S. (1987). The concept of craving: Let us not throw the bayb out with the bath water. British Journal of Addiction, 82, 37-38.

SHIFFMAN, S. (2004). Immediate antecedents of cigarette smoking: an analysis of unrestricted smoking patterns. Journal of abnormal psychology, 113, 166-171.

SHIFFMAN, S. (2007). Nicotine replacement therapy for smoking cessation in the "real world". Thorax, 62, 930-931. 
SHIFFMAN, S., BALABANIS, M. H., GWALTNEY, C. J., PATY, J. A., GNYS, M., KASSEL, J. D., HICKCOX, M. and PATON, S. M. (2007). Prediction of lapse from associations between smoking and situational antecedents assessed by ecological momentary assessment. Drug and Alcohol Dependence, 91, 159-168.

SHIfFMAN, S., ENGBERG, J. B., PATY, J. A., PERZ, W. G., GNYS, M., KASSEL, J. D. and HICKCOX, M. (1997). A day at a time: Predicting smoking lapse from daily urge. Journal of Abnormal Psychology, 106, 104-116.

SHIFFMAN, S., GWALTNEY, C. J., BALABANIS, M. H., LIU, K. S., PATY, J. A., KASSEL, J. D., HICKCOX, M. and GNYS, M. (2002). Immediate Antecedents of Cigarette Smoking: An Analysis From Ecological Momentary Assessment. Journal of Abnormal Psychology, 111, 531-545.

SHIFFMAN, S., KASSEL, J., GWALTNEY, C. and MCCHARGUE, D. (2005). Relapse prevention for smoking. in G. Marlatt and D. Donovan (Ed.). Relapse Prevention: Maintenance Strategies in the Treatment of Addictive Behaviors. New York, Guilford Press: 92-129.

SHIFFMAN, S., PATY, J. A., GNYS, M., KASSEL, J. A. and HICKCOX, M. (1996). First lapses to smoking: within-subjects analysis of real-time reports. J Consult Clin Psychol, 64, 366-379.

SHIFFMAN, S. and WATERS, A. J. (2004). Negative Affect and Smoking Lapses: A Prospective Analysis. Journal of Consulting and Clinical Psychology, 72, 192-201.

SHIFTMAN, S., HICKCOX, M., PATY, J., GNYS, M., KASSEL, J. and RICHARDS, T. (1996). Progression from a smoking lapse to relapse: Prediction from abstinence violation effects, nicotine dependence, and lapse characteristics. Journal of Consulting and Clinical Psychology, 64, 993-1002.

SMEETS, T., BRUG, J. and DE VRIES, H. (2008). Effects of tailoring health messages on physical activity. Health Education Research, 23, 402-413.

SMIT, E., DE VRIES, H. and HOVING, C. (2012). Effectiveness of a Web-Based Multiple Tailored Smoking Cessation Program: A Randomized Controlled Trial Among Dutch Adult Smokers. Journal of Medical Internet Research, 14, e82.

SNIEHOTTA, F., F. , SCHWARZER, R., SCHOLZ, U. and SCHÜZ, B. (2005). Action planning and coping planning for long-term lifestyle change: theory and assessment. European Journal of Social Psychology, 35, 565-576.

SNIEHOTTA, F., SCHOLZ, U. and SCHWARZER, R. (2005). Bridging the intention-behaviour gap: Planning, self-efficacy, and action control in the adoption and maintenance of physical exercise. Psychology and Health, 20, 143-160.

SNIEHOTTA, F., SCHOLZ, U. and SCHWARZER, R. (2006). Action plans and coping plans for physical exercise: a longitudinal intervention study in cardiac rehabilitation. British Journal of Health Psychology, 11, 23-37.

SNIEHOTTA, F. F. (2009). Towards a theory of intentional behaviour change: Plans, planning, and self-regulation. British Journal of Health Psychology, 14, 261-273.

SRNT (2002). SRNT: subcommittee on biological verification: Biochemical verification of tobacco use and cessation. Nicotine \& Tobacco Research, 4, 149-159.

STACY, A. (1997). Memory activation and expectancy as prospective predictors of alcohol and marijuana use. Journal of Abnormal Psychology, 106, 61-73.

STACY, A. W. and WIERS, R. W. (2010). Implicit cognition and addiction: a tool for explaining paradoxical behavior. Annual Review of Clinical Psychology, 6, 551-575.

STAUGAARD, S. R. (2009). Reliability of two versions of the dot-probe task using photographic faces. Psychology Science Quarterly, 51, 339-350.

STEAD, L. F., PERERA, R., BULLEN, C., MANT, D. and LANCASTER, T. (2008). Nicotine replacement therapy for smoking cessation. Cochrane Database of Systematic Reviews, Issue 1. Art. No.: CD000146, DOI: 10.1002/14651858.CD14000146.pub14651853.

STEELE, R. M., MUMMERY, W. K. and DWYER, T. (2007). Examination of program exposure across intervention delivery modes: face-to-face versus internet. The international journal of behavioral nutrition and physical activity, 4, 7.

STEPHAN, W. G. (2006). Bridging the Researcher-Practitioner Divide in Intergroup Relations. Journal of Social Issues, 62, 597-605. 
STEVENS, V. and HOLLIS, J. (1989). Preventing smoking relapse: using an individually tailored skillstraining technique. Journal of Consulting and Clinical Psychology, 57, 420-424.

STIVORO (2010). Van onderop en van bovenaf. De toekomst van tabaksontmoediging in Nederland 2011 - 2020 [The future of tobacco control in the Netherlands 2011-2020]. Den Haag, STIVORO.

STIVORO (2011). Kerncijfers roken in Nederland 2010. Een overzicht van recente Nederlandse basisgegevens over rookgedrag [An overview of data on smoking behavior in the Netherlands]. Den Haag, STIVORO.

STIVORO (2012). Trendpublicatie percentage rokers. Percentage rokers in de Nederlandse bevolking 1958-2011 [Trend publication smoking rates. Smoking rates in the Dutch population 19582011]. Den Haag, STIVORO.

STOMARK, K., FIELD, N., HUGDAHL, K. and HOROWITZ, M. (1997). Selective processing of visual alcohol cues in abstinent alcoholics: an approach-avoidance conflict? Addictive Behaviors, 22, 509-519.

STRACK, F. and DEUTSCH, R. (2004). Reflective and Impulsive Determinants of Social Behavior. Personality and Social Psychology Review, 8, 220-247.

STRASSER, A. A., PICKWORTH, W. B., PATTERSON, F. and LERMAN, C. (2004). Smoking Topography Predicts Abstinence following Treatment with Nicotine Replacement Therapy. Cancer Epidemiol Biomarkers Prev, 13, 1800-1804.

STRECHER, V. (2007). Internet methods for delivering behavioral and health-related interventions (eHealth). Annual Review of Clinical Psychology, 3, 53-76.

STRECHER, V., SHIFFMAN, S. and WEST, R. (2005). Randomized controlled trial of a web-based computer-tailored smoking cessation program as a supplement to nicotine patch therapy. Addiction, 100, 682-688.

STRECHER, V. J. (1999). Computer-tailored smoking cessation materials: A review and discussion. Patient Education and Counseling, 36, 107-117.

STRECHER, V. J. (2007). Internet methods for delivering behavioral and health-related interventions (eHealth). Annual Review of Clinical Psychology, 3, 53-76.

STRECHER, V. J., KREUTER, M., DEN BOER, D. J., KOBRIN, S., HOSPERS, H. J. and SKINNER, C. S. (1994). The effects of computer-tailored smoking cessation messages in family practice settings. Journal of Family Practice, 39, 262-270.

SUN, X., PROCHASKA, J. O., VELICER, W. F. and LAFORGE, R. G. (2007). Transtheoretical principles and processes for quitting smoking: A 24-month comparison of a representative sample of quitters, relapsers, and non-quitters. Addictive Behaviors, 32, 2707-2726.

TATE, D. F. and ZABINSKI, M. F. (2004). Computer and Internet applications for psychological treatment: Update for clinicians. Journal of Clinical Psychology, 60, 209-220.

TE POEL, F., BOLMAN, C., REUBSAET, A. and DE VRIES, H. (2009). Efficacy of a single computertailored email for smoking cessation: results after six months. Health Education Research, 24, 930-940.

TIFFANY, S. T. (1990). A cognitive model of drug urges and drug-use behavior: role of automatic and non-automatic processes. Psychological Review, 97, 147-168.

TNS-NIPO (2009). Continu onderzoek rookgewoonten (1979-2009), [Research report smoking habits (1979-2009)] Amsterdam, TNS-NIPO.

TOWNSHEND, J. and DUKA, T. (2001). Attentional bias associated with alcohol cues: differences between heavy and occasional social drinkers. Psychopharmacology, 157, 67-74.

TOWNSHEND, J. and DUKA, T. (2007). Avoidance of alcohol-related stimuli in alcohol-dependent inpatients. Alcohol Clinical Experimental Research, 31, 1-9.

VAN OSCH, L., LECHNER, L., REUBSAET, A. and DE VRIES, H. (2010). From theory to practice: an explorative study into the instrumentality and specificity of implementation intentions. Psychology \& Health, 25, 351-364.

VAN OSCH, L., LECHNER, L., REUBSAET, A., WIGGER, S. and DE VRIES, H. (2008). Relapse prevention in a national smoking cessation contest: Effects of coping planning. British Journal of Health Psychology, 13, 525-535. 
VANDELANOTTE, C., SPATHONIS, K. M., EAKIN, E. G. and OWEN, N. (2007). Website-Delivered Physical Activity Interventions: A Review of the Literature. American Journal of Preventive Medicine, 33, 54-64.

VELICER, W., DICLEMENTE, C., ROSSI, J. and PROCHASKA, J. (1990). Relapse Situations and SelfEfficacy: An Integrative Model. Addict Behav, 15, 271-283.

VELICER, W., PROCHASKA, J., ROSSI, J. and SNOW, M. (1992). Assessing outcome in smoking cessation studies. Psychologicial Bulletin, 11, 23-41.

VELICER, W. F. and PROCHASKA, J. O. (2004). A comparison of four self-report smoking cessation outcome measures. Addictive Behaviors, 29, 51-60.

WALTERS, S. T., WRIGHT, J. A. and SHEGOG, R. (2006). A review of computer and Internet-based interventions for smoking behavior. Addictive Behaviors, 31, 264-277.

WANGBERG, S., BERGMO, T. and JOHNSEN, J. (2008). Adherence in Internet-based Interventions. Patient Preference and Adherence, 2, 57-65.

WATERS, A., SHIFFMAN, S., BRADLEY, B. and MOGG, K. (2003). Attentional shifts to smoking cues in smokers. Addiction, 98, 1409-1417.

WATERS, A. J. and FEYERABEND, C. (2000). Determinants and effects of attentional bias in smokers. Psychology and addictive behaviors, 14, 111-120.

WATERS, A. J., SHIFFMAN, S., SAYETTE, M. A., PATY, J. A., GWALTNEY, C. J. and BALABANIS, M. H. (2003). Attentional bias predicts outcome in smoking cessation. Health Psychology, 22, 378-387.

WATSON, P., DE WIT, S., HOMMEL, B. and WIERS, R. W. (2012). Motivational mechanisms and outcome expectancies underlying the approach bias toward addictive substances. Frontiers in Psychology, 3.

WEBB, T. L. and SHEERAN, P. (2006). Does Changing Behavioral Intentions Engender Behavior Change? A Meta-Analysis of the Exerimental Evidence. Psychological Bulletin, 132, 249-268.

WEINSTEIN, N. (1988). The precaution adoption process. Health Psychology, 7, 355-386.

WERTZ, R. (1995). Intention to treat: Once randomized, always analyzed. Clinical Aphasiology, 23, 57-64.

WEST, R., HAJEK, P., STEAD, L. and STAPLETON, J. (2005). Outcome criteria in smoking cessation trials: proposal for a common standard. Addition, 100, 299-303.

WEST, R., MCEWEN, A., BOLLING, K. and OWEN, L. (2001). Smoking cessation and smoking patterns in the general population: a 1-year follow-up. Addiction, 96, 891-902.

WEST, R. J., HAJEK, P. and BELCHER, M. (1989). Severity of withdrawal symptoms as a predictor of outcome of an attempt to quit smoking. Psychol Med, 19, 981-985.

WHO (2001). WHO evidence based on recommendations on the treatment of tobacco dependence Copenhagen, World Health Organization.

WHO (2008). World Health Report on the Global Tobacco Epidemic: 2008: The Mpower Package. Geneve, World Health Organisation.

WHO (2009). WHO Report on the Global Epidemic (http://www.who.int/tobacco/mpower/2009/en/index.html). Geneva: World Health Organization, 2008.

WIERS, R., BARTHOLOW, B., VAN DEN WILDENBERG, E., THUSH, C., ENGELS, R., SHER, K., GRENARD, J., AMES, S. and STACY, A. (2007). Automatic and controlled processes and the development of addictive behaviors in adolescents: a review and a model. Pharmacology, Biochemistry and Behavior, 86, 263-283.

WIERS, R., RINCK, M., DICTUS, M. and VAN DEN WILDENBERG, E. (2009). Relatively strong automatic appetitive action-tendencies in male carriers of the OPRM1 G-allele. . Genes, Brain and Behavior, 8, 101-106.

WIERS, R. and STACY, A. (2006). Handbook of implicit cognition and addiction. Thousand Oaks, CA: SAGE Publishers.

WIERS, R., STACY, A., AMES, S., NOLL, J., SAYETTE, M., ZACK, M. and KRANK, M. (2002). Implicit and explicit alcohol related cognitions. Alcoholism: clinical and experimental research, 26, 129-137.

WIERS, R., VAN DE LUITGAARDEN, J., VAN DEN WILDENBERG, E. and SMULDERS, F. (2005). Challenging implicit and explicit alcohol-related cognitions in young heavy drinkers. Society for the study of addiction, 100, 806-819. 
WIERS, R., VAN WOERDEN, N., SMULDERS, F. and DE JONG, P. (2002). Implicit and explicit alcoholrelated cognitions in heavy and light drinkers. Journal of abnormal psychology., 111, 648-658.

WIERS, R. W., EBERL, C., RINCK, M., BECKER, E. and LINDENMEYER, J. (2011). Re-training automatic action tendencies changes alcoholic patients' approach bias for alcohol and improves treatment outcome. Psychological Science, 22, 490-497.

WIERS, R. W., GLADWIN, T. E., HOFMANN, W., SALEMINK, E. and RIDDERINKHOF, K. R. (in press). Cognitive bias modification training in addiction and related psychopathology: mechanisms, clinical perspectives and ways forward. Clinical Psychological Science

WILLEMSEN, M., WAGEMA, E. J. and SCHAYCK VAN, C. P. (2003). De effectiviteit van stoppen-metroken methoden die in Nederland beschikbaar zijn: een systematische review op basis van Cochrane gegevens. Nederlands Tijdschrift voor Geneeskunde, 147, 922-927.

WINTER, S. and SZULANSKI, G. (2001). Replication as Strategy. Organization Science, 12, 730-743.

XU, J., AZIZIAN, A., MONTEROSSO, J., DOMIER, C. P., BRODY, A. L., LONDON, E. D. and FONG, T. W. (2008). Gender effects on mood and cigarette craving during early abstinence and resumption of smoking. Nicotine and Tobacco Research, 10, 1653-1661.

ZHOU, X., NONNEMAKER, J., SHERRILL, B., GILSENAN, A. W., COSTE, F. and WEST, R. (2009). Attempts to quit smoking and relapse: factors associated with success or failure from the ATTEMPT cohort study. Addictive Behaviors, 34, 365-373.

ZHU, S., MELCER, T., SUN, J., ROSBROOK, B. and PIERCE, J. P. (2000). Smoking cessation with and without assistance: a population-based analysis. Am J Prev Med, 18, 305-311.

ZHU, S. H., STRETCH, V., BALABANIS, M., ROSBROOK, B., SADLER, G. and PIERCE, J. P. (1996). Telephone counseling for smoking cessation: Effects of single-session and multiple-session interventions. . Journal of Consulting and Clinical Psychology, 64, 202-211.

ZIEGELMANN, J. P., LIPPKE, S. and SCHWARZER, R. (2006). Adoption and maintenance of physical activity: Planning interventions in young, middle-aged, and older adults. Psychology \& Health, 21, 145-163.

ZIMMERMANN, B. (2000). Attaining self-regulation: A social cognitive perspective. in (Ed.). Handbook of self-regulation. San Diego, Academic Press: 13-39.

ZINSER, M. C., BAKER, T. B., SHERMAN, J. E. and CANNON, D. S. (1992). Relation between selfreported affect and drug urges and cravings in continuing and withdrawing smokers. J Abnorm Psychol, 101, 617-629. 


\section{SUMMARY}

Tobacco use is a serious harm for human health. Although most smokers want to quit smoking only very few are successful in their attempts. The fallback into smoking after a quit-attempt is referred to as smoking relapse and it forms an evident problem in the process of successful smoking cessation. Furthermore, current smoking relapse prevention programs have shown only modest behavioral effects. The alarming relapse rates after a quit-attempt and the lack of effective prevention programs underline the need to further understand the factors that are important in the process of smoking relapse and to develop new effective prevention programs. Theoretical models on explicit as well as on implicit processes in behavior change can be consulted in order to fulfill this need. In this dissertation, the I-Change Model - a theoretical model integrating several social cognitive approaches - was used in order to understand and influence the explicit cognitions underlying smoking relapse. Neurobiological theories of addiction were consulted in order to understand and influence implicit cognitions.

The research reported in this dissertation had two central goals. The first goal was to better understand the factors that are important in the process of smoking relapse (chapter 2 and 3). The second goal was to develop and test two Web-based relapse prevention programs: a) Stay Quit for You (SQ4U), a program consisting of two versions (Action Planning (AP) and Action Planning Plus $(\mathrm{AP}+))$ that both provide tailored feedback at baseline and incorporate six action planning assignments (three before and three after the quit-date), but with only one of the versions (the AP+ program) also providing tailored feedback after the quit-date (chapter 4, 5, 6 and 7); and b) Train Yourself Smoke-free, an attentional bias modification training program (chapter 8). The SQ4U programs were developed to target explicit cognitions underlying smoking relapse, while the Train Yourself Smoke-free training was developed to target implicit cognitions.

Chapter 1 forms the introductory chapter of this dissertation. This chapter introduces the problem of smoking relapse, discusses the theoretical frameworks used in this dissertation, and reflects on the current state of knowledge and crucial knowledge gaps. Furthermore, this chapter discusses the rationalization for the series of studies reported in this dissertation and the considerations made for the development of the SQ4U programs and the Train Your Smoke-free training.

Chapter 2 describes a three-round Delphi-study that was conducted among 47 international smoking relapse prevention researchers and 61 national 
coaches (who provide smoking-cessation counselling). The Delphi-study aimed to further understand the factors that are associated with smoking relapse, the role of relatively disregarded factors such as action planning and implicit cognitions and the factors that need to be imbedded in prevention programs. Differences and similarities between researchers and coaches and therefore between theory and practice were revealed. The study, furthermore, pointed out that high levels of consensus were reached on the importance of action planning, implicit cognitions and several other concepts (e.g. stress) and suggests a need to intensify the development and testing of relapse prevention programs that include action planning and implicit cognitions as strategies to prevent relapse.

Chapter 3 reports on a longitudinal quasi-experimental study conducted among smokers quitting individually $(\mathrm{N}=64)$ and smokers quitting in a cessation course $(\mathrm{N}=57)$. The study aimed to identify the role of preparatory planning, self-efficacy and recovery self-efficacy with regard to short-term smoking relapse. Low levels of self-efficacy consistently predicted relapse, while less preparatory planning significantly predicted relapse at one month after the quit attempt among group quitters only.

Chapter 4 provides a detailed outline of the development and design of the SQ4U study. The SQ4U study aimed to test the efficacy of two SQ4U programs (AP and AP+ program) in preventing smoking relapse among smokers who were motivated to quit smoking within one month.

Chapter 5 describes a randomized controlled trial testing the efficacy of the two Web-based SQ4U programs (AP and $\mathrm{AP}+$ ) in preventing longer-term (twelve months after baseline) smoking relapse among smokers who were motivated to quit smoking within one month. Both programs were compared with a control group with no intervention. Three different samples were analyzed: (1) all respondents as randomized ( $N=2031)$; (2) a modified sample that excluded respondents who did not make a quit-attempt in conformance with the program protocol ( $\mathrm{N}=1812)$; and (3) a minimum dose sample that also excluded respondents who did not adhere to at least one of the intervention elements $(\mathrm{N}=1324)$. For all samples the results of the observed case as well as the conservative analyses (considering dropouts as smokers) are reported. In the observed case analyses of sample 1 , the AP and AP+ program were both significantly more effective than the control group in fostering longer-term abstinence. The program effects were, however, no longer significantly more effective than the control group when conducting a conservative analysis in sample 1. Abstinence rates and effects further differed per sample and per analysis. Moreover, the results suggest a dose-response relationship between abstinence and the number of program elements completed by the respondents

Chapter 6 reports on the effects of the two Web-based SQ4U programs (AP and $\mathrm{AP}+$ ) with regard to preventing short-term (six months after baseline) smoking relapse among smokers who were motivated to quit smoking within one month. The study is a randomized controlled trial (RCT) and the sample 
analyzed was a modified sample excluding respondents who did not make a quit-attempt in conformance with the program protocol $(\mathrm{N}=1812)$. Both programs were compared to a control group with no intervention. Observed case analyses as well as the conservative analyses are reported. None of the programs was significantly more effective in fostering short-term continued smoking abstinence compared to the control group. Again, abstinence rates in the programs depended on adherence to the program elements.

Chapter 7 describes a study that was part of a larger randomized controlled trial (SQ4U study) and only included data of AP and AP+ program participants who completed the coping planning assignment that was part of the programs $(\mathrm{N}=563)$. This in-depth study aimed to gain insight into the situational and affective risk situations of smoking relapse as perceived by the SQ4U respondents, to assess the plan quality (instrumentality and specificity) of the implementation intentions formulated to deal with these risk situations (distinguishing between situational and affective risk situations) and to assess the impact of plan quality on continued smoking abstinence after six and twelve month. Feeling stressed and craving for a cigarette were most often selected as risk situations. The specificity of implementation intentions formed to deal with affective situations was significantly lower than the specificity of plans formed to cope with situational risk situations. Furthermore, plan specificity had a behavioral impact on continued smoking abstinence at six and twelve months after baseline.

Chapter 8 describes a randomized controlled trial (RCT) testing the efficacy of an attentional bias modification training with regard to preventing shortterm (six months after baseline) smoking relapse among smokers who were motivated to quit smoking within one month. In addition, the study assessed the differential effects of the training for regular smokers (defined as smoking more than fifteen cigarettes per day) and non-regular smokers (defined as: not smoking more than fifteen cigarettes per day) and showed promising behavioral effects for regular smokers.

Chapter 9 includes the general discussion of this dissertation and reflects on the findings on smoking relapse prevention as derived from the results of the studies presented in the previous chapters. This chapter discusses current findings, future directions, strengths of the studies conducted and challenges to meet in the future. The chapter ends with six general conclusions. First, more insight into the transition from theory to practice is essential for the development as well as the dissemination and adoption of new smoking relapse prevention programs. Second, computer-tailored approaches combined with multiple action planning assignments as utilized in the SQ4U programs have the potential to foster longer-term continued smoking abstinence. However, improvements to the program are needed in order to reach better results. Third, the support for providing short tailored feedback at various moments after the quit attempt over and above planning strategy assignments is limited. More research is needed in order to assess whether providing this feedback when most needed, for 
instance by using real-time interventions such as ecological momentary interventions, will result in better effects. Fourth, improvements of the SQ4U programs are required in order to foster adherence among smokers and adoption among national health care institutes. Fifth, attentional bias modification strategies are successful in fostering short-term smoking abstinence and should therefore be included in prevention programs. Improving the assessment tools that are used for measuring implicit cognitive biases is, however, essential. Finally, new initiatives are required in order to assess the effects of combined strategies (explicit cognition and implicit cognition approaches altogether in one program), to assess the efficacy of the approaches as reported in this dissertation among other groups of smokers (e.g. smokers who are not motivated to quit smoking), and to test whether implicit tendencies underlie explicit cognitions such as self-efficacy and action planning. 


\section{SAMENVATTING}

Roken brengt serieuze schade toe aan de menselijke gezondheid. Hoewel de meeste rokers willen stoppen met roken, zijn er maar heel weinig die hierin slagen. Deze terugval na een stoppoging vormt een groot probleem voor rokers die willen stoppen met roken. Bovendien blijken huidige terugvalpreventieprogramma's maar weinig effectief in het voorkomen van terugval. De schokkende terugvalpercentages na een stoppoging in combinatie met het gebrek aan effectieve terugvalpreventieprogramma's bevestigen de behoefte aan meer inzicht in de factoren die terugval voorspellen en in de ontwikkeling van nieuwe effectieve preventieprogramma's. Zowel theoretische modellen die zich richten op de expliciete processen als modellen die zich richten op impliciete processen van gedragsverandering kunnen hiervoor gebruikt worden. In dit proefschrift is gebruik gemaakt van het I-Change Model - een theoretisch kader dat meerdere sociaal cognitieve modellen integreert - om de expliciete processen waaraan terugval onderhevig is te begrijpen en te beïnvloeden. Neurobiologische modellen zijn gebruikt voor de impliciete processes.

Het onderzoek dat wordt beschreven in dit proefschrift had twee hoofddoelen. Het eerste doel was om meer inzicht te krijgen in de factoren die terugval voorspellen (hoofdstuk 2 en 3). Het tweede doel was om twee Internet terugvalpreventieprogramma's te ontwikkelen en te testen. Het eerste programma heet SQ4U (Stay Quit for You) en bestaat uit twee versies (het Actie Plannen (AP) programma en het Actie Plannen Plus ( $\mathrm{AP}+$ ) programma): beide versies bestaan uit een advies-op-maat na het invullen van de voormetingsvragenlijst en uit zes planningsopdrachten (drie voor en drie na de stopdatum), maar alleen in het AP+ programma wordt ook advies-op-maat op meerdere momenten na de stopdatum gegeven (hoofdstuk 4, 5, 6 en 7). Het tweede programma was een aandachttraining met de naam Train jezelf Rookvrij. De SQ4U programma's zijn ontwikkeld om de expliciete processen waar terugval bij roken aan onderhevig is te beinvloeden, terwijl het Train jezelf Rookvrij programma is ontwikkeld om de impliciete processen te beinvloeden (hoofdstuk 8).

Hoofdstuk 1 vormt de inleiding van dit proefschrift. Dit hoofdstuk heeft als doel om het probleem van terugval na een stoppoging te introduceren, de theoretische modellen te bespreken en de huidige stand van zaken met betrekking tot terugval in beeld te brengen. Verder omschrijft dit hoofdstuk de rationale voor de reeks aan studies die in dit proefschrift staan als wel de ontwikkeling van het SQ4U programma en de Train jezelf Rookvrij training. 
Hoofdstuk 2 beschrijft een Delphi-studie van drie rondes die uitgevoerd is onder experts ( 47 onderzoekers en 61 stoppen-met-roken coaches). Deze studie had als als doel inzicht te krijgen in meningen van experts met betrekking tot de factoren die terugval voorspellen, effectieve terugvalpreventie en de rol van actieplannen en impliciete cognities. De resultaten bestaan uit overeenkomsten en verschillen tussen onderzoekers en coaches, en daarmee tussen theorie en praktijk. In beide groepen was er een duidelijke mate van consensus met betrekking tot de rol van actieplannen, impliciete cognities en verschillende andere concepten (zoals stress). De uitkomsten van de Delphi studie suggereren dat het nodig is om terugvalpreventieprogramma's te ontwikkelen en testen die actieplannen en impliciete cognities opnemen als strategieën om terugval te voorkomen.

Hoofdstuk 3 beschrijft een quasi-experimenteel longitudinaal onderzoek dat is uitgevoerd onder rokers die met behulp van een stoppen-met-roken cursus probeerden te stoppen met roken $(\mathrm{N}=57)$ en rokers die individueel probeerden te stoppen met roken $(\mathrm{N}=64)$. Deze studie had als doel inzicht te krijgen in de rol van voorbereidende plannen en self-efficacy met betrekking tot korte termijn terugval (na 1 en 3 maanden). Een lage self-efficacy op de voormeting bleek een consequente voorspeller van terugval, terwijl een gebrek aan planning een voorspeller van terugval was voor groepsstoppers, maar niet voor zelfstandige stoppers.

Hoofdstuk 4 beschrijft de ontwikkeling en het onderzoeksdesign van de SQ4U studie. De SQ4U studie had als doel de effectiviteit te testen van twee SQ4U programma's ( $\mathrm{AP}$ en $\mathrm{AP}+$ ) met betrekking tot het voorkomen van terugval op de korte (na zes maanden) en lange termijn (na twaalf maanden) bij rokers die gemotiveerd waren om binnen een maand te stoppen met roken.

Hoofdstuk 5 beschrijft een gerandomiseerde experimenteel onderzoek dat als doel had de effectiviteit te testen van twee SQ4U programma's (AP en het $\mathrm{AP}+$ ) met betrekking tot het voorkomen van terugval op de lange termijn (twaalf maanden na de voormeting) bij rokers die gemotiveerd waren om binnen een maand te stoppen met roken. Beiden programma's werden vergeleken met een controle groep zonder interventie. De analyses zijn uitgevoerd op drie verschillende onderzoeksgroepen: (1) alle respondenten zoals deze gerandomiseerd zijn ( $N=2031), 2)$ een gemodificeerde groep zonder deelnemers die geen stoppoging volgens het programma protocol hebben ondernomen ( $N=1812)$, en (3) een minimale dosis groep zonder deelnemers die geen van de interventieonderdelen hebben doorlopen $(\mathrm{N}=1324)$. Voor alle groepen zijn analyses met alleen complete cases en conservatieve analyses (waarin uitvallers als rokers gecodeerd werden) uitgevoerd. In onderzoeksgroep 1 bleken beide SQ4U programma's effectiever in het bevorderen van abstinentie na twaalf maanden (wanneer alleen de complete cases geïncludeerd werden) in vergelijking met de controle groep. Deze effecten verdwenen wanneer er conservatieve analyses uitgevoerd werden. De percentages en effecten verschilden echter per onder- 
zoeksgroep en per uitgevoerde analyse. Tot slot suggereren de resultaten een relatie tussen de interventiedosis en abstinentie.

Hoofdstuk 6 beschrijft de effecten van twee SQ4U programma's (AP en het $\mathrm{AP}+$ ) in het voorkomen van terugval op de korte termijn (zes maanden na de voormeting) bij rokers die gemotiveerd zijn om te stoppen met roken. De studie was een gerandomiseerd experimenteel onderzoek en de onderzoekssample was een gemodificeerde groep zonder deelnemers die geen stoppoging volgens het programma protocol hebben ondernomen $(\mathrm{N}=1812)$. Beide programma's werden vergeleken met een controle groep zonder interventie. Voor alle groepen zijn analyses met alleen complete cases en conservatieve analyses (waarin uitvallers als rokers gecodeerd werden) uitgevoerd. Geen van de SQ4U programma's was significant beter dan de controle conditie in het bevorderen van abstinentie na zes maanden. Uit de resultaten bleek wel dat de abstinentie percentages afhangen van de mate waarin de programma's doorlopen waren.

Hoofdstuk 7 beschrijft een studie die onderdeel was van een groter gerandomiseerd experimenteel onderzoek (SQ4U studie) en waarin alleen de data is gebruikt van deelnemers in de AP en AP+ programma's die het copingplan gemaakt hebben $(\mathrm{N}=563)$. Deze studie had als doel meer inzicht te krijgen in de situationele en affectieve risicosituaties van de deelnemers, de kwaliteit van de implementatie intenties die zij maakten om met deze risicosituaties om te gaan en de rol van deze plankwaliteit in het bevorderen van abstinentie op de korte (na zes maanden) en lange termijn (na twaalf maanden). Stress en het verlangen naar een sigaret werden het vaakst gekozen als risicosituaties. De specificiteit van de plannen om met affectieve situaties om te gaan bleek significant lager dan de specificiteit voor situationele risicosituaties. Bovendien bleek de specificiteit van plannen geassocieerd te zijn met de abstinentie na zes en twaalf maanden.

Hoofdstuk 8 beschrijft een gerandomiseerd experimenteel onderzoek met als doel om de effectiviteit te testen van een aandachttraining met betrekking tot het voorkomen van terugval op de korte termijn (na zes maanden). In deze studie werden ook differentiële effecten van de training voor reguliere rokers (roken meer dan 15 sigaretten) en niet-reguliere rokers (roken niet meer dan 15 sigaretten) onderzocht. Uit de resultaten is gebleken dat de training significant beter is in het bevorderen van abstinentie dan de controle conditie, deze effecten werden echter alleen in de groep van reguliere rokers gevonden.

Hoofdstuk 9 vormt de algemene discussie van dit proefschrift en beschrijft de belangrijkste bevindingen uit de studies die beschreven staan in de voorgaande hoofdstukken. Verdere worden in dit hoofdstuk aanbevelingen gegeven, worden de sterke punten van de uitgevoerde studies beschreven en worden de uitdagingen voor de toekomst benoemd. Het hoofdstuk eindigt met zes algemene conclusies. Ten eerste is het voor de ontwikkeling, disseminatie en adoptie van nieuwe terugvalpreventie programma's belangrijk om meer inzicht te verkrijgen in de transitie van theorie naar praktijk. Ten tweede kunnen advies-op- 
maat programma's gecombineerd met meerdere actieplan-opdrachten (zoals in het SQ4U programma) een veelbelovende methode zijn om lange termijn abstinentie te bevorderen. Het is echter noodzakelijk om de huidige SQ4U programma's te verbeteren om betere resultaten te verkrijgen. Ten derde is de steun voor het nut van korte adviezen na de stoppoging beperkt. Meer onderzoek is nodig om te achterhalen of korte adviezen na de stoppogingen wel nut hebben wanneer zij op momenten worden gegeven dat de deelnemers ze het hards nodig hebben. Ten vierde is het nodig om de SQ4U programma's te verbeteren om volledig gebruik door de doelgroep (rokers) en de implementatie en adoptie door landelijke (gezondheid) organisaties mogelijk te maken. Ten vijfde zijn aandachttrainingen veelbelovend voor het bevorderen van abstinentie, vooral bij reguliere rokers. Het wordt daarom aangeraden om deze strategieën op te nemen in preventie programma's. De meetinstrumenten die gebruikt worden dienen echter verbeterd te worden. Tot slot zijn nieuwe initiatieven nodig om de effecten van gecombineerde strategieën te testen (expliciete en impliciete benaderingen samen in een programma), om de effecten van SQ4U en Train jezelf Rookvrij in andere groepen van rokers te testen (bijv. de lager gemotiveerden) en om te onderzoeken of expliciete concepten zoals self-efficacy en actieplannen onderhevig zijn aan impliciete tendensen. 


\section{DANKWOORD}

Velen hebben bijgedragen aan dit onderzoek en aan de totstandkoming van dit proefschrift. Ik wil daarom iedereen bedanken die hierin een rol gespeeld heeft. Een aantal mensen wil ik in het bijzonder bedanken.

Allereerst, wil ik natuurlijk mijn promotoren Hein de Vries en Reinout Wiers en naar mijn co-promotor Catherine Bolman bedanken.

Hein, ik kan jou gerust als drijfveer achter deze promotie beschouwen, zowel door de mogelijkheden die je me geboden hebt, als je inhoudelijk bijdrage. Je hebt mij ondersteund in mijn ontwikkeling, creativiteit en persoonlijke groei. Je vermogen om abstract te denken, je intelligentie (ook al heb je ongewild gedurende onze samenwerking al verschillende varianten van mijn achternaam gefabriceerd en vrees ik dat er nog meer zullen volgen) en je ervaring maken je tot een bewonderenswaardige promotor. Het feit dat mede door jouw betrokkenheid onze onderzoeksaanvraag is verwezenlijkt, bevestigt je inzet en bijdrage en heeft mij voor nu een toekomstige wetenschappelijke carrière en een positieve impuls gegeven, waarvoor mijn welgemeende dank.

Reinout, jou wil ik heel erg bedanken voor het in goede banen leiden van de studie naar impliciete cognities. Op inhoudelijk vlak kon ik me wat dat betreft geen betere begeleider wensen. Ik vond het heel jammer dat je zo kort na de start van mijn promotietraject naar de Universiteit van Amsterdam bent vertrokken, maar achteraf gezien heeft dat me een aantal nieuwe leuke collegae en nuttige contacten opgeleverd. En ondanks dat die nieuwe leuke collegae jouw nieuwe team vormden, gaf je mij nooit het gevoel dat je het aio-meisje in Maastricht vergeten bent ... je hebt me altijd zoveel mogelijk proberen uit te nodigen voor de activiteiten die voor mij relevant zijn en je hebt altijd tijd gemaakt voor mijn begeleiding. Ik bedank je hiervoor!

Catherine, ik bewonder jouw kritische kijk en de tijd die jij uittrekt om een artikel of interventie-onderdeel te bekijken. Jouw precisie en oog voor detail zorgden altijd voor de puntjes op de i en hebben op veel vlakken voor verscherping gezorgd. Om de lezer een idee te geven van jouw precisie en jouw oog voor detail: soms was het letterlijk een puntje op de 'i' (-).

De leden van de beoordelingscommissie, Prof. dr. N.K. de Vries, Prof. dr. Ir. C.P. van Schayck, Prof. dr. M. Willemsen, Prof. dr. L. Lechner en Dr. D. Kotz dank ik voor het kritisch lezen van mijn proefschrift en het deelnemen aan de oppositie. 
Natuurlijk gaat mijn dank ook uit naar al mijn collegae, zowel van de Universiteit Maastricht als van de Universiteit van Amsterdam als daarbuiten. Een aantal mensen wil ik expliciet bedanken.

Ik had tijdens mijn promotietraject de luxe om samen te werken met zeer bekwame onderzoeksassistenten. Verina en Claire (Jeukens), jullie hebben - onder andere met jullie ondersteuning bij de ontwikkeling van de programma's en bij de werving van deelnemers - een hele belangrijke bijdrage aan de uitvoering van dit project geleverd. Bedankt voor jullie geweldige inzet! Verder wil ik ook Kim, Roos, Matti, en Michelle bedanken voor de verschillende vormen van project ondersteuning die zij geboden hebben.

Math, wat ben ik blij dat ik op jou kon terugvallen als ik vastliep tijdens het uitvoeren van analyses. Na een overleg met jou leek alles zo makkelijk en duidelijk ... dat heeft alles te maken met jouw manier van uitleggen. Bedankt!

Leon, ik wil jou bedanken voor alle keren dat je klaarstond om mijn technische problemen op te lossen. Maar, ik weet bijna zeker dat jij stiekem uitkeek naar mijn volgende probleem, omdat het je vaak een bedankje in de vorm van een bord baklava opleverde. Ik vind het super leuk dat jij mijn paranimf wilt zijn.

Marja, jij bent zo'n leuke vrouw! Je kunt je niet voorstellen hoe vaak ik buiten werk om (in m'n eentje) om iets wat jij gezegd of geschreven hebt, heb gelachen. Jij staat altijd voor iedereen klaar en het verbaast me keer op keer hoeveel weet jij van verschillende dingen hebt. Ik ben blij dat jij tijdens de verdediging van mijn proefschrift achter me staat!

Patricia, wat zouden we zonder jou moeten, wat zouden we zonder jou moeten? Bedankt voor alle hulp die je geboden hebt!

Francine, Nicola, Eline, Gera, Daniel, Paul, Astrid en Carolien, bedankt voor alle gezelschap tijdens congressen die we samen bezocht hebben.

Thomas en Wouter, jullie hebben een ongelooflijk belangrijke rol gespeeld bij de ontwikkeling van het Train jezelf Rookvrij programma. Ik wil jullie heel erg bedanken dat jullie niet weggerend zijn (omdat ik een technisch dieptepunt ben), maar juist altijd de moeite hebben genomen om mij wat te leren van de technische kneepjes achter een programma. Dankzij jullie weet ik nu hoe een requirements document geschreven moet worden en heb ik er zelfs laatst nog eentje geschreven. Ik kreeg van de betrokken technici de feedback gekregen dat ze nog nooit een dergelijk gedetaileerd document gekregen hebben van een onderzoeker. Toen Hein dat hoorde, keek hij alsof de technicus zojuist had gezegd dat ik vloeiend Chinees spreek (zijn blik zei: Iman? Een technisch document schrijven?). Bedankt jongens!

Tim, Denise, Thomas, Ozlem en Elske, wij hebben elkaar maar een aantal keer gezien de afgelopen jaren, maar elke keer dat ik op de UvA was (en tijdens de schrijfweek in Duitsland), hebben jullie mij ontzettend wegwijs gemaakt en me altijd aan een werkplekje en gezelschap geholpen. Bedankt! 
Het onderzoek dat beschreven is in dit proefschrift was niet mogelijk geweest zonder de subsidiegever: ZonMw. Ook kon het project niet uitgevoerd worden zonder de hondertallen deelnemers die aan de studies meegedaan hebben. Stivoro wil ik graag bedanken voor de hulp bij het werven van deelnemers voor verschillende studies.

Dan zijn er personen die misschien niet altijd in directe zin aan dit proefschrift bijgedragen hebben, maar wel absoluut elke dag opnieuw een bijdrage leveren aan de persoon achter dit proefschrift.

Reduan, als grote broer was je altijd bereid om je bijdrage te leveren, ondanks je eigen drukke bezigheden. Je hebt altijd je eigen visie en met je manier van brengen heb je absoluut een positieve bijdrage geleverd aan het geheel. Tevens wil ik je bedanken voor je genetische bijdrage aan mijn kleine neefje Ilias, zo jong en toch al zijn plekje veroverd. Zijn glimlachje is zijn manier van ondersteuning van zijn lievelings (en enige) tante.

Solaiman, als broertje, ben je ook op je eigen manier betrokken, je toonde altijd je interesse en je was een gewillig slachtoffer bij de voorbereiding van mijn presentaties, al hoopte ik altijd dat het publiek niet dezelfde blik zou opzetten als jij. Je bereidwilligheid om altijd klaar te staan siert je enorm en daarom verdien jij ook je lettertjes in dit boekje.

Hamid, jij bent mijn lieve leuke oom, bedankt voor alle gezelligheid die jij biedt.

Tot slot wil ik de allerbelangrijkste twee personen in mijn leven bedanken. Papa en mama, de positieve impact die jullie liefde, zorg en steun op mijn leven heeft, is niet in een paar woorden uit te drukken. Als ik alles zou moeten opschrijven wat ik aan jullie te danken heb, wordt dit dankwoord dikker dan mijn hele proefschrift. En, zelfs dan zouden de woorden en zinnen die ik schrijf nooit de mate waarin ik jullie zou willen bedanken kunnen dekken. Er is geen persoon aan wie ik meer te danken heb dan aan jullie en er is geen persoon die ik meer zou willen bedanken dan jullie. Bedankt voor alles!

Iman 



\section{CURRICULUM VITAE}

Iman Elfeddali was born on May 27, 1984, in Brunssum, The Netherlands. After receiving her secondary school diploma in 2002, she moved to Leiden where she studied Psychology. As part of the master's curriculum she wrote her thesis about the smoking behavior of Dutch, Moroccan and Turkish men in the Netherlands. At the same time, she did a research internship at the Trimbos Institute in Utrecht (Dutch institute that conducts research on mental health, mental resilience and addiction). During this internship she worked on three projects: 1 . a project on work-related psychological problems in non-western immigrants in the Netherlands, 2 . a project on anxiety and depression among diabetes patients, 3. a project on the treatment of mental disorders in the primary care setting in the Netherlands.

After receiving her master degree, she started working as a PhD-student on the project described in this dissertation. In 2008, she was certified as a smoking cessation coach after following a training provided by the Dutch Foundation for a Smoke-free Future (Stivoro). She has presented the research described in this dissertation at different national and international conferences.

Iman is the co-applicant of a research project - about implicit tendencies underlying explicit cognitions - that is funded by The Netherlands Organisation for Health Research and Development (ZonMw). Since 2011, Iman has been working on this postdoctoral research project at the Department of Health Promotion (School for Public Health and Primary Care (Caphri), Maastricht University). In March 2013 she started to combine her work at Maastricht Univesity with working part-time (at Tilburg University) on a European project that aims to develop a comprehensive, consensus-based roadmap to promote and integrate mental health and well-being research in Europe (ROAMER)

\section{Obtained grants}

The Netherlands Organisation for Health Research and Development: Rethinking Prevention: testing implicit retraining for public health purposes $(\mathrm{H}$. de Vries, I. Elfeddali), co-applicant.

\section{Nominations}

European Health Psychology Society Conference 2007, poster nomination. 



\section{LIST OF PUBLICATIONS}

\section{Publications from this dissertation}

ELFEDDALI, I., BOLMAN, C., MESTERS, I., WIERS, R. and DE VRIES, H. (2010). Factors underlying smoking relapse prevention: results of an international Delphi study. Health Education Research, 25, 1008-1020.

ELFEDDALI, I., BOLMAN, C., CANDEL, M. J., WIERS, R. W. and DE VRIES, H. (2012). The role of self-efficacy, recovery self-efficacy and preparatory planning in predicting short-term relapse. British Journal of Health Psychology, 17, 185201.

ELFEDDALI, I., BOLMAN, C. and DE VRIES, H. (2012). SQ4U - a computer tailored smoking relapse prevention program incorporating planning strategies and multiple feedback moments after the quit-attempt: development and design protocol. Contemporary Clinical Trials, 33, 151-158.

ELFEDDALI, I., BOLMAN, C., CANDEL, M. J. J. M., WIERS, R. W. and DE VRIES, H. (2012). Preventing smoking relapse via Web-based computer tailored feedback in the SQ4U-study: a randomized controlled trial.Journal of Medical Internet Research 14, e109

ELFEDDALI, I., BOLMAN, C., CANDEL, M. J. J. M., WIERS, R. W. and DE VRIES, H. (under review). The role of adherence in a computer tailored smoking relapse prevention program: six months results of the SQ4U-study.

ELFEDDALI, I., BOLMAN, C. and DE VRIES, H. (in press) Situational and affective risk situations of relapse and the quality of implementation intentions in an ehealth smoking relapse prevention programme. Substance Use and Misuse.

ELFEDDALI, I., DE VRIES, H. and WIERS, R. W. (in preparation). Preventing short-term smoking relapse among smokers via a web-based multiple-session attentional bias modification training: a randomized controlled trial. 


\section{Other publications}

VAN DER FELTZ-CORNELIS, C., KNISPEL, A. and ELFEDDALI, I. (2006). Afbakening eerste en tweede lijns zorg voor psychische problemen. Utrecht, Trimbos Instituut.

VAN DER FELTZ-CORNELIS, C., MEEUWISSEN, J., DE JONG, F., HOEDEMAN, R. and ELFEDDALI, I. (2007). Randomised controlled trial of a psychiatric consultation model for treatment of common mental disorder in the occupational health setting._BMC Health Services Research, 27, 7-29.

VAN DER FELTZ-CORNELIS, C., KNISPEL, A. and ELFEDDALI, I. (2008). Treatment of mental disorder in the primary care setting in the Netherlands in the light of the new reimbursement system: a challenge? International Journal of Integrated Care, 8, e56.

KNISPEL, A., ELFEDDALI, I. and VAN DER FELTZ-CORNELIS, C. (2008). Gezond leven en werken. Werkboek voor de cliënt. Utrecht, Trimbos Instituut. 